\title{
Regulation of the homeoprotein Hesx1 via Mad2/2 and the anaphase promoting complex
}

\author{
Doctoral Thesis \\ In partial fulfillment of the requirements \\ for the degree "Doctor rerum naturalium (Dr. rer. nat.)" \\ in the Molecular Biology Program \\ at the Georg-August University Göttingen, \\ Faculty of Biology
}

submitted by

Sven Pilarski

born in

Wolfsburg, Germany

Göttingen, March 2008 


\section{AFFIDAVIT}

Here I declare that my doctoral thesis entitled "Regulation of the homeoprotein Hesx1 via Mad2/2 and the anaphase promoting complex" has been written independently with no other sources and aids than quoted.

Sven Pilarski, Göttingen, March 2008 
To my family 


\section{TABLE OF CONTENTS}

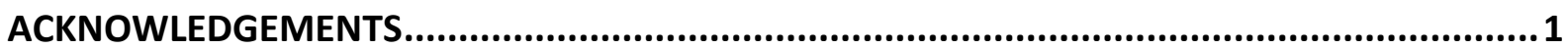

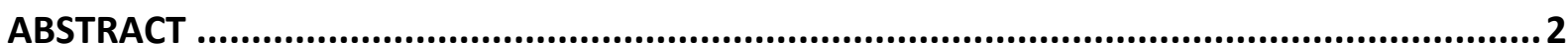

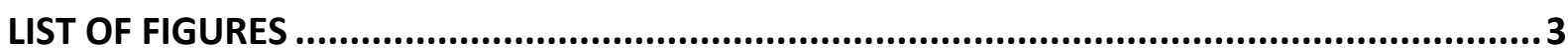

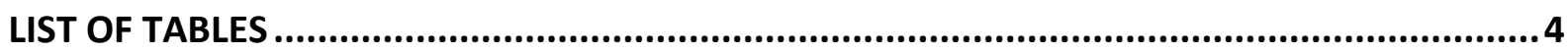

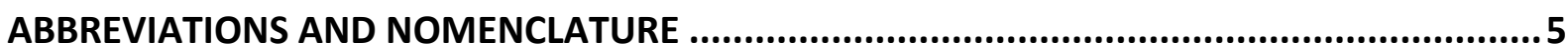

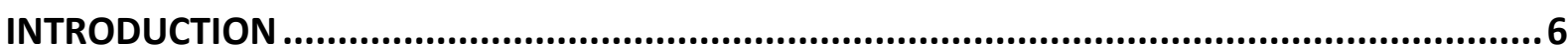

Role of Hesx1 during early embryonic and pituitary development ................................6

The ubiquitin ligase Cdh1-APC and its inhibitor Mad2/2 ...........................................15

Polymerase ५: Function of Mad2I2 and Rev3 in DNA damage repair...............................20

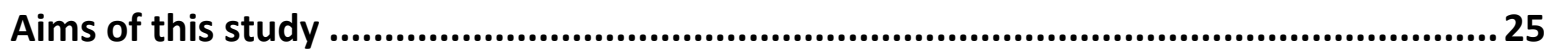

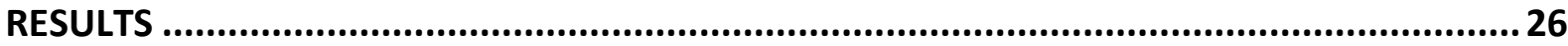

Hesx1 interacts with Mad2I2 and the APC recognition subunit Cdh1 ...........................26

Hesx1, Mad2/2 and Cdh1 have overlapping expression domains................................. 28

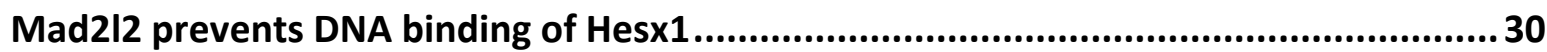

The E3 ubiquitin ligase Cdh1-APC polyubiquitinates Hesx1 .......................................32

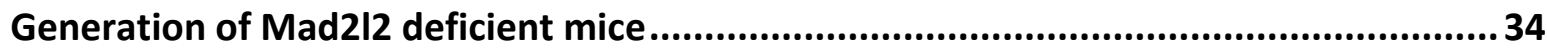

Use of Recombineering to create the conditional knockout targeting vector .................35

Gene targeting in ES-cells and Cre mediated deletion of Mad2/2 in mice ......................38

Phenotypic analysis of Mad2/2 knockout mice........................................................4 41

Variable viability and growth retardation in Mad2/2 deficient embryos ........................4 41

Mad2/2 targeted MEF's show decelerated proliferation............................................ 43

Mad2/2 deficient MEF's show an altered cell cycle phase distribution............................44

Accumulation of $\mathrm{Y}-\mathrm{H} 2 \mathrm{AX}$ in Mad2/2 deficient MEF's ............................................................ 46

Pituitary gland displays impaired cell differentiation ................................................ 47

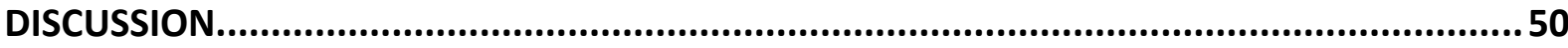

Hesx1 regulation through Mad2I2 and Cdh1-APC ......................................................50

Mad2I2 prevents Hesx1 from DNA binding ............................................................... 50

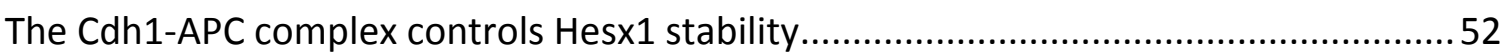

Phenotypical analysis of Mad2/2 deficiency ................................................................5 54

Infertility, reduced viability and size in Mad2/2 deficient embryos ..............................54

Proliferation and DNA damage in Mad2/2 deficient MEF's ............................................56

Mad2/2 deficiency impairs pituitary cell lineage differentiation.....................................58 
SUMMARY AND CONCLUSIONS 61

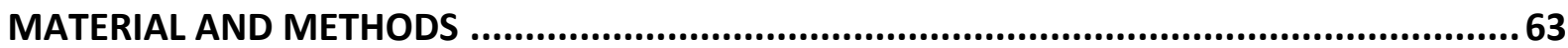

Isolation, analysis and manipulation of nucleic acids ............................................63

Total RNA isolation from eukaryotic cells or mouse embryos.......................................63

Genomic DNA extraction from mammalian cells or mouse tissues ..............................63 63

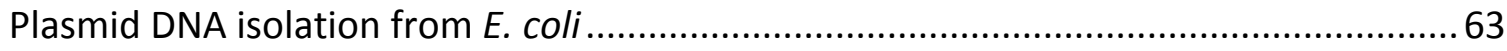

$\mathrm{P} 1-$ derived artificial chromosome (PAC) isolation from $E$. coli .......................................64

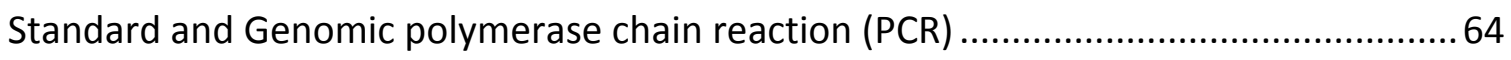

Reverse transcriptase - polymerase chain reaction (RT-PCR) ....................................6 65

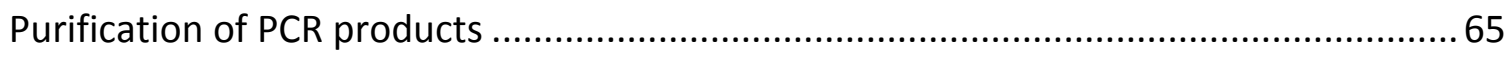

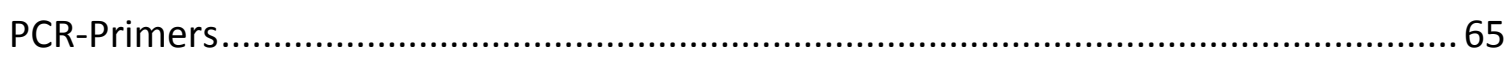

DNA electrophoresis and purification from agarose gel...........................................67

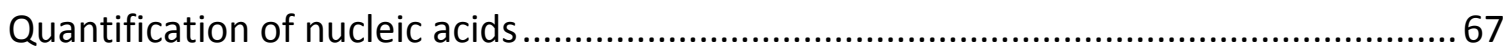

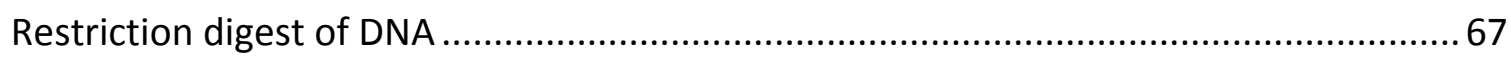

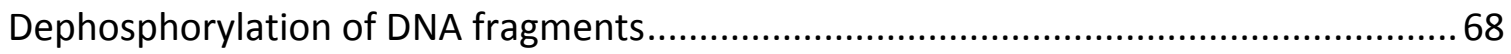

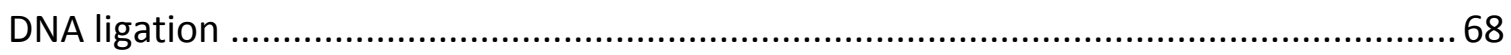

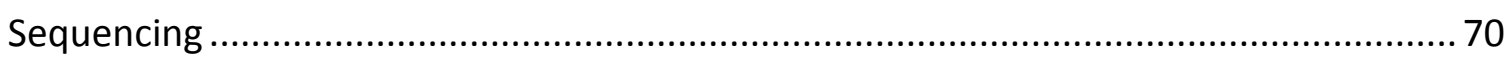

Dig-labeled antisense RNA probe preparation .......................................................... 70

Preparation of random radioactively labeled DNA probes............................................ 70

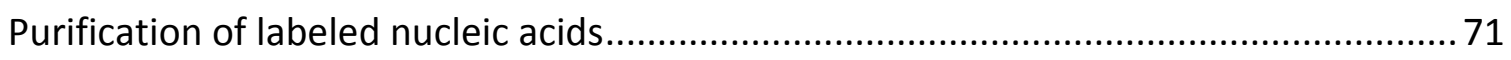

Phenol extraction and ethanol precipitation of DNA …............................................. 71

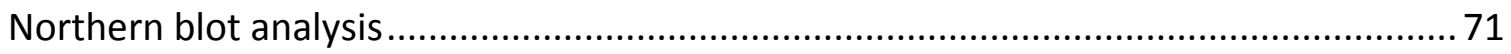

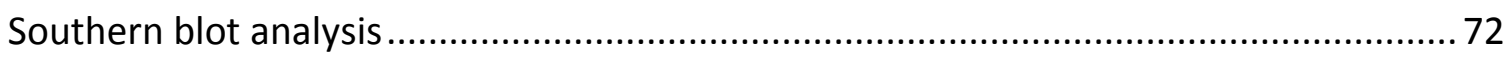

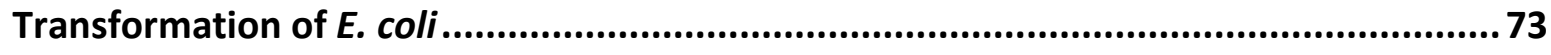

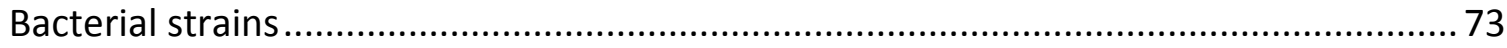

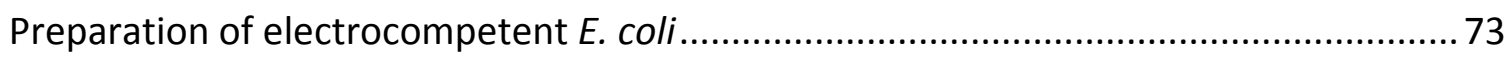

Preparation of E. coli competent for heat shock transformation.................................... 74

Transformation of E. coli by electroporation ............................................................... 74

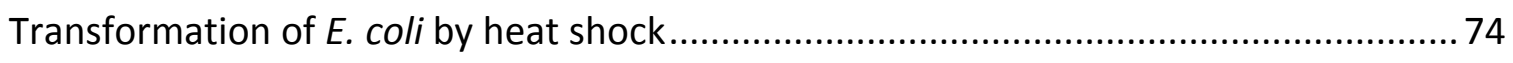

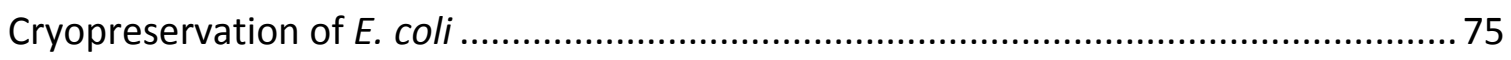

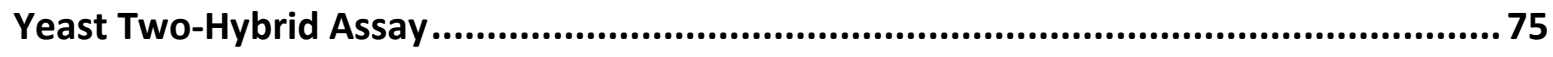

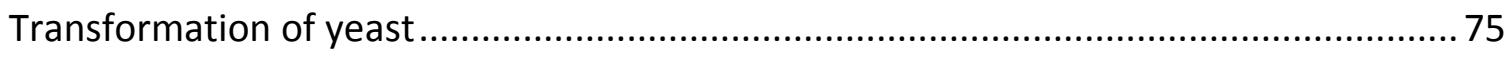

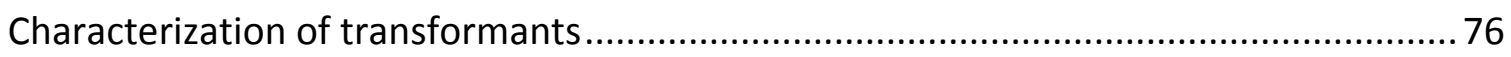




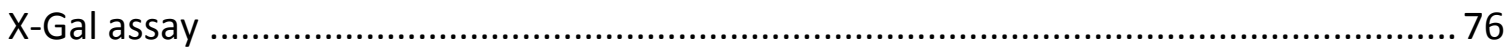

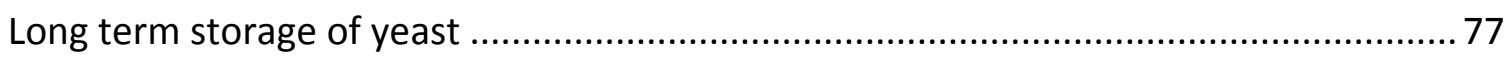

Purification and analysis of proteins .............................................................. 77

Expression and purification of GST-fused recombinant proteins ................................. 77

Thrombin cleavage of GST-fused recombinant proteins ............................................. 78

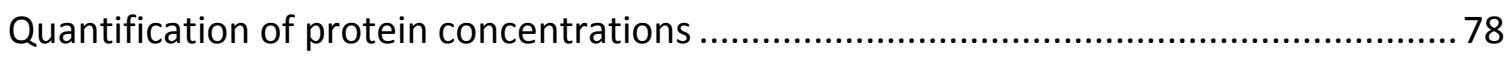

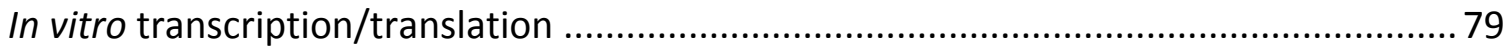

SDS-polyacrylamide gel electrophoresis of proteins (SDS-PAGE) .................................. 79

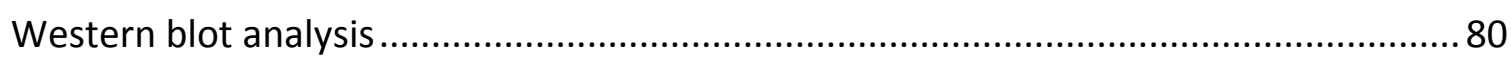

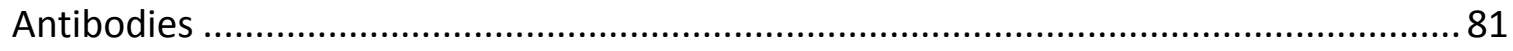

Analysis of protein-protein interactions............................................................. 82

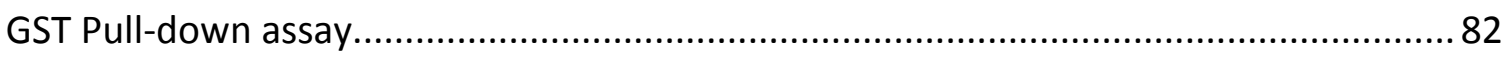

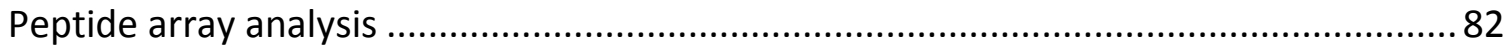

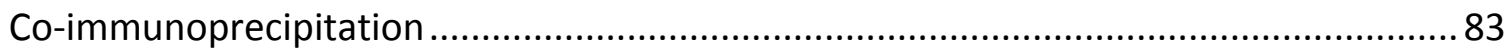

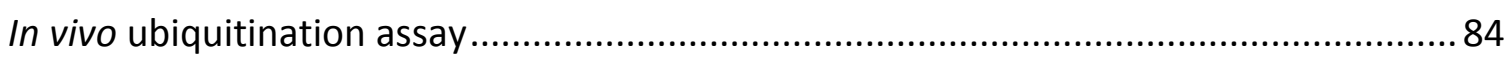

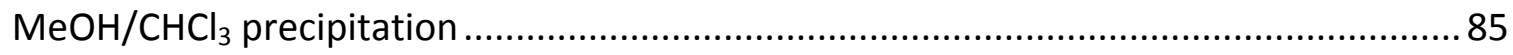

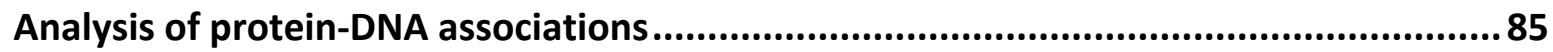

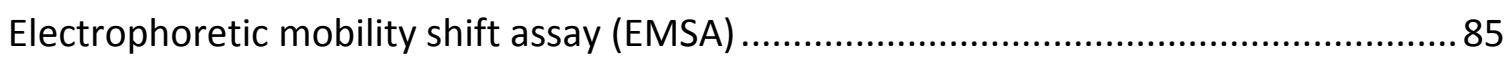

Generation of the Mad2/2 conditional knockout vector via recombineering ...................86

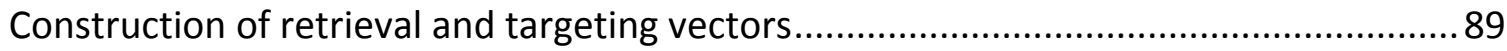

Transformation of PAC or plasmid DNA into recombinogenic strains ............................ 89

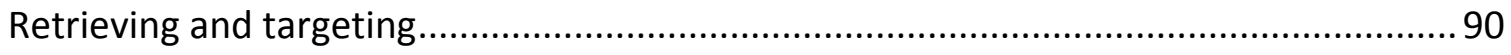

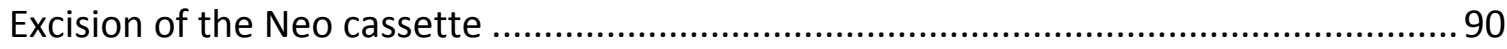

Gene targeting in mouse ES cells and production of chimeras ................................... 91

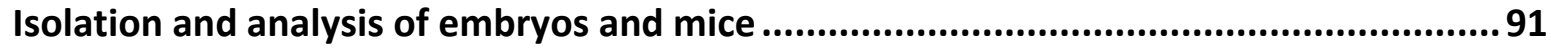

Dissection and fixation of mouse embryos ................................................................ 91

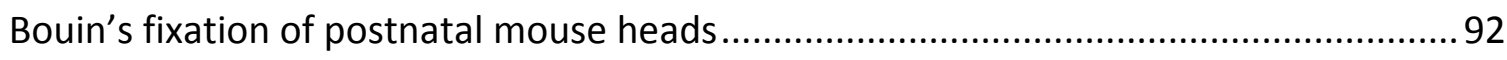

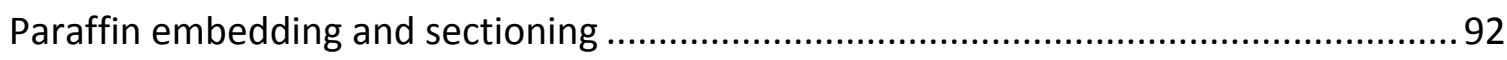

Hematoxylin and Eosin staining (H\&E staining) ........................................................... 93

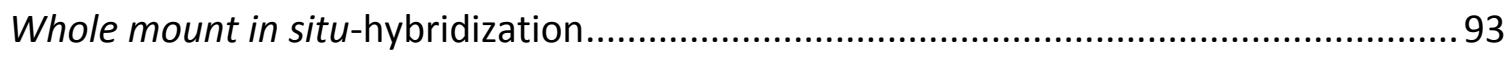

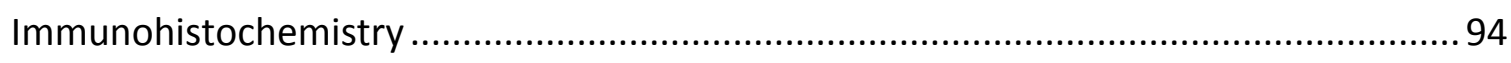

Cell culture

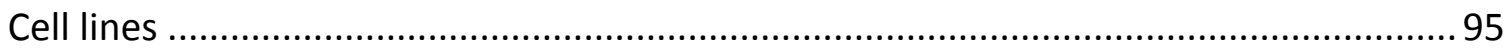




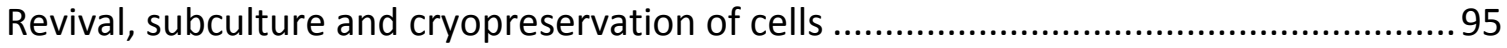

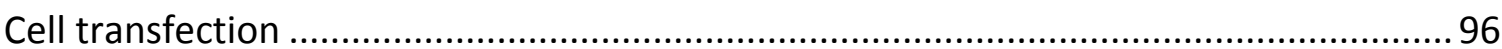

Preparation of primary mouse embryonic fibrobasts (MEF's) .......................................97

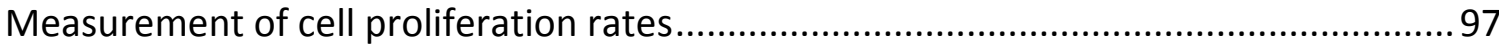

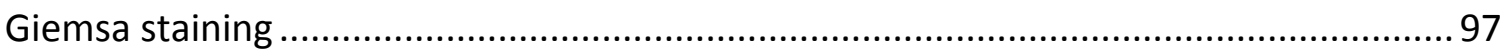

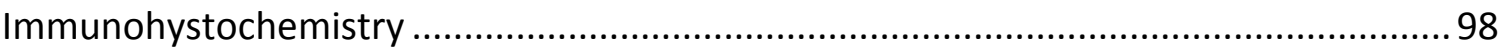

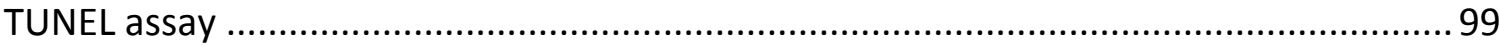

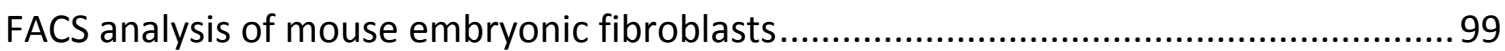

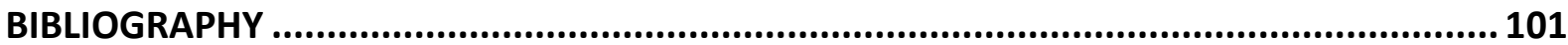

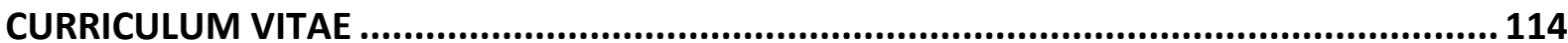




\section{ACKNOWLEDGEMENTS}

I would like to thank my supervisor Prof. Dr. Michael Kessel for giving me the opportunity to work in his laboratory on this interesting project. His continuous support, guidance and the many helpful discussions are the cornerstones of this work and have added value to my scientific and personal development.

I am thankful to Prof. Dr. Tomas Pieler and Prof. Dr. Herbert Jäckle, the members of my thesis committee. The thesis committee meetings are a central feature of the graduate program "Molecular Biology" and the additional advice, guidance and critical comments I received during these meetings were very helpful. In addition, I would like to thank Dr. Steffen Burkhardt and the coordination office of the "Molecular Biology" program for their helpfulness and untiring dedication.

Furthermore, I am grateful to the members of the Department Molecular Cell Biology for their continuous support. My special thanks go to Dr. Anastassia Stoykova, Prof. Dr. Ahmed Mansouri and Dr. Kamal Chowdhury for helpful discussions and advice, to Dr. Stephen Blanke, Martina Daniel, Dr. Gundula Griesel, Sharif Mashur and Dr. Tran Cong Tuoc for all their help, technical advice and scientific as well as non-scientific discussions. I would like to thank Dr. Ulrike Teichmann and Daniela Wollradt for their help and advice concerning the mice. Moreover, I am grateful to Prof. Dr. Detlef Doenecke, Krisitina Haenecke and Dr. Nicole Happel for their help with the FACS analysis.

My thanks also go to all my current and former lab mates of the Kessel-lab. I am very thankful to Naisana Seyed Asli, Alexander Klimke, Dr. Lingfei Luo, Dr. Mara Pitulescu, Petra Rus, Yvonne Uerlings and Dr. Lars Wittler for all their help, discussions and just for sharing good and bad times. They really created a pleasant lab atmosphere, which made the whole work fun!

I would like to thank Oliver Arendt, Stefan Klose and Dr. Pia Schmidt for patiently listening to problems, discussions, "taking a day off" and proofreading parts of the present thesis.

I am grateful to my non-scientific advisory board, my parents Elke and Hartmut and my brother Björn Pilarski for all their continuous support and advice. Finally, I would like to thank Claudia Hennecke for all her patience, help and just for being there and sharing a great time together. 


\section{ABSTRACT}

Understanding the functional significance of the coordinate expression and interaction of homeobox transcription factors remains a critical question in developmental biology. Hesx1 is a paired-like homeodomain transcription factor, which is required for normal forebrain and pituitary gland formation. Hesx1 deficient mice display variable degrees of forebrain and pituitary gland defects. A comparable phenotype in humans is septo optical dysplasia (SOD) and humans harboring mutations in HESX1 were observed to display some form of SOD.

This study has identified so far unknown Hesx1 interaction partners. As an interesting binding partner Mad2l2 was found to bind Hesx1. Mad2l2 is involved in DNA damage repair as a component of the polymerase $\zeta$ as well as in cell cycle regulation by inhibiting the anaphase promoting complex (APC). The interaction with Hesx1 resulted in a diminished ability of Hesx1 to bind to target DNA. Furthermore, Cdh1, the substrate recognition subunit of the APC, was found to bind Hesx1. The Cdh1-APC complex is an E3 ubiquitin ligase that targets proteins for proteolysis via the $26 \mathrm{~S}$ proteasome. Indeed, Hesx 1 could be identified as a target of the Cdh1-APC complex and was polyubiquitinated and subsequently degraded.

To study the consequence of Mad2/2 inactivation in mice, knockout animals were produced. These animals and mouse embryonic fibroblasts (MEF's) displayed DNA damage as well as a pituitary gland phenotype, indicating that Mad2/2 is a crucial factor during embryonic development. It was previously shown, that precise spatially and temporally expression of Hesx1 is crucial for proper pituitary gland development. Interactions of Mad2I 2 and Cdh1 with Hesx1 suggest that these factors are responsible for regulation and timed degradation of Hesx1 in the developing anterior pituitary gland.

Therefore, the present study has extended the regulative network in which Hesx1 is embedded and identified novel mechanisms of Hesx1 regulation, involving binding to Mad2/2 and ubiquitination via the Cdh1-APC complex. 


\section{LIST OF FIGURES}

Figure 1. Hesx 1 expression during pituitary organogenesis.

Figure 2. Signaling molecules, selected transcription factors and hormones during pituitary development.

Figure 3. Cdh1-APC substrate ubiquitination in the presence of Mad2/2.

Figure 4. DNA lesion bypass by $S$. cerevisiae Rev1-polymerase $\zeta$ at a stalled replication fork 22

Figure 5. Mad2/2 and Cdh1 interact with Hesx1.

Figure 6. Hesx1 expression pattern during mouse development. ........................................28

Figure 7. Mad212 and Cdh1 expression overlaps with Hesx1..............................................29

Figure 8. Mad2I2 binds to the N-terminal part of the homeodomain of Hesx1.....................31

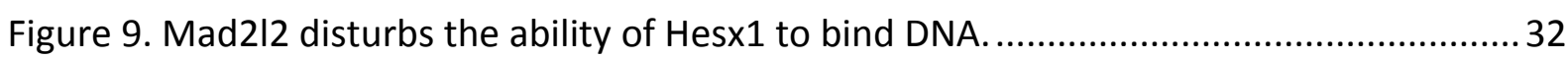

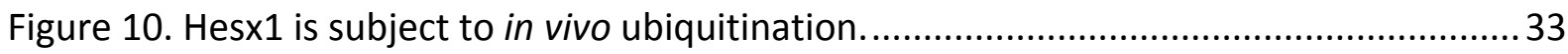

Figure 11. Search results for Mad2I2 in the Ensembl database...........................................35

Figure 12. Construction and functional analysis of the Mad2/2 conditional knockout

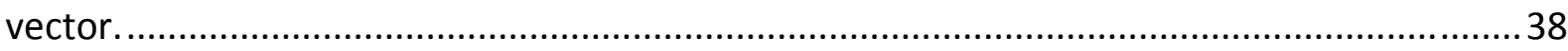

Figure 13. Targeting of the Mad2I2 genomic locus with the cko construct in ES cells............39

Figure 14. Generation of Mad2I2 knockout mice............................................................ 40

Figure 15. Genotypic analysis of progeny from $\mathrm{Mad} 2 / 2^{+/-}$intercrosses reveals embryonic

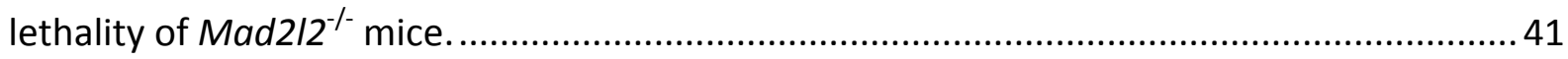

Figure 16. Mad2/2 deficient mice are reduced in size and weight. ....................................... 42

Figure 17. Growth curve of $\mathrm{Mad} 212^{-/-}$newborns and wild-type littermates. ..........................43

Figure 18. Influence of Mad2/2 deficiency on plating efficiency and proliferation rate of

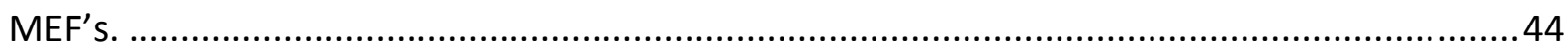

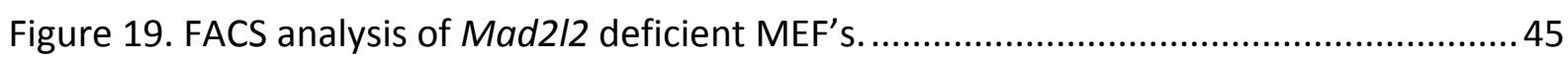

Figure 20. Elevation of $\mathrm{Y}$-H2AX expression levels in Mad2I2 deficient MEF's. .........................46

Figure 21. Mad2/2 deficient mice display a morphologically normal pituitary. ....................47

Figure 22. Expression of TSH in the developing pituitary gland............................................ 48

Figure 23. GH expression in the developing anterior pituitary gland. ................................. 49

Figure 24. The $\mathrm{N}$-terminal arm of paired homeodomains is involved in DNA binding............51

Figure 25. Possible model of Hesx1 ubiquitination during anterior pituitary gland

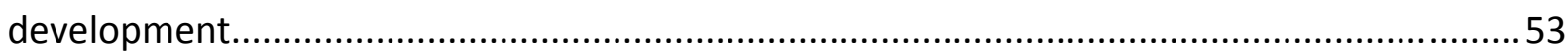

Figure 26. DNA lesion bypass by polymerase $\zeta$ might be disturbed in $\mathrm{Mad}_{2} / 2^{-{ }^{-}}$mice.............58

Figure 27. Delayed somatotrope differentiation in Mad2/2 deficient mice. .........................60

Figure 28. Standard curve for the determination of protein concentrations........................79

Figure 29. Generation of the Mad2I2 conditional knockout vector via recombineering. ........88 


\section{LIST OF TABLES}

Table 1. Pituitary phenotypes due to Hesx1 misexpression and mutations. 14

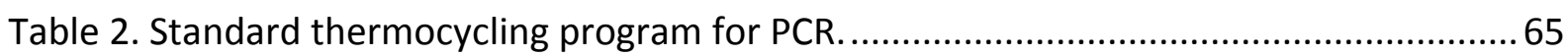

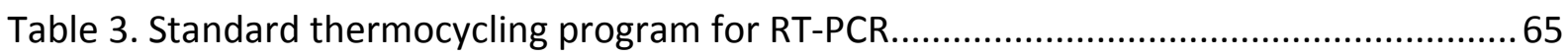

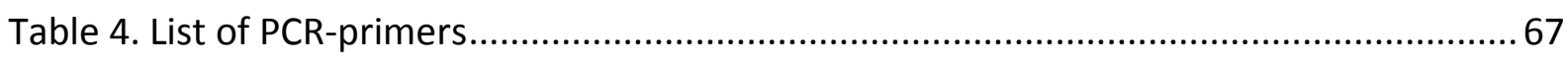

Table 5. Concentration of agarose used for separating DNA of different sizes....................67

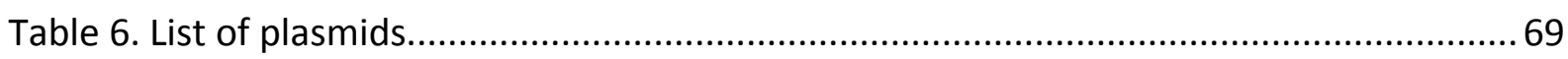

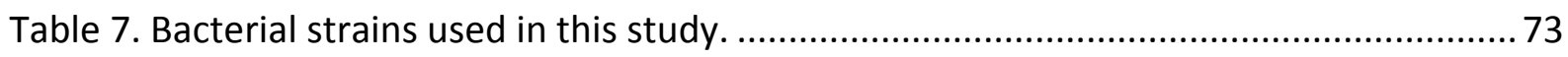

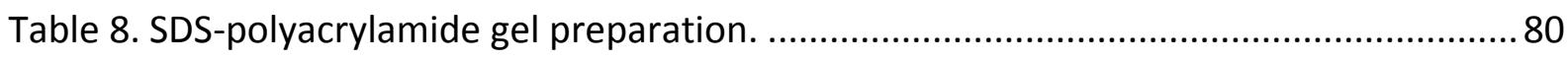

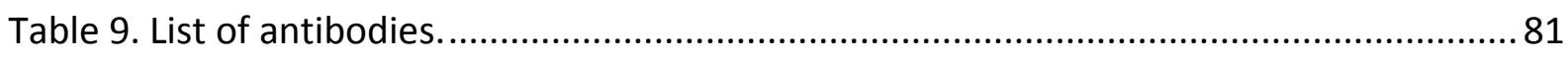

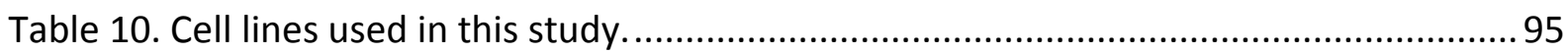




\section{ABBREVIATIONS AND NOMENCLATURE}

\begin{tabular}{|c|c|}
\hline 3AT & 3-Amino-1,2,4-Triazole \\
\hline АСТН & adrenocorticotropin \\
\hline$\alpha G S U$ & $\alpha$-glycoprotein subunit \\
\hline APS & Ammonium persulphate \\
\hline BBR & Boehringer Blocking Reagent \\
\hline bHLH & Basic helix-loop-helix \\
\hline bp & Base pairs \\
\hline BSA & Bovine serum albumin \\
\hline cDNA & complementary DNA \\
\hline cko & Conditional knockout \\
\hline CMV & Cytomegalovirus \\
\hline CPHD & $\begin{array}{l}\text { Combined pituitary hormone } \\
\text { deficiency }\end{array}$ \\
\hline $\mathrm{cpm}$ & Counts per minute \\
\hline Cre & Cre recombinase \\
\hline DMF & $\mathrm{N}, \mathrm{N}$-dimethyl formamide \\
\hline DNA & Deoxyribonucleic acid \\
\hline dpc & Days post coitum \\
\hline DTT & Dithiothreitol \\
\hline E. coli & Escherichia coli \\
\hline EDTA & Ethylenedinitrilotetraacetic acid \\
\hline ES cell & Embryonic stem cell \\
\hline FACS & $\begin{array}{l}\text { Fluorescence-activated cell } \\
\text { sorting }\end{array}$ \\
\hline FCS & Inactivated fetal calf serum \\
\hline Flpe & Flp recombinase \\
\hline FRT & DNA recognition site for Flpe \\
\hline FSH & Follicle-stimulating hormone \\
\hline g & gravity \\
\hline $\mathrm{GH}$ & Growth hormone \\
\hline HIS3 & $\begin{array}{l}\text { Imidazoleglycerol-phosphate } \\
\text { dehydratase }\end{array}$ \\
\hline IGHD & $\begin{array}{l}\text { Isolated growth hormone } \\
\text { deficiency }\end{array}$ \\
\hline $\mathrm{kb}$ & Kilo base pairs \\
\hline lacZ & $\beta$-galactosidase \\
\hline
\end{tabular}

LB Luria Bertani medium

$\mathrm{LH} \quad$ Luteinizing hormone

LiAc Lithium acetate

IoxP DNA recognition site for Cre

MEF Mouse embryonic fibroblasts

neo neomycin

OD Optical density

o/n Overnight

P Postnatal

PAC P1-derived artificial chromosome

PBS Phosphat buffered saline

PFA Paraformaldehyd

PMSF Phenylmethanesulphonylfluoride

POMC proopiomelanocortin

PRL Prolactin

RNA Ribonucleic acid

RNAi RNA interference

RNase Ribonuclease

rpm Revolutions per minute

SC- $\quad$ Synthetic complete medium

medium lacking a specific amino acid

SDS Sodium dodecyl sulfate

SOD Septo optical dysplasia

TBE Tris-borate buffer

TBS Tris bufferd saline

TEMED Tetramethylethylendiamin

TK Thymidine kinase

TSH Thyroid-stimulating hormone

U Units

V Volt

X-Gal 5-bromo-5-chloro-3-indolyl-(-Dgalactoside)

YPDG yeast-rich glycerol medium containing $0.1 \%$ glucose 


\section{INTRODUCTION}

The development from a single cell, the fertilized egg, into a multicellular organism, whether fly, frog, chicken, mouse or human, implies a sophisticated coordination of growth and differentiation. Each cell needs to maintain the integrity of its genome; inconsistencies or changes might induce cell death or have dramatic effects on the development of the entire organism. Cell proliferation has to be coordinated with cell cycle exit and differentiation. The spatial and temporal expression and interaction of transcription factors finally initiates the specialization of cell types to allow the proper formation of the embryo and its organs. These processes are most likely to involve genes capable of coordinating and crosslinking more than just one operation at any point in time.

\section{Role of Hesx1 during early embryonic and pituitary development}

The murine transcription factor Hesx1 (also referred to as Rpx; Hermesz et al., 1996; Thomas et al., 1995; Thomas and Rathjen, 1992) and its homologue the Xenopus laevis Xanf gene (Zaraisky et al., 1992) belong to the anterior neural fold (Anf) gene family (Kazanskaya et al., 1997). It is a class of paired-like homeobox genes that is probably unique to vertebrates since there are no orthologues found e.g. in Drosophila melanogaster and Caenorhabditis elegans genomes.

\section{Expression of Hesx1 in mice}

The murine Hesx 1 transcript was initially identified in embryonic stem (ES) cells where it is down-regulated upon ES cell differentiation (Thomas et al., 1995; Thomas and Rathjen, 1992). During development, Hesx 1 transcripts can be first detected before the onset of gastrulation in the anterior visceral endoderm. During primitive streak elongation the expression remains in this small patch of cells, but soon afterwards ( 7.5 days past coitum $(\mathrm{dpc})$ ) transcripts can be detected in the prospective neuroectoderm adjacent to the endoderm Hesx 1 expressing cells. This expression domain intensifies and spreads laterally during the formation of the cranial neural folds ( $8 \mathrm{dpc}$ ). In $8.5 \mathrm{dpc}$ embryos, Hesx 1 expression gets restricted to the neuroectoderm of the prospective prosencephalon and a small region of anterior foregut endoderm. At 9-9.5 dpc, transcripts are limited to the ventral diencephalon and a thickened layer of oral ectoderm. Subsequently, Hesx 1 is 
expressed only in the oral ectoderm cells that will give rise to Rathke's pouch, the primordium of the anterior and intermediate lobe of the pituitary gland (Hermesz et al., 1996; Thomas and Beddington, 1996).

The expression level of Hesx1 remains high throughout these oral ectodermal cells that subsequently invaginate and eventually detach to form the definitive pouch structure (Figure 1. e9.5-12). With the onset of pituitary gland cell differentiation around $12.5 \mathrm{dpc}$, Hesx1 expression is down-regulated in a progressive ventral to dorsal direction (Figure 1. e12-14.5), resembling the spatial and temporal appearance of differentiated pituitary cell types (Japon et al., 1994; Simmons et al., 1990). Hesx1 transcripts become undetectable around 15 dpc (Dasen et al., 2001; Hermesz et al., 1996).
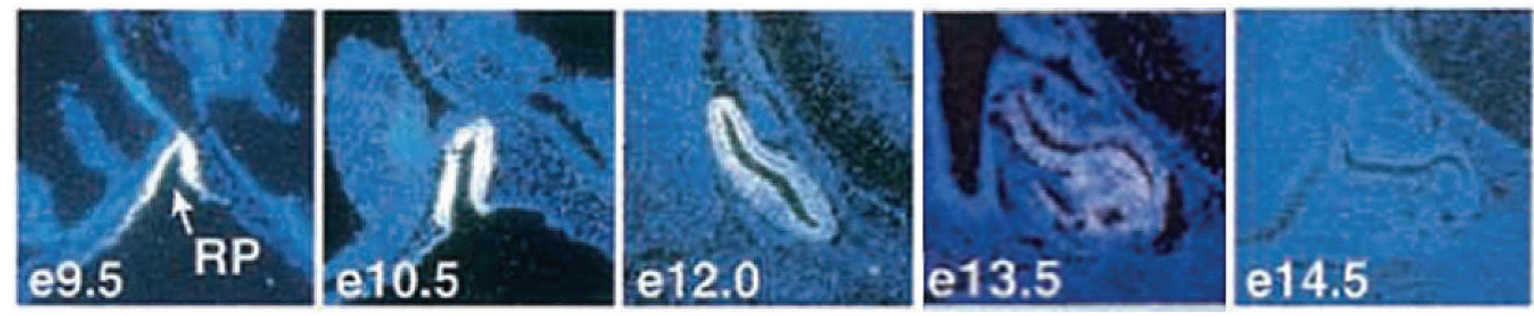

Figure 1. Hesx1 expression during pituitary organogenesis.

Hesx1 expression in Rathke's pouch (RP) at mouse embryonic stage (e) 9.5-14.5. Transcripts are found in a patch of cells from the oral ectoderm that invaginate and form Rathke's pouch. Hesx1 is strongly expressed in the developing Rathke's pouch and subsequently gets down-regulated in a ventral to dorsal pattern (modified from Dasen et al., 2001).

Similar expression pattern of Hesx 1 in the anterior neuroectoderm and the developing pituitary gland are described in other vertebrates e.g. in Xenopus laevis (Zaraisky et al., 1995) and Gallus gallus (Knoetgen et al., 1999). However, an exception might be the human HESX1 gene which is not transcriptionally silenced during adult life in normal pituitaries nor in pituitary adenomas (Mantovani et al., 2006).

In mice, this dynamic and complex expression pattern is regulated by at least two functional independent genomic elements. The early expression of Hesx 1 is controlled by a highly conserved 5' cis-regulatory element while a 3' regulatory sequence drives the expression in Rathke's pouch (Chou et al., 2006; Hermesz et al., 2003; Spieler et al., 2004). The 5' element is bound by LIM-homeodomain-containing proteins, Otx2 and Pax6 which seem to be key molecules in regulating early Hesx1 expression (Chou et al., 2006; Spieler et al., 2004). Moreover, it contains conserved paired-like homeodomain sites which are 
bound by Prop1/ $\beta$-catenin to repress Hesx1 transcription (Olson et al., 2006). The 3' element is bound by Pitx2 and GATA transcription factors (Chou et al., 2006). In Xenopus laevis it has been shown that the 5 ' regulatory element (Eroshkin et al., 2002) is bound by X-nkx-5.1, FoxA4a and Xvent2. These factors define the posterior border of the Xanf expression by inhibiting its transcription (Bayramov et al., 2004; Martynova et al., 2004). Since the $5^{\prime}$ regulatory region is highly conserved, murine orthologues of X-nkx-5.1, FoxA4a and Xvent2 might play a similar role in Hesx1 regulation in mice.

\section{Hes $x 1$ and its function}

The size of the Hesx1 proteins varies from 161 (Danio rerio) to 187 amino acids (Xenopus laevis; Figure 8. C). The homeodomains reveal an identity of over $75 \%$ if compared to each other and is less than 55\% compared to other known classes (Kazanskaya et al., 1997). In addition to the homeodomain, all Hesx1 homologues contain two conserved motifs which are located at the $\mathrm{N}$-terminus of the protein. The engrailed homology domain (eh1) was originally characterized in the Drosophila repressor engrailed but has also been found in other homeoprotein classes including goosecoid, Nkx, and msh (Smith and Jaynes, 1996) and a sequence similar to the WPRW motif found in several basic helixloop-helix (bHLH) proteins (Paroush et al., 1994). Both of these motifs are linked to the Groucho class of corepressors (Jimenez et al., 1997; Tolkunova et al., 1998) and indeed Hesx1 was shown to bind to the Groucho-like TLE1 corepressor. This interaction occurs at the eh1 domain and is sufficient for the repressive action of Hesx1. In addition, the homeodomain can recruit the $\mathrm{N}-\mathrm{CoR} / \mathrm{mSin} 3 / \mathrm{HDAC}(1 / 2)$ and $\mathrm{Brg}-1$ complexes to mediate repression (Dasen et al., 2001). These interactions are not mutually exclusive and might strengthen the repressive potential of Hesx1. Furthermore, the DNA methyltransferase 1 (DNMT1) was identified as a Hesx1 binding protein. This interaction led to the idea that Hesx1 might permanently silence target genes by CpG methylation (Sajedi et al., 2007). Several other studies contributed evidence that Hesx1 acts in vivo and in vitro as a transcriptional repressor (Brickman et al., 2001; Carvalho et al., 2003; Ermakova et al., 1999; Ermakova et al., 2007; Quirk and Brown, 2002; Susa et al., 2007). More recently it was found that the eh1 domain of Xanf binds in addition to the LIM-domain protein Zyxin which might inhibit the transcriptional repressor function. This interaction might add another level of regulation to the repressive function of Xanf (Martynova et al., 2008). 
The previously described dynamic spatially and temporal restricted expression of Hesx1 in the anterior visceral endoderm, the neuroectoderm and finally Rathke's pouch was shown to be crucial for proper rostral development in mice. Hesx 1 deficient mice display reduction of the anterior forebrain, defects in the dorsal forebrain commissural structures, eye abnormalities and pituitary gland dysplasia to a variable degree (Dattani et al., 1998; Martinez-Barbera et al., 2000). This phenotype is comparable to the human congenital disorder septo-optic dysplasia (SOD). Several mutations in the eh1 domain and the homeodomain of the human Hesx1 orthologue could be linked to familial cases of SOD and hypopituitarism (Brickman et al., 2001; Carvalho et al., 2003; Cohen et al., 2003; Dattani et al., 1998; Sobrier et al., 2006; Sobrier et al., 2005).

Recent studies showed that the absence of Hesx1 in mice leads to a posterior transformation of the anterior forebrain (Andoniadou et al., 2007). These findings were in line with data from Xenopus, where downregulation of Xanf leads to an anterior shift of genes involved in posterior forebrain regulation (Ermakova et al., 2007). Even though overexpression of Xanf results in an expansion of the rostral forebrain in Xenopus (Ermakova et al., 1999), this effect could not be observed in mice (Andoniadou et al., 2007).

Taken together, previous research has revealed an important role of Hesx 1 as a transcriptional repressor during early anterior forebrain and pituitary development in vertebrates.

\section{Anterior pituitary development and consequences of Hesx1 misregulation}

The pituitary gland is a crucial component of the endocrine system. It is composed of two anatomically and functionally distinct structures: the posterior lobe or the neurohypophysis and the non-neural adenohypophysis, including the anterior and intermediate lobe.

The posterior lobe is composed of terminal axons of the hypothalamic magnocellular neurons. These neurons synthesize peptide hormones oxytocin and vasopressin, which are transported down to the axonal terminals of the posterior lobe. From the posterior lobe they are released into the blood circulation, where they target the uterus, the mammary glands and the kidney tubules respectively. 
The anterior pituitary gland regulates a great variety of processes, including growth, metabolism, reproduction, lactation and the body's response to stress by means of secreting specific hormones. Secretion of hormones from distinct endocrine cell types is regulated by the hypothalamus and positive/negative feedback loops from the peripheral organs. The anterior lobe consists of five different endocrine cell types.

(1) Somatotropes secrete growth hormone $(\mathrm{GH})$ that regulates linear growth and metabolism by targeting the liver, kidney and most other tissues.

(2) Lactotropes synthesize prolactin (PRL) which targets the mammary gland and controls milk production in females.

(3) Thyrotropes produce thyroid-stimulating hormone (TSH) and affect the thyroid.

(4) Corticotropes secrete adrenocorticotrophic hormone (ACTH), a proteolytic product of proopiomelanocortin (POMC), which stimulates the production and secretion of glucocorticoids by the adrenal cortex.

(5) Gonadotropes synthesize luteinizing hormone (LH) and follicle-stimulating hormone (FSH) which stimulate the gonads to initiate sexual maturation and maintain reproductive function.

FSH, LH and TSH are glycoproteins consisting of a common $\alpha$-subunit ( $\alpha$ GSU), and a specific $\beta$-subunit (FSH $\beta, \mathrm{LH} \beta$, and TSH $\beta$; (Rizzoti and Lovell-Badge, 2005; Scully and Rosenfeld, 2002; Zhu et al., 2007; Zhu et al., 2005)).

Development of the anterior pituitary gland is highly conserved in vertebrates. The anterior pituitary anlage is localized in the midline portion of the anterior neural ridge, rostral to the region of the neural plate that is destined to give rise to the hypothalamus and the posterior lobe of the pituitary (Couly and Le Douarin, 1988; Eagleson and Harris, 1990; Gleiberman et al., 1999). Due to growth of the forebrain, the cells of the midline anterior neural ridge are displaced and become a layer of thickened cells in the oral ectoderm. The formation of Rathke's pouch, the primordium of the anterior pituitary gland, from these cells is induced by the infundibulum at around $8.5 \mathrm{dpc}$ (Gleiberman et al., 1999). The infundibulum, an evagination of the ventral diencephlon that will subsequently give rise to the posterior lobe, is in direct contact with Rathke's pouch and 
acts as a key organizing center for the patterning and commitment. This initial phase of proliferation and determination involves the combinatorial and opposing activity of signaling molecules like BMPs, Wnts, FGFs, Shh, Notchs and EGF (reviewed in Scully and Rosenfeld, 2002; Zhu et al., 2007). These transient signaling gradients induce the differential expression of specific transcription factors which subsequently lead to the precise spatial and temporal differentiation of hormone secreting cell types (Figure 2.; Japon et al., 1994; Simmons et al., 1990).

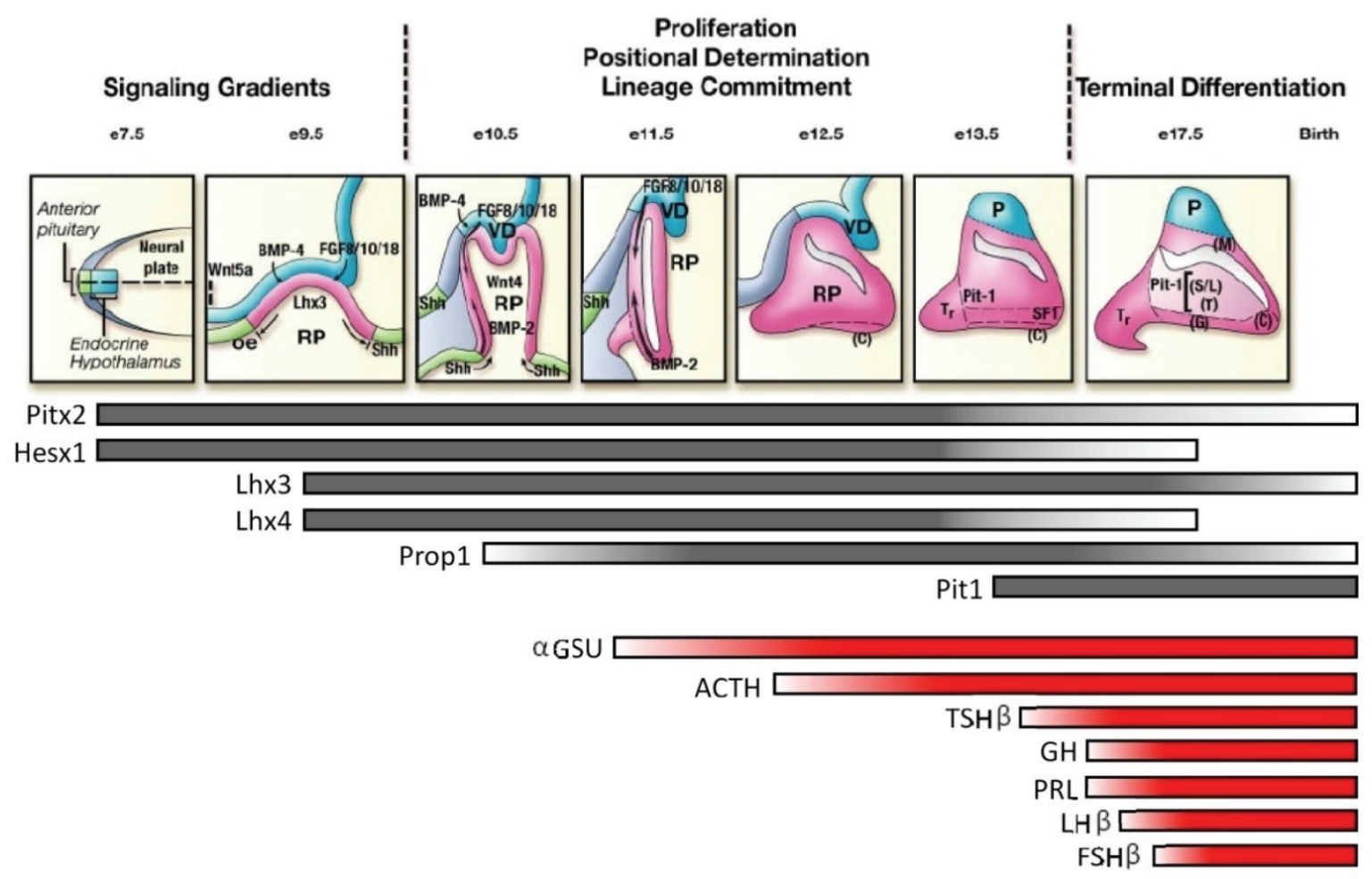

Figure 2. Signaling molecules, selected transcription factors and hormones during pituitary development.

The midline anterior neural ridge gives rise to Rathke's pouch (RP) and subsequently to the anterior pituitary gland. Adjacent to this field is the prospective endocrine hypothalamus located. The ventral diencephalon (VD) expresses BMP4, FGF8/10/18 and Wnt5a and directly contacts the oral ectoderm that is induced to form Rathke's pouch. Shh is expressed throughout the entire oral ectoderm with the exception of Rathke's pouch. The opposing dorsal BMP4/FGF and ventral BMP2/Shh signals during development provide proliferative as well as positional cues by regulating the appearance of several transcription factors (grey bars). This combinatorial expression of transcription factors leads finally to the differentiation of the pituitary cell lineages, corticotropes $(C)$, rostral tip thyrotropes $\left(T_{r}\right)$, thyrotropes $(T)$, somatotropes $(S)$, lactotropes (L) and gonadotropes (G). The approximate expression of the hormones is indicated (red bars). The dorsal region of the anterior pituitary becomes the intermediate lobe populated by melanotropes (M) and the invaginating ventral diencephalon gives rise to the posterior lobe of the pituitary gland (modified from Zhu et al., 2007). 
Some transcription factors that are directly or indirectly involved in Hesx 1 regulation and activity are described below and are displayed in Figure 2., an in-depth review with detailed description of signaling molecules and transcription factors was recently published by Zhu et al. (Zhu et al., 2007).

The bicoid-related Pitx1/2 transcription factors are expressed together with Hes $x 1$ in the anterior neural plate. They regulate cell proliferation, survival and differentiation. Pit $\times 1^{-1}$ mice display mild pituitary defects with a decrease of $F S H \beta, L H \beta$, and TSH $\beta$ expression but an increase of POMC expressing cells (Szeto et al., 1999). Pitx2 deficiency does not allow a pituitary development past pouch formation with only a few cells producing POMC. These phenotypes were shown to be due to a decrease in proliferation and an increase in apoptosis (Kioussi et al., 2002; Suh et al., 2002). Together, Pitx1 and 2 are essential for the induction of $\operatorname{Lh} \times 3$ (Charles et al., 2005).

The LIM-homeodomain proteins $L h x 3$ and $L h x 4$ are expressed in the developing pouch from $9.5 \mathrm{dpc}$ on. Whereas $L h x 3$ is expressed in the anterior and intermediate lobe during development and throughout adulthood, $L h \times 4$ remains restricted to the anterior lobe and is down-regulated at around $15.5 \mathrm{dpc}$. Lhx3 deficient mice form a definitive Rathke's pouch but in this case the pouch fails to develop any further from this initial induction. The pouch is not able to maintain Hesx1 expression and to induce Pit1. Endocrine cell types of the anterior and intermediate lobe are completely absent with the exception of some corticotropes (Sheng et al., 1996). The anterior lobe of $L h \times 4^{-/}$mice is hypoblastic due to increased cell death during development. Numbers of somatotropes, corticotropes, thyrotropes and gonadotropes are significantly reduced (Raetzman et al., 2002).

Prop1 (Prophet of Pit1) is a paired-like homeodomain transcription factor that is expressed in the developing pituitary gland in a reciprocal but overlapping fashion with Hesx1. The first transcripts can be found around $10.5 \mathrm{dpc}$ with a peak at $12.5 \mathrm{dpc}$, and the expression attenuates from $14.5 \mathrm{dpc}$ on. Both Prop1 and Hesx1 can bind as homo- or hetero dimers to a well-described palindromic site (Sornson et al., 1996; Wilson et al., 1993). Prop1 acts as a transcriptional repressor for Hesx1 and as an activator for Pit1 (Olson et al., 2006; Sornson et al., 1996). Hesx1 prevents Prop1 from initiating the program required for Pit-1 and gonadotrope lineage differentiation (Dasen et al., 2001). A 
homozygous mutation in the homeodomain of Prop1 in the Ames dwarf mice (Sornson et al., 1996) and a target deletion of Prop1 (Nasonkin et al., 2004) display an absence in Pit1 dependent cell types (somatotropes, lactotropes and thyrotropes) and a delay in the differentiation of gonadotropes. Interestingly, the Armes dwarf mice display a prolonged expression of Hesx1 (Sornson et al., 1996). Premature expression of Prop1 under the control of the Pitx1 promoter leads to an absence of the anterior pituitary gland with no induction of Lhx3 (Dasen et al., 2001). In addition, continuous expression of Prop1 under the control of the $\alpha$ GSU regulatory element leads to a delay in terminal differentiation of gonadotropes, resulting in transient hypogonadism and hypothyroidism (Cushman et al., 2001).

Pit1 is a POU domain containing transcription factor that is initially expressed in the anterior lobe from $13.5 \mathrm{dpc}$ on and continues in somatotropes, lactotropes and thyrotropes throughout adult life. In mouse mutant models, Pit1 has been shown to be essential for the differentiation of these cell types (Camper et al., 1990; Li et al., 1990). Transcriptional regulation of GH,PRL,TSH 3 and Pit1 itself is Pit1-dependent (Andersen and Rosenfeld, 2001).

Hesx 1 and its co-repressor TLE1 have a spatial and temporal overlapping expression pattern in the developing Rathke's pouch with a slightly longer expression of TLE1 (Dasen et al., 2001).

Targeted deletion of Hesx1 results in a phenotype similar to SOD (Dattani et al., 1998). The pituitary gland of Hesx 1 deficient mice displays a variable phenotype. In approximately $5 \%$ of the mice an initial thickening of the oral ectoderm and $L h \times 3$ induction is observed but the pituitary gland is lacking at $18.5 \mathrm{dpc}$. Yet, the majority of the Hes $\times 1^{-1-}$ mice display multiple oral ectoderm invaginations and overproliferation of all endocrine pituitary cell types. The expression domains of $L h x 3$ and Prop1 are increased within Rathke's pouch and FGF8 and FGF10 domains are expanded rostrally (Dasen et al., 2001; Dattani et al., 1998; Martinez-Barbera et al., 2000). Misexpression of Hesx1 under the control of either the Pitx 1 or the $\alpha$ GSU promoter to maintain expression during later stages of development displayed a modest reduction of some anterior lobe cell lineages. In contrast, co-expression of TLE1 under the Pitx1 regulating element results in a near to complete absence of all ventral pituitary gland cell types resembling the Prop1 mutant 
phenotype (Gage et al., 1996; Sornson et al., 1996). All Prop1/Pit1 dependent cell lineages as well as gonadotropes are absent while the expression of Prop1 appears to be normal. This phenotype does not occur by the co-expression of TLE1 and a Hesx1 variant with a mutated eh1 domain that prevents TLE1 binding of Hesx1 (Dasen et al., 2001).

\begin{tabular}{|c|c|c|c|}
\hline Mutation & $\begin{array}{l}\text { Molecular } \\
\text { phenotype }\end{array}$ & Effect on pituitary gland & References \\
\hline \multicolumn{4}{|l|}{ Mouse mutants } \\
\hline Hesx1 knockout & $\begin{array}{l}\text { Loss of Hesx } 1 \text {; } \\
\text { Increase of } L h \times 1 \text { and } \\
\text { Prop1; } \\
\text { Rostral extension of } \\
\text { FGF8/10 }\end{array}$ & $\begin{array}{l}\text { Absence of the pituitary gland or } \\
\text { multiple oral ectoderm invaginations } \\
\text { and cellular overproliferation }\end{array}$ & $\begin{array}{l}\text { (Dattani et al., } \\
\text { 1998) }\end{array}$ \\
\hline $\begin{array}{l}\text { Pitx1- or } \alpha G S U \text { - } \\
\text { promoter driving } \\
\text { Hesx1 }\end{array}$ & $\begin{array}{l}\text { Prolonged Hesx1 } \\
\text { expression }\end{array}$ & $\begin{array}{l}\text { Modest reduction of some pituitary } \\
\text { cell lineages }\end{array}$ & (Dasen et al., 2001) \\
\hline $\begin{array}{l}\text { Pitx1-promoter } \\
\text { driving Hesx1/TLE1 }\end{array}$ & $\begin{array}{l}\text { Prolonged } \\
\text { Hesx1/TLE1 } \\
\text { expression }\end{array}$ & $\begin{array}{l}\text { Near complete absence of all ventral } \\
\text { pituitary gland cell types }\end{array}$ & (Dasen et al., 2001) \\
\hline $\begin{array}{l}\text { Pitx1-promoter } \\
\text { driving Hesx1 eh1 } \\
\text { mut/TLE1 }\end{array}$ & $\begin{array}{l}\text { Prolonged } H e s \times 1_{e h 1} \\
\text { mut } / T L E 1 \text { expression }\end{array}$ & No pituitary gland defects & (Dasen et al., 2001) \\
\hline Prop1 mutants & $\begin{array}{l}\text { Prolonged Hesx1 } \\
\text { expression }\end{array}$ & $\begin{array}{l}\text { Absence of somatotropes, } \\
\text { lacktotropes and thyrotropes; } \\
\text { Delay gonadotropes }\end{array}$ & $\begin{array}{l}\text { (Sornson et al., } \\
\text { 1996) }\end{array}$ \\
\hline \multicolumn{4}{|l|}{ Human mutations } \\
\hline $\begin{array}{l}\text { HESX1 mutations in } \\
\text { the homeodomain }\end{array}$ & $\begin{array}{l}\text { Absence, decrease or } \\
\text { increase in DNA } \\
\text { binding ability }\end{array}$ & IGHD, CPHD and SOD & $\begin{array}{l}\text { (reviewed in } \\
\text { Dattani, 2005; Zhu } \\
\text { et al., 2005) }\end{array}$ \\
\hline $\begin{array}{l}\text { HESX1 mutations in } \\
\text { the eh1 domain }\end{array}$ & $\begin{array}{l}\text { Impaired TLE1 } \\
\text { recruitment }\end{array}$ & CPHD & $\begin{array}{l}\text { (Carvalho et al., } \\
\text { 2003) }\end{array}$ \\
\hline
\end{tabular}

Table 1. Pituitary phenotypes due to Hesx1 misexpression and mutations.

To date several Hesx1 mutations in humans were found to be involved in SOD and hypopituitarism. These mutations were found to be spread across all four exons and lead to an absence (Sobrier et al., 2006; Tajima et al., 2003), decrease (Dattani et al., 1998; Thomas et al., 2001), or increase (Cohen et al., 2003) of the DNA binding ability. In one case, the eh1 domain of Hesx 1 contained a missense mutation leading to an impaired ability to recruit TLE1 (Carvalho et al., 2003). The patients displayed isolated GH 
deficiency (IGHD) or combined pituitary hormone deficiency (CPHD) together with various degrees of extrapituitary SOD phenotypes. The mutations were found in the homozygous as well as the heterozygous state. Interestingly, heterozygous mutation in humans result in a milder phenotype as it is observed in $1 \%$ Hes $\times 1^{+/-}$mice (Dattani et al., 1998).

In summary, these data suggest that the tightly regulated expression of signaling molecules and transcription factors in a correct temporal and spatial order is vital for the proper development of the anterior pituitary gland. Disruptions of the normal transcriptional patterns and levels have a tremendous influence on the developing gland and the subsequent differentiation of the endocrine cell lineages of the pituitary. Hesx 1 showed to be a critical homeodomain transcription factor involved in early pituitary gland development. Moreover, spatial and temporal distinct downregulation of Hesx1 during later development is necessary to allow ventral pituitary cell lineage differentiation (see as well Table 1.).

\section{The ubiquitin ligase Cdh1-APC and its inhibitor Mad2/2}

The spatial and temporal control of Hesx1 at the transcriptional level is crucial for normal anterior pituitary gland development. Besides control at the transcriptional level and alternative RNA splicing, the precise tuning of protein activity and abundance can be achieved by post-translational modifications (PTMs). PTMs allow cells to respond instantly to cues received from their environment, such as growth factors, cell-cycle checkpoints, nutrient status and DNA damage. They include methylation, acetylation, phosphorylation, hydroxylation, sumoylation and ubiquitination. These modifications expand the properties of the protein, including alteration of its function, modulation of proteininteraction domains and half-life (reviewed in Seet et al., 2006; Yang, 2005).

Among these PTMs ubiquitination plays a key role in the regulation of both protein function and levels. Monoubiquitination of the e.g. proliferating cell nuclear antigen (PCNA), a polymerase processivity factor that forms a sliding clamp around DNA, is a response to DNA damage and stabilizes the interactions with translesion synthesis polymerases to bypass DNA lesions (Andersen et al., 2008; Hoege et al., 2002; Kannouche et al., 2004; Stelter and Ulrich, 2003). At the same time, polyubiquitination of substrates with chains of at least four ubiquitins is a well characterized signal which renders proteins 
susceptible to degradation via the $26 \mathrm{~S}$ proteasome (Thrower et al., 2000). Ubiquitination of target proteins is a result of the sequential activity of three classes of enzymes. The ubiquitin activating enzyme (E1) forms a thioester linkage between its active site cysteine and the carboxyl-terminal glycine of ubiquitin. This activated ubiquitin on E1 is then transferred to the ubiquitin conjugating enzyme (E2) by transesterfication. Finally, the ubiquitin protein ligase (E3) binds to the ubiquitin-charged E2 and a target protein and enables the formation of an isopeptide linkage between the carboxyl-terminal glycine of the ubiquitin and the $\varepsilon$-amino-group of a lysine residue of the substrate or an already attached ubiquitin (reviewed in Hershko and Ciechanover, 1998; Pickart, 2001). Substrate specificity is mediated mainly through the E3 ligase and there are several hundreds of predicted E3 ligases based on the so far known E3 motifs, including HECT, RING, U-box and PHD/LAP finger domains (reviewed in Fang and Weissman, 2004).

\section{The anaphase promoting complex}

The anaphase promoting complex/cyclosome (APC/C; APC) is a RING-type E3 ligase that has essential functions in and outside of the eukaryotic cell cycle. The APC consists of at least 12 subunits with APC11, the RING finger protein and APC2, a Cul1-related scaffold protein, being the catalytic core of the complex.

Still, this complex can only ubiquitinate substrates by interacting with a E2 enzyme and a co-activator (among them; Cdc20 or Cdh1; (reviewed in Peters, 2006)). Substrate specificity is largely achieved by the co-activators which target proteins with distinct recognition motifs. Both Cdc20 and Cdh1 recognize substrates with a destruction or D-box (RXXLXXXXN/D/E) motif in its sequence (Fang et al., 1998; Glotzer et al., 1991), in addition Cdh1 targets proteins primarily containing a KEN-box (KENXXXN/D), A-box (QRVL), O-box (LXXXN) or CRY-box (CRYXPS) motif (Araki et al., 2005; Littlepage and Ruderman, 2002; Pfleger and Kirschner, 2000; Reis et al., 2006).

Initially, the APC complex was identified as an ubiquitin ligase specific for cell cycle control, more recently it was found that the APC complex adopted new roles in postmitotic differentiated cells. In both cases proteins containing a recognition motif are targeted for polyubiquitination and subsequent degradation (reviewed in Kim and Bonni, 2007; Peters, 2002). 


\section{$A P C$ regulation and cell cycle control}

The APC plays a central role in the rapid, coordinated and oscillating degradation of specific cell cycle proteins required for an appropriate cell cycle progression. It is involved in regulating mitosis and the $\mathrm{G} 1$ phase by targeting cyclins for degradation and coordinating sister-chromatid separation (reviewed in Thornton and Toczyski, 2006). Activation of the APC in early mitosis is achieved by binding of Cdc20. The co-activator Cdc20 has already been synthesized during S and G2 phase, but an association with the APC requires the preceded phosphorylation of several APC subunits (Kraft et al., 2003; Rudner and Murray, 2000). Cdc20-APC mediates the degradation of cyclins as well as securin, permitting sister chromatid separation and disassembly of the mitotic spindle. Cdh1 that was phosphorylated during the S and G2 phases by different cyclin-dependent kinases (Cdks) is dephosphorylated upon the deactivation of these Cdks and subsequent associates with the APC complex. The assembly of Cdh1-APC renders Cdc20 as a substrate of the APC which is degraded between mitosis and G1/S phase (Prinz et al., 1998). Cdh1APC activity during late mitosis and G1 phase targets cyclins thereby keeping Cdk activity levels low which prevents a premature entry into S phase and allows loading of the prereplication complexes onto the origin of replication (Diffley, 2004). In addition, Cdh1-APC targets the substrate adaptor subunit of the E3 ligase SCF. SCF controls the G1-S transition by targeting Cdk inhibitors (Bashir et al., 2004; Wei et al., 2004). The stimulation of G1-S transition occurs finally by at least two mechanisms. On the one hand, an APC specific E2 enzyme is targeted by Cdh1-APC, therefore initiating its own deactivation and in addition the early mitotic inhibitor (Emi1) is expressed at the G1-S transition. Emi1 is able to inhibit preformed Cdc20-APC and Cdh1-APC complexes (Hsu et al., 2002; Reimann et al., 2001). Besides the Emi1 inhibition and the opposing phosphorylation on Cdc20-APC and Cdh1-APC that is required for a coordinated progression through $M$ and G1 phase, several other APC inhibitors are known (Peters, 2006; Thornton and Toczyski, 2006). Among them are Mad1, Mad2 and BubR1 as components of the mitotic checkpoint complex. This complex is part of the spindle assembly checkpoint that inhibits Cdc20-APC function as a response to unattached kinetochors delaying subsequently the degradation of cyclin B and securin (Li et al., 1997; Sudakin et al., 2001). 
A homolog of Mad2 is the Mad2I2 protein, also referred to as MAD2B and Rev7. The human MAD2L2 shares 23\% identity and 54\% similarity with MAD2. The murine Mad2I2 protein consists of 211 amino acids that shows high degree of identity among vertebrates (about $94 \%$ ) but only $23 \%$ identity and $53 \%$ similarity when compared to Saccharomyces cerevisiae Rev7 (Cahill et al., 1999; Lawrence et al., 1985; Murakumo et al., 2000). The protein consists basically of one domain (amino acids 13-183), the HORMA domain. This domain has been suggested to be involved in protein-protein interaction as well as in recognizing chromatin status (Aravind and Koonin, 1998).

Mad2/2 is able to inhibit ubiquitination through Cdh1-APC and to a lesser extent by Cdc20-APC. This inhibition does not prevent substrate binding to Cdc20 and Cdh1 but it prevents substrate release (Figure 3.). Interestingly, preformed Cdc20-APC and Cdh1-APC complexes are not inhibited by Mad2I2 (Chen and Fang, 2001; Pfleger et al., 2001).

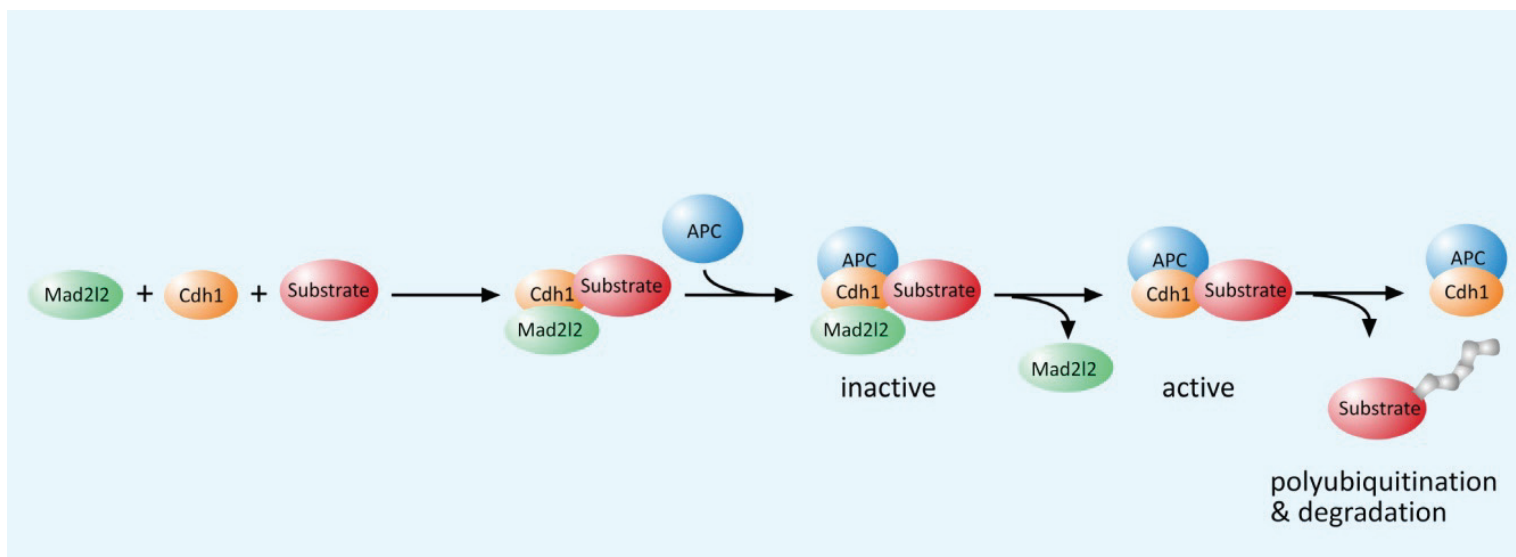

Figure 3. Cdh1-APC substrate ubiquitination in the presence of Mad2/2.

Mad212 binds to the co-activator Cdh1 which does not prevent the targeting of substrates but leads to an inactive complex. Polyubiquitination and subsequent degradation of the substrate through the $26 \mathrm{~S}$ proteasome is mediated only in the absence of Mad212.

The role of the inhibitory effect of Mad2I2 on Cdc20/Cdh1-APC in cell cycle control is still not clear; it seems not to be associated with the spindle assembly checkpoint even though the human MAD2L2 interacts with MAD2 but not with MAD1 alone or in a complex with MAD2 (Chen and Fang, 2001; Murakumo et al., 2000; Pfleger and Kirschner, 2000). Mad2/2 gain and loss of function experiments concerning its function in cell cycle regulation are ambiguous. Overexpression in Xenopus laevis embryos results in a gastrulation arrest after mid blastula transition with cells displaying large nuclei or arrested late in nuclear division (Pfleger et al., 2001). In cell culture systems, 
overexpression of the human MAD2L2 does not lead to alterations of the cell cycle (Murakumo et al., 2000). Knockdown or deletion of Mad2I2 in HeLa or chicken DT40 cells led to retarded growth kinetics (Iwai et al., 2007; McNally et al., 2008; Okada et al., 2005). In contrast, downregulation of Mad2I2 by shRNA in human nasopharyngeal carcinoma cells has no effect on proliferation rate and mitotic exit (Cheung et al., 2006). These differing observations may reflect differences due to the model-systems and due to the distinct RNAi constructs that were used and might affect the extent of Mad2/2 knockdown. Moreover, these different, but not necessarily conflicting observations may reflect the difficulties in identifying changes in the complex regulatory processes. To interpret these results, a function of Mad2I 2 as part of the translesion polymerase $\zeta$ needs consideration (see next chapter).

Overall, the intricate functions of the APC complex and its co-activators in cell cycle control require a precise and tight regulation of its activity. This regulation is achieved by phosphorylation, interaction with regulatory proteins and ubiquitination. Mad2/2 was shown to be one of them.

\section{Patterning during embryonic development}

Mutations in the APC or its activator Cdc20 in Saccharomyces cerevisiae, Drosophila melanogaster and Caenorhabditis elegans resulted in cells arrested at the metaphase to anaphase transition (Furuta et al., 2000; Golden et al., 2000; Irniger et al., 1995; Sigrist and Lehner, 1997). In mice deficient for the subunits Apc2 and Apc10 embryos are lethal early in development (Pravtcheva and Wise, 1996; Wirth et al., 2004). Interestingly, Cdh1 and core subunits of the APC are expressed in differentiated adult mouse tissues, whereas Cdc20 and Cdk1 are not, suggesting that Cdh1-APC is not restricted to proliferating cells. In fact, postmitotic neurons express functional Cdh1-APC (Gieffers et al., 1999). Knockdown experiments of Cdh1 by RNAi in rodent postmitotic neurons revealed a function of the Cdh1-APC complex in axon growth and patterning (Konishi et al., 2004). SnoN, a transcriptional co-repressor involved in TGF- $\beta$-Smad2 signaling, was found to be a target of Cdh1-APC. The ubiquitination of SnoN by Cdh1-APC in these postmitotic neurons and subsequent axonal morphogenesis is regulated by TGF- $\beta$-Smad 2 signaling (Stegmuller et al., 2008; Stegmuller et al., 2006). Furthermore Id2 (inhibitor of DNA binding 2) was identified as a substrate of Cdh1-APC. Id2 is a transcriptional 
regulator that among others enhances cell proliferation probably by inhibiting bHLH transcription factors. Stabilization of Id2 by mutating the D-box revealed a similar phenotype in cerebellar granule neurons as earlier described by Konishi et al. (Lasorella et al., 2006). Studies in Drosophila and C. elegans have revealed additional functions of Cdh1-APC in the nervous system. A loss-of-function mutant for APC2 in Drosophila revealed an increase of neuromuscular junction size (van Roessel et al., 2004). In C. elegans it was furthermore found that Cdh1-APC is involved in regulating the abundance of glutamate receptors (Juo and Kaplan, 2004).

Besides these functions in the nervous system, Cdh1-APC has also been identified to play a crucial role in lens differentiation. Upon TGF- $\beta$ signaling SnoN is targeted by Cdh1-APC for degradation (see also Stegmuller et al., 2008) resulting in a cell cycle arrest followed by terminal lens cell differentiation (Wu et al., 2007). This finding fits with observations from quiescent hepatocytes, where an deletion of APC2 leads to a re-entry into the cell cycle and an subsequent arrest in a mitotic-like state (Wirth et al., 2004). In addition to Id2, two other proteins involved in cell cycle regulation and differentiation where found to be targeted for degradation by the APC. The homeoproteins Six1 and HOXC10 displayed a cell cycle dependent degradation mediated by the APC complex (Christensen et al., 2006; Gabellini et al., 2003).

In conclusion, these studies clearly identify a role of the Cdh1-APC complex and its function as an E3 ligase besides cell cycle regulation. One important function is apparently the mediation of the $\mathrm{G} 1$ phase cell cycle arrest and subsequent terminal differentiation of cell lineages. This is achieved amongst other things by targeting different substrates for ubiquitination, including factors involved in transcriptional regulation.

\section{Polymerase $\zeta:$ Function of Mad2/2 and Rev3 in DNA damage repair}

Cells need to deal with thousands of DNA lesions per cell cycle. DNA lesions are created by the influence of environmental agents, like UV-irradiation or chemicals and by endogenous damage. Endogenous damage is mediated through metabolic byproducts including reactive oxygen species, spontaneous depurination, and DNA single- and double-strand breaks from deoxyribose oxidation or replication fork collapse. Approximately 5000 DNA single-strand lesions are generated per nucleus during a single 
cell cycle (Vilenchik and Knudson, 2003). Most of these lesions are repaired by essentially error-free mechanisms, including nucleotide excision repair, base excision repair or mismatch repair. However, about $1 \%$ of these single-strand lesion remain unrepaired and give rise to double-strand breaks (Vilenchik and Knudson, 2003). An early response to double-strand breaks is the phosphorylation of H2AX on Ser 139 ( $\gamma-\mathrm{H} 2 \mathrm{AX}$; Rogakou et al., 1998), leading finally in the homologous recombination or non-homologous end-joining pathway (reviewed in Li and Heyer, 2008; Weterings and Chen, 2008). To prevent unrepaired non-coding lesion from stalling DNA replication which may cause a collapse of the replication fork and a subsequent double-strand break, cells have translesion synthesis (TLS) polymerases (polymerase $\eta, \mathrm{L}, \mathrm{K}, \zeta$ and Rev1). These polymerases incorporate a nucleotide opposite a lesion with low fidelity and are able to extend DNA from mismatch primer templates. In other words, these polymerases enable DNA replication to be continued but at the expense of a high probability of generating mutations (reviewed in Lehmann, 2006). The "polymerase switch" from the replicative polymerase to a TLS polymerase is achieved by mono-ubiquitination of PCNA (reviewed in Andersen et al., 2008; Hoege et al., 2002).

\section{Polymerase $\zeta$}

Mad2I2 as an inhibitor of the Cdh1-APC complex has been already earlier found in Saccharomyces cerevisiae to be involved in TLS as a subunit of polymerase $\zeta$ (Lawrence et al., 1985). Polymerase $\zeta$ consists of two subunits, the catalytic polymerase subunit Rev3, a B-family type polymerase with low fidelity and no 3' to 5' exonuclease activity (reviewed in McCulloch and Kunkel, 2008), and the accessory subunit Mad2/2 which enhances the catalytic activity up to 20 to 30 folds (Nelson et al., 1996). In S. cerevisiae, polymerase $\zeta$ interacts with Rev1 and mono-ubiquitinated PCNA at stalled replication forks. Rev1 displays a dCMP transferase activity and seems to be an important scaffold protein which associates as well with other TLS polymerases. Polymerase $\zeta$ in concert with Rev1 is able to extend DNA from mismatched primer-templates and AP (apurinic and apyrimidinic) sites but only at the expense of creating mutations (Figure 4.). In fact, studies in $S$. cerevisiae showed that Rev1 and polymerase $\zeta$ are responsible for most of the spontaneous and damage-induced mutations created by DNA damaging agents (reviewed in Murakumo, 2002). In addition, polymerase $\zeta$ has been shown to be involved in 
recombinational repair of double-strand breaks by a not yet defined mechanism (Holbeck and Strathern, 1997; Rattray et al., 2002).

A

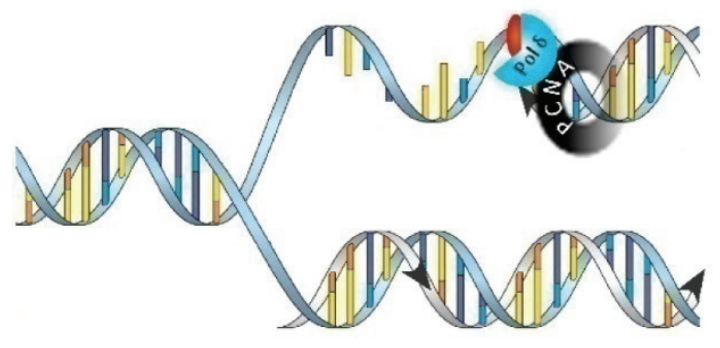

$\mathrm{C}$

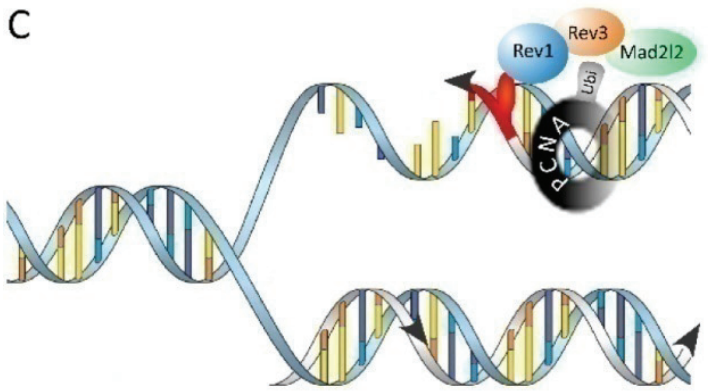

B

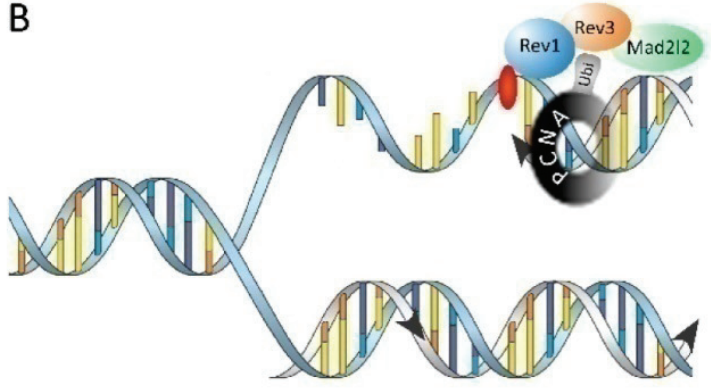

D

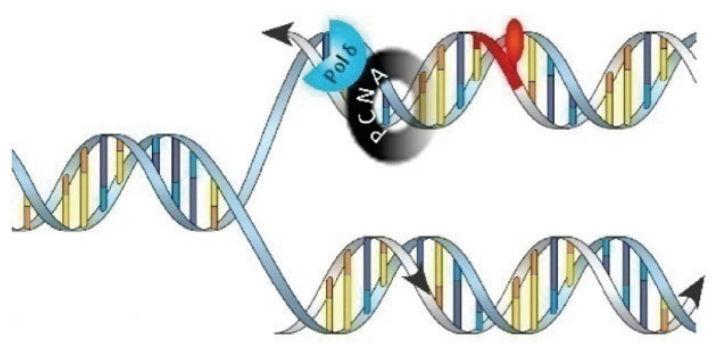

Figure 4. DNA lesion bypass by S. cerevisiae Rev1-polymerase $\zeta$ at a stalled replication fork.

(A) DNA replication polymerase $\delta$ is unable to bypass the non-coding lesion (red) and is stalled. (B) The stalled replication fork induces the mono-ubiquitination (Ubi, grey) of PCNA by the ubiquitin E2-E3 complex Rad6-Rad18. Mono-ubiquitination of PCNA causes the "polymerase switch" from polymerase $\delta$ to TLS polymerases, including Rev1-polymerase $\zeta$. (C) Rev1-polymerase $\zeta$ inserts a nucleotide opposite the noncoding lesion and extends several nucleotides. (D) Deubiquitination of PCNA enables that the high fidelity replication is continued (after Gan et al., 2008).

REV3L is widely expressed in several different human tissues and cell lines (Kawamura et al., 2001; Lin et al., 1999). During mouse development expression of Rev3/ starts around $7.5 \mathrm{dpc}$ within the somites followed by an expression in mesoderm derived tissues. The expression becomes more ubiquitously during further development and is later on highest in brain, ovaries and testes (Van Sloun et al., 1999; Wittschieben et al., 2000). Mad2/2 displays quite a similar expression pattern. In Xenopus laevis transcripts can be found from stage 1 on, and later during development it shows a ubiquitous expression across the different tissues with a strong domain in reproductive tissues (van den Hurk et al., 2004). In human tissues transcripts can be found also across all different tissues analyzed so far with a particularly high expression in testes (Murakumo et al., 2000; Nelson et al., 1999; Ying and Wold, 2003). Interaction of REV1, REV3L and Mad2I2 found 
in S. cerevisiae could be confirmed in the human orthologues apart from the REV1-REV3L interaction (Masuda et al., 2003; Murakumo et al., 2001; Murakumo et al., 2000).

Recently it was found that Mad2/2 might also be involved in the integration of the cellular DNA damage response at the transcriptional level. The JNK MAP kinase cascade is activated by several stress signals including DNA damage (reviewed in Kyriakis and Avruch, 2001). The transcription factor Elk-1 is one of the targets that are activated through phosphorylation by the JNK MAP kinase cascade upon DNA damage. Mad2/2 was found to bind Elk-1 and enhances its phosphorylation and subsequent activation, which finally promotes the expression of target genes (Zhang et al., 2007).

\section{Polymerase $\zeta$ deficiency}

Several approaches have been used to study the consequences of Rev gene deficiency. Knockdown experiments of Rev3 in human and mice fibroblasts using RNA interference show a reduced UV radiation-induced mutagenesis rate but neither significant change in sensitivity to UV radiation nor cell viability was observed (Diaz et al., 2001; Li et al., 2002). In contrast, Rev3L showed to be indispensible during mouse development. Three independently generated knockout mice strains display embryonic lethality between 8.5 $\mathrm{dpc}$ and $12.5 \mathrm{dpc}$. Embryos that survive until mid-gestation are disorganized with significantly reduced cell density (Bemark et al., 2000; Esposito et al., 2000; Wittschieben et al., 2000). Generation of Rev3L $L^{-1-}$ mouse embryonic fibroblasts was unsuccessful; the cells entered a quiescent state with cell death occurring over weeks (Wittschieben et al., 2006; Zander and Bemark, 2004). The discrepancy in the results from the anti-sense RNA knockdown and the genetic ablation of Rev3L might be due to the fact that a low level of Rev3L is sufficient for cell survival. However, $\operatorname{Rev} 3 \mathrm{~L}^{-1-}, p 53^{-/-}$mouse embryonic fibroblasts are viable. These cells reveal a slower growth rate, sensitivity towards genotoxic agents, accumulate in the $\mathrm{G} 2 / \mathrm{M}$ phase with a decrease in $\mathrm{S}$ phase cells and display striking chromosomal instability (Wittschieben et al., 2006; Zander and Bemark, 2004). Chicken DT40 cells lacking either Rev3 or Mad2I2 display a decreased viability and growth kinetics. These cells are more sensitive towards genotoxic agents and show an increase in chromosomal aberrations but an elevated level of sister chromatid exchange, a marker for homologous recombination in post-replication repair (Okada et al., 2005). Mad2/2 knockdown experiments in nasopharyngeal carcinoma cells and human fibroblasts display 
as well more sensitivity towards genotoxic agents with a decreased rate of mutagenesis (Cheung et al., 2006; McNally et al., 2008). Moreover, nasopharyngeal carcinoma cells show an elevated level of $\mathrm{Y}-\mathrm{H} 2 \mathrm{AX}$ with an increase in chromosomal aberration but a reduced frequency of sister chromatid exchange (Cheung et al., 2006) and MAD2L2 deficient fibroblasts display a slower progression through the $\mathrm{S}$ phase (McNally et al., 2008). Disruption of the Drosophila melanogaster Rev3 orthologue leads to an increase of sensitivity towards UV radiation and alkylating agents but has no effect on the mutagenesis rate (Eeken et al., 2001). In Arabidopsis thaliana Rev3 ablation is not lethal but root growth is sensitive to UV-B radiation and even in the absence of radiation root stem cells display an increased mortality (Curtis and Hays, 2007; Sakamoto et al., 2003). AtMad2/2 disruption displays only a minor phenotype with an increased sensitivity to a DNA cross-linker agent and long-term UV-B radiation (Takahashi et al., 2005).

In summary, Rev3 and Mad2l2 as subunits of the polymerase $\zeta$ are required for TLS to prevent the accumulation of double-strand breaks induced by endogenous damage through metabolic side-products. This TLS is responsible for a major fraction of mutations in our genome but its function was shown to be crucial for survival and normal proliferation of cells and during vertebrate embryonic development. 


\section{Aims of this study}

The homeodomain protein Hesx1 is involved in forebrain and anterior pituitary gland development. Spatially and temporally precise expression of this transcription factor has been shown to be crucial for normal anterior pituitary gland development. The regulation of differential gene expression can be accomplished at the level of gene transcription, RNA processing/translation and protein modification. In order to identify and understand the protein modification pathways and protein-protein interactions involved in the regulation of transcription factor function, the aim of this work was to gain further insight into the regulative network in which Hesx1 is embedded.

In a previous study a yeast two-hybrid screen was performed to identify proteins which bind to Hesx1 and might regulate its function during forebrain and pituitary organogenesis. Among others, Mad2l2 a so far unknown interaction partner of Hesx1 was identified (Pilarski, 2004). Since Mad2I2 was shown to be involved in regulating cell cycle progression and DNA damage repair probably coordinating both events, the observed interaction raised the question whether broader functionality of Mad2/2 towards transcriptional regulation could be found. Furthermore, the function of Mad2/2 in inhibiting the Cdh1-APC complex led to the suspicion that Hesx1 might be targeted for ubiquitination by this complex.

The aims of this work were therefore, to (1) verify the binding of Mad2/2 to Hesx1 and (2) to elucidate the biological function of this interaction on a biochemical level. Moreover, (3) the possibility of an ubiquitination of Hesx1 through the Cdh1-APC complex was addressed and (4) Mad2/2 deficient mice were generated in order to gain further insight into the biological function of Mad2/2, both on cell cycle progression, and on DNA damage. The developing pituitary gland of these animals might provide an excellent model system to investigate the significance of the Mad2I2-Hesx1 interaction. The role of Hesx1 is well defined during anterior pituitary gland development and already minor changes in cell type differentiation can be monitored by the expression of different transcription factors and hormones. 


\section{RESULTS}

\section{Hesx1 interacts with Mad2/2 and the APC recognition subunit Cdh1}

In order to verify the interactions of Hesx1 and the potential binding partners found in the $8.5 \mathrm{dpc}$ mouse library screen (Pilarski, 2004) the full length open reading frames including a short linker sequence were cloned into the pPC86 vector. Therefore, the Hesx1 protein was fused to the GAL4 DNA-binding domain (pDB-Leu-Hesx1) and the potential interaction partners were fused to the GAL4 activation domain ( $p P C 86-X)$. The interaction of two proteins, led to the reconstitution of an active GAL4 transcription factor. This functional transcription factor activated the expression of reporter genes, which were driven by promoters containing the GAL4 binding site. The reporters used in this assay were driven by different promoters to reduce the probability of false positives. The $p D B L e u-H e s \times 1$ and candidate pPC86 vectors were transformed into the MaV203 yeast strain and monitored for reporter gene activation. The induction of these reporters was assayed on SC-Leu-Trp-His 50 mM 3AT selection plates (HIS3 reporter) and by the X-Gal assay (lacZ reporter). Hesx 1 was used as a positive control since it is known to homodimerize (Brickman et al., 2001; Dattani et al., 1998; Sornson et al., 1996). All four candidates verified the interaction and showed no self-activation activity. Mad2/2 and Map-1 displayed a strong to very strong interaction with Hesx1 whereas Traf4 and Importin13 showed a weak to moderately strong binding affinity to Hesx1 (Figure 5. A).

As Mad2/2 functions as a regulator of the cell cycle by inhibiting the Cdh1-APC complex (Chen and Fang, 2001; Pfleger et al., 2001) and displays regulatory function in DNA damage repair (Lawrence, 2002; Okada et al., 2005), it was chosen for further analysis as an interesting candidate that might link its functions to transcriptional control.

The Mad212-Hesx1 interaction found in the yeast two-hybrid assay was confirmed by in vitro pull-down experiments. Bacterial recombinant GST-Hesx1 and GST-Mad2/2 fusion proteins were produced and purified. These fusion proteins were tested for binding to Mad2I2 and Hesx1 that were synthesized by in vitro transcription/translation in the presence of $\mathrm{L}-\left[{ }^{35} \mathrm{~S}\right]$ methionine. In these pull-down assays Mad2/2 bound weakly to GSTHesx1 but not to GST alone and Hesx1 bound to GST-Mad2I2 but not to GST (Figure 5. B). 
A

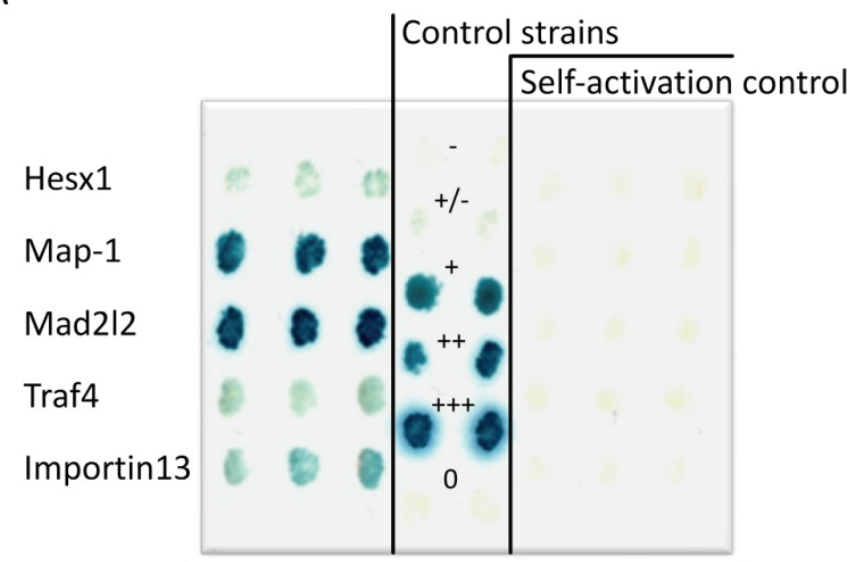

C

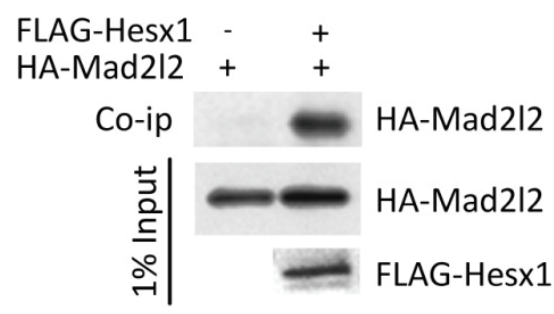

B

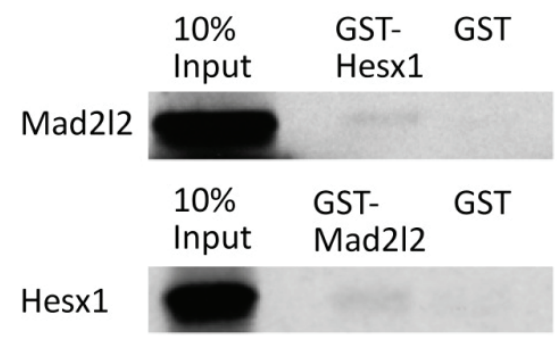

D

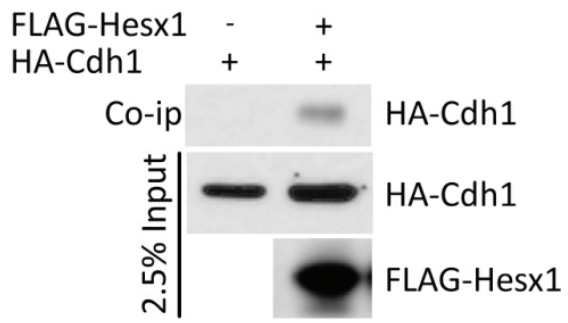

Figure 5. Mad2/2 and Cdh1 interact with Hesx1.

(A) The yeast two-hybrid assay with full orf of Map-1, Mad212, Traf4 and Importin13 confirmed the interaction found in the $8.5 \mathrm{dpc}$ mouse library screen (Pilarski, 2004) as indicated by lacz activity. Control strains: - = no interaction; +/- = weak; + = moderately strong; ++ = strong; +++ = very strong and $0=$ Hesx 1 self activation. (B) In vitro transcribed/translated Mad2I2 binds to a GST-Hesx1 fusion protein but not to GST alone and vice versa. (C) FLAG-Hesx1 specifically co-immunoprecipitates HA-Mad2/2 from COS-7 cell extracts. (B) FLAG-Hesx1 co-immunoprecipitates HA-Cdh1 from COS-7 cell extracts.

Since the interaction strength varied greatly between the yeast two-hybrid assay and the pull-down experiment the binding was validated in mammalian cells. Since no cell line expressing Hesx1 is available and Mad212 expression levels are relatively low, overexpression experiments were performed. Plasmids expressing $\mathrm{N}$-terminal FLAG tagged Hesx1 (FLAG-Hesx1) and HA tagged Mad2/2 (HA-Mad2/2) were transiently transfected in COS-7 cells, and FLAG-Hesx1 was immunoprecipitated with an ANTI-FLAG resin. In analogy to the previously described experiments HA-Mad2/2 was coimmunoprecipitated. However, there was no binding to the negative control where only the FLAG backbone vector was co-transfected with HA-Mad2I2 (Figure 5. C). The interaction of Hesx1 and Mad2I2 raised the question if Hesx1 would bind to the APC substrate recognition subunit Cdh1 as well. Since Mad2I 2 is binding and regulating Cdh1, this interaction would qualify Hesx1 as a potential target of the APC complex. After FLAG- 
Hesx1 and HA-Cdh1 co-transfection in COS-7 cells, FLAG-Hesx1 could specifically coimmunoprecipitate HA-Cdh1 (Figure 5. D).

Taken together, these results confirmed an interaction of Hesx1 with Mad2I2 in vivo and in vitro. Furthermore, Hesx1 bound to the APC substrate recognition subunit Cdh1 in vivo.

\section{Hesx1, Mad2/2 and Cdh1 have overlapping expression domains}

The biological significance of Hesx1 interaction with Mad2I 2 and Cdh1 would imply that these proteins have a spatial and temporal overlapping expression pattern. Hes $x 1$ displays a highly restricted expression pattern in the developing mouse, transcripts are found mainly in the anterior neural ectoderm and Rathke's pouch as confirmed by whole mount in-situ hybridization (Figure 6.; Hermesz et al., 1996; Thomas and Beddington, 1996).

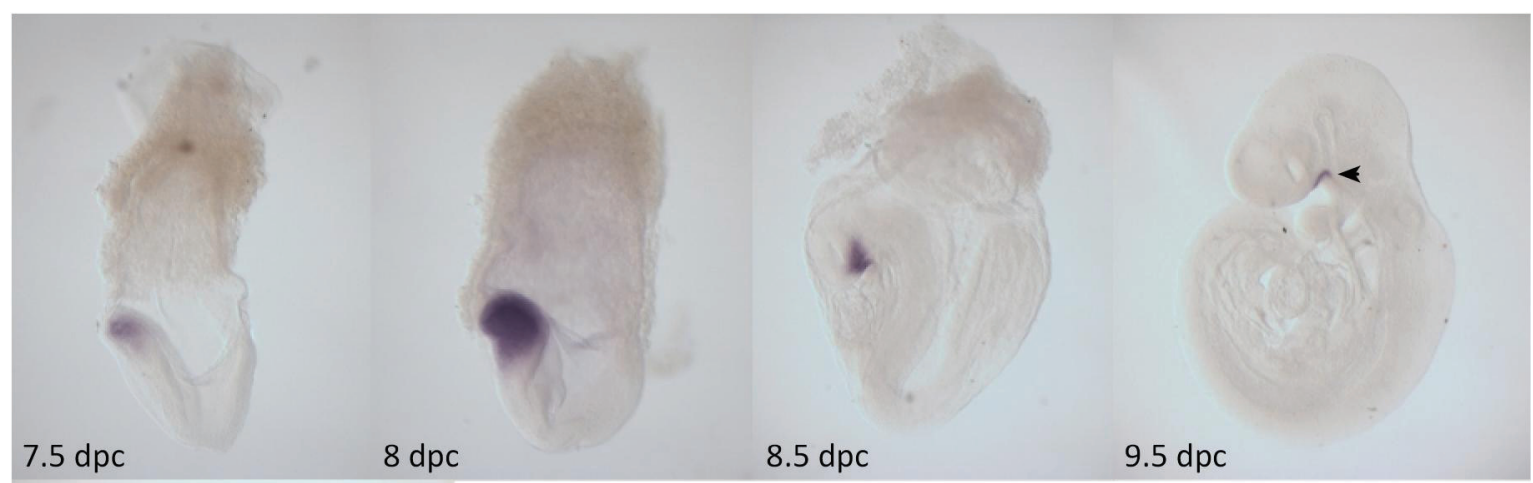

Figure 6. Hesx1 expression pattern during mouse development.

At $7.5 \mathrm{dpc}$ transcripts can be found in the anterior neural ectoderm. This expression domain increases until it gets restricted at $8.5 \mathrm{dpc}$ to the rostral neuroectoderm and forgut endoderm. At $9.5 \mathrm{dpc}$ the expression is restricted to the ventral diencephalon and oral ectoderm, which will give rise to Rathke's pouch (arrow head). Hesx1 transcripts are exclusively

$10.5 \mathrm{dpc}$ found in the developing Rathke's pouch at $10.5 \mathrm{dpc}$ (arrow head).

As described in the introduction, Mad2/2 shows a ubiquitous expression pattern throughout human tissues and Xenopus laevis tissues and embryonic stages. Whole mount in-situ hybridization analysis of Mad2/2 in mice gave no conclusive result (data not shown). Cdh1 is expressed in a variety of mouse tissues and is not restricted to proliferating cells (see introduction). 
To address the question whether Mad2/2, Cdh1 and Hesx1 have overlapping expression domains in mice a RT-PCR analysis was carried out. $8 \mathrm{dpc}$ mouse embryos were isolated and separated in an anterior and posterior part. Subsequently, RNA was isolated from these tissues. RT-PCR analysis revealed that Hesx 1 was only expressed in the anterior part whereas Mad2/2 and Cdh1 were present in anterior as well as posterior tissues (Figure 7. A). Transient expression of FLAG-Hesx1 and HA-Mad2/2 followed by a double immunofluorescent staining with antibodies against the FLAG and HA epitop uncovered a co-localization in the nucleus of COS-7 cells (Figure 7. B). In addition northern blot analysis was performed to assess gene expression across several adult mouse tissues. The result confirmed the expected mRNA size of $1.2 \mathrm{~kb}$ and indicated a ubiquitous expression of Mad2/2 with a slightly higher abundance in kidney, $14 \mathrm{dpc}$ embryos and ovary and a very high level in testis (Figure 7. C).

A

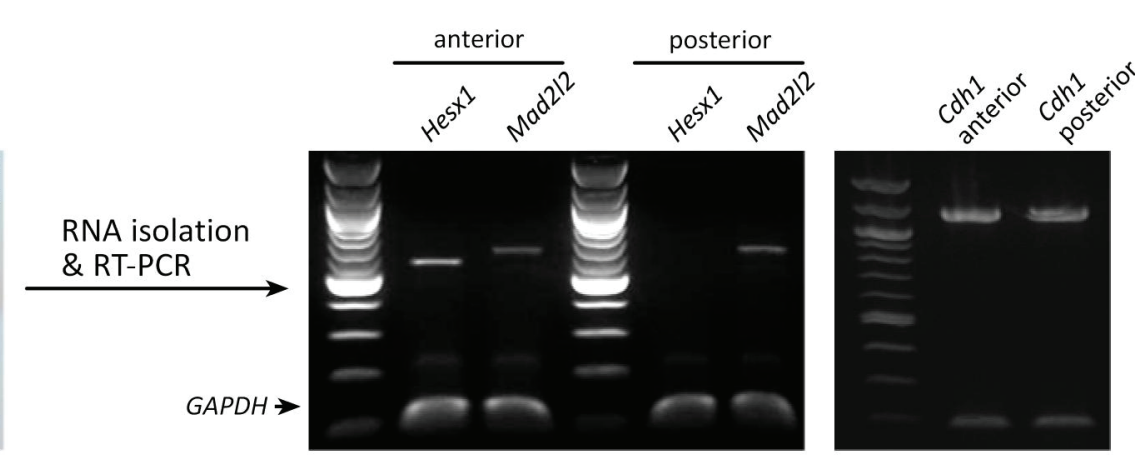

B

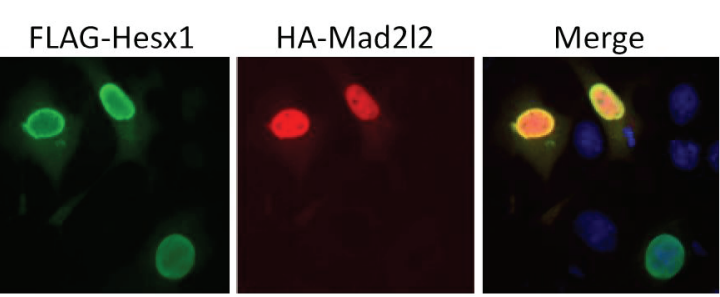

C

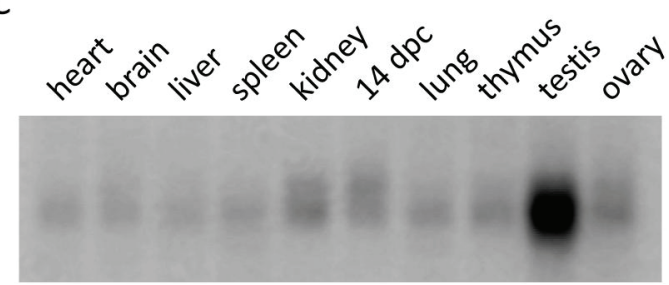

Figure 7. Mad2/2 and Cdh1 expression overlaps with Hesx1.

(A) RNA was isolated from the anterior and posterior part of an $8 \mathrm{dpc}$ embryo. RT-PCR analysis revealed that Hesx 1 was only expressed in the anterior part whereas Mad2/2 and Cdh1 are expressed anterior as well as posterior. GAPDH served as a loading control. (B) Co-expression of FLAG-Hesx1 and HA-Mad2I2 in COS-7 cells display co-localization in the nucleus. (C) Northern blot analysis showed a ubiquitous presence of Mad2/2 RNA in mice with a slight elevation in kidney, $14 \mathrm{dpc}$ embryos and ovary and a strong expression in testis. The northern blot (Ambion FirstChoice Northern Blot) contained $2 \mu \mathrm{g}$ poly(A) RNA per lane. 


\section{Mad2/2 prevents DNA binding of Hesx1}

To gain insight into the nature of the Mad2/2-Hesx1 interaction, the Hesx1 binding site of Mad2/2 was specified by a peptide array. The amino acid sequence of Hesx1 was spotted as 20 meric peptides which were overlapping by 17 amino acids on a cellulose membrane. Recombinant Mad2l2 was shown to bind two elements at the amino-terminal part of the homeodomain (Figure 8. A, B).

A

27. RPEERAPKYENYFSASETRS

28. ERAPKYENYFSASETRSLKR

29. PKYENYFSASETRSLKRELS

30. ENYFSASETRSLKRELSWYR

31. FSASETRSLKRELSWYRGRR

32. SETRSLKRELSWYRGRRPRT

33. RSLKRELSWYRGRRP RTAFT

34. KRELSWYRGRRPRTAFTQNQ

35. LSWYRGRRPRTAFTQNQVEV

36. YRGRRPRTAFTQNQVEVLEN

37. RRPRTAFTQNQVEVLENVFR

B

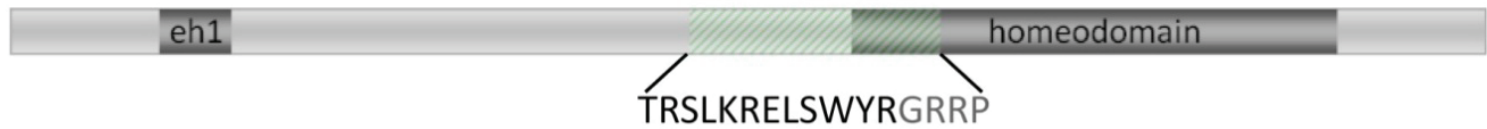

C

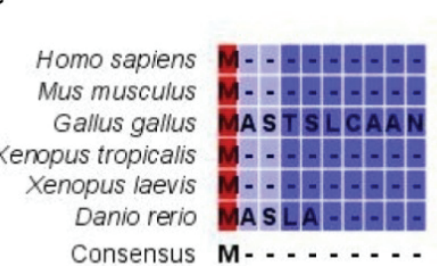

HRPW

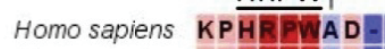

Mus musculus RPHRPWTD-

Gallus gallus KPHR PWMD

Xenopus tropicalis $\mathrm{KHHR} P$ W IQ-

Xenopus laevis KHHRPM I E--
Danio rerio - P YR PW T DV

Danio rerio - P YREWT DVE

Consensus KPHRPWXD -

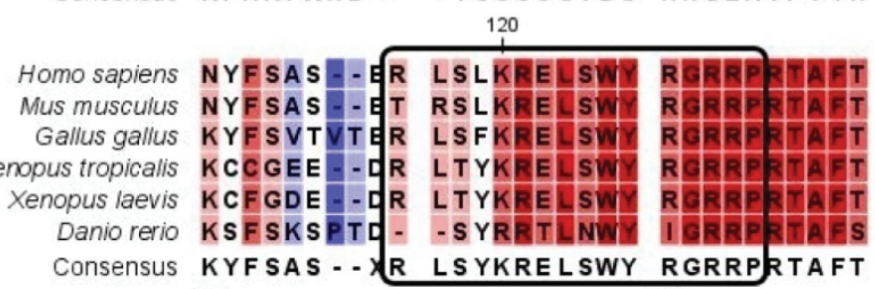

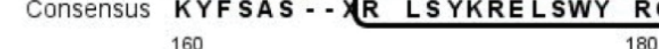

Homo sapiens

Mus musculus DEA QKL N E E

Gallus gallus E L A R K D D E

Xenopus tropicalis E LA GKLA A D

Xenopus laevis E L A S K A A D

Danio rerio ELEKKLQLD

Consensus ELAQKLXLXE DRIQIWFQNR

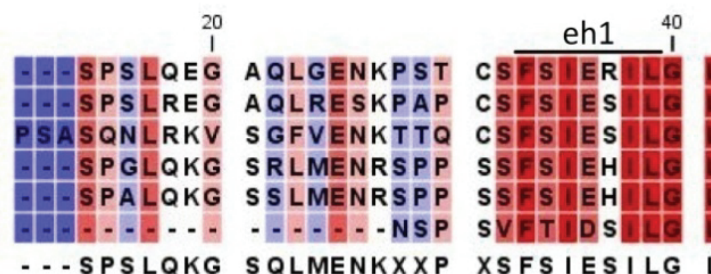

80

\begin{tabular}{l}
-TCSSSGKDG NLCLHVPNPP \\
\hline TCGNSEKDG NPPLHAPDLP
\end{tabular}

- G MH--QLG DPHLQIPVVS

- NSEGV -D GT FWH I PVIS

- CSKGVVN GTCWQIPVIA

PACQNRRV - - ...-.-.VTE

XXCLHIPVIX 180

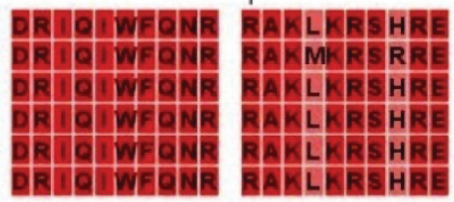

RAKLKRS HRE

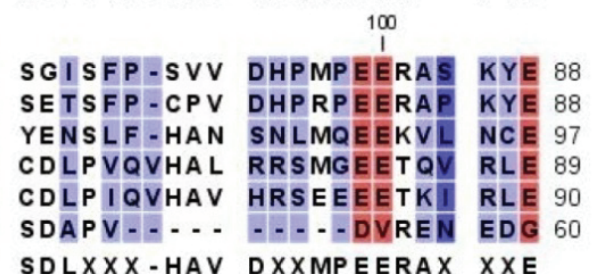

DXXX-HAV DXXMPEERAX XXE

140

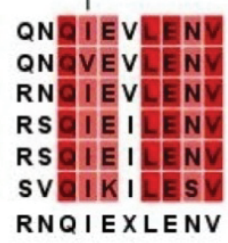

FRVNCYPGDD IRE 139

R R V C Y F C D IRE 139

FMNS YPCID IRE 150

RVNSYPGID IRE 140

RVNS YPGiD VRE 141

EQVNSYPGID IRE 111

FRVNSYPGID IRE

200

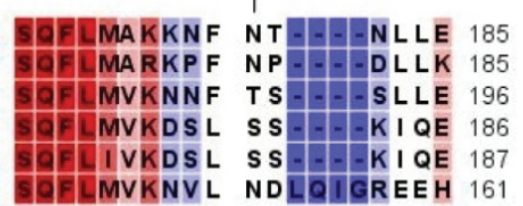

SQFLMVKXXX NS - . - KLLE 
Figure 8. Mad2/2 binds to the N-terminal part of the homeodomain of Hesx1.

(A) Recombinant Mad2l2 binds to the Hesx1 peptide array. The bound peptides are listed and the core peptides are framed in green. (B) The Mad2I2 binding domain of Hesx1 is localized at the N-terminal part of the homeodomain (grey letters = start of the homeodomain). (C) Sequence alignment of Hesx1 in different species. The Mad2/2 binding domain of Hesx1 is highly conserved among the species (framed in black). The background color of the amino acids varies from blue (nonconserved residues) to red (conserved residues).

This region is highly conserved across species like only few other regions of the protein are; such as the engrailed homology domain, the HRPW region and the carboxy-terminal region of the homeodomain (Figure 8. C; (Kazanskaya et al., 1997)).

This finding lead to the idea, that binding of Mad2I2 in this region of Hesx1 might impair the interaction with the N-CoR complex or its DNA binding properties (Figure 9. A). To address the latter, electrophoretic mobility shift assays (EMSA) were performed. Hesx 1 is known to bind to an oligonucleotide containing a palindromic PIII site (PrdQ) (Dattani et al., 1998; Sornson et al., 1996; Wilson et al., 1993). In vitro transcribed/translated Hesx1 was shown to bind to radioactive labeled double-stranded PrdQ-oligonucleotides which led to a prominent shift during electrophoresis, whereas the free oligonucleotides did not led to any shift (Figure 9. B, Lane $3 \&$ 7). This shift was specific to Hesx1 binding as shown by the prominent super-shift when Hesx1 antibodies were added (Figure 9. B, Lane 1). Pre-incubation of Hesx1 with increasing amounts of recombinant Mad2/2 reduced the binding of Hesx1 to the oligonucleotide as indicated by the reduction of the shifted probe (Figure 9. B, Lane 4, 5, 6). Mad2I2 had no binding affinity to the PrdQ sequence (Figure 9. $B$, Lane 2). To determine the specificity of this effect, the same amount of recombinant GST protein was pre-incubated with Hesx1 but had almost no influence on the ability of Hesx1 to bind to the oligonucleotides (Figure 9. B, Lane 8). This demonstrates that Mad2I2 is able to prevent Hesx 1 from binding to its target DNA. 
A

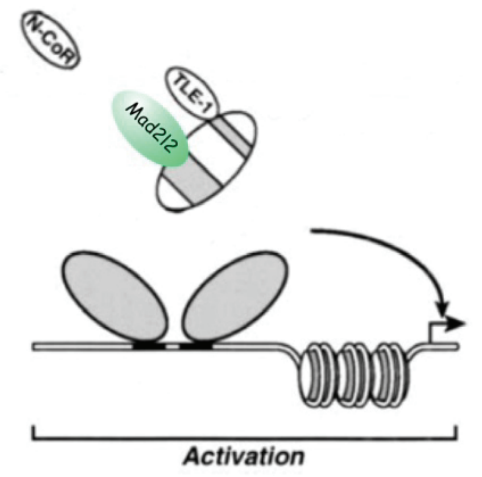

B

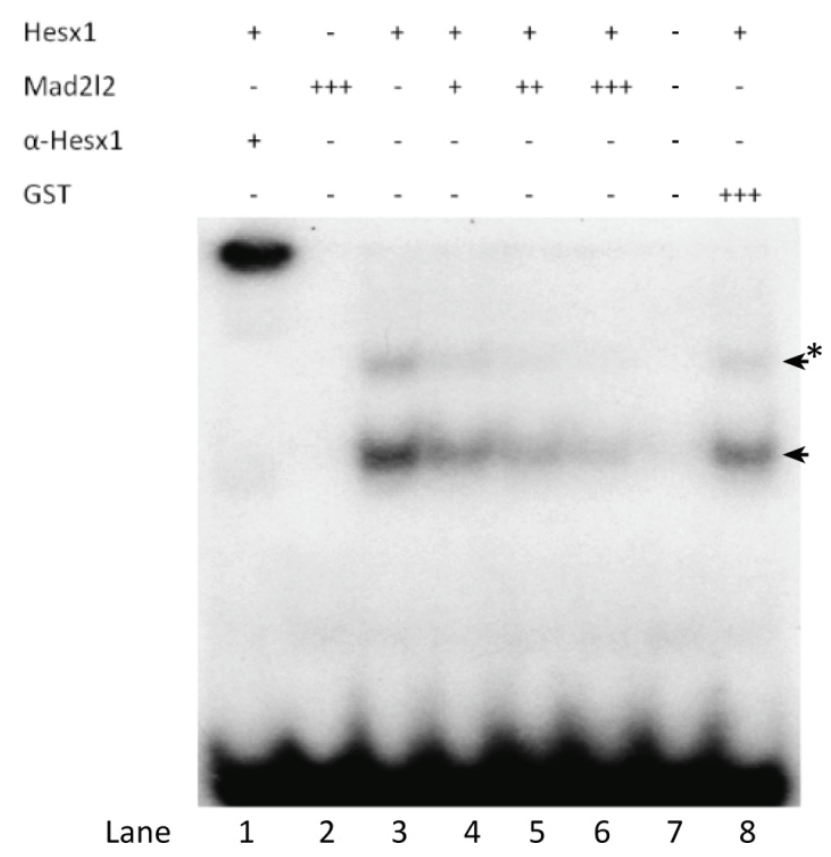

Figure 9. Mad2/2 disturbs the ability of Hesx1 to bind DNA.

(A) Mad212 might prevent Hesx1 from binding to its target DNA and subsequently disturb its repressive activity (modified from Dasen et al., 2001). (B) Increasing amounts of Mad2/2 interfere with the binding of Hesx1 to target DNA in vitro. Arrow heads indicate Hesx1 bound to the radioactive PrdQ-oligonucleotide as monomer and probably as homodimers $(*)$.

\section{The E3 ubiquitin ligase Cdh1-APC polyubiquitinates Hesx1}

The interaction of the APC substrate recognition subunit Cdh1 and Hesx1 raised the question if Hesx1 might be targeted for ubiquitination through the formation of the complex. Several Cdh1 recognition sequences are known to be necessary for Cdh1-APC mediated ubiquitination. Sequence analysis of Hesx1 revealed an imperfect KEN box (Pfleger and Kirschner, 2000) and an imperfect D-box (Fang et al., 1998; Glotzer et al., 1991). The D-box and KEN-box sequence was conserved in the human as well as the mouse protein but not in other species (Figure 10. A \& Figure 8. C). The presence of these motifs led to the assumption that Hesx1 is targeted by the Cdh1-APC complex and subsequently ubiquitinated. An intitial co-immunoprecipitation experiment in COS-7 cells provided evidence that HA-Cdh1 binds to the conserved carboxy-terminal region of Hesx1 (FLAG-Hesx1 $\Delta$ eh1; amino acids 88-185) but not to the amino-terminal domain (FLAGHesx1 $\Delta \mathrm{HD}$; amino acids 1-86) (Figure 10. B). 
A

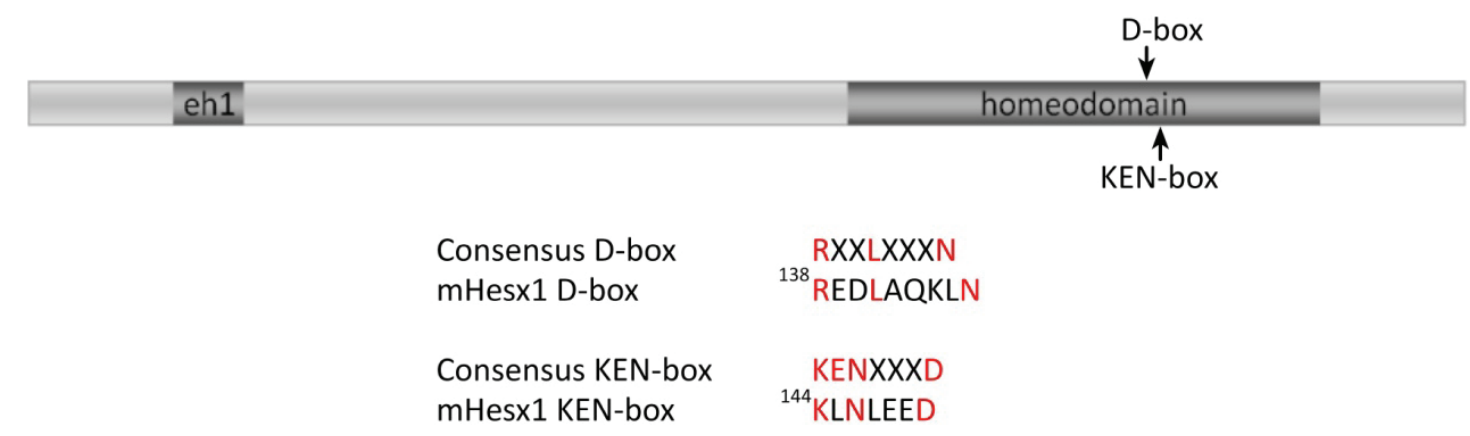

B

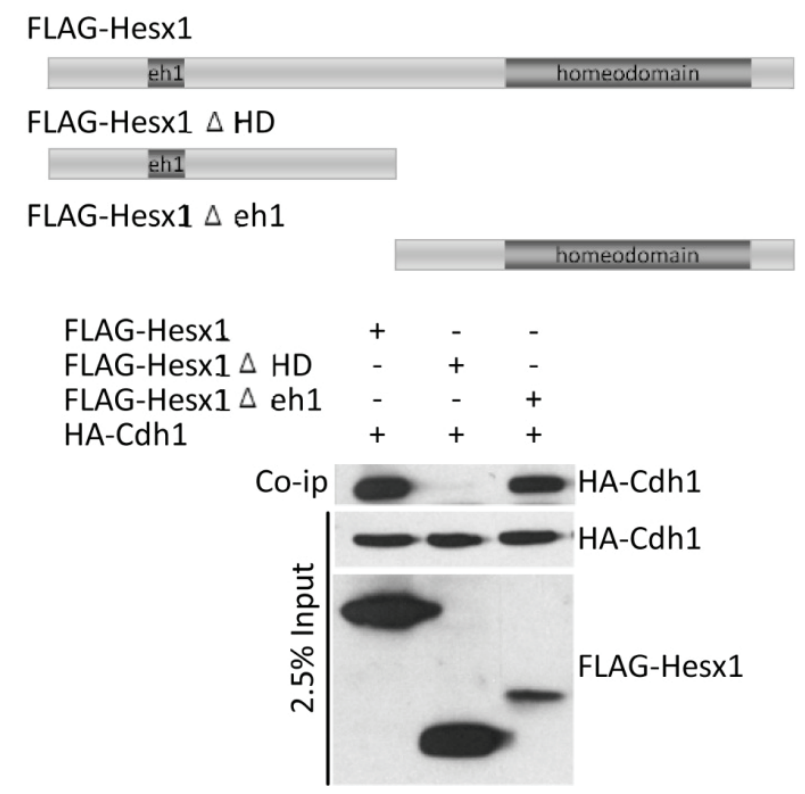

C

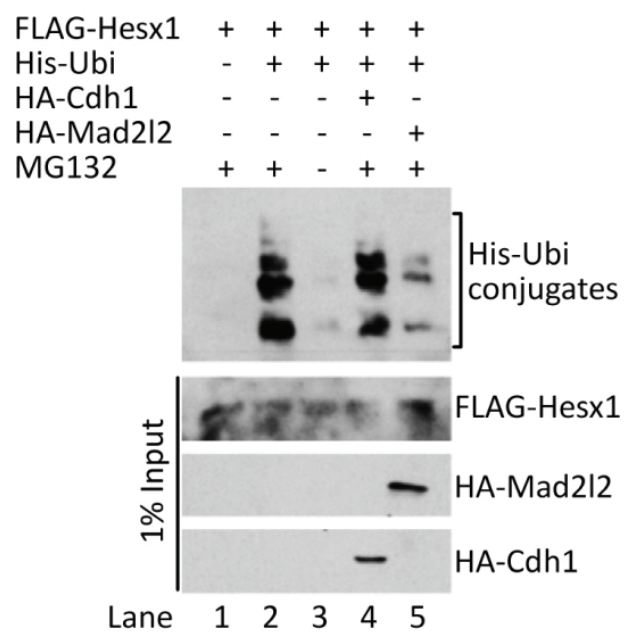

Figure 10. Hesx1 is subject to in vivo ubiquitination.

(A) The protein sequence of Hesx 1 contains two imperfect destruction motifs. (B) In COS-7 cell extracts HACdh1 co-immunoprecipitates specifically with FLAG-Hesx1 and the FLAG-Hesx1 $\Delta$ eh1 containing only the Cterminal homeodomain region. (C) FLAG-Hesx1 is ubiquitinated in NIH3T3 cells and the co-expression of HAMad2/2 attenuates this ubiquitination.

To assess whether Hesx1 is a substrate of the Cdh1-APC E3 ubiquitin ligase complex, FLAG-Hesx1 was used in an in vivo ubiquitination assay. In this assay, ubiquitin conjugates were purified using His tagged Ubiquitin (His-Ubi) and Ni-NTA Agarose. Substrate conjugation to ubiquitin was detected in the form of high molecular weight polyubiquitin conjugates. Transient overexpression of FLAG-Hesx1 and His-Ubi in NIH-3T3 cells revealed a large amount of polyubiquitinated Hesx1 in the presence of the $26 \mathrm{~S}$ proteasome inhibitor MG132 (Figure 10. C, Lane 2). In the absence of MG132 only a small amount of polyubiquitinated Hesx1 could be purified (Figure 10. C, Lane 3). The additional cotransfection with HA-Cdh1 did not significantly increase the level of Hesx1 polyubiquitin 
conjugates in the presents of MG132 (Figure 10. C, Lane 4.). In contrast, the cotransfection of HA-Mad2I2 strongly reduced the level of polyubiquitinated Hesx1 (Figure 10. C, Lane 5).

Hence, Hesx1 is subject to polyubiquitination which can be inhibited by Mad2/2, the inhibitor of the Cdh1-APC E3 ubiquitin ligase complex.

\section{Generation of Mad2/2 deficient mice}

In order to gain further insight into the biological function of Mad212 and its influence on developmental processes, gene targeting in ES cells was used to generate Mad2/2 deficient mice. Since a null mutation can result in early embryonic lethality which might be uninformative for the function of Mad2/2 at later stages of development or adulthood, a conditional knockout targeting construct was created. The design of the conditional targeting construct is based on the inducible Cre/loxP system. Cre is a site-specific DNA recombinase that recognizes a $34 \mathrm{bp}$ site called loxP and catalyzes the DNA recombination between two loxP sites. The recombination leads to excision of the DNA between these sites (Sauer, 1998; Sauer and Henderson, 1989).

The genomic region of the murine Mad2/2 is located on chromosome 4 at position 147514599 bp to 147519805 bp (NC_000070.5 Reference assembly (C57BL/6J)). The Mad2/2 targeting vector was designed to flank the entire coding region by loxP sites to generate a null allele upon expression of Cre. The loxP sites were introduced $113 \mathrm{bp}$ upstream of the first coding exon and $20 \mathrm{bp}$ downstream of the last exon, finally deleting a region of $5330 \mathrm{bp}$. This strategy was chosen because the protein comprises several methionine (amino acid position: $1,54,160,181,192,199)$ that could serve as a start codon leading to a truncated Mad2/2 protein. Especially the first three methionine residues, encoded in coding exon 1, 3 and 6 bear the risk of creating a dominant negative or active form of Mad2/2. At the time the targeting construct was designed only the Ensemble "common known proteincoding" transcript was known (Figure 11., yellow annotation) meanwhile several other transcripts were annotated (Figure 11.). However, the targeting construct deletes the entire Mad2/2 coding region.

To minimize the probability of deleting regulatory domains, introns and adjacent genomic regions were analyzed for highly conserved elements across different species using the 
databases of the National Center for Biotechnology Information (NCBI, http://www.ncbi.nih.org) and Ensemble (http://www.ensembl.org). The first regulatory region predicted by cisRED/miRANDA was found 696 bp upstream of the first coding exon (Robertson et al., 2006). These elements were not disturbed nor deleted by the targeting construct.

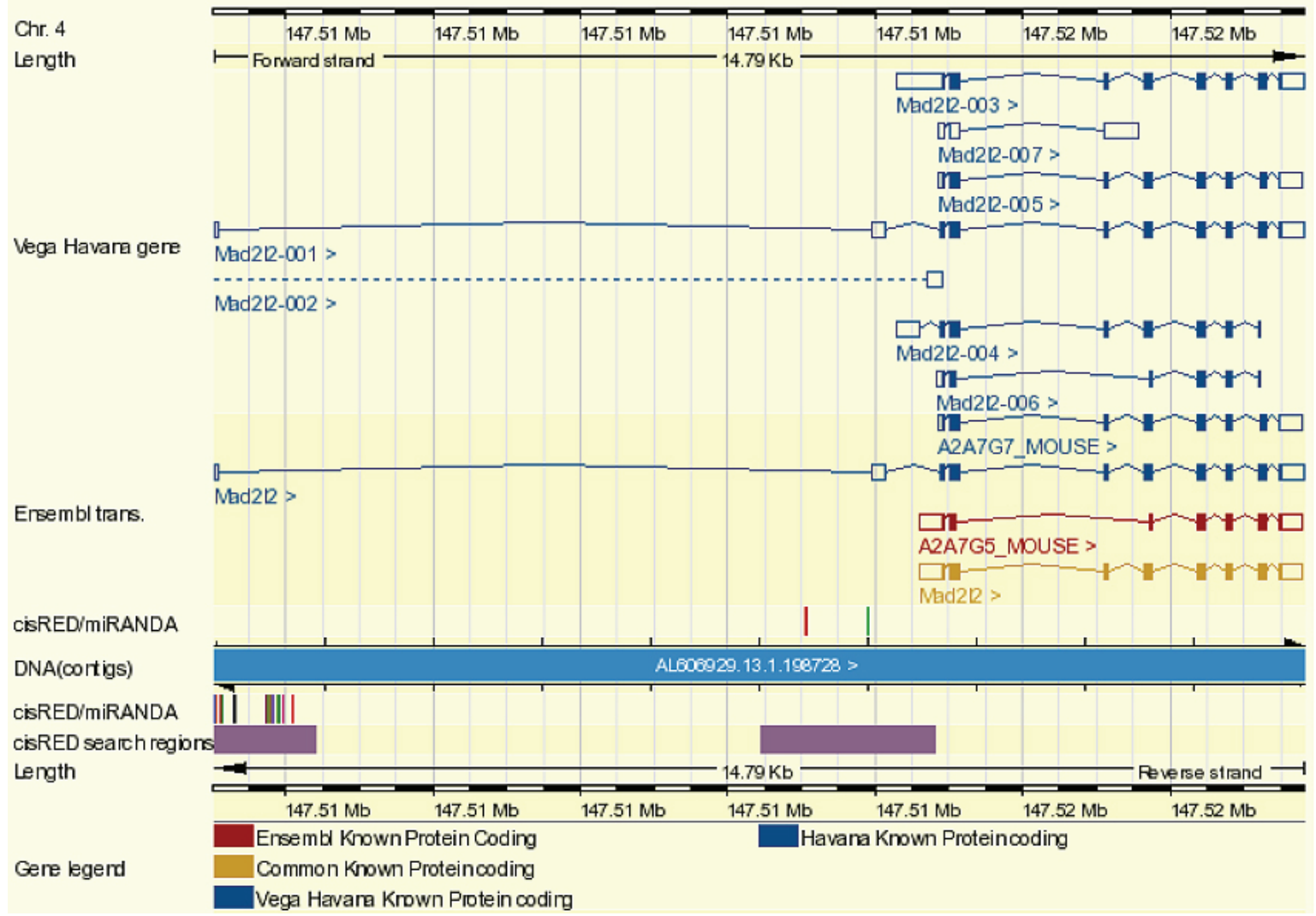

Figure 11. Search results for Mad2/2 in the Ensembl database.

The annotations all relate to Mad212 but there are differences in the structural details between VEGA (Vertebrate Genome Annotation Group) manual annotation, showing multiple transcripts and the computational predictions of Ensemble. cisRED/miRANDA are databases that provide information about regulatory modules and elements (Robertson et al., 2006). Filled boxes display coding exons whereas open boxes represent untranslated exons. Source: http://www.ensembl.org.

\section{Use of Recombineering to create the conditional knockout targeting vector}

To isolate Mad2/2 genomic DNA the Mouse PAC (RPCl-21) library 711 (Strain: 129/SvevTACfBR) (RZPD; (Osoegawa et al., 2000)) was screened using a radioactive labeled probe of Mad2/2 cDNA. Five PAC clones were identified and three of them used for subsequent analysis. All three clones contained the Mad2/2 genomic region necessary for the generation of the targeting vector as it was identified by PCR analysis. 
The targeting vector was created using a method described as recombineering or recombinogenic engineering (Liu et al., 2003; Muyrers et al., 2001; Warming et al., 2005). This method is based on homologous recombination via the gap repair mechanism mediated by the $\lambda$ phage Red proteins in E. coli. The entire procedure is described in detail in the material and methods section (Figure 29.).

One of the positive PAC clones (RPCIP711B01141Q6) was used to subclone the targeting region including a $4 \mathrm{~kb} 5^{\prime}$ homology and a $3 \mathrm{~kb} 3^{\prime}$ homology arm via gap repair into the retrieval plasmid (Retrieving; Figure 12. A). The 5' and 3' homology arms are important to ensure correct targeting in ES cells by homologous recombination. For the negative selection process in ES cells, the retrieval plasmid contains a Mc1-driven Thymidine Kinase $(t k)$ cassette. In a next step, the floxed Neo cassette was targeted 113 bp upstream of the first coding Mad2/2 exon (First Targeting; Figure 12. A). Thereupon, the floxed Neo cassette was excised by the expression of Cre recombinase in $E$. coli leaving a single loxP site behind (Cre recombinase; Figure 12. A). Next, the positive selection cassette was targeted 20 bp down stream to the last Mad2/2 coding exon. This cassette contains a Neo cassette flanked by two frt and a downstream loxP site. The expression of the neo gene is regulated by the prokaryotic em 7 and the eukaryotic $P g K$ promoter for positive selection in the ES cells (Second Targeting; Figure 12. A).

To test the functionality of the frt sites in the conditional targeting vector, the plasmid was electrotransformed into E. coli expressing Flpe recombinase. The Neo cassette was excised leaving a single frt site behind. This step was performed to ensure that the positive selection cassette could be removed in the ES cells (Flpe recombinase test; Figure 12. A). This excision step might be necessary in case the eukaryotic promoter of the Neo cassette alone creates a phenotype in the conditional targeted mice. In the knockout situation it would be removed together with the Mad2/2 coding region. In order to test the functionality of the IoxP sites which would create the null allele, the targeting vector was electroporated into E. coli expressing the Cre recombinase. The genomic Mad2/2 locus together with the Neo cassette was successfully removed (Cre recombinase test; Figure 12. A). 


\section{A}

PAC

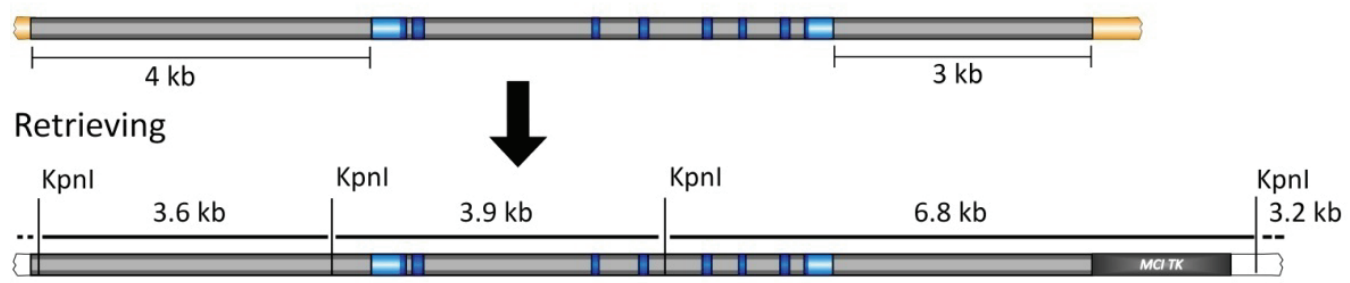

First Targeting

PL253 backbone

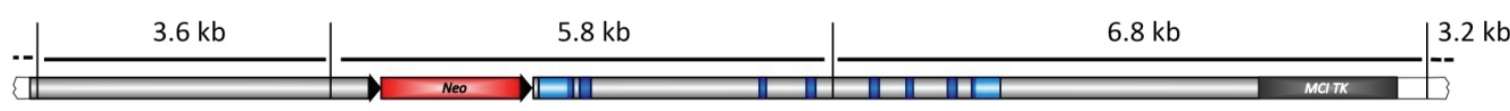

Cre recombinase

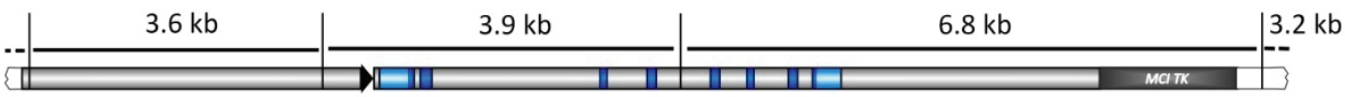

Second Targeting

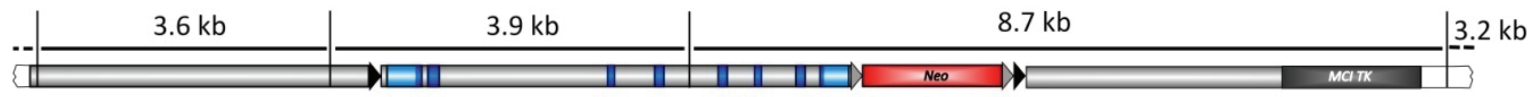

Flpe recombinase test

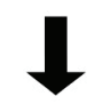

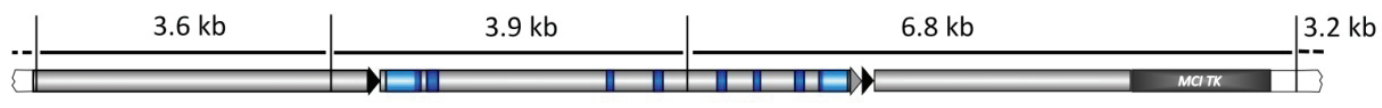

Cre recombinase test
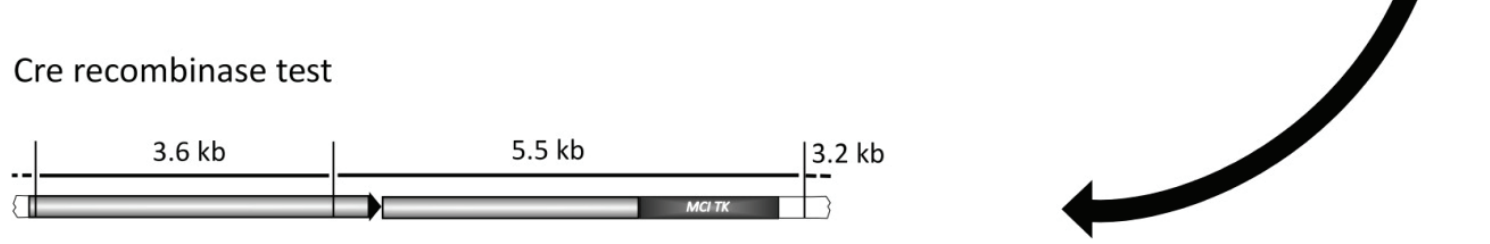

B

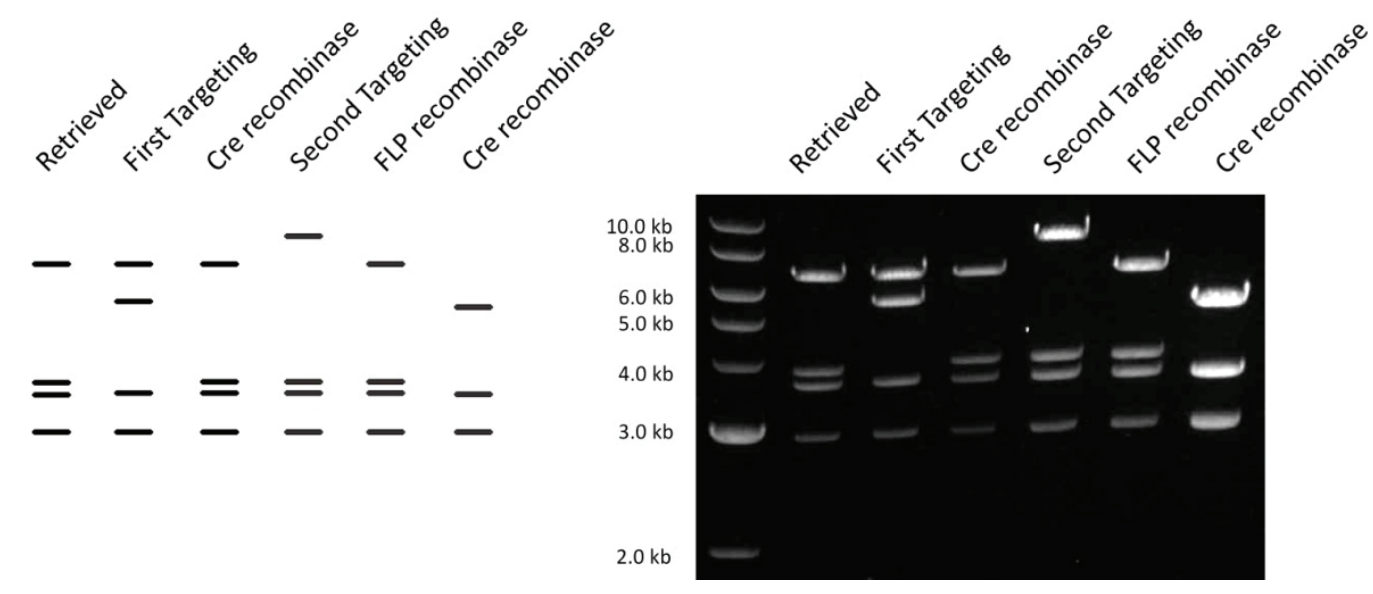


Figure 12. Construction and functional analysis of the Mad2/2 conditional knockout vector.

(A) Retrieving and targeting of the $12.2 \mathrm{~kb}$ genomic region containing the Mad2/2 coding exons. Targeting region is depicted in grey. Blue are Mad2/2 coding exons and light blue display untranslated regions. Black arrow heads are loxP sites and grey arrow heads are frt sites. The Neo cassette is depicted in red whereas the $t k$ cassette is grey. (B) Kpnl-digestion pattern of the plasmids at every stage of the targeting vector construction (left: expected pattern; right: actual pattern).

All the steps described above were monitored by restriction enzyme digestion. Kpnl digestion gave a distinct pattern at every stage of the targeting vector construction (Figure 12. B). In addition each step was followed by sequencing of the targeted region to ensure that no additional mutations were inserted in the genomic Mad2/2 locus. The final conditional knockout vector was also sequenced at all altered position, exonic regions and intron-exon boundaries to exclude any additional modifications.

\section{Gene targeting in ES-cells and Cre mediated deletion of Mad2/2 in mice}

The linearized Mad2/2 conditional knockout targeting vector was electroporated into the MPI-II ES cells and subsequently went through a positive/negative selection with G418 and ganciclovir (Ganc) respectively. Cells which underwent correct homologous recombination contained the Neo cassette and survived the exposure to G418. In addition, the ES cells lost the $t k$ cassette and thus also survived the exposure to ganciclovir (Figure 13. A).

217 ES cell clones survived the positive/negative selection process and were analyzed by southern blotting. Genomic DNA was isolated from each clone and the correct insertion of the $5^{\prime}$ loxP site was monitored by a Bgll digestion and southern blotting with the $5^{\prime}$ probe. A Bgll restriction site was integrated upstream of the loxP site, creating a $9.5 \mathrm{~kb}$ band instead of the $14 \mathrm{~kb}$ band found in the wild-type situation (Figure 13. A \& B). The integration of the Neo cassette with the flanking frt sites and the $3^{\prime}$ loxP site was analyzed by southern blotting with the $3^{\prime}$ probe following a Dral digestion. Correct insertion was marked by a $6.2 \mathrm{~kb}$ band due to the insertion of a Dral site $5^{\prime}$ to the Neo cassette. The wild-type band was around $4.9 \mathrm{~kb}$ (Figure 13. A \& B). Two clones (SP-34 and 106) were found to be positive for both, the $5^{\prime}$ and $3^{\prime}$ probe (Figure 13. B). 

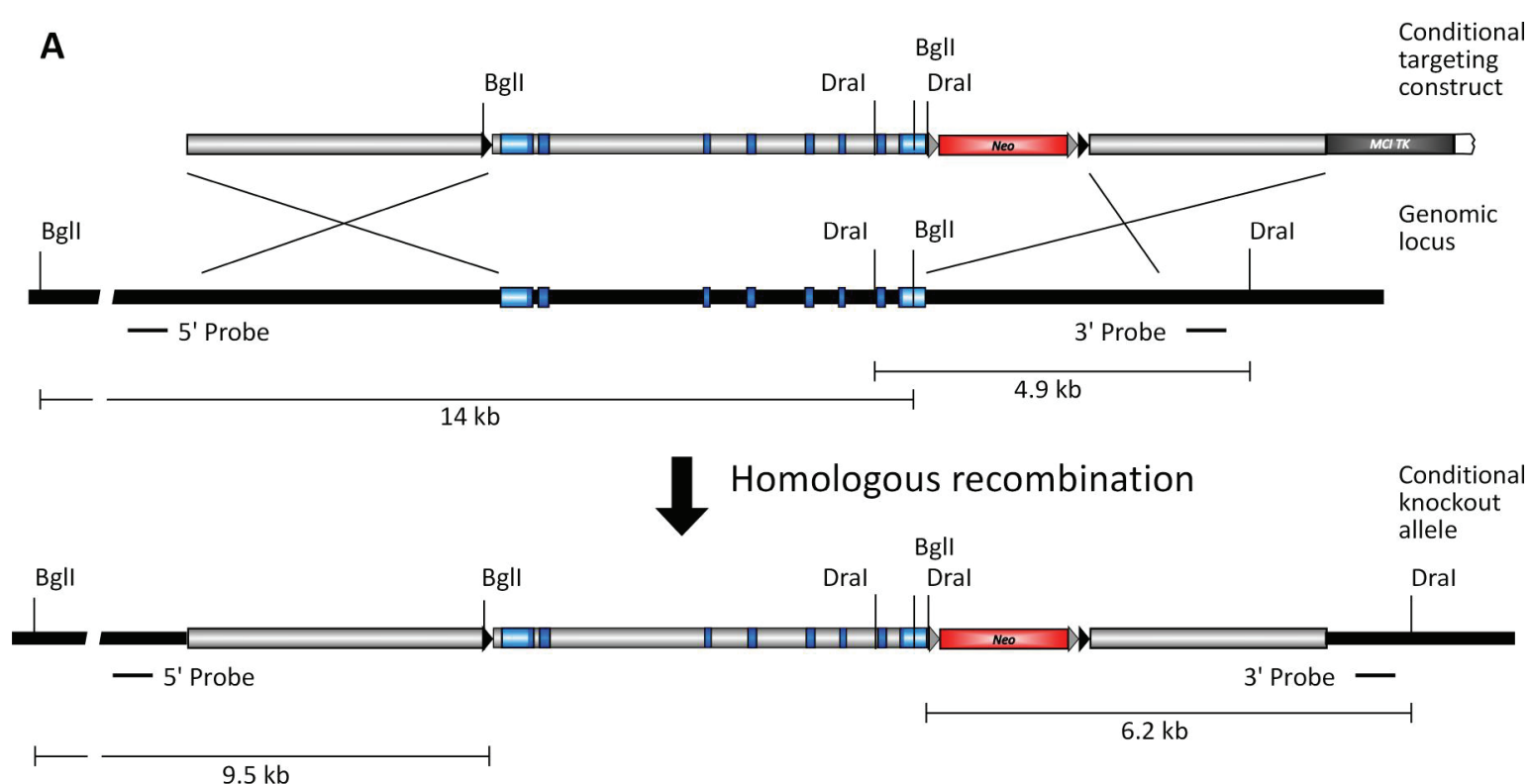

B

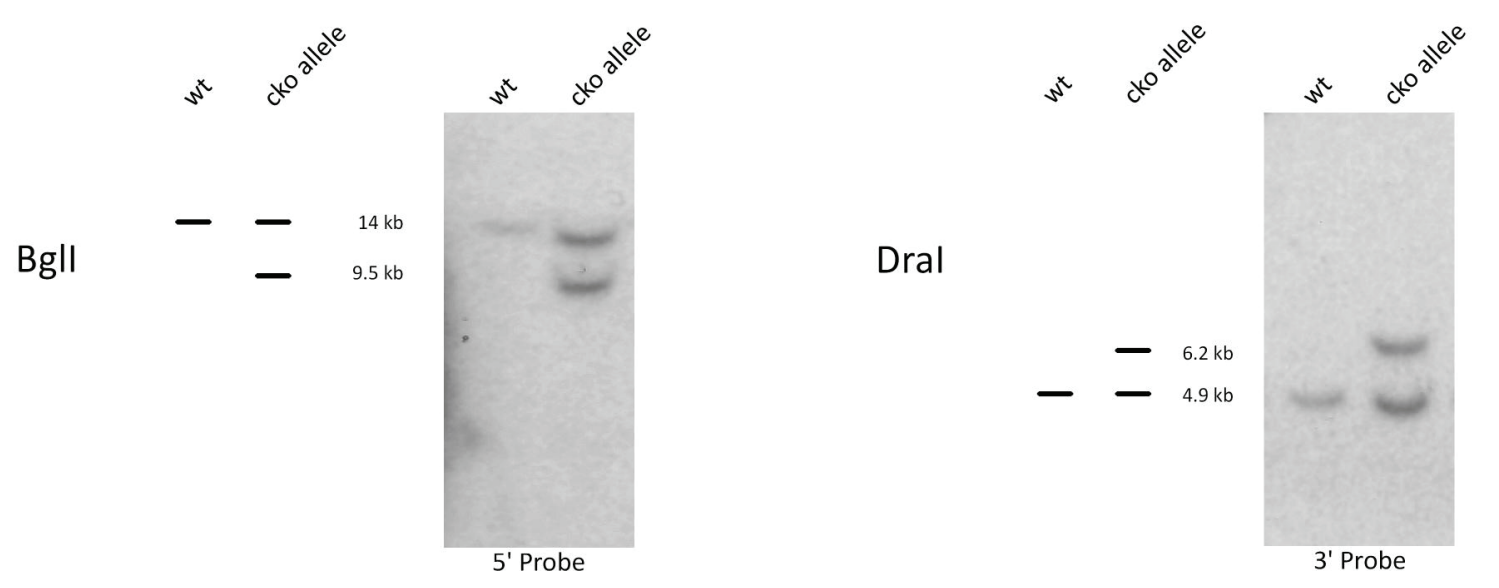

Figure 13. Targeting of the Mad2/2 genomic locus with the cko construct in ES cells.

(A) Structure of the conditional targeting construct, Mad2/2 genomic locus and targeted locus. (B) Confirmation of Mad2/2 targeting by southern blot analysis of Bgll (5' Probe) and Dral (3' Probe) digested ES cell DNA. Clone SP-34 is shown (left: expected pattern; right: actual pattern).

The two positive ES cell clones were used for the production of aggregation chimeras. The ES cells were aggregated with $C D-1^{\circledast} / \mathrm{ICR}$ morula-stage embryos and cultured to the blastocyst-stage. The aggregated blastocysts were transferred into the oviduct of pseudopregnant female recipient mice. Chimeric offspring could be easily detected on the basis of the coat color when the fur becomes visibile at around 10 days after birth. MPI-II ES cells are derived from an agouti-pigmented substrain of the 129 strain whereas CD$1^{\circledast / I C R}$ mice are albino. Test breedings with $C D-1^{\circledast} / \mathrm{ICR}$ and chimeras, primarily with at least $50 \%$ ES derived coat color were done to identify germ-line transmission of the 
transgenic MPI-II cells. Only ES cell clones from SP-34 gave germ-line transmission. Additional test breedings of mice heterozygous for the Mad2/2 conditional knockout allele revealed, that homozygous mice are viable, fertile and without any obvious phenotype. This indicates that the targeted region is functional and does not disturb the genomic locus.

In order to generate Mad2/2 deficient mice, SP-34 chimeric mice which gave germ-line transmission were crossed with CMV-Cre mice (CMV promoter driven Cre recombinase; (Schwenk et al., 1995)) to generate Mad2/2 ${ }^{+-}$(heterozygous) offspring (Figure 14. A). Heterozygous Mad2/2 mice where without pathological findings, viable and fertile. Matings of $\mathrm{Mad}_{2} / 2^{+/-}$mice gave birth to wild-type, heterozygous as well as homozygous animals as determined by PCR-genotyping of tail DNA (Figure 14. A \& B).

To confirm that Mad2/2 deficient mice do not express the Mad2/2 RNA and protein, primary mouse embryonic fibroblasts (MEF's) were prepared from 13.5 dpc embryos. RTPCR analysis of total RNA extracts confirmed the loss of Mad2/2 transcripts in the homozygous lines (Figure 14. B). Western blotting following whole protein extraction approved the loss of Mad212 protein in Mad2/2/- cells (Figure 14. D).

A

Wild-type

allele

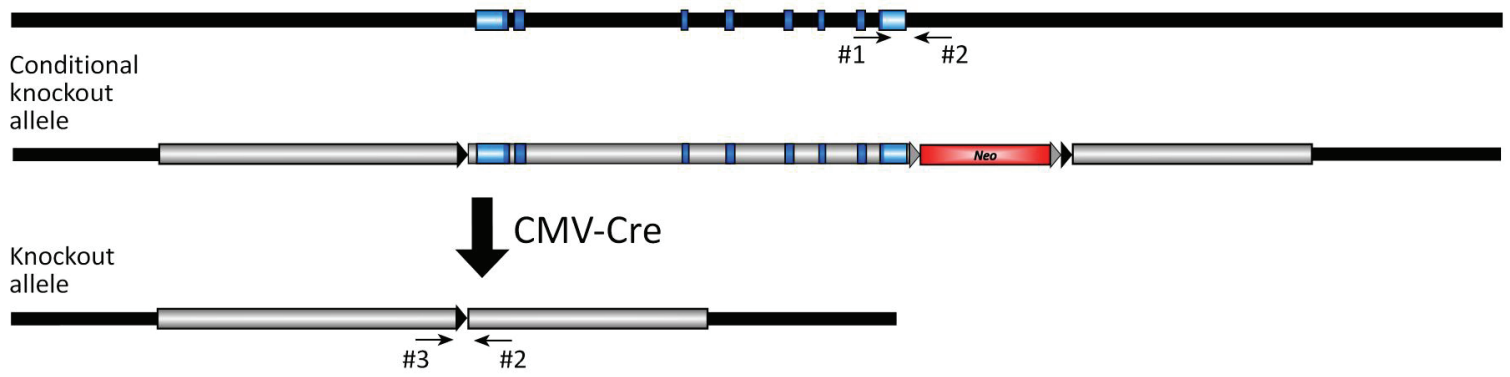

B

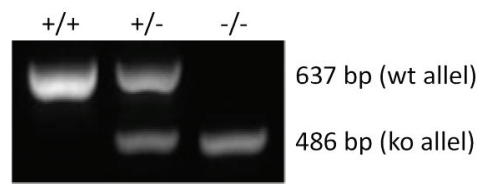

C

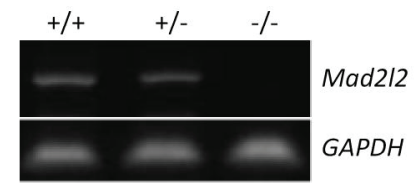

D

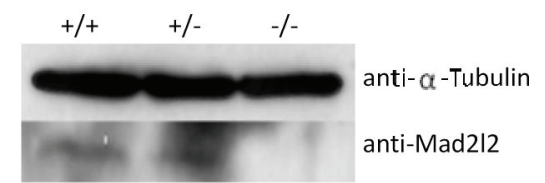

Figure 14. Generation of Mad2/2 knockout mice.

(A) Heterozygous Mad2/2 cko chimeric mice were crossed with CMV-Cre mice to obtain heterozygous Mad2/2 ko mice. (B) PCR analysis of tail DNA using primers \#1, \#2 and \#3. (C) RT-PCR of RNA obtained from MEF's. (D) Western blot analysis of full protein extracts generated from MEF's. 


\section{Phenotypic analysis of Mad2/2 knockout mice}

\section{Variable viability and growth retardation in Mad2/2 deficient embryos}

Offspring of $\mathrm{Mad}_{2} / 2^{+/-}$mice intercrosses diverged from the expected Mendelian frequency of $25 \%$ Mad2/2 ${ }^{--}$mice. Only $13 \%$ of the offspring were homozygous Mad2/2 mutants, indicating intra-uterine lethality (Figure 15. A). To determine the time point of lethality several different stages were analyzed but did not give conclusive results so far. Most of the examined stages did not match the expected number of Mad2/2 deficient animals according to the Mendelian rules (Figure 15. B). Even though the number of homozygous mutant embryos at 10.5 and $12.5 \mathrm{dpc}$ was found to be higher, in general it was found to be significantly lower than anticipated.

A

\begin{tabular}{|c|c|c|c|c|c|}
\hline \multirow[b]{2}{*}{ stage (dpc) } & \multirow[b]{2}{*}{ litter } & \multicolumn{4}{|c|}{ Number per genotype } \\
\hline & & $+/+$ & $+1-$ & $-1-$ & Total \\
\hline Mice born & 15 & $29(30 \%)$ & $57(59 \%)$ & $13(13 \%)$ & 97 \\
\hline 8.5 & 1 & 4 & 8 & 2 & 14 \\
\hline 10.5 & 1 & 3 & 3 & 4 & 10 \\
\hline 11.5 & 2 & 6 & 15 & 0 & 21 \\
\hline 12.5 & 2 & 5 & 3 & 5 & 13 \\
\hline 13.5 & 3 & 6 & 15 & 1 & 22 \\
\hline 14.5 & 3 & 8 & 16 & 2 & 26 \\
\hline 15.5 & 1 & 3 & 4 & 1 & 8 \\
\hline 16.5 & 1 & 2 & 5 & 2 & 9 \\
\hline 17.5 & 1 & 1 & 4 & 1 & 6 \\
\hline
\end{tabular}

B

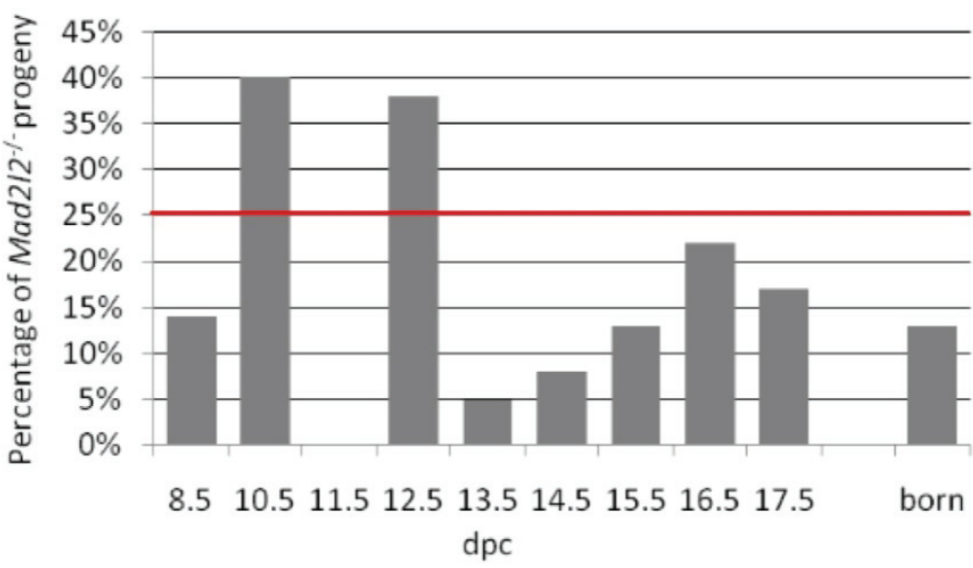

Figure 15. Genotypic analysis of progeny from Mad212 ${ }^{+/-} \quad$ intercrosses reveals embryonic lethality of $\mathrm{Mad}_{212^{-1}}$ mice.

(A) Total numbers of progenies. The number of $\operatorname{Mad} 212^{-{ }^{-}}$offspring is reduced by $50 \%$. (B) Percentage of $\mathrm{Mad}_{2} / 2^{-1-}$ embryos at different stages and progeny. Most stages do not reach the expected number of Mad212 deficient embryos. The red line indicates the expected percentage according to the Mendelian rules. 
Newborns, pups and adult Mad2/2 deficient animals showed no obvious abnormal behavior, but were infertile. Matings of $\mathrm{Mad} 2 / 2^{--}$female and male animals among themselves as well as with heterozygous or C57BL/6 wild-type animals resulted in no offspring. To exclude a mating behavioral phenotype, the female animals were checked for vaginal plugs and were positive.

Mad $2 / 2^{--}$embryos, newborns and adult animals were morphologically normal but smaller than their heterozygous or wild-type littermates. Embryos and animals of each stage and age were proportional reduced in size (Figure 16).

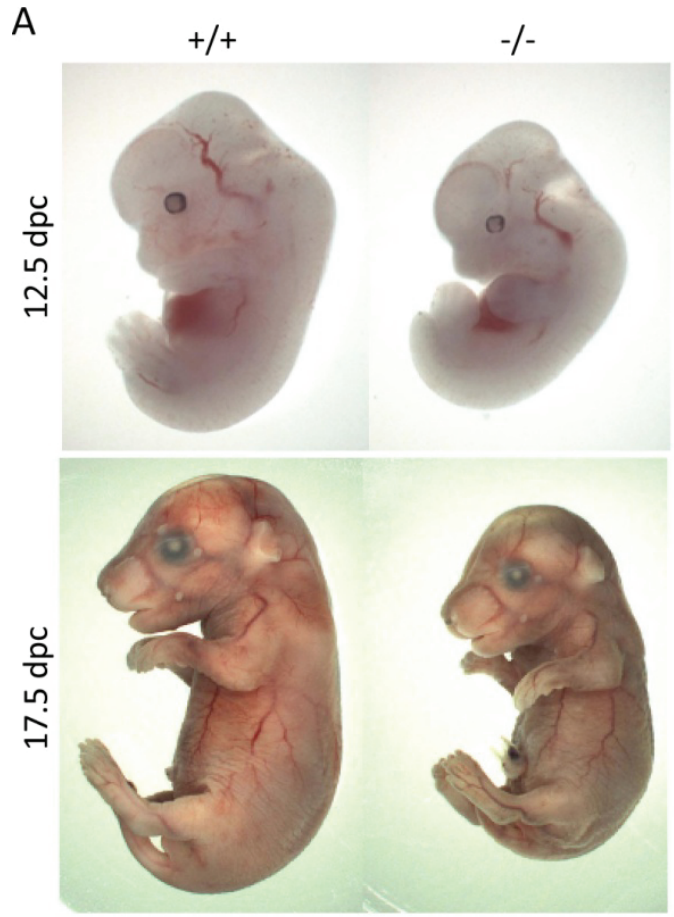

B

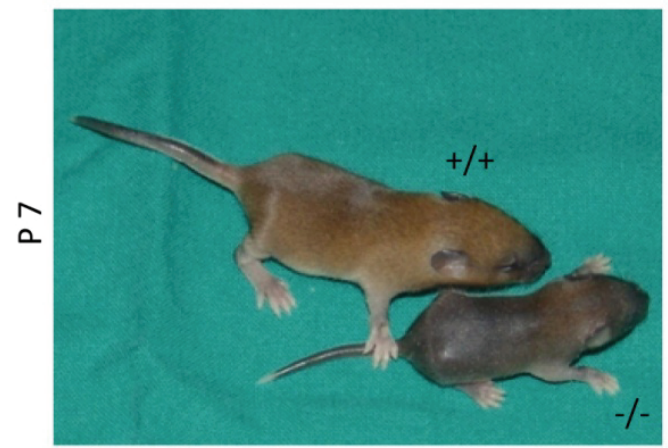

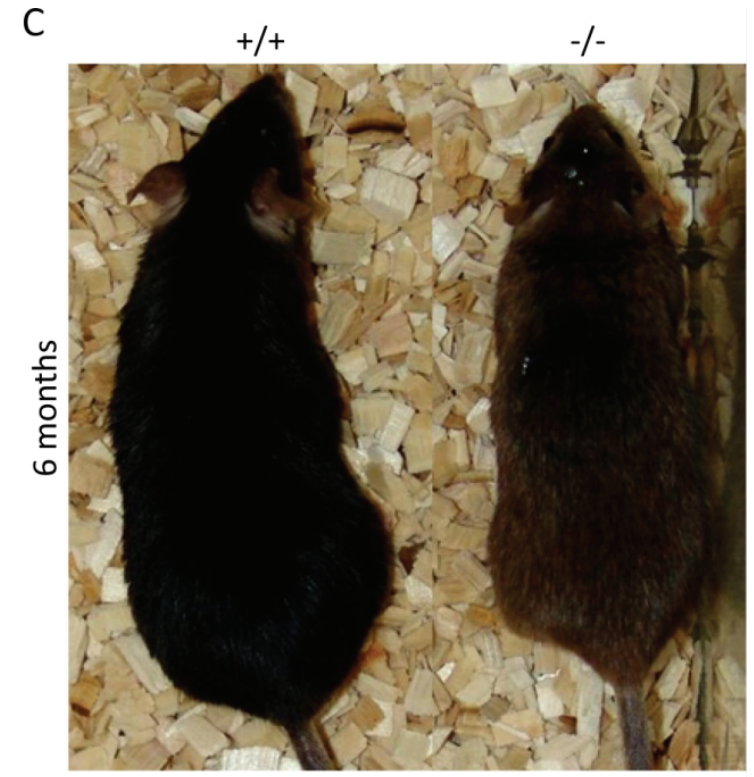

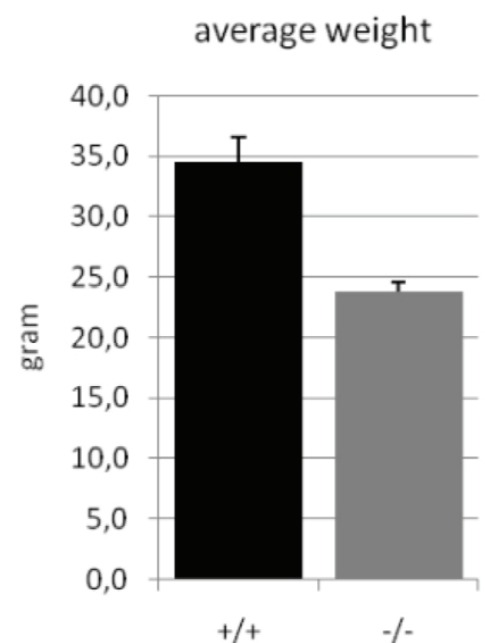

Figure 16. Mad2/2 deficient mice are reduced in size and weight.

(A) Embryos lacking Mad212 are smaller in comparison to their wild-type littermates. (B) Shortly after birth Mad212 ${ }^{-1-}$ pups at P7 are reduced in size. (C) At six months of age the wild-type mice are still larger and approximately $1 / 3$ heavier than their homozygous, transgenic littermates. Error bars indicate standard errors of the means. 
During development and maturation Mad2/2 deficient mice were not able to catch up with their wild-type littermates (Figure 17.). At six months of age they were still smaller and only two-thirds of the weight of a wild-type animal (Figure 16. C).

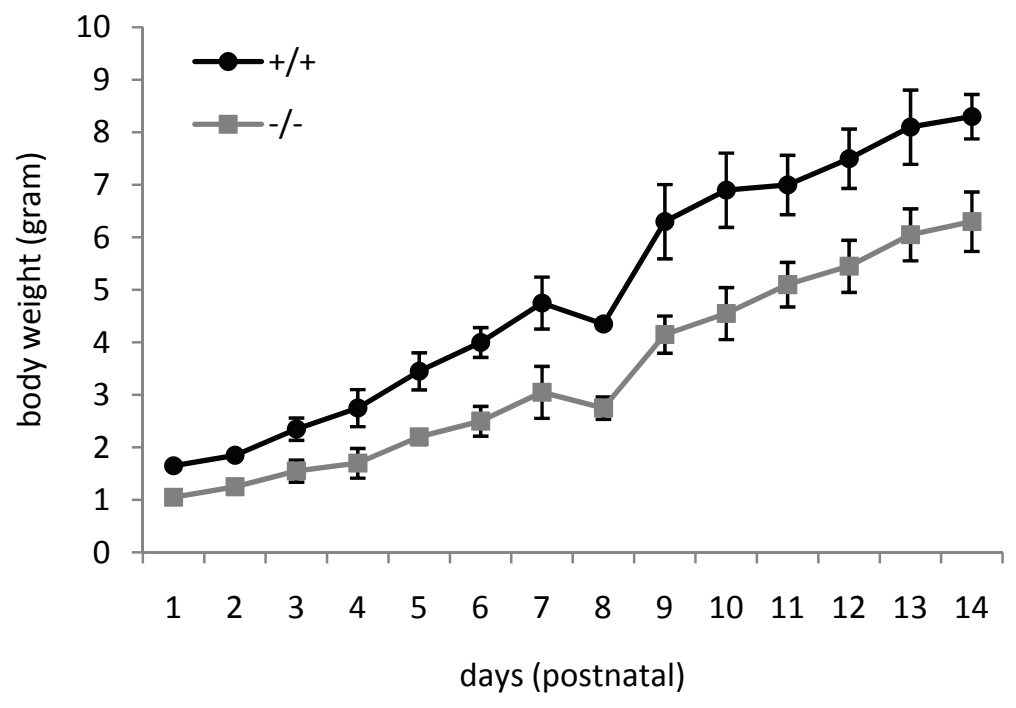

Figure 17. Growth curve of $\operatorname{Mad} 212^{-/-}$newborns and wild-type littermates. The graph displays animals from a representative litter. Error bars indicate standard errors of the means.

\section{Mad2/2 targeted MEF's show decelerated proliferation}

Primary embryonic fibroblasts were isolated from 13.5 and $14.5 \mathrm{dpc}$ embryos to study the consequences of Mad2/2 deficiency under well-defined culture conditions. As the life span of primary cultured mouse embryonic fibroblasts is limited, and the mortality of Mad2/2 $2^{-1-}$ embryos was above-average, the attempt to establish a MEF cell line with permanent growth features was undertaken. There are two major pathways to establish an immortalized MEF cell line, including transformation by overexpression of one or more oncogenes and serial passage of primary MEF's until they pass their growth-crisis (Aaronson and Todaro, 1968; Todaro and Green, 1963). In order to establish an immortalized Mad2/2 deficient cell line a serial of passages was done but Mad2/2 ${ }^{-/}$cells failed to grow after several passages and thinned out with each passage. In contrast, the wild-type cells could be passaged and presumably would have given rise to an immortalized cell line.

Due to these observations the plating efficiency as well as the growth rate of Mad2/2/MEF's and their wild-type equivalents was monitored. The plating efficiency of Mad2/2-MEF's did not significantly differ from their wild-type counterparts but the growth rate was substantially reduced (Figure 18. A \& B). 
A

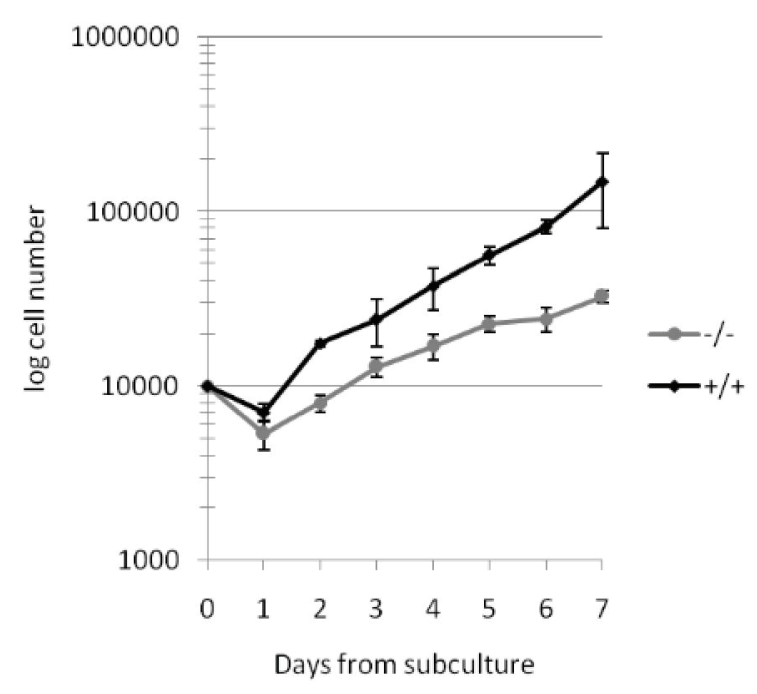

B

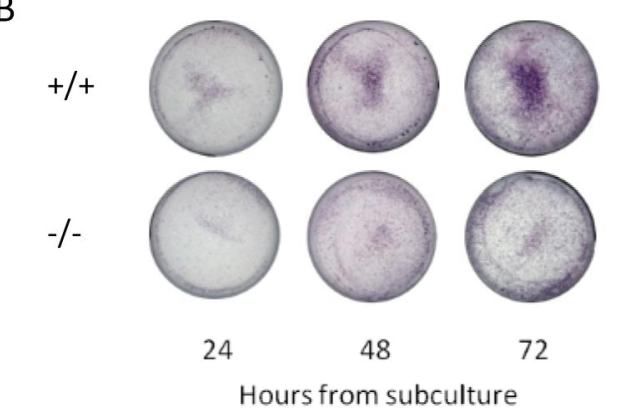

C

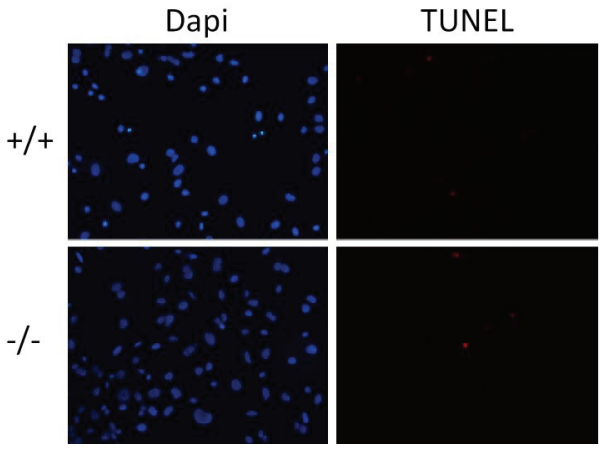

Figure 18. Influence of Mad2/2 deficiency on plating efficiency and proliferation rate of MEF's.

(A) The cell number of wild-type and Mad2/2/- MEF's was monitored for seven days after subculture. The plating efficiency was only slightly different but the proliferation rate of wild-type cells was higher. Error bars indicate standard errors of the means. (B) Giemsa staining of wild-type and Mad2/2 deficient MEF's. The population of Mad212-/- cells seems to be almost constant between 48 and 72 hours of subculture. (C) TUNEL assay displayed no significant differences in the occurrence of apoptosis.

To address the question whether the Mad2/2/- MEF's had either a reduced growth rate or a higher ratio of mortality the occurrence of apoptosis was assessed. Observations of the cell cultures revealed no obvious apoptosis visible to the eye therefore a TUNEL assay was performed. The Mad2/2 deficient cells showed no sign of elevated apoptosis, as there was no increase in TUNEL-positive nuclei compared to the wild-type control cells (Figure 18. C). This observation was further strengthened by FACS analysis. Apoptosis will ultimately lead to nuclear condensation followed by segmentation into apoptotic bodies. These apoptotic bodies appear in a FACS analysis in front of the G1 peak that represents all cells with a diploid DNA content (Darzynkiewicz et al., 1997). The FACS analysis showed no significant nuclear debris in front of the G1 peak in both wild-type and Mad2/2 deficient cells (Figure 19. A).

\section{Mad2/2 deficient MEF's show an altered cell cycle phase distribution}

Due to the involvement of Mad2l2 in cell cycle control by the regulation of the Cdh1-APC complex (Chen and Fang, 2001; Pfleger et al., 2001) as well as in DNA damage repair 
(Lawrence, 2002; Okada et al., 2005) an effect of MEF's lacking Mad2I2 on cell cycle distribution could not be excluded. In addition, the previously described proliferation phenotype (Figure 18) suggested the possibility of alterations in the cell cycle. To address this question Mad2/2-- and wild-type MEF's were cultured until they reached $80-90 \%$ confluency before they were analyzed by flow cytometry.
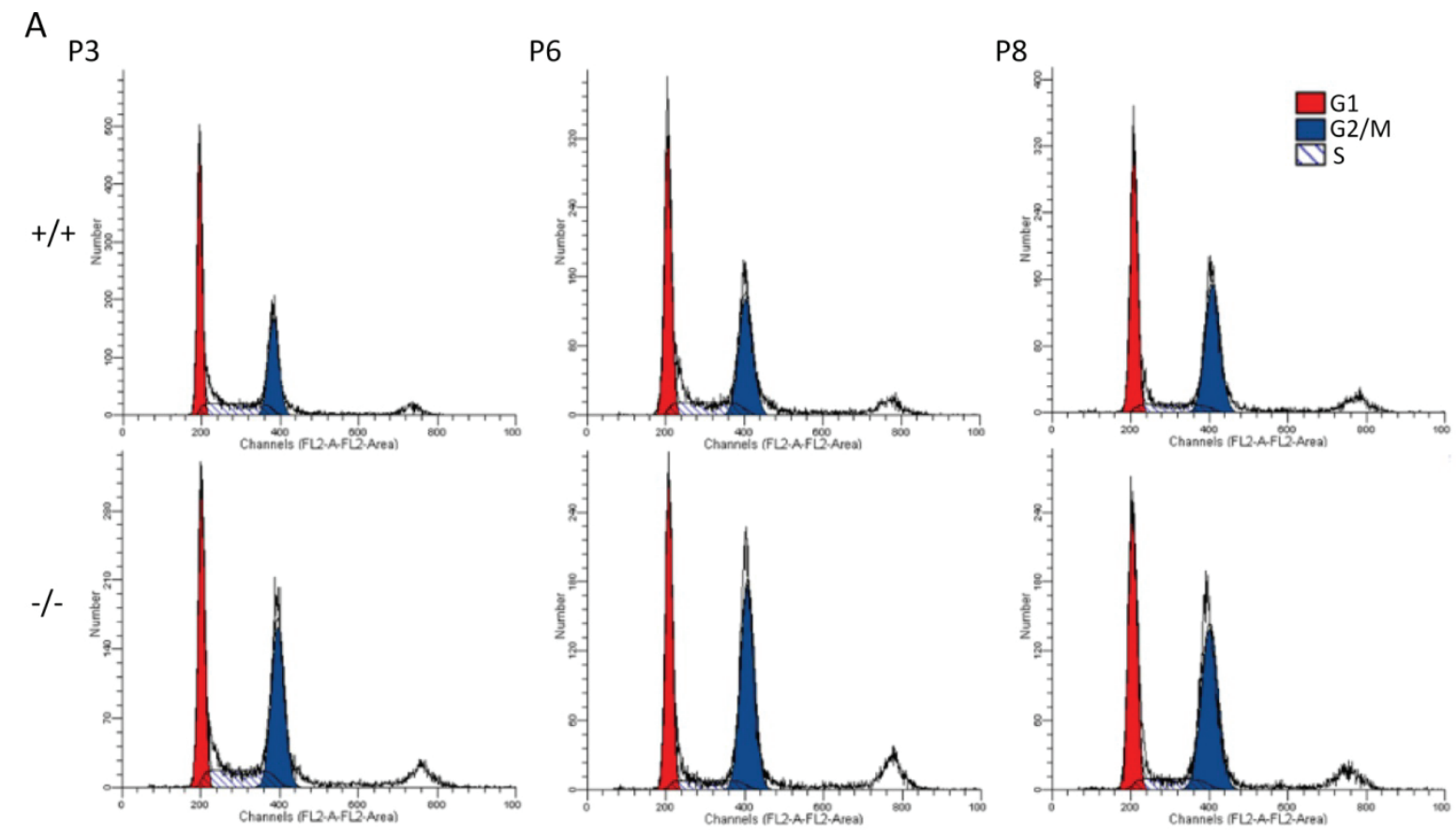

B
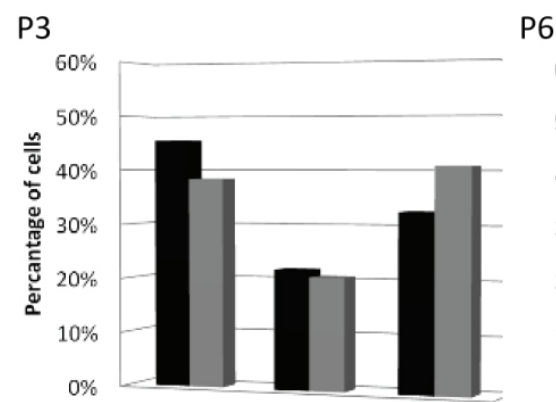
6 $60 \%$

P8
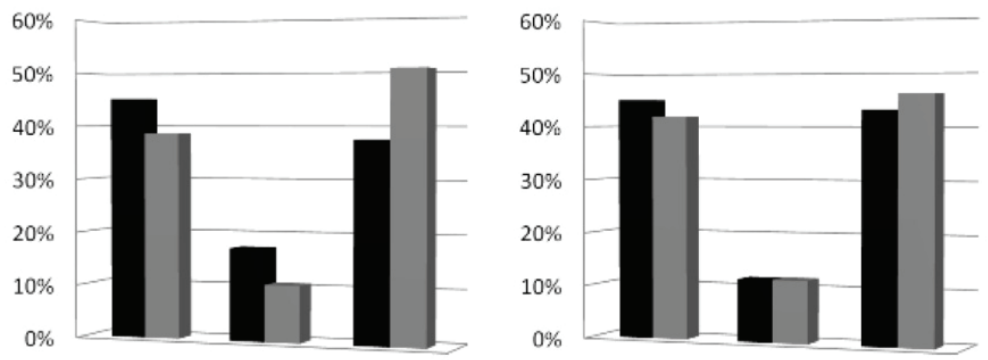

G1

G2/M

G1

$\mathrm{G} 2 / \mathrm{M}$

$\begin{array}{cccc} & \text { G1 } & \mathrm{S} & \mathrm{G} 2 / \mathrm{M} \\ \mathrm{m}+\mathrm{+} & 45 \% & 22 \% & 33 \% \\ -/- & 38 \% & 21 \% & 41 \%\end{array}$

$\begin{array}{cccc} & \text { G1 } & \text { S } & \text { G2/M } \\ \text { - }+/+ & 45 \% & 17 \% & 38 \% \\ -/- & 39 \% & 11 \% & 51 \%\end{array}$

-

G1

$\mathrm{S}$

G2/M

$+/+\quad 45 \% \quad 12 \%$

$43 \%$

$42 \% \quad 12 \%$

$46 \%$

Figure 19. FACS analysis of Mad2/2 deficient MEF's.

(A) Cell cycle distribution of wild-type and Mad2I2 deficient MEF's at different passages. (B) The percentage of $\mathrm{Mad} 2 / 2^{--}$MEF's in the G1 phase is reduced whereas there are more Mad $2 / 2^{-\gamma^{-}}$cells in the G2/M phase throughout all the different passages. $\mathrm{P}=$ passage.

The early passages of primary MEF's (passage 3 and 6) displayed a significant alteration in the cell cycle phase distribution. The percentage of cells in the G1 phase was reduced in 
the Mad2/2 knockout situation compared to the wild-type cells whereas the number of Mad2/2 $/$ cells in the G2/M phase was significantly increased (Figure 19. B). In one of the later passages (passage 8 ) the difference was not as obvious but still present. In addition there was a small population of wild-type and knockout cells that seemed to be octaploid (Figure 19. A).

\section{Accumulation of $\mathrm{Y}$-H2AX in Mad2/2 deficient MEF's}

The phosphorylation of histone $\mathrm{H} 2 \mathrm{AX}(\nu-\mathrm{H} 2 \mathrm{AX})$ at $\operatorname{Ser}^{139}$ is an early response to DNA double-strand breaks that occurs within minutes. These phosporylated molecules are cytologically visible as foci (Paull et al., 2000; Rogakou et al., 1998). To investigate whether Mad2l2 deficiency leads to an increase of double-strand breaks due to unrepaired lesions, immunofluorescent staining of $\mathrm{p}-\mathrm{H} 2 \mathrm{AX}$ was performed. Under normal culture conditions the Mad2/2 deficient MEF's displayed an elevated level of $\mathrm{Y}-\mathrm{H} 2 \mathrm{AX}$ foci in comparison to their wild-type counterparts (Figure 20. A \& B). This elevated expression was confirmed by western blot analysis of whole cell extract lysates (Figure 20. C).

A

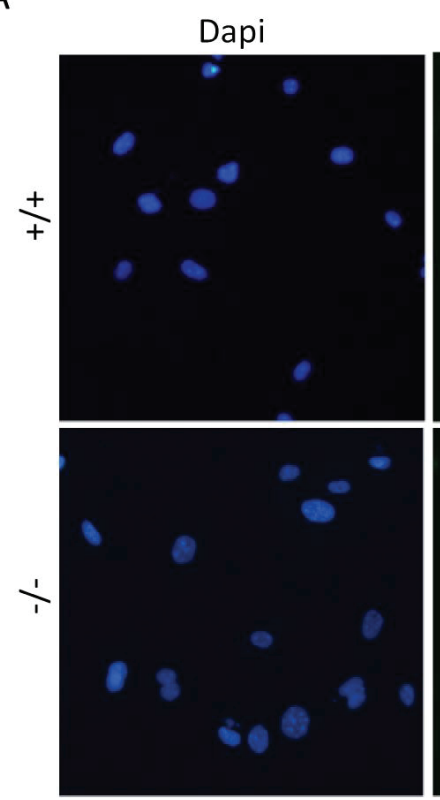

$y-\mathrm{H} 2 \mathrm{AX}$

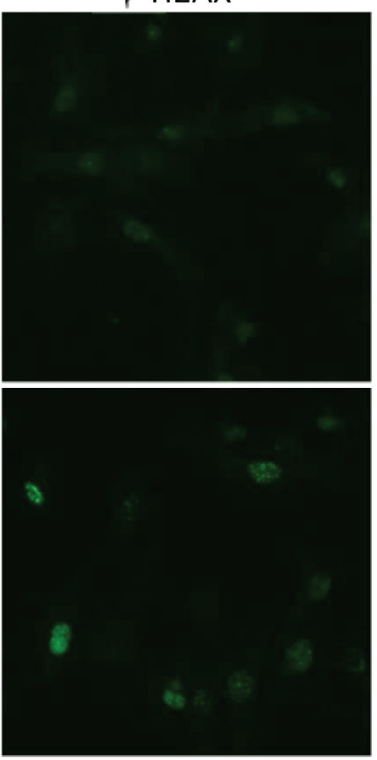

B

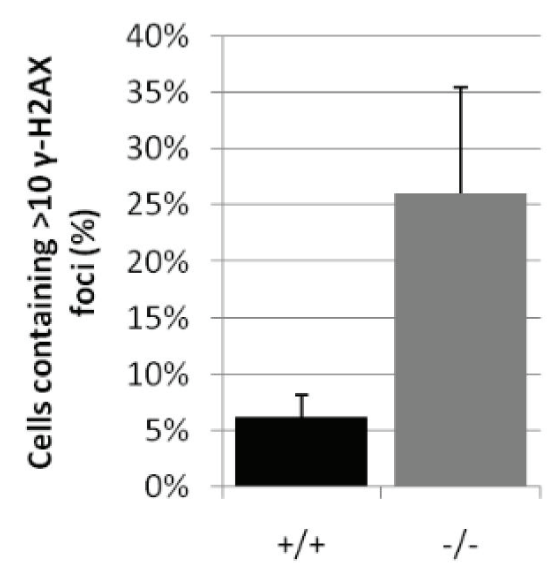

C

$$
\begin{aligned}
& \text { anti- } \alpha \text {-Tubulin } \\
& \text { anti- } \gamma-H 2 A X
\end{aligned}
$$

Figure 20. Elevation of $\mathrm{Y}$-H2AX expression levels in Mad2/2 deficient MEF's.

(A) Immunofluorescent staining of $\mathrm{Y}-\mathrm{H} 2 \mathrm{AX}$ revealed an elevated level in Mad2/2 ${ }^{--} \mathrm{MEF}$ 's compared to wildtype cells. (B) Quantitation of cells containing $>10 \gamma-\mathrm{H} 2 \mathrm{AX}$ foci. Error bars indicate standard errors of the means. (C) Western blot analysis displayed an increase of $\mathrm{Y}-\mathrm{H} 2 \mathrm{AX}$ in $\mathrm{Mad} 212^{-/-} \mathrm{MEF}^{\prime}$ s. 


\section{Pituitary gland displays impaired cell differentiation}

Mad2/2 deficient mice displayed no obvious developmental and morphological defects in the anterior central nervous system as it was previously observed in mice lacking Hesx 1 (Dattani et al., 1998). Since intra-uterine lethality was observed among Mad2/2 ${ }^{--}$mice, the animals which were born probably display only a mild phenotype. To further investigate the molecular mechanism of the binding of Mad2/2 to Hesx1 and the developmental as well as cellular consequences of Mad2/2 deficiency, the pituitary gland was used as a model system. Generally, the different anterior pituitary gland cell types appear from a common premordium in a precise spatial and temporal order (Japon et al., 1994; Simmons et al., 1990). Hesx1 deficiency and misexpression results in phenotypes especially in the four ventral cell types (somatotropes, lactotropes, thyrotropes and gonadotropes; (Table 1.; Dasen et al., 2001).

An initial hematoxylin and eosin staining of a newborn $M a d 2 / 2^{-/-}$animal revealed a morphologically intact pituitary gland. The pituitary consisted of an anterior lobe, an intermediate lobe and a posterior lobe sitting on top of the cartilage element of the sphenoid bone (Figure 21).

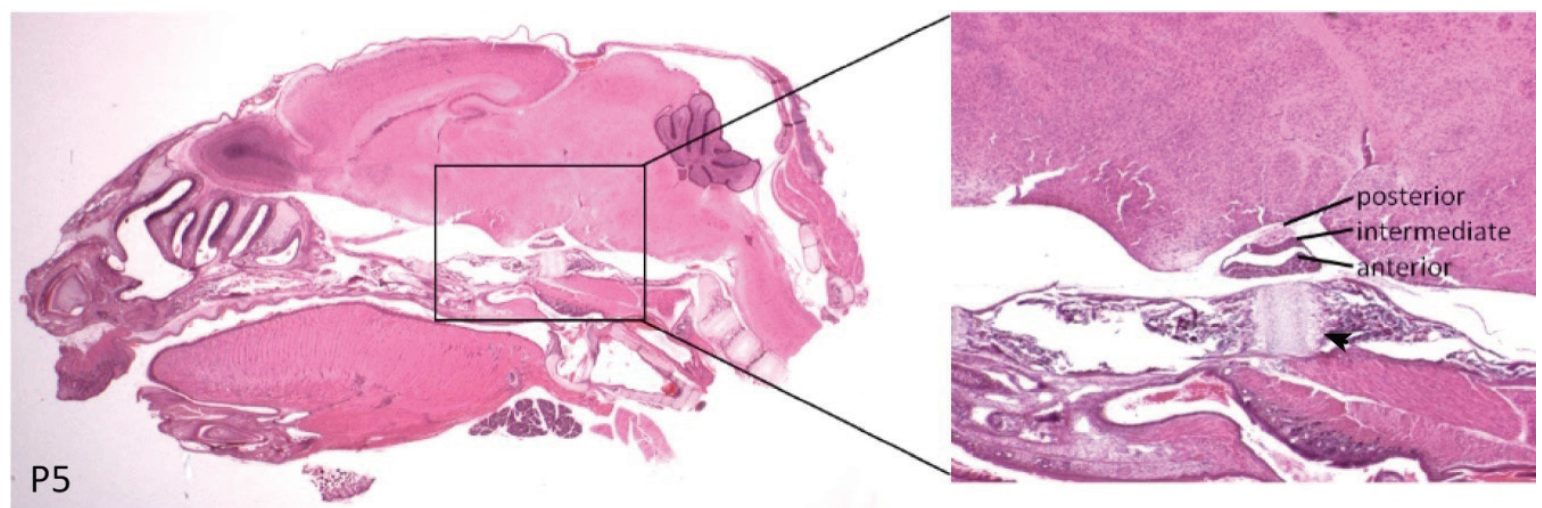

Figure 21. Mad2/2 deficient mice display a morphologically normal pituitary.

$\mathrm{H} \& \mathrm{E}$ staining of P5 Mad212\% mouse head mid-sagital section. Mice display a morphological normal pituitary gland consisting of a posterior, intermediate and anterior lobe sitting on the cartilage element of the sphenoid bone (arrow head).

To assess the specification of the different cell types of the anterior pituitary in the Mad2/2 deficient mice, an immunohistochemical analysis was performed. Cell types were identified by their expression of the specific hormones. $\alpha$ GSU is a shared common subunit of the heterodimeric peptide hormones FSH, LH and TSH which can be detected in cells 
becoming gonadotropes or thyrotopes respectively. Its expression can be detected as early as $11.5 \mathrm{dpc}$; ACTH is secreted by the corticotropes from $12.5 \mathrm{dpc}$ on; TSH is secreted by the thyrotropes at around $14.5 \mathrm{dpc}$; $\mathrm{GH}$ is secreted from somatotropes and can be detected around $15.5 \mathrm{dpc}$; at the same stage PRL secretion starts from the lactotropes and FSH and LH are secreted by gonadotropes around $16.5 \mathrm{dpc}$ and $17.5 \mathrm{dpc}$ respectively.

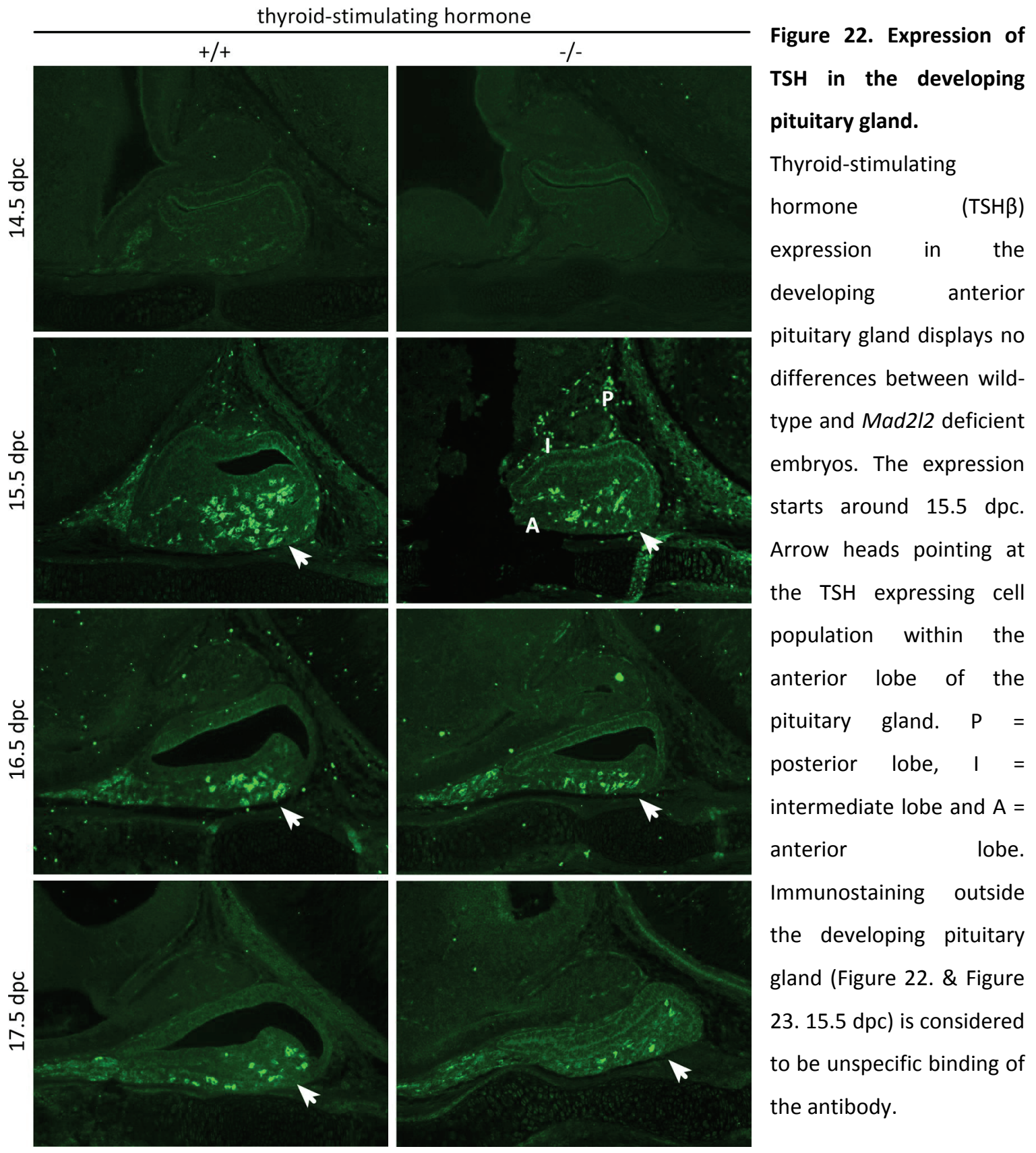

The analysis was done with embryos from $12.5 \mathrm{dpc}$ to $17.5 \mathrm{dpc}$ because most of the cell types appear around these stages. Staining with $\alpha \mathrm{GSU}, \mathrm{ACTH}, \mathrm{TSH} \beta, \mathrm{PRL}$ and LH$\beta$ specific antisera did not reveal any significant changes in the Mad2/2\% embryos compared to the 
wild-type (data not shown and Figure 22.). There might be a minor delay in the expression of the respective hormones in the mutant embryos but so far this could not be specified.

The appearance of the somatotrophic cell linage secreting GH was significantly delayed. In the wild-type embryos a lot of somatotropes populated the anterior pituitary gland already around $16.5 \mathrm{dpc}$ whereas the Mad2/2 deficient embryos displayed no $\mathrm{GH}$ secreting cells at this stage. At $17.5 \mathrm{dpc}$ some somatotropes could be detected in the mutant embryos but the number was severely reduced (Figure 23.). In addition, one 17.5 dpc Mad2/2 deficient embryo displayed an aberration of the cartilage element usually underlying the developing anterior pituitary gland (asterisk, Figure 23.).

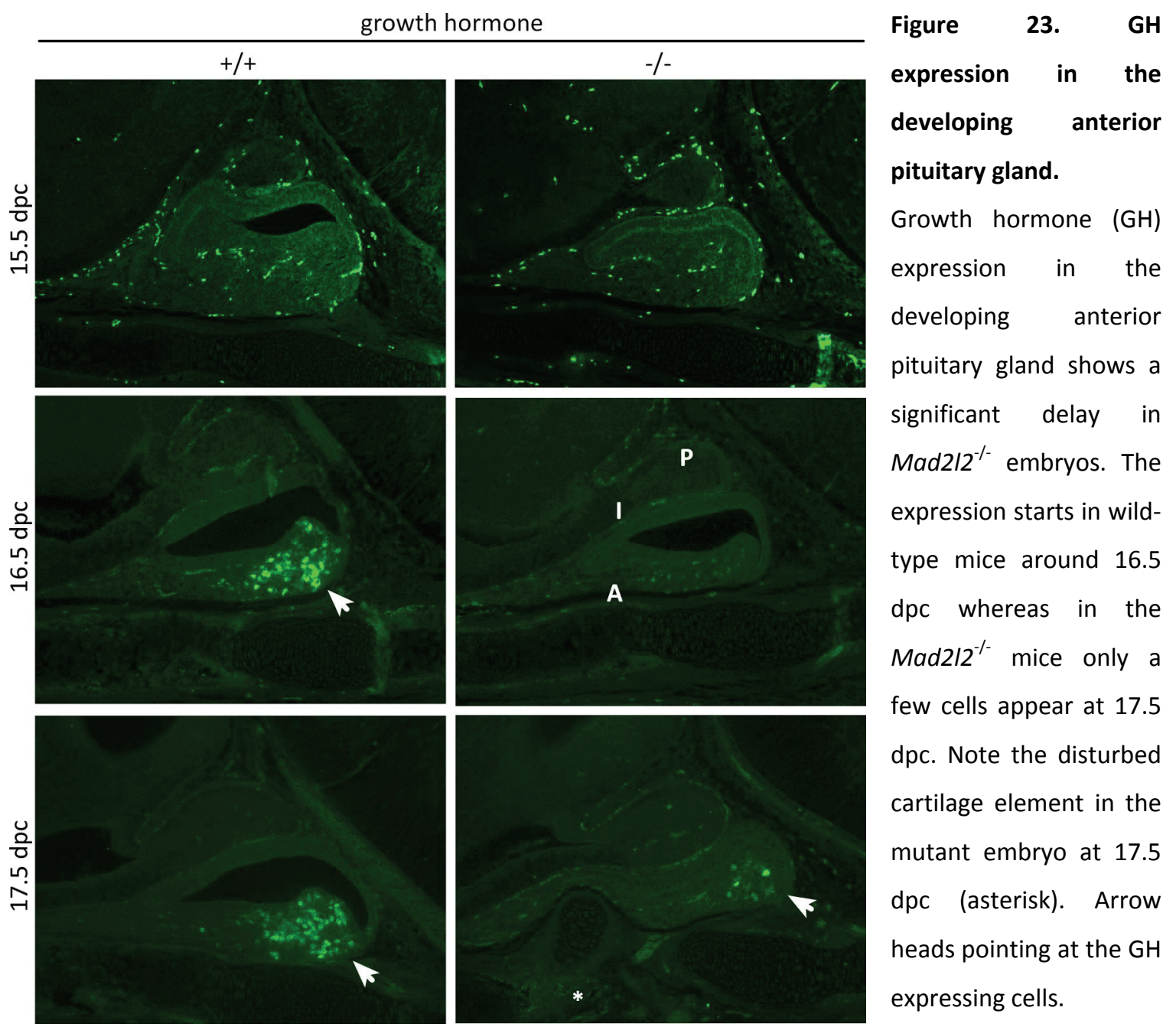

Altogether, these results present a cell type specific anterior pituitary gland phenotype in Mad2/2 deficient embryos. The somatotrophic cell lineage was significantly delayed or reduced, whereas all other pituitary gland cell lineages appeared to develop normal. 


\section{DISCUSSION}

Understanding the functional significance of the coordinate expression and interaction of homeobox transcription factors remains a critical question in developmental biology. Hesx 1 is an important transcriptional repressor during forebrain and pituitary gland development (Dattani et al., 1998; Martinez-Barbera et al., 2000). Mutations in the human Hesx1 gene are linked to the congenital disorder septo optical dysplasia, isolated growth hormone deficiency and combined pituitary hormone deficiency. However, the overall frequency of Hesx1 mutations in patients displaying SOD, IGHD or CPHD is less than 5\% (reviewed in Reynaud et al., 2004). This observation suggests that mutations in other known or unknown genes may participate in this complex disorder. Some of these genes are possibly involved in regulation and fine-tuning of the activity of transcription factors involved in normal development of the forebrain and pituitary.

The present study has extended the regulative network in which Hesx1 is embedded and identified so far unknown mechanisms of Hesx1 regulation, involving binding to Mad2/2 and ubiquitination through the E3 ligase Cdh1-APC.

\section{Hesx1 regulation through Mad2/2 and Cdh1-APC}

\section{Mad2/2 prevents Hesx1 from DNA binding}

Hesx1 and Mad2/2 are co-expressed and interact

In a previous study, Mad2/2 was isolated in a yeast two-hybrid screen as a potential binding partner of Hesx1 (Pilarski, 2004). The present work has verified this interaction using a yeast two-hybrid assay, by GST pull-down experiments and coimmunoprecipitation (Figure 5. A-C). Interestingly, there was potent interaction detected in the yeast two-hybrid system and the co-immunoprecipitation experiments, but only very weak binding in the GST pull-down. This discrepancy might result from differences of the assay approaches. The yeast two-hybrid system and the co-immunoprecipitations have in common that they detect interactions in an in vivo environment, whereas the GST pull-down, even though the transcription/translation process takes place in a reticulocyte lysate, is an in vitro assay. However, direct binding was detected in the peptide array. These results eventually suggest that the binding of Mad2l2 to Hesx1 is assisted by cofactors which strengthen the interaction. 
RNA expression profiling revealed that Mad2/2 is, not abundantly but ubiquitously, expressed in the mouse embryo as well as in adult tissues (Figure 7. A \& C). These results may account for the non-conclusive in situ-hybridization results but are similar to the results found in Homo sapiens and Xenopus laevis (Chan et al., 2001; van den Hurk et al., 2004; Ying and Wold, 2003). This expression pattern is in contrast with the restricted and dynamic expression of Hesx1 (Figure 6.; Hermesz et al., 1996; Thomas and Beddington, 1996).

In context of the finding that both Hesx1 and Mad2I2 are co-localized in the nucleus (Figure 7. B), these results make a biological significant interaction possible.

\section{Mad2/2 binds the $N$-terminal arm of the homeodomain}

Mapping of the Mad2I2 binding domain within Hesx1 revealed a binding to a highly conserved domain at the N-terminal arm of Hesx1 homeodomain (Figure 8.). This conservation beyond the homeodomain indicates a critical role within the protein. Interestingly, the $\mathrm{N}$-terminal arm of the homeodomain contributes substantially to both the DNA binding ability and to sequence recognition by contacting the minor groove of the DNA helix (Figure 24.; Kissinger et al., 1990; Kornberg, 1993; Wilson et al., 1995).

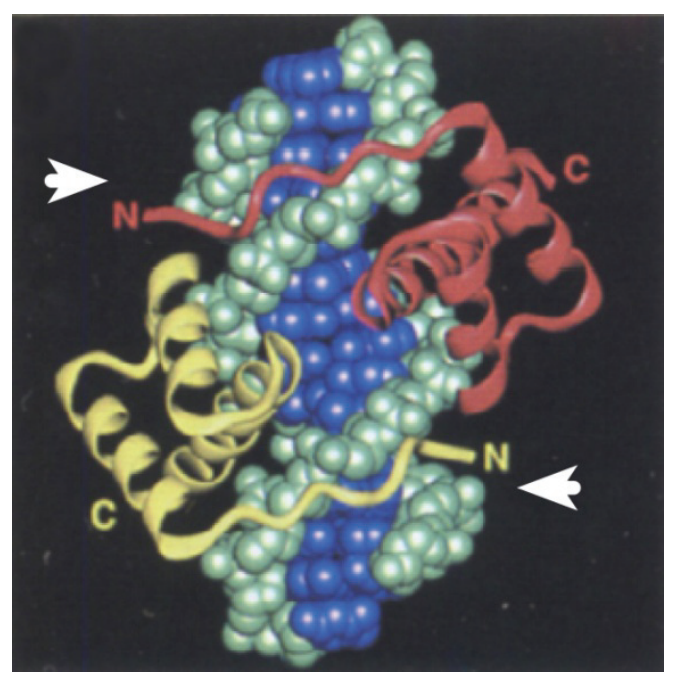

Figure 24. The $\mathrm{N}$-terminal arm of paired homeodomains is involved in DNA binding.

Structure of paired homeodomains that are binding as homodimers to a palindromic PIII site. The N-terminal arm of the paired homeodomain binds to the minor groove of the DNA helix (arrow heads). The DNA is displayed in a space-filling model with phosphoribose backbone in green and bases in blue. The homeodomains are indicated as ribbons (red and yellow) representing the polypeptide backbone (Wilson et al., 1995).

Furthermore, binding of Mad2I2 prevents Hesx1 from binding a palindromic PIII site (Figure 9.). This finding suggests that Mad2/2 is involved in the regulation of Hes 1 activity. Binding of Mad2/2 might prevent Hesx1 from binding its target promoters.

In summary, these results indicate a role of Mad2I2 in the regulation of Hesx1 on the protein level by interfering with its ability to bind to target DNA. This inhibitory 
mechanism might be critical during pituitary gland cell differentiation when Hesx1 levels need to be precisely downregulated in order to allow a normal anterior lobe development (Dasen et al., 2001; Sornson et al., 1996). Downregulation of Hesx1 might therefore occur at three levels: (1) the transcriptional level and the protein level, which can be subdivided into (2) the functional control and (3) the control of protein half-life (discussed below). Mad2/2 binding to Hesx1 might be involved in regulating Hesx1 at the functional level.

\section{The Cdh1-APC complex controls Hesx1 stability}

\section{Cdh1 and Hesx1 are co-expressed and interact}

Since Mad2I2 is an inhibitor of the Cdh1-APC complex (Chen and Fang, 2001; Pfleger et al., 2001), the observed Mad2I2-Hesx1 interaction led to the idea that Hesx1 might be a substrate of Cdh1. Co-immunoprecipitation experiments confirmed the hypothesis that Cdh1 binds to Hesx1 (Figure 5. D). Furthermore, Cdh1 displays an almost ubiquitous expression pattern in Mus musculus, Gallus gallus and Xenopus laevis (Gieffers et al., 1999; Wan and Kirschner, 2001; Zhou et al., 2002). Together with the data from the RTPCR analysis, a spatially and temporally overlapping expression of $C d h 1$ and Hesx 1 is very likely. In addition, Hesx 1 presents two motifs in its amino acid sequence that are similar to Cdh1 recognition motifs, the D-box and the KEN-box. These motifs are located within the homeodomain, and Cdh1 has been shown to bind within this region (Figure 10. B).

This observation also reduces the possibility of unspecific binding. Both the Hesx1 corepressor TLE1 and Cdh1 contain WD40 domains that have been shown to be responsible for the interaction with the Hesx1 eh1 domain and target substrates, respectively (Dasen et al., 2001; Kraft et al., 2005). The co-immunoprecipitation of Cdh1 with a Hesx1 deletion mutant lacking the eh1 domain diminishes the eventuality that Cdh1 binds unspecific to the eh1 domain (Figure 10. B). Nevertheless, co-immunoprecipitation experiments with Hesx1 bearing mutations in the recognition motifs should strengthen this result.

\section{Hesx 1 is ubiquitinated in vivo}

The finding that Hesx1 is a target for ubiquitination in vivo together with the observed interaction with Cdh1 suggests that Hesx1 is a target of the E3 ligase Cdh1-APC complex (Figure 10.). The observation that Mad2/2 co-expression diminishes this polyubiquitination supports this idea. Mad212 might inhibit the Cdh1-APC complex, and 
the subsequent ubiquitination or binding of Mad2I2 to Hesx1 might block its accessibility. The finding that co-expression of Cdh1 did not increase the polyubiquitination pattern might be due to the fact that the overall level of ubiquitination in the presence of the proteasome inhibitor MG132 is already relatively high. Cdh1 knockdown or in vitro experiments with purified APC complexes should be performed in the future to confirm Cdh1-APC as the E3 ubiquitin ligase involved in Hesx1 ubiquitination.

Taken together, these experiments show that Hesx1 is targeted for degradation via the ubiquitin pathway. Since downregulation on the transcriptional level can only ensure an indirect control of Hesx 1 activity, these findings suggests a precise tuning of Hes $x 1$ at the protein level. This regulation on the protein level might be crucial during anterior pituitary gland development. At the border between proliferation and differentiation a removal of present Hesx1 protein might promote the switch from one state into the other (Figure 25.). Evidence for such a function for Hesx1 comes from ES cells where Hesx1-RNA levels are downregulated upon differentiation (Thomas et al., 1995). Furthermore, a similar role of Cdh1-APC was found to be involved in terminal lens differentiation where the complex is responsible for the coordination of proliferation, cell cycle arrest and differentiation (Wu et al., 2007).

Therefore, Cdh1-APC may have a similar function in pituitary gland development by regulating the exit of the cell cycle and at the same time coordinating the onset of differentiation by targeting most probably among other proteins, Hesx1.

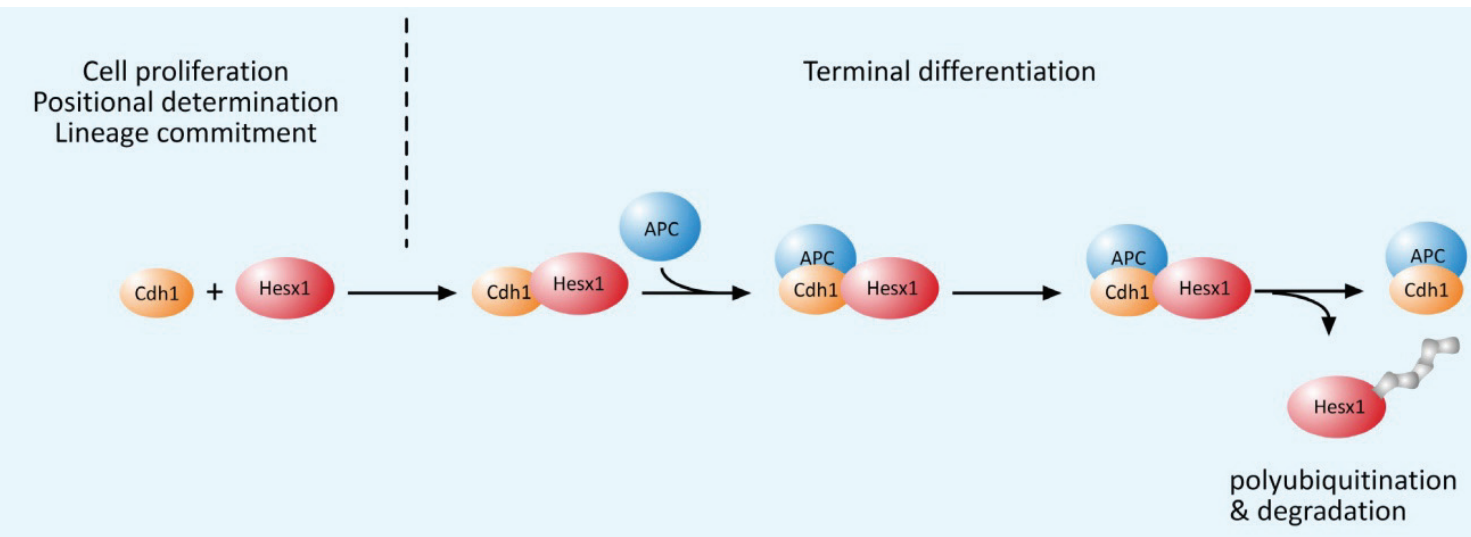

Figure 25. Possible model of Hesx1 ubiquitination during anterior pituitary gland development.

Targeting of Hesx1 for ubiquitination and subsequent degradation might allow terminal differentiation of the specific cell lineages within the anterior pituitary lobe. 
At present there is no evidence indicating that Mad2/2 is involved in substrate recognition or binding, suggesting that Hesx1 ubiquitination and interaction with Mad2/2 might be two independent processes. However, Mad2/2 was found to function as an adapter between JNK MAP kinases and the transcription factor Elk-1 (Zhang et al., 2007). Therefore, a similar role could be conceivable during the ubiquitination process of Hes $x 1$, especially if one considers the low in vitro binding affinity of Hesx1 and Mad2/2. To address this question, ubiquitination experiments of Hesx1 in Mad2/2 deficient MEF's might be elucidative.

\section{Phenotypical analysis of Mad2/2 deficiency}

In order to gain further insight into the function of Mad2/2 during mouse development as a subunit of polymerase $\zeta$ and as an inhibitor of the Cdh1-APC complex, Mad2/2 deficient mice were generated. Mad2/2 heterozygous mice were viable, morphologically normal and fertile. In contrast, homozygous Mad2/2 deficient mice displayed a non-mendelian distribution with the occurrence of intra-uterine lethality. Mad2/2 ${ }^{--}$embryos and adult mice were smaller in size and infertile. MEF's generated from Mad2/2 deficient embryos showed a reduced proliferation rate, an accumulation of cells in the G2/M phase and an elevated level of $\mathrm{Y}-\mathrm{H} 2 \mathrm{AX}$. Moreover, the developing anterior pituitary gland in Mad2/2 deficient mice displayed a significant delay in the differentiation of somatotropes.

\section{Infertility, reduced viability and size in Mad2/2 deficient embryos}

Offspring of $\mathrm{Mad}_{2} / 2^{+/-}$mice intercrosses did not correspond to the expected Mendelian frequency. Only $13 \%$ of the offspring were homozygous Mad2/2 mutants, indicating intrauterine lethality (Figure 15.). The exact point in time of lethality could not be determined so far. Most of the examined stages did not agree with the expected number of Mad2/2 deficient animals according to Mendelian rules.

Mad2/2 deficient embryos and mice could be distinguished readily by their size compared to wild-type and heterozygous littermates (Figure 16.). Besides proportional growth retardation, the embryos seemed not to be significantly retarded in development, which was confirmed by later molecular analysis of the anterior lobe of the pituitary. Furthermore, neither embryos nor adult mice displayed any morphological anterior forebrain or eye abnormalities as it was found in Hesx1 deficient mice (Dattani et al., 
1998; Martinez-Barbera et al., 2000), suggesting that an interaction of Mad2/2 and Hesx1 is not essential at these early stages of development.

Both processes, TLS by polymerase $\zeta$ and ubiquitination mediated by the Cdh1-APC complex, involve the regulatory function of $\mathrm{Mad} 2 \mathrm{~L} 2$ and are of comprehensive relevance during mouse embryonic development (Bemark et al., 2000; Esposito et al., 2000; Wirth et al., 2004; Wittschieben et al., 2000).

On the one hand, the observed phenotype could be linked to Mad2I2 and its role in DNA damage repair. The rapidly dividing cells of the developing embryo might progressively accumulate DNA damage caused by e.g. endogenous metabolic byproducts. These lesions would be normally efficiently bypassed by polymerase $\zeta$. Since Mad2/2 increases the catalytic activity of Rev3 by up to 20 to 30 folds (Nelson et al., 1996), cells lacking Mad2l2 might not be able to sufficiently repair lesions. As a consequence, cells of the embryo that accumulated too many unrepaired lesions and subsequent double-strand breaks might undergo apoptosis (reviewed in Borges et al., 2008).

On the other hand, this phenotype could be caused by a failure in cell cycle progression due to a diminished Cdh1-APC regulation, even though the mechanisms which induce Mad2/2 mediated inhibition are not yet understood. The timing of the exit from mitosis or entry into the $\mathrm{S}$ phase might be disturbed, leading to cell cycle arrest or apoptosis.

Nevertheless, some embryos survived and gave rise to viable $M a d 212^{-/}$animals. The observed variability in survival rates could be explained with the fact that Mad2/2 acts in both processes as a regulatory subunit. Rev3 is the catalytical subunit of polymerase $\zeta$ and able to bypass lesions even in the absence of Mad2I2 (Nelson et al., 1996), and the Cdh1APC complex is regulated by a variety of mechanisms which might compensate the lack of Mad212 (reviewed in Peters, 2006). Therefore, some embryos survive development without accumulating too much DNA damage and deregulation of the cell cycle. However, these embryos and mice might lose cells due to apoptosis resulting in the observed proportional small size of embryos and adult mice.

Interestingly, Mad2/2 deficient mice exhibited infertility. This infertility was shown to be independent of gender. Since Mad2/2 is highly expressed in Mus musculus (Figure 7. C), human (Nelson et al., 1999) and Xenopus laevis (van den Hurk et al., 2004) testes, and to 
a lesser extent in ovaries, this phenotype is consistent with the expression pattern of Mad2/2. The high expression could implicate two possible functions of Mad2/2 during gametogenesis: (1) Mad2/2 might be involved in regulating meiosis by inhibiting Cdh1APC (Marangos et al., 2007; Reis et al., 2007) or (2) the elevated level of Mad2/2 in testes accounts for the increased requirement of polymerase $\zeta$ to maintain the genomic stability in the constantly proliferating gametes. The loss of Mad2/2 suggests either an increased rate of apoptosis in the gonads due to genomic instability or a meiotic phenotype which needs to be further investigated.

In summary, these observations indicate that Mad2/2 is an important factor for normal embryonic development. The fact that Mad2l2 is involved in the regulation of two fundamental processes during development, namely cell cycle control and TLS to maintain genomic stability, may account for the observed more general phenotypes. The high Mad2/2 expression levels in testes and ovaries are consistent with the infertility phenotype in $\mathrm{Mad} 212^{-/-}$mice, and suggest a critical role of Mad2/2 in gametogenesis. Furthermore, an interaction of Hesx1 and Mad2/2 during anterior forebrain development seems not to be essential, since surviving embryos display no obvious malformations of the anterior forebrain structures or behavioral phenotypes.

\section{Proliferation and DNA damage in Mad2/2 deficient MEF's}

MEF's isolated from Mad2/2 deficient embryos had a reduced proliferation rate and failed to give rise to an immortalized proliferating cell line. Early passages showed neither a significant increase in apoptosis nor a significant difference in the plating efficiency. But MEF's lacking Mad2/2 had an elevated number of cells in the G2/M phase and displayed an accumulation of $\mathrm{\gamma}-\mathrm{H} 2 \mathrm{AX}$ foci.

These observations suggest that Mad2/2 is a critical component in the TLS pathway. MEF's lacking Mad2/2 accumulate DNA lesions which are not repaired due to the diminished activity of Rev3. These lesions subsequently give rise to DNA double-strand breaks, as indicated by the elevated levels of $\mathrm{y}-\mathrm{H} 2 \mathrm{AX}$ foci (Rogakou et al., 1998). The accumulation of DNA double-strand breaks could explain the observed increased number of cells present in the G2/M phase. The approximate threshold for activating the G2/M DNA damage checkpoint has been shown to be around 10-20 double-strand breaks per nucleus (Deckbar et al., 2007; reviewed in Lobrich and Jeggo, 2007). Mad2/2 deficient 
MEF's may have an activated G2/M checkpoint due to an increased level of DNA doublestrand breaks which would account for the low proliferation rate. Furthermore, this could explain why these cells did not give rise to a proliferating cell line. The DNA damage that is accumulated in these cells over time might induce cellular senescence with an arrest in G2/M. The MEF's cease proliferation and may potentially become resistant to apoptosis, both characteristics are probably mediated among others by the tumor suppressor protein p53 (reviewed in Campisi and d'Adda di Fagagna, 2007). The mechanism by which senescent cells escape apoptosis is not completely clear, but this characteristic could explain why the Mad2/2 ${ }^{-/}$MEF's did not display an increase in apoptotic cells in comparison to their wild-type counterparts. Interestingly, these results are consistent with observation from Rev3L deficient MEF's. Cells lacking Rev3L divided poorly and entered a quiescent state with apoptosis occurring over weeks to months (Wittschieben et al., 2006). Moreover, Rev3L deficient MEF's in a $p 53$ null background proliferate, even though slower than wild-type cells, and display an increased frequency of cells in the G2/M phase together with an elevated sensitivity to genotoxic agents (Wittschieben et al., 2006; Zander and Bemark, 2004).

Results from other cell lines and experiments targeting Mad2/2 differ from the observation in Mad2/2 null MEF's. In chicken DT40 cells, the disruption of Mad2/2 leads to proliferating cells. These cells showed retarded growth kinetics, an higher apoptosis rate and an increased sensitivity towards genotoxic treatments (Okada et al., 2005). Interestingly, the chicken DT40 cells do not express p53 (Takao et al., 1999) a certainty which might explain the ability to proliferate and the increased apoptotic rate. Knockdown experiments in several cell lines revealed similar results (Cheung et al., 2006; Iwai et al., 2007; McNally et al., 2008) but these cells may have residual levels of Mad2/2 left. Low levels of Mad2I2 may be enough to repair most lesions and therefore preventing the cells from going into senescence which subsequently leads to a less pronounced phenotype.

In summary, these results provide evidence for a vital role of Mad2/2 in mouse embryonic fibroblasts. Cells lacking Mad2/2 may induce the G2/M DNA damage checkpoint due to an accumulation of unrepaired DNA lesions and subsequent double-strand breaks. Finally, cells could be driven into senescence which would explain the observed phenotype 
(Figure 26.). Further analysis using senescence markers, such as p16 or senescenceassociated $\beta$-galactosidase (reviewed in Campisi and d'Adda di Fagagna, 2007) should provide evidence for this hypothesis. In addition, transfection of Mad2/2 to rescue the MEF phenotype could provide additional information to dissect the function of Mad2I2 in vivo.

A

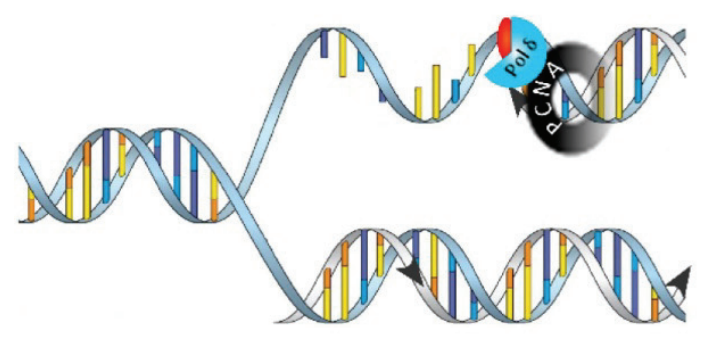

B

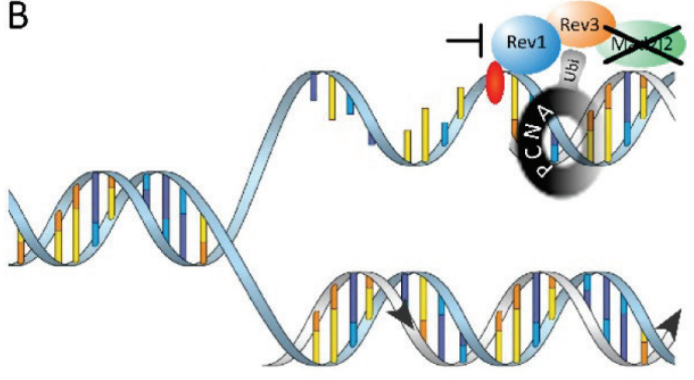

C

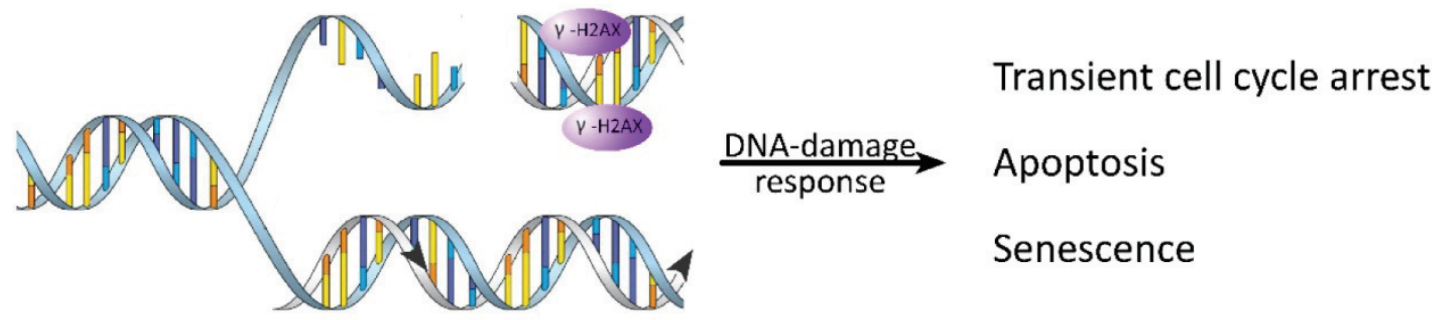

Figure 26. DNA lesion bypass by polymerase $\zeta$ might be disturbed in $\mathrm{Mad}_{2} / 2^{-1-}$ mice.

(A) DNA replication polymerase $\delta$ is unable to bypass the non-coding lesion (red) and is stalled. (B) The stalled replication fork induces the mono-ubiquitination (Ubi; grey) of PCNA. Mono-ubiquitination of PCNA causes the "polymerase switch" from polymerase $\delta$ to TLS polymerases. Lack of Mad212 might reduce the bypass efficiency of Rev3 and result in unrepaired lesions (C) Unrepaired lesions subsequently give rise to double-strand breaks which induce H2AX phosphorylation ( $\gamma-\mathrm{H} 2 \mathrm{AX})$, followed by transient cell cycle arrest, apoptosis or senescence.

Furthermore, a cell cycle effect of Mad2/2 deficiency in MEF's cannot be excluded. The observed accumulation of cells in the $\mathrm{G} 2 / \mathrm{M}$ phase might indicate a perturbation of the Cdh1-APC regulation at the exit of mitosis. Cells might not be able to finish mitosis and are blocked within the $\mathrm{M}$ phase.

\section{Mad2/2 deficiency impairs pituitary cell lineage differentiation}

Since Mad2/2 binding of Hesx1 showed not to be substantial for morphologically normal anterior forebrain development, the developing anterior pituitary gland provided an 
excellent model system to monitor any Hesx1 dependent alteration. Mad2/2 deficient embryos displayed no alteration in the differentiation of corticotropes, thyrotropes, lactotropes and gonadotropes as indicated by the expression of $\alpha \mathrm{GSU}, \mathrm{ACTH}, \mathrm{TSH} \beta, \mathrm{PRL}$ and LH $\beta$. Strikingly, the somatotrophic cell linage identified by the expression of GH was almost absent in all investigated stages so far (Figure 23.).

Interestingly, Prop-1 deficiency leads to a prolonged expression of Hesx1 and a hypoplasia of all Pit-1 dependent cell types, including thyrotropes, somatotropes and gonadotropes (Nasonkin et al., 2004; Sornson et al., 1996). A prolonged expression of Hesx1 together and without TLE1 confirmed that these lineages are dependent among other transcription factors on the downregulation of Hesx1 (Dasen et al., 2001). Moreover, there is a human mutation in Hesx1 that impairs the interaction with the co-repressor TLE1 which was shown to reduce partially the repressor function of Hesx1. This patient displayed GH deficiency and subsequently developed gonadotropin, ACTH and TSH deficiencies (Carvalho et al., 2003). Furthermore, loss-of-function or gain-of-function mutations in the homozygotic or heterozygotic state in humans involve, among other phenotypes, a variable degree of GH deficiency (reviewed in Dattani, 2004, 2005). These finding suggest, that the somatotrophic cell lineage is most sensitive to perturbances of Hesx1 activity and this could explain why only the somatotrophic cell lineage is affected in Mad2/2 deficient mice.

These observations, together with the finding that Mad2l2 deficient mice display a delay in the differentiation of somatotropes, suggest that Mad2/2 binding of Hesx1 is of biological significance and might be necessary to negatively regulate its activity at the onset of Pit-1 dependent cell linage differentiation. Whether this effect is due to the interference of Mad2/2 on Hesx1 DNA binding capacity or due to a disturbed degradation via the Cdh1-APC complex needs to be determined. Therefore, prolonged Hesx1 activity may be the reason for a delay in the somatotrophic cell lineage differentiation due to a retarded Pit-1 activation through Prop-1 (Figure 27.; Dasen et al., 2001).

A complete absence of the somatotropes in Mad2/2 deficient mice is unlikely because the postnatal growth rate (despite of their smaller stature) is only mildly affected. Analysis of later stages, expression of transcription factors like Pit-1 and down-stream targets like IGF-1 levels in the blood, should clarify this. In addition, future analyses needs to be done 
in order to monitor the presence of all cell lineages of the pituitary gland and to determine whether there is a loss during postnatal development as described in human patients (reviewed in Dattani, 2004, 2005). The loss of e.g. gonadotropes could be an additional reason for the observed infertility phenotype.

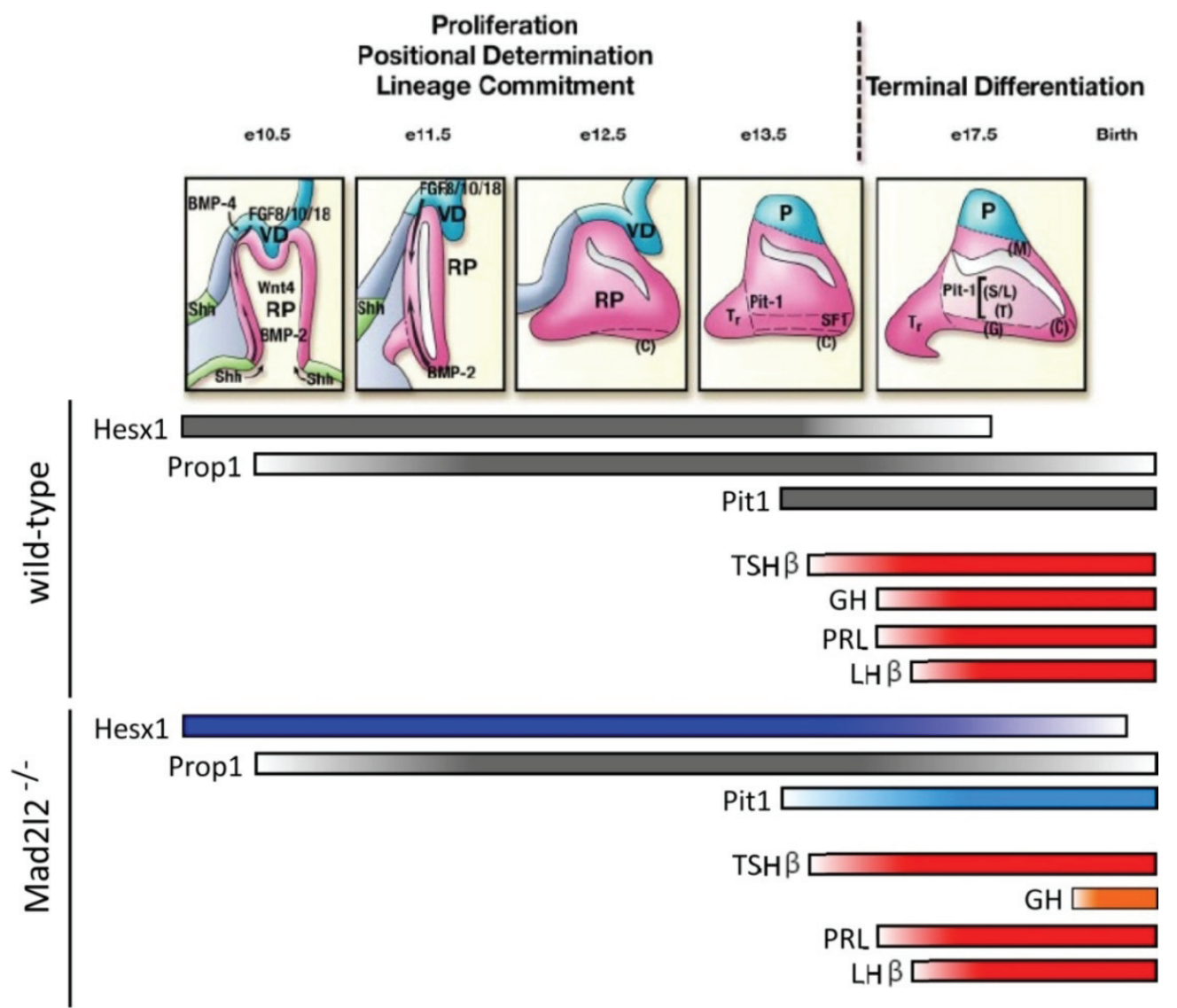

Figure 27. Delayed somatotrope differentiation in Mad2/2 deficient mice.

A possible prolonged Hesx1 presence and activity (blue bar) in Mad2/2 deficient mice may be the reason for a delay in somatotrophic lineage (GH; orange bar) differentiation due to a retarded Pit-1 (light blue bar) activation through Prop-1 (adapted from Zhu et al., 2007). 


\section{SUMMARY AND CONCLUSIONS}

Hesx1 is a paired-like homeodomain transcription factor, which is required for normal forebrain and pituitary gland formation. Its dynamic expression pattern especially during anterior pituitary gland development has been shown to be crucial for normal development. Hesx1 deficient mice display variable degrees of forebrain and pituitary gland defects. A comparable phenotype in humans is septo optical dysplasia (SOD) and humans harboring mutations in HESX1 were observed to display some form of SOD.

In a previous study, Mad2/2 was identified as a so far unknown binding partner of Hesx1 (Pilarski, 2004). Mad212 has been shown to be involved in the regulation of the cell cycle progression and DNA damage repair, probably coordinating both events. The observed interaction raised the question whether broader functionality of Mad2/2 towards transcriptional regulation could be found. Furthermore, the function of Mad2/2 in inhibiting the E3 ligase Cdh1-APC-complex led to the question if Hesx1 might be targeted for ubiquitination by this complex. Both processes might be involved in the regulation of Hesx1 at the protein level.

In this study the interaction of Mad2/2 with Hesx1 was confirmed in several independent experiments. The binding of Mad2/2 to Hesx1 was shown to take place at the $\mathrm{N}$-terminal region of the homeodomain and resulted in a diminished ability of Hesx1 to bind target DNA. Furthermore, a binding of Cdh1 to Hesx1 was found and Hesx1 could be identified as a target of the Cdh1-APC complex. Hesx1 was found to be polyubiquitinated and subsequently degraded via the 265 proteasome.

To study the consequence of Mad2/2 inactivation in mice, knockout animals were produced. These animals displayed a variable intra-uterine lethality, growth retardations and infertility. Mouse embryonic fibroblasts generated from these mice display a DNA damage phenotype confirming a crucial role of Mad2I2 as a subunit of polymerase $\zeta$ and translesion synthesis. Taken together, Mad212 showed to be a crucial factor during embryonic development.

Furthermore, Mad2/2 deficient mice displayed a delay in the differentiation of somatotropes within the developing anterior pituitary gland. Hesx1 activity during anterior pituitary development has been shown to be involved in the initial organ 
commitment and to keep cells in a proliferative state. Differentiation has been shown to require Hesx1 to be downregulated. This study provides evidence that besides transcriptional control which is a more indirect process, Hesx1 may also be regulated on the protein level. Hesx1 protein activity and levels within the differentiating cells may be negatively regulated by Mad2l2 by interfering with the ability of Hesx1 to bind to target DNA and by degradation mediated through ubiquitination by the E3 ubiquitin ligase Cdh1APC complex.

Eventually, the present study has extended the regulative network in which Hesx1 is embedded and identified so far unknown mechanisms of Hesx1 regulation at the protein level. 


\section{MATERIAL AND METHODS}

\section{Isolation, analysis and manipulation of nucleic acids}

\section{Total RNA isolation from eukaryotic cells or mouse embryos}

Total RNA from cultured eukaryotic cells or mouse embryonic tissues way isolated using the RNeasy ${ }^{\circledR}$ Mini Kit (QIAGEN), as described by the manufacturer.

\section{Genomic DNA extraction from mammalian cells or mouse tissues}

In $10 \mathrm{~cm}$ dishes cultured mammalian cells were washed with PBS twice and trypsinized in $2 \mathrm{ml}$ Trypsin (0.05\% Trypsin/EDTA; Gibco BRL ${ }^{\circledR}$ ). The Trypsin digestion was stopped by adding $8 \mathrm{ml}$ of culture medium and the cells were transferred into a $15 \mathrm{ml} \mathrm{Falcon}^{\mathrm{TM}}$ tube. $^{\circ}$ Cells were collected by centrifugation at $210 \mathrm{~g}$ (Heraeus Megafuge 1.0 - 1000rpm) for five minutes. The cell pellet was washed with PBS twice and resuspended in $500 \mu$ I DNA lysis buffer (100 mM Tris-Cl, pH 8.0, 5 mM EDTA, 0.2\% SDS, $200 \mathrm{mM} \mathrm{NaCl)} \mathrm{containing} \mathrm{freshly}$ added $25 \mu \mathrm{l}$ of $100 \mu \mathrm{g} / \mathrm{ml}$ Proteinase $\mathrm{K}$. The cells were incubated at $55^{\circ} \mathrm{C}$ shaking for 6 hours. Afterwards, the lysis product was centrifuged at $13000 \mathrm{rpm}$ for five minutes. $450 \mu \mathrm{l}$ of the supernatant was transferred into a new $1.5 \mathrm{ml}$ tube. The DNA was now precipitated by the addition of $350 \mu$ of isopropanol and subsequent vigorous shaking. The DNA was pelleted by centrifugation at $13000 \mathrm{rpm}$ for five minutes, washed with $70 \%$ ethanol and air dried. DNA was dissolved in 200-300 $\mu$ TE buffer (10 mM Tris-Cl, pH 7.5, 1 mM EDTA) shaking at $37^{\circ} \mathrm{C}$ for 30 minutes.

Mouse tissues were washed with PBS once and incubated in $500 \mu$ DNA lysis buffer at $55^{\circ} \mathrm{Co} / \mathrm{n}$. The following treatments were the same as described above for mammalian cells.

\section{Plasmid DNA isolation from $E$. coli}

To isolate plasmid DNA from E. coli, the QIAprep Spin Miniprep Kit (QIAGEN) was used to isolate up to $20 \mu \mathrm{g}$ from a 3 to $5 \mathrm{ml}$ o/n culture and the QIAfilter ${ }^{\mathrm{TM}}$ Plasmid Maxi Kit (QIAGEN) was used to isolate up to $500 \mu \mathrm{g}$, from a 100 to $250 \mathrm{ml} \mathrm{o} / \mathrm{n}$ culture. Both systems are based on alkaline lysis of bacterial cells (Birnboim and Doly, 1979) followed by an absorption of DNA onto silica or an anion-exchange resin, respectively. The procedure was done according to the instructions of the manufacturer. The plasmid DNA was eluted or re-dissolved using $\mathrm{dH}_{2} \mathrm{O}$. 


\section{P1-derived artificial chromosome (PAC) isolation from E. coli}

The following protocol was used in order to isolate large PAC's from E.coli. Buffers P1, P2, N3 and TE were used from the QIAprep ${ }^{\circledR}$ Miniprep Kit (QIAGEN).

A $5 \mathrm{ml}$ overnight culture was inoculated and harvested by centrifugation for five minutes at $5000 \mathrm{rpm}$. The supernatant was removed; the cell pellet dissolved in $250 \mu \mathrm{l} \mathrm{P1}$ Buffer and everything was transferred into a $1.5 \mathrm{ml}$ eppendorf tube. $250 \mu \mathrm{l}$ P2 Buffer was added, mixed thoroughly and incubated for five minutes at room temperature to lyse the cells. Afterwards $350 \mu \mathrm{l}$ of N3 Buffer was added, mixed and placed on ice for five minutes. The mixture was centrifuged two times for five minutes at $13200 \mathrm{rpm}$ and each time the supernatant was transferred into a new tube. To precipitate the DNA, $750 \mu$ I isopropanol was added, mixed and placed on ice for 10 minutes. Now, it was centrifuged for 10 minutes at $13200 \mathrm{rpm}$, the supernatant was removed and the pellet was washed with 1 $\mathrm{ml}$ of $70 \%$ ethanol. Finally, the DNA was dissolved in $50 \mu \mathrm{l}$ TE Buffer at $37^{\circ} \mathrm{C}$ for three hours. Only freshly prepared DNA was used for transformations.

\section{Standard and Genomic polymerase chain reaction (PCR)}

The PCR (Saiki et al., 1988) was used to selectively amplify DNA fragments. Annealing temperatures were adjusted to fit the respective primer melting temperature (approximately $5^{\circ} \mathrm{C}$ below). Extension times were matched to fit the length of the DNA fragment and the speed of the respective polymerase. To minimize the probability of mutations (exchange, deletion, etc.) a Pwo DNA polymerase (Roche) or the PfuUltra ${ }^{\circledR}$ Hotstart DNA polymerase (Stratagene) was used. These polymerases possesses a $3^{\prime}-5^{\prime}$ exonuclease activity (proofreading activity) which results in an over 10-fold increased fidelity of DNA synthesis compared to Taq DNA polymerase. The GoTaq ${ }^{\circledR}$ DNA polymerase (Promega) was used for genotyping. All polymerases were used according to the instructions of the manufacturer. The thermocycling program (Table 2) was carried out using the Mastercycler ${ }^{\circledR}$ Gradient (Eppendorf). 


\begin{tabular}{llll}
\hline Segment & Number of cycles & Temperature & Duration \\
\hline 1) Initial denaturation & 1 & $94^{\circ} \mathrm{C}$ & 2 minutes \\
2) Denaturation & $30-40$ & $94^{\circ} \mathrm{C}$ & 30 seconds \\
Annealing & & $55-65^{\circ} \mathrm{C}$ & 30 seconds \\
Elongation & & $72^{\circ} \mathrm{C}$ & $1-2$ minutes \\
3) Final elongation & 1 & $72^{\circ} \mathrm{C}$ & 10 minutes \\
\hline
\end{tabular}

Table 2. Standard thermocycling program for PCR.

\section{Reverse transcriptase - polymerase chain reaction (RT-PCR)}

The QIAGEN OneStep RT-PCR Kit (QIAGEN) was used to amplify selectively DNA fragments from RNA templates. This kit is designed to carry out reverse transcription and PCR sequentially in the same tube. The enzyme mix contains the Ominscript and Sensiscript reverse transcriptases for efficient and specific reverse transcription and the HotStarTaq DNA polymerase for subsequent amplification. Annealing temperatures were adjusted approximately $5^{\circ} \mathrm{C}$ below the respective primer melting temperature. Extension times were matched to fit the length of the DNA fragment. The RT-PCR was performed according to the instructions of the manufacturer. The thermocycling program (Table 3) was carried out using the Mastercycler ${ }^{\circledR}$ Gradient (Eppendorf).

\begin{tabular}{llll}
\hline Segment & Number of cycles & Temperature & Duration \\
\hline 1) Reverse Transcription & 1 & $50^{\circ} \mathrm{C}$ & 30 minutes \\
2) Initial PCR activation step & 1 & $95^{\circ}$ & 15 minutes \\
3) Initial denaturation & 1 & $94^{\circ} \mathrm{C}$ & 2 minutes \\
4) Denaturation & $30-40$ & $94^{\circ} \mathrm{C}$ & 30 seconds \\
Annealing & & $55-65^{\circ} \mathrm{C}$ & 30 seconds \\
Elongation & & $72^{\circ} \mathrm{C}$ & $1-2$ minutes \\
5) Final elongation & 1 & $72^{\circ} \mathrm{C}$ & 10 minutes \\
\hline
\end{tabular}

Table 3. Standard thermocycling program for RT-PCR.

\section{Purification of PCR products}

PCR products were purified using the QIAquick ${ }^{\circledR}$ PCR Purification Kit (QIAGEN), following the instructions of the manufacturer.

\section{PCR-Primers}

Primers were designed using the Sequencher ${ }^{\mathrm{TM}} 3.1 .1$ software (Gene Codes Corporation), the CLC Free Workbench 4.0.3 program (CLC bio A/S; http://www.clcbio.com) and the online tool Oligo Calc (http://www.basic.northwestern.edu/biotools/oligocalc.html). This program calculates the physical constants of the oligonucleotide, checks self- 
complementarity and allows a direct access to the NCBI BLAST interface. Oligonucleotides were obtained either from IBA (Goettingen, Germany) or Operon (Cologne, Germany).

\begin{tabular}{|c|c|c|c|}
\hline Name/Purpose & Direction & Tag & Sequence $\left(5^{\prime} \rightarrow 3^{\prime}\right)$ \\
\hline \multicolumn{4}{|l|}{ Cloning } \\
\hline Mad2I2_5'Sall & Forward & Sall & ACGCGTCGACGCCAAGGATGACCACC \\
\hline Mad2I2_3'Notl & Reverse & Notl & ATAAGAATGCGGCCGCGCCCTCAGCTGTTCTTATGC \\
\hline Map-1_5'Sall & Forward & Sall & ACGCGTCGACGAGCACCATGACACTGAG \\
\hline Map-1_3’Notl & Reverse & Notl & ATAGTTTAGCGGCCGCGGGTCAAGTGCAATAGCCT \\
\hline Importin13_5'EcoRI & Forward & EcoRI & GGAATTCCAAAGATGGAGCGGCGGG \\
\hline Importin13_3'Notl & Reverse & Notl & ATAGTTTAGCGGCCGCCCCTCAGTAGTCAGCTGTG \\
\hline Traf4_5'Sall & Forward & Sall & ACGCGTCGACGCCCGCCATGCCCGGC \\
\hline Traf4_3'Notl & Reverse & Notl & ATAAGAATGCGGCCGCCTCTACTCAGCTGAGGATC \\
\hline pGEX_Hesx1_BamHI & Forward & BamHI & CGGGATCCCAGAAGAGAATGTCTCCCAGCC \\
\hline pGEX_Hesx1_HindIII & Reverse & HindIIII & CCCAAGCTTCTACCTATTTCAGAAGATCTGGG \\
\hline 5'GST-Mad2I2 Smal & Forward & Smal & TCCCCCGGGGATGACCACCCTCACGC \\
\hline 3'GST-Mad2l2 Xbal & Reverse & Xbal & GCTCTAGACCTCAGCTGTTCTTATGCG \\
\hline pSP64_Mad2I2_3'Xbal & Reverse & Xbal & GCTCTAGAGCCCTCAGCTGTTCTTATG \\
\hline Cdh1 5' EcoRI & Forward & EcoRI & GGAATTCCCATGGACCAGGACTATGAGC \\
\hline Cdh1 3' Sall & Reverse & Sall & ACGCGTCGACCCTGCGGGGTCTATCGGATC \\
\hline Hesx1 5' EcoRI & Forward & EcoRI & GGAATTCAATGTCTCCCAGCCTTCG \\
\hline Hesx1 3’ BamHI & Reverse & BamHI & CGGGATCCTACCTATTTCAGAAGATCTGG \\
\hline Hesx1*3' $\Delta$ HD BamHI & Reverse & BamHI & CGGGATCCTCAAGTCTCACTGGGAAGATC \\
\hline Hesx1*5' $\Delta$ eh1 EcoRI & Forward & EcoRI & GGAATTCTCCTTGTCCAGTGGATCACC \\
\hline \multicolumn{4}{|l|}{ Northern blot analysis } \\
\hline Mad212northernS5 & Forward & - & GACCTCAACTTTGGCCAAG \\
\hline Mad212northernS3 & Reverse & - & GGTTGTGATCCAGGACAG \\
\hline \multicolumn{4}{|c|}{ Mad2/2 cko vector - recombineering } \\
\hline A & Forward & Notl & ATAAGAATGCGGCCGCACTCCAGTTCCAGGTTATCCG \\
\hline B & reverse & Spel & GGACTAGTTTACATAATAAGAGTCCTCCTCC \\
\hline $\mathrm{Y}$ & Forward & Spel & GGACTAGTAGCTTCTGAGTGGAATCTAGG \\
\hline Z & Reverse & BamHI & GGATCCCCATGAGAGAGTCCTGTCTG \\
\hline c & Forward & Sall & ACGCGTCGACCTGAAGATTTATTGAGTCAACTCC \\
\hline D & Reverse & EcoRI, Bgll & GGAATTCGCCTGCAGGGCCGAGCTAAACCGCCTTTGG \\
\hline $\mathrm{E}$ & Forward & BamHI & CGCGGATCCTTCCTTGGAGATTCCTGTAGC \\
\hline $\mathrm{F}$ & Reverse & Notl & ATAAGAATGCGGCCGCTCCCTCTCGGCGGAAATCC \\
\hline G & Forward & Sall & ACGCGTCGACACTTCCAGGCTCGAATCTGC \\
\hline $\mathrm{H}$ & Reverse & EcoRI, Dral & GGAATTCTTTAAATACACATGTTCATCCTGTTTGG \\
\hline I & Forward & BamHI & CGCGGATCCTCGAAGCTGCCCTGAGAAG \\
\hline J & Reverse & Notl & AGAATGCGGCCGCCTTCTCTGATTACCCTCCAGG \\
\hline \multicolumn{4}{|l|}{ Southern blot analysis } \\
\hline S1 Dral (3' Probe) & Forward & - & GGAGAAGCTGTCATCAGATGTC \\
\hline S2 Dral (3' Probe) & Reverse & - & GCT CCT TAG TGC TTG GAA CAC \\
\hline S3*Bgll (5’ Probe) & Forward & - & GTC AGC TTC TTG CCA CTC TCC \\
\hline S4*Bgll (5' Probe) & Reverse & - & CAT CTA CTG GCC ATG CAC ACC \\
\hline \multicolumn{4}{|l|}{ EMSA } \\
\hline PrdQ-EMSA-sense & Forward & - & AGCTTGAGTCTAATTGAATTAACTGTAC \\
\hline PrdQ-EMSA-antisense & Reverse & - & GTACAGTTAATTCAATTAGACTCAAGCT \\
\hline \multicolumn{4}{|l|}{ Genotyping } \\
\hline neof & Forward & - & CAGCTGTGCTCGACGTTGTCACTG \\
\hline
\end{tabular}




\begin{tabular}{llll}
\hline neoR & Reverse & - & CCATGATATTCGGCAAGCAGGCATCG \\
3' out of neo & Forward & - & CAGCGCATCGCCTTCTATC \\
M2125genotyp (\#1) & Forward & - & GCTCTTATTGCCTTGACATGTGGCTGC \\
M2123genotyp (\#2) & Reverse & - & GGACACTCAGTTCTGGAAAGGCTGG \\
M2125loxPgenotyp (\#3) & Forward & - & CTGCAGCCCAATTCCGATCATATTCAATAAC \\
GAPDH 5' & Forward & - & ACCTTCGATGCCGGGGCTG \\
GAPDH 3' & Reverse & - & ATGAGGTCCACCACCCTGTTG \\
\hline
\end{tabular}

Table 4. List of PCR-primers

\section{DNA electrophoresis and purification from agarose gel}

To analyze and separate fragments of restriction digests or products of PCR reactions agarose gels were made. Depending on the fragment size $0.3-2 \%$ agarose gels (Table 5) were prepared in 1x TBE buffer ( $89 \mathrm{mM}$ Tris-base, $89 \mathrm{mM}$ Boric acid, $2 \mathrm{mM}$ EDTA $0.5 \mathrm{M}$, $\mathrm{pH}$ 8) containing $10 \mu \mathrm{g} / \mathrm{ml}$ of ethidium bromide. The DNA was mixed with an appropriate amount of $6 x$ gel loading buffer $(0,25 \%(w / v)$ Bromophenol blue, 0,25\% (w/v) Xylene cyanol FF, 30\% (v/v) Glycerol in $\mathrm{dH}_{2} \mathrm{O}$ ) before being loaded into the gel. The gel was run at a voltage of 80 to 110 in 1x TBE. UV-light (Biometra TI2) with a wave length of $258 \mathrm{~nm}$ was used to visualize DNA for analytical purposes. AlphaEase ${ }^{\mathrm{TM}} \mathrm{FC}$ software was used for documentation. Preparative Gels were examined at a wave length of $366 \mathrm{~nm}$ with less intensity to prevent DNA damage.

\begin{tabular}{ll}
\hline Agarose concentration (\% w/v) & DNA fragment range (kb) \\
\hline 0.3 & $5-60$ \\
0.5 & $1-30$ \\
0.7 & $0.8-12$ \\
1.0 & $0.5-10$ \\
1.2 & $0.4-7$ \\
1.5 & $0.2-3$ \\
2.0 & $0.05-2$ \\
\hline
\end{tabular}

Table 5. Concentration of agarose used for separating DNA of different sizes. Modified from Qiagen Bench Guide, 2001.

\section{Quantification of nucleic acids}

The concentration of DNA or RNA was determined using the BioPhotometer (Eppendorf) or the NanoDrop ${ }^{\circledR}$ Spectrometer ND-1000 (Thermo Fisher Scientific). Readings were taken at wavelength of $260 \mathrm{~nm}$ and $280 \mathrm{~nm}$. The reading of $260 \mathrm{~nm}$ allows calculation of the concentration of nucleic acid, whereas the ratio of $\mathrm{OD}_{260} / \mathrm{OD}_{280}$ provides an estimate of the purity. Pure preparations have values in the range of 1.8 and 2.0.

\section{Restriction digest of DNA}

Restriction digests of DNA using restriction endonucleases were performed as recommended by the manufacturer (New England Biolabs, Roche). Double digestions 
could be performed if both enzymes needed the same conditions. Otherwise a sequential digestion was performed and the DNA was purified, using the QIAquick PCR Purification Kit (QIAGEN), between the different digestions. For analytical digests $5 \mathrm{U}$ restriction enzyme was used per $\mu \mathrm{g}$ DNA. The digest was accelerated by using a microwave oven two times for 12 seconds at half power and afterwards incubating the reaction for an half an hour at $37^{\circ} \mathrm{C}$. Preparative digests were performed using up to $10 \mathrm{U}$ of restriction endonuclease per $\mu \mathrm{g}$ of DNA and the reaction mix was incubated for two to four hours at $37^{\circ} \mathrm{C}$. If cleavages close to the end of a DNA fragment were desired the incubation was $\mathrm{o} / \mathrm{n}$ at room temperature. If required, BSA was added to a final concentration of 100 $\mu \mathrm{g} / \mathrm{ml}$.

\section{Dephosphorylation of DNA fragments}

Dephosphorylations of cloning vectors were performed to prevent religation of the vector itself. The alkaline phosphatase hydrolyzes the 5'-phosphate group at the DNA. The reaction assay was adjusted with one tenth volumes of the 10x dephosphorylation buffer and $1 \mathrm{U}$ alkaline phosphatase $(1 \mathrm{U} / \mu \mathrm{l}$, Roche) was subsequently added. The reaction was incubated at $37^{\circ} \mathrm{C}$ for one hour. Afterwards the vector DNA was purified using the QIAquick PCR Purification Kit (QIAGEN).

\section{DNA ligation}

DNA ligations were performed using T4 DNA Ligase (MBI Fermentas). 25-100 ng vector DNA was used and the insert DNA mass was determined according to the following equation: mass $_{\text {insert }}[n g]=\frac{5 \times \text { mass }_{\text {vector }}[\mathrm{ng}] \times \text { length }_{\text {insert }}[\mathrm{bp}]}{\text { length }_{\text {vector }}[\mathrm{bp}]}$ (Mülhardt, 2004). The ligation reaction was performed in $10 \mu \mathrm{l}$ and contained $1 \mu \mathrm{l}$ of ligase $(3 U / \mu \mathrm{l}), 1 \mu \mathrm{l} 10 \mathrm{x}$ ligation buffer, the appropriate amount of DNA and $\mathrm{dH}_{2} \mathrm{O}$. Incubation took place for one hour at room temperature or overnight at $16^{\circ} \mathrm{C}$. At the end of the incubation time the reaction was heat inactivated for $10 \mathrm{~min}$ at $65^{\circ} \mathrm{C}$.

\begin{tabular}{|c|c|c|c|c|}
\hline Name & $\begin{array}{l}\text { Backbone } \\
\text { (supplier) }\end{array}$ & Insert & Purpose & Reference \\
\hline IRAVp968E0724D6 & $\begin{array}{l}\text { pCMV-SPORT6 } \\
\text { (RZPD) }\end{array}$ & Mad2I2 & General cloning & RZPD clone \\
\hline IRAKp961H2324Q & $\begin{array}{l}\text { pCMV-SPORT6 } \\
\text { (RZPD) }\end{array}$ & Importin13 & General cloning & RZPD clone \\
\hline IRAKp961C2016Q & $\begin{array}{l}\text { pCMV-SPORT6 } \\
\text { (RZPD) }\end{array}$ & Traf 4 & General cloning & RZPD clone \\
\hline $2610209 C 10$ & Modified & Map-1 & General cloning & RIKEN \\
\hline
\end{tabular}




\begin{tabular}{|c|c|c|c|c|}
\hline & bluscript 1 & & & $\begin{array}{ll}\text { Fantom } & 1 \\
\text { library) } & \end{array}$ \\
\hline IRAVp968A1021D6 & $\begin{array}{l}\text { pCMV-SPORT6 } \\
\text { (RZPD) }\end{array}$ & Cdh1 & General cloning & RZPD clone \\
\hline pDBLeu & $\left(\right.$ Gibco BRL $\left.{ }^{\circledR}\right)$ & - & Yeast Two-Hybrid Screen & $\begin{array}{l}\text { (Chevray and } \\
\text { Nathans, } \\
\text { 1992) }\end{array}$ \\
\hline pDBLeu-Hesx1 & $\begin{array}{l}\text { pDBLeu (Gibco } \\
\left.\mathrm{BRL}^{\circledR}\right)\end{array}$ & Hesx1 & Yeast Two-Hybrid Screen & $\begin{array}{l}\text { (Pilarski, } \\
\text { 2004) }\end{array}$ \\
\hline pPC86 & $\left(\right.$ Gibco BRL $\left.{ }^{\circledR}\right)$ & - & Yeast Two-Hybrid Screen & $\begin{array}{l}\text { (Chevray and } \\
\text { Nathans, } \\
\text { 1992) }\end{array}$ \\
\hline pPC86-Mad212 & $\begin{array}{ll}\mathrm{pPC} 86 & \text { (Gibco } \\
\left.\mathrm{BRL}^{\circledR}\right) & \end{array}$ & $\operatorname{Mad} 212$ & Yeast Two-Hybrid Screen & This study \\
\hline pPC86-Map-1 & $\begin{array}{l}\text { pPC86 (Gibco } \\
\left.\mathrm{BRL}^{\circledR}\right)\end{array}$ & Map-1 & Yeast Two-Hybrid Screen & This study \\
\hline pPC86-Traf 4 & $\begin{array}{l}\text { pPC86 (Gibco } \\
\left.\mathrm{BRL}^{\circledR}\right)\end{array}$ & Traf 4 & Yeast Two-Hybrid Screen & This study \\
\hline pPC86-Imp13 & $\begin{array}{l}\text { pPC86 (Gibco } \\
\left.\mathrm{BRL}^{\circledR}\right)\end{array}$ & Importin13 & Yeast Two-Hybrid Screen & This study \\
\hline pGEX-KT/mHesx 1 & $\begin{array}{l}\text { pGEX-KT } \\
\text { (Amersham } \\
\text { Biosciences) }\end{array}$ & Hesx1 & $\begin{array}{l}\text { GST-Hesx1 protein } \\
\text { expression and purification }\end{array}$ & This study \\
\hline pGEX-KT/Mad2/2 & $\begin{array}{l}\text { pGEX-KT } \\
\text { (Amersham } \\
\text { Biosciences) }\end{array}$ & $\operatorname{Mad} 212$ & $\begin{array}{l}\text { GST-Mad212 protein } \\
\text { expression and purification }\end{array}$ & This study \\
\hline pSP64/Mad212 & $\begin{array}{l}\text { pSP64 Poly }(A) \\
\text { (Promega) }\end{array}$ & $\operatorname{Mad} 212$ & $\begin{array}{l}\text { In vitro } \\
\text { transcription/translation }\end{array}$ & This study \\
\hline pSP64/Hesx1 & $\begin{array}{l}\text { pSP64 Poly (A) } \\
\text { (Promega) }\end{array}$ & Hesx1 & $\begin{array}{l}\text { In vitro } \\
\text { transcription/translation }\end{array}$ & This study \\
\hline pCMV-HA/Mad2I2 & $\begin{array}{l}\text { pCMV-HA } \\
\text { (Clontech) }\end{array}$ & $\operatorname{Mad} 212$ & $\begin{array}{l}\text { Co-immunoprecipitation, } \\
\text { Ubiquitination assay }\end{array}$ & This study \\
\hline pCMV-HA/Cdh1 & $\begin{array}{l}\text { pCMV-HA } \\
\text { (Clontech) }\end{array}$ & Cdh1 & $\begin{array}{l}\text { Co-immunoprecipitation, } \\
\text { Ubiquitination assay }\end{array}$ & This study \\
\hline pFLAG-CMV/Hesx1 & $\begin{array}{l}\text { pFLAG-CMV }{ }^{\mathrm{TM}}-2 \\
\text { (Sigma) }\end{array}$ & Hesx1 & $\begin{array}{l}\text { Co-immunoprecipitation, } \\
\text { Ubiquitination assay }\end{array}$ & This study \\
\hline $\begin{array}{l}\text { pFLAG-CMV/Hesx1 } \Delta \\
\text { HD }\end{array}$ & $\begin{array}{l}\text { pFLAG-CMV }{ }^{\mathrm{TM}}-2 \\
\text { (Sigma) }\end{array}$ & Hesx1 $\Delta \mathrm{HD}$ & Co-immunoprecipitation & This study \\
\hline $\begin{array}{l}\text { pFLAG-CMV/Hesx1 } \Delta \\
\text { eh1 }\end{array}$ & $\begin{array}{l}\text { pFLAG-CMV }{ }^{\mathrm{TM}}-2 \\
\text { (Sigma) }\end{array}$ & Hesx1 $\Delta$ eh1 & Co-immunoprecipitation & This study \\
\hline $\begin{array}{l}\text { pFLAG-CMV/Hesx1 } \Delta \\
2 / 3 \mathrm{HD}\end{array}$ & $\begin{array}{l}\text { pFLAG-CMV }{ }^{\mathrm{TM}}-2 \\
\text { (Sigma) }\end{array}$ & $\operatorname{Hesx} 1 \Delta 2 / 3 \mathrm{HD}$ & Co-immunoprecipitation & This study \\
\hline pGEM-T/Hesx1 & $\begin{array}{l}\text { pGEM }^{\circledR}-\mathrm{T} \\
\text { (Promega) }\end{array}$ & Hesx1 & $\begin{array}{l}\text { Whole mount in situ- } \\
\text { hybridization }\end{array}$ & $\begin{array}{l}\text { (Pilarski, } \\
\text { 2004) }\end{array}$ \\
\hline pEGFP-N2 & (Clontech) & GFP & Transfection control & - \\
\hline $\begin{array}{l}\text { pcDNA3.1(-)- } \\
\text { His }_{6} \text { Ubiquitin }\end{array}$ & $\begin{array}{l}\text { pcDNA3.1(-) } \\
\text { (Invitrogen) }\end{array}$ & $\mathrm{His}_{6}$ Ubiquitin & Ubiquitination assay & $\begin{array}{l}\text { F. Melchior } \\
\text { lab. }\end{array}$ \\
\hline RPCIP711B01141Q6 & pPAC4 (RZPD) & $\begin{array}{l}\text { Mad212 genomic } \\
\text { region }\end{array}$ & Recombineering & $\begin{array}{l}\text { (Osoegawa et } \\
\text { al., 2000) }\end{array}$ \\
\hline PL451 & (NCl-Frederick) & $\begin{array}{l}\text { Frt-Pgk-em7- } \\
\text { Neo-Frt-loxP }\end{array}$ & Recombineering - targeting & $\begin{array}{l}\text { (Liu et al., } \\
2003)\end{array}$ \\
\hline PL452 & (NCl-Frederick) & $\begin{array}{l}\text { loxP-Pgk-em7- } \\
\text { Neo-loxP }\end{array}$ & Recombineering - targeting & $\begin{array}{l}(\text { Liu et al., } \\
2003)\end{array}$ \\
\hline PL253 & $\begin{array}{l}\text { pBluescript } \\
\text { (NCl-Frederick) }\end{array}$ & $\begin{array}{l}\text { Mc1-driven } \\
\text { Thymidine } \\
\text { Kinase }(T K)\end{array}$ & Recombineering - retrieving & $\begin{array}{l}(\text { Liu et al., } \\
2003)\end{array}$ \\
\hline
\end{tabular}

Table 6. List of plasmids. 


\section{Sequencing}

Sequencing was performed in the Molecular Cell Biology department by Sigurd Hille using Taq Dye Deoxy Terminator Kits (Perkin Elmer) and an ABI Prism 377 DNA Sequencer (Applied Biosystems) or by GATC Boiotech (Konstanz).

Sequence analysis was performed with the Sequencher ${ }^{\mathrm{TM}}$ 3.1.1 software (Gene Codes Corporation) or the CLC Free Workbench 4.0.3 program (CLC bio A/S; http://www.clcbio.com). Database analysis was performed using the different databases of the National Center for Biotechnology Information (NCBI, http://www.ncbi.nih.org), the exPASy Molecular Biology Server (http://us.expasy.org), Ensemble (http://www.ensembl.org/index.html) and Mouse Genome Informatics (MGI) (http://www.informatics.jax.org).

\section{Dig-labeled antisense RNA probe preparation}

Dig-labeled antisense RNA in vitro transcription was performed from a linearized plasmid which contains the cDNA of the gene which transcripts should be monitored in the tissue. The linearization of the plasmid DNA was done with restriction enzymes which leave a 5'overhang to prevent the RNA polymerase from "turning" around and synthesizing a sense strand. The transcription reaction was done in a total volume of $20 \mu$ l containing $1 \mu \mathrm{l}$ linearized plasmid $(1 \mu \mathrm{g} / \mu \mathrm{l}), 2 \mu \mathrm{l}$ 10x transcription buffer (Roche), $2 \mu \mathrm{I}$ DIG RNA labeling mix (Roche), $2 \mu \mathrm{l}$ RNasin (40 U/ $\mu \mathrm{l}), 1 \mu \mathrm{l}$ RNA polymerase and $12 \mu \mathrm{ld} \mathrm{H}_{2} \mathrm{O}$. This reaction was mixed and incubated for 2 hours at $37^{\circ} \mathrm{C}$. Digoxigenin-11-UTP is incorporated in the antisense RNA during the in vitro transcription, which was later on detected by anit-DIGAP conjugated antibodies. To purify the RNA probes ProbeQuant G-50 columns (GE

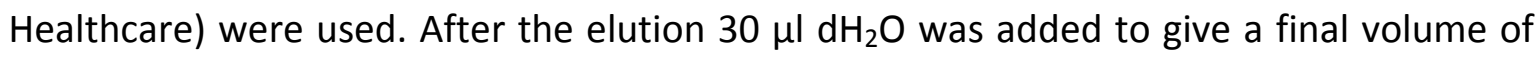
$100 \mu \mathrm{l} .5 \mu \mathrm{l}$ of the reaction were controled on a non-denaturing $1 \%$ agarose gel and should result in one strong and a possibly second weaker band. The sizes of the single stranded RNA just fits very roughly to the DNA marker.

\section{Preparation of random radioactively labeled DNA probes}

The DNA probes for northern and southern blot analysis were prepared using the Amersham Rediprime II Random Prime Labelling System (GE Healthcare) and $\left[\alpha-{ }^{32} P\right]-d C T P$ (Amersham Biosciences). The labeling reaction was performed as recommended by the manufacturer. 


\section{Purification of labeled nucleic acids}

ProbeQuant G-50 Sephadex Micro Columns (GE Healthcare) were used to purify DIG or radioactively labeled nucleic acids. The Micro Columns were used according to the instruction of the manufacturer. The specific activity of radioactive labeled DNA was measured using the LS 1701 scintillation counter (BeckMan).

\section{Phenol extraction and ethanol precipitation of DNA}

The DNA solution was first extracted with a phenol/chloroform/isoamyl alcohol mixture to remove protein contaminants, and then precipitated with $100 \%$ ethanol. The DNA was pelleted after the precipitation step, washed with $70 \%$ ethanol to remove salts and small organic molecules, and resuspended in $\mathrm{dH}_{2} \mathrm{O}$ at a concentration suitable for further experimentation.

An equal volume of phenol/chloroform/isoamyl alcohol $(25: 24: 1(\mathrm{v} / \mathrm{v} / \mathrm{v}))$ was added to the DNA solution to be purified in a $1.5 \mathrm{ml}$ microcentrifuge tube. This was vigorously vortexed for 10 seconds and microcentrifuged 15 seconds at maximum speed, room temperature. The top (aqueous) phase containing the DNA was removed using a $200 \mu \mathrm{l}$ pipettor and transfered to a new tube. The same step was performed using 24:1 chloroform/isoamyl alcohol $(24: 1(\mathrm{v} / \mathrm{v}))$. Now, 1/10 volume of sodium acetate $(3 \mathrm{M}, \mathrm{pH}$ 5.2) was added to the solution of DNA and mixed by vortexing briefly. Subsequently, 2 to $2.5 \mathrm{vol}$ (calculated after salt addition) of ice-cold $100 \%$ ethanol was added, again mixed by vortexing and placed in a $-20^{\circ} \mathrm{C}$ freezer for at least $30 \mathrm{~min}$. Afterwards the tube was microcentrifuged for five minutes at maximum speed and the supernatant removed. $1 \mathrm{ml}$ room temperature $70 \%$ ethanol was added, the tube several times inverted and microcentrifuged as previously described. The supernatant was removed and the pellet dried at room temperature. The dry DNA pellet was dissolved in an appropriate volume of $\mathrm{dH}_{2} \mathrm{O}$.

\section{Northern blot analysis}

Northern blot analysis was performed using the FirstChoice ${ }^{\mathrm{TM}}$ Northern Blot Mouse Blot I (Ambion), which is a ready-to-hybridize Northern blot of different mouse tissues. The assay was done using a radioactive labeled PCR amplified DNA probe $\left(1 \times 10^{6} \mathrm{cpm} / \mathrm{ml}\right)$ and a hybridization temperature of $42^{\circ} \mathrm{C}$. Otherwise the analysis was done using the 
ULTRAhyb ${ }^{\text {TM }}$ ULTRAsensitive Hybridization Solution and the NorthernMax High and Low Stringency Wash Solutions (Ambion) following the instructions of the manufacturer.

\section{Southern blot analysis}

Restriction digestions of genomic DNA were set up in a total volume of $50 \mu \mathrm{l}$. 5-10 $\mu \mathrm{g}$ genomic DNA was digested with the appropriate restriction enzyme (10 $\mathrm{U} / \mu \mathrm{g}$ of DNA) and $2 \mu \mathrm{l}$ RNase A (1 mg/ml stock) was added. The reaction was incubated at $37^{\circ} \mathrm{C}$ overnight. Agarose gel electrophoresis of this reaction was performed using a $0.7 \%$ gel in $0.5 \times$ TBE containing $10 \mu \mathrm{g} / \mathrm{ml}$ of ethidium bromide. $6 \times$ gel loading buffer was mixed to the samples to load them on the gel. If the digested DNA was stored at $4^{\circ} \mathrm{C}$, it was heated to $56^{\circ} \mathrm{C}$ for two to three minutes before it was applied on the gel. The gel was run at $<1$ $\mathrm{V} / \mathrm{cm}$ at approximately $30 \mathrm{~V}$ overnight. Afterwards the upper part of the gel above the wells and all unnecessary parts were removed. On edge of the gel was marked by cutting off a piece, and a photo with a ruler adjacent to the gel was taken under UV-light. In order to prepare the gel for blotting it was shaken for 15 minutes in $0.25 \mathrm{M} \mathrm{HCl}$ and afterwards washed with $\mathrm{dH}_{2} \mathrm{O}$. Again it was shaken for 40 minutes in Blot Buffer I $(1.5 \mathrm{M} \mathrm{NaCl}, 0.5 \mathrm{M}$ $\mathrm{NaOH}$ ), washed with $\mathrm{dH}_{2} \mathrm{O}$ and shaken for 40 minutes in Blot Buffer II (1 M Tris, pH 7.2, 1.5 M NaCl). The gel was now transferred into $20 \times$ SSC ( $3 \mathrm{M} \mathrm{NaCl}, 300 \mathrm{mM} \mathrm{Na}$-Citrate) and shaken for 20 minutes. Meanwhile the nylon membrane (GeneScreen ${ }^{\mathrm{TM}}$ Hybridization Transfer Membrane, PerkinElmer) was first incubated in $\mathrm{dH}_{2} \mathrm{O}$ and afterwards shaken for $>10$ minutes in $20 \times$ SSC until the color had totally changed to light grey and no white areas were left. The blotting was performed for $24-48 \mathrm{hrs}$ in $20 \times$ SSC. The wells of the gel were marked on the membrane with a pencil before the gel was removed. Cross linking of the DNA to the membrane was done by UV irradiation $\left(0.5 \mathrm{~J} / \mathrm{cm}^{2}\right.$, Fluo Link). The radiolabeled probes were prepared and purified as described earlier. Probes were used if they had more than $800.000 \mathrm{cpm} / \mu \mathrm{l}$. After the blotting, membranes were transferred in roller bottles and washed with prewarmed $\left(65^{\circ} \mathrm{C}\right) 2 \times$ SSC containing $0.5 \%$ SDS for 30 minutes at $65^{\circ} \mathrm{C}$. Blots were prehybridized in approximately $0.1 \mathrm{ml}$ prewarmed prehybridization solution $/ \mathrm{cm}^{2}$ membrane ( $5 x$ Denhardt's solution, $5 x$ SSPE, $0.5 \%$ SDS and 5 mg/ml Salmon sperm DNA; 50xDenhardt's (10 g Ficoll 400, 10 g Polyvinylpyrrolidone, 10 g BSA in 1 liter $\mathrm{dH}_{2} \mathrm{O}$ ); $20 x$ SSPE (174 g NaCl, $27.4 \mathrm{~g} \mathrm{NaH}_{2} \mathrm{PO}_{4} \mathrm{xH}_{2} \mathrm{O}, 7.4 \mathrm{~g}$ EDTA, pH 7.4 in 1 liter $\mathrm{dH}_{2} \mathrm{O}$ )) for at least two hours at $65^{\circ} \mathrm{C}$. For hybridization the prehybridization solution was poured off and replaced with fresh hybridization solution (prehybridization solution 
containing the probe $\left.\left(1 \times 10^{6} \mathrm{cpm} / \mathrm{ml}\right)\right)$. Hybridization took place overnight while gently rotating at $65^{\circ} \mathrm{C}$. The next day the hybridization solution was removed and the membranes were washed twice with prewarmed $\left(65^{\circ} \mathrm{C}\right) 2 \times$ SSC containing $0.5 \%$ SDS for 30 minutes. Afterwards they were washed once with prewarmed $\left(65^{\circ} \mathrm{C}\right) 0.1 \times \mathrm{SSC}$ containing $0.5 \%$ SDS for an half an hour. Now blots were air dried for $30 \mathrm{~min}$ on a Whatman 3MM paper. The corners of the blots were stuck to a Whatman 3MM paper and everything was wrapped in Saran wrap. The wrapped membranes were transferred into a film cassette. In the dark room, an X-ray film (Biomax MR film, Kodak) was placed on it. Exposure took place at $-70^{\circ} \mathrm{C}$. Optimal exposure times were empirically determined and were probe dependent.

\section{Transformation of $E$. coli}

\section{Bacterial strains}

\begin{tabular}{lll}
\hline Name & Purpose & Supplier/Reference \\
\hline DH5- $\alpha$ & Propagation of plasmid DNA & Invitrogen \\
DH10B & Propagation of plasmid DNA & $\begin{array}{l}\text { Invitrogen } \\
\text { BL21-CodonPlus }\end{array}$ \\
$\begin{array}{l}\text { (DE3)-RIL } \\
\text { Rosetta }\end{array}$ & Protein expression & \\
SW102 & Protein expression & Novagen \\
& Recombineering (temperature-sensitive exo, bet, & (Warming et al., \\
SW105 & $\begin{array}{l}\text { and gam genes) } \\
\text { Recombineering (ara-inducible Flpe gene) }\end{array}$ & $\begin{array}{l}\text { 2005) } \\
\text { (Warming et al., }\end{array}$ \\
SW106 & & $\begin{array}{l}\text { 2005) } \\
\text { (Warming et al., }\end{array}$ \\
& Recombineering (ara-inducible Cre gene) & 2005) \\
\hline
\end{tabular}

Table 7. Bacterial strains used in this study.

\section{Preparation of electrocompetent $E$. coli}

A single colony was inoculated in $2 \times 10 \mathrm{ml} \mathrm{LB}$ medium (10 g tryptone, $5 \mathrm{~g}$ yeast extract, 10 $\mathrm{g} \mathrm{NaCl}$ and $\mathrm{dH} 20$ up to 1 liter, autoclaved) and incubated at $37^{\circ} \mathrm{C}$ shaking at $220 \mathrm{rpm}$ for $\mathrm{o} / \mathrm{n}$. These starter cultures were used to inoculate $2 \times 1$ liter LB medium, which were incubated at $37^{\circ} \mathrm{C}$ until they reached an $\mathrm{OD}_{600}$ of $\sim 0.6-0.8$ (mid-log phase). Now the cells were chilled on ice for 20 minutes and harvested at $5000 \times g$ for 20 minutes at $4^{\circ} \mathrm{C}$. The cells were washed 1:1 (referring to the $2 \times 1$ liter culture) with prechilled $\mathrm{dH}_{2} \mathrm{O}$ while not disturbing the pellet and harvested again. Afterwards the cells were washed 1:10, 1:50 and 1:500 with prechilled $10 \%$ glycerol/ $\mathrm{dH}_{2} \mathrm{O}$ and harvested at $5500 \times \mathrm{g}$ for 10 minutes (5 
minutes last step) at $4^{\circ} \mathrm{C}$. They were resuspended with prechilled $10 \%$ glycerol/ $/ \mathrm{dH}_{2} \mathrm{O}$ and divided in $50 \mu \mathrm{l}$ aliquots. The aliquots were frozen in liquid nitrogen and then stored at $80^{\circ} \mathrm{C}$.

\section{Preparation of $E$. coli competent for heat shock transformation}

One colony was inoculated in $5 \mathrm{ml}$ LB medium and grown overnight at $37^{\circ} \mathrm{C}$. This preculture was inoculated in $50 \mathrm{ml}$ LB medium. Cells were grown to reach an $\mathrm{OD}_{600}$ of $\sim 0.7$ (mid-log phase). They were harvested for 10 minutes at $2000 \mathrm{rpm}$ and resuspended in 25 $\mathrm{ml}$ of ice-cold $\mathrm{CaCl}_{2}(50 \mathrm{mM})$. After an additional centrifugation for 10 minutes at 2000 rpm, cells were resuspended with $3 \mathrm{ml}$ of ice-cold $\mathrm{CaCl}_{2} /$ glycerol $(50 \mathrm{mM}, 10 \%$ glycerol) and aliquoted $(50 \mu \mathrm{l})$. These aliquots were frozen in liquid nitrogen and then stored at $80^{\circ} \mathrm{C}$.

\section{Transformation of $E$. coli by electroporation}

Electro competent $E$. coli were thawed on ice and mixed with $5 \mu \mathrm{l}$ of a ligation reaction or 1-10 ng plasmid DNA. This mixture was pipetted in an E. coli Pulser Cuvette (BioRad). The electroporation was performed using the Gene Pulser (BioRad, capacity: $25 \mu \mathrm{F}$, voltage: $2.5 \mathrm{kV}$, resistance: $200 \Omega$ ). An efficient transformation required a pulse length of 3.8-4.6 msec. After the electroporation the bacteria were directly mixed with $950 \mu \mathrm{l}$ of prewarmed LB medium and incubated for an half an hour shaking at $200 \mathrm{rpm}$ at $37^{\circ} \mathrm{C} .50$ $\mu \mathrm{l}$ of this culture were put on prewarmed LB-agar plates containing either ampicillin, kanamycin $(50 \mu \mathrm{g} / \mathrm{ml})$ or chloramphenicol $(25 \mu \mathrm{g} / \mathrm{ml})$, depending on the resistance gene included in the plasmid DNA. The plates were cultured at $37^{\circ} \mathrm{Co} / \mathrm{n}$. (Dower et al., 1988)

\section{Transformation of $E$. coli by heat shock}

The heat shock competent cells were thawed on ice and transferred into a Falcon ${ }^{\mathrm{TM}} 2059$ polypropylene tube (BD Falcon). $10 \mathrm{ng}$ plasmid DNA or $5 \mu$ ligation reaction was directly added to the competent cells and mixed well by gently flicking. The mixture was incubated on ice for 30 minutes, heat shocked at $42{ }^{\circ} \mathrm{C}$ for 1 minute, and incubated on ice for 1.5-2 minutes. Afterwards, $950 \mu$ prewarmed LB medium was added to the heat shocked cells, and they were incubated at $37{ }^{\circ} \mathrm{C}$ rotating for 1 hour. The recovered cells were subsequently spun down at $3000 \mathrm{rpm}$ for 2 minutes, resuspended in $200 \mu \mathrm{l} \mathrm{LB}$ medium and plated on appropriate LB-agar plates. 


\section{Cryopreservation of $E$. coli}

For long term storage of bacterial clones, $800 \mu$ l of a colony, grown until stationary phase, were mixed with $300 \mu$ autoclaved $80 \%$ glycerol/ $\mathrm{dH}_{2} \mathrm{O}$, frozen in liquid nitrogen and then stored at $-80^{\circ} \mathrm{C}$. If aliquots were taken from this glycerol stock and used for inoculation of a culture, the glycerol stock was kept frozen.

\section{Yeast Two-Hybrid Assay}

The yeast two-hybrid assay was performed using the ProQuest ${ }^{\mathrm{TM}}$ Two-Hybrid System (Gibco $B R L^{\circledR}$ ), essentially according to the instructions of the manufacturer.

\section{Transformation of yeast}

LiAc was used to make competent yeast cells which are able to take up plasmid DNA (Ito et al., 1983). To increase the efficiency of genetic transformation heat denatured sonicated salmon sperm DNA (Stratagene) was used as carrier DNA (Schiestl and Gietz, 1989)

Several isolated colonies of the yeast strain MaV203 (MAT $\alpha$, leu2-3,112, trp1-901,

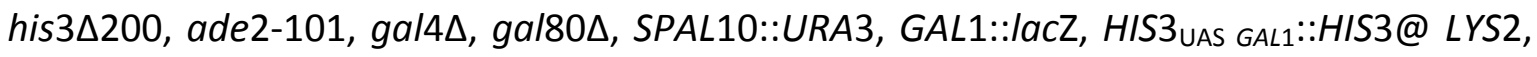
$\operatorname{can} 1^{R}, c y h 2^{R}$ ) (Vidal, 1997) were suspended in $50 \mu l \mathrm{dH}_{2} \mathrm{O}$ and spread onto the center of an YPDG plate (10 g Bacto-yeast extract, $20 \mathrm{~g}$ Bacto-peptone, $20 \mathrm{~g}$ Dextrose, $100 \mathrm{mg}$ Adenine sulfate, $20 \mathrm{~g}$ bacteriological-grade agar, $\mathrm{dH}_{2} \mathrm{O}$ ad 1 liter). They were incubated at

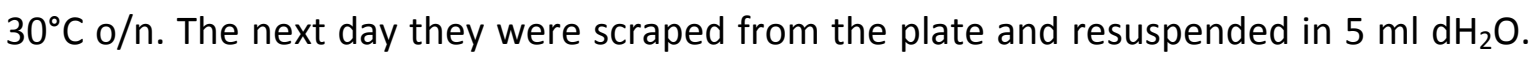
This cell suspension was used to inoculate a $100 \mathrm{ml}$ YPDG broth (10 g Bacto-yeast extract, 20 g Bacto-peptone, $20 \mathrm{~g}$ Dextrose, $100 \mathrm{mg}$ Adenine sulfate, $\mathrm{dH}_{2} \mathrm{O}$ ad 1 liter) to a final $\mathrm{OD}_{600}$ of 0.1 . They were incubated shaking $(180 \mathrm{rpm})$ at $30^{\circ} \mathrm{C}$ until the $\mathrm{OD}_{600}$ reached $\sim 0.4$. Now the $100 \mathrm{ml}$ culture was split into two $50 \mathrm{ml}$ aliquots and centrifuged at $3000 \mathrm{xg}$ for five minutes at room temperature. The supernatant was discarded and each pellet suspended in $20 \mathrm{ml} \mathrm{dH_{2 }} \mathrm{O}$. The cells were harvested by centrifugation at $3000 \times g$ for five minutes at room temperature, the supernatant was discarded and each pellet was suspended in $10 \mathrm{ml}$ freshly prepared $1 \mathrm{x}$ TE/LiAc solution (10 mM Tris- $\mathrm{HCl}(\mathrm{pH} 7.5), 1 \mathrm{mM}$ EDTA, $100 \mathrm{mM}$ lithium acetate). The cells were harvested again by centrifugation at 3000 $x g$ for five minutes at room temperature, the supernatant was poured of and each pellet was suspended in $175 \mu \mathrm{l}$ fresh 1x TE/LiAc solution. Booth suspensions were pooled. 
For each transformation $50 \mu$ l cells were combined with $5 \mu$ l freshly boiled carrier DNA $(10 \mu \mathrm{g} / \mu \mathrm{l}$, five minutes boiled and stored on ice to prevent annealing) and $100 \mathrm{ng}$ of each plasmid DNA. This was gently mixed by pipetting up and down; $300 \mu \mathrm{l} \mathrm{PEG/LiAc} \mathrm{(10} \mathrm{mM}$ Tris- $\mathrm{HCl}$ (pH 7.5), $1 \mathrm{mM}$ EDTA, $100 \mathrm{mM}$ lithium acetate, 40\% PEG-3350) was added and the solution was mixed again. All transformations were incubated for 30 minutes at $30^{\circ} \mathrm{C}$ and afterwards heat shocked for 15 minutes at $42^{\circ} \mathrm{C}$. The cells were harvested at $7000 \times \mathrm{g}$ for 20 seconds and the supernatant was removed. $500 \mu \mathrm{dH}_{2} \mathrm{O}$ was used to suspend the pellet and $100 \mu \mathrm{l}$ undiluted and $100 \mu \mathrm{l}$ of a 1:10 dilution were plated on appropriated selection plates. These plates were incubated at $30^{\circ} \mathrm{C}$ for $48-72$ hours.

\section{Characterization of transformants}

The two monitored reporter genes in this system (HIS3 and lacZ) were induced in MaV203 cells that contain pDBLeu-Hesx1 and pPC86-Y encoding interacting proteins. To analyze the colonies grown on SC-Leu-Trp-His+50 mM 3AT selection plates, two freshly single purified colonies of control strains A-F and MaV203 (pDBLeu-Hesx1, pPC86) and three colonies of each potential positive clone were plated onto a single SC-Leu-Trp plate. After an incubation of 18 hours at $30^{\circ} \mathrm{C}$ every plate was replica plated onto an YPDG plate containing a Nytran ${ }^{\circledR} \mathrm{N}$ membrane (Schleicher \& Schuell) and a SC-Leu-Trp-His+50 mM 3AT plate, which was replica cleaned afterwards. All plates were incubated for $\sim 24$ hours at $30^{\circ} \mathrm{C}$ and the X-Gal assay was performed with the colonies grown on the Nytran ${ }^{\circledR} \mathrm{N}$ membranes. The other plates were replica cleaned again, incubated for 2 additional days and analyzed.

\section{X-Gal assay}

To detect the induction of the lacZ reporter gene, $10 \mathrm{mg} \mathrm{X-Gal} \mathrm{was} \mathrm{dissolved} \mathrm{in} 100 \mu \mathrm{l}$ DMF and combined with $60 \mu \mathrm{l}$ ß-mercaptoethanol and $10 \mathrm{ml}$ Z-buffer $(16.1 \mathrm{~g}$ $\mathrm{Na}_{2} \mathrm{HPO}_{4} * 7 \mathrm{H}_{2} \mathrm{O}, 5.5 \mathrm{~g} \mathrm{NaH}_{2} \mathrm{PO}_{4} * \mathrm{H}_{2} \mathrm{O}, 0.75 \mathrm{~g} \mathrm{KCl}, 0.25 \mathrm{~g} \mathrm{MgSO}_{4} * 7 \mathrm{H}_{2} \mathrm{O}$ in a total volume of 1 liter). Two round Whatman $^{\circledR} 541$ filter were stacked and saturated with the X-Gal containing solution removing any air bubble. The Nytran ${ }^{\circledR} \mathrm{N}$ membrane was immersed in liquid nitrogen for 20-30 seconds to lyse the cells, and then placed colony side up onto the soacked Whatman ${ }^{\circledR}$ filters. The plates were slightly tipped to prevent accumulation of $\mathrm{X}$-Gal solution on the membrane and incubated at $37^{\circ} \mathrm{C}$ for 24 hours. The appearance of blue color was monitored over this 24 hour period. 


\section{Long term storage of yeast}

Yeast strains can be stored for periods of 6-12 months on tightly sealed agar plates. For longer periods yeast strains were stored in $50 \%(\mathrm{v} / \mathrm{v})$ glycerol at $-70^{\circ} \mathrm{C}$.

\section{Purification and analysis of proteins}

\section{Expression and purification of GST-fused recombinant proteins}

GST-fused Hesx1 and Mad212 protein were expressed in and purified from E. coli. Fulllength Hesx 1 and Mad2/2 cDNAs were cloned in frame with the N-terminal GST-tag into the pGEX-KT vector. This vector contains a thrombin cleavage site between the GST-tag and the multiple cloning site, which allows a subsequent removal of the tag. pGEX$\mathrm{KT} /$ Hesx1 was transformed via thermal shock into chimiocompetent BL21-CodonPlus ${ }^{\circledR}$ (DE3)-RIL cells and pGEX-KT/Mad2/2 was transformed by electroporation into Rosetta cells.

Single colonies were used to inoculate $100 \mathrm{ml}$ LB medium containing the appropriate antibiotics for selection. $50 \mu \mathrm{g} / \mathrm{ml}$ ampicilin (Sigma) was used for BL21-CodonPlus ${ }^{\circledR}$ (DE3)RIL cells or ampicilin and $25 \mu \mathrm{g} / \mathrm{ml}$ chloramphenicol (Boehringer) was used for the Rosetta strain. This culture was grown overnight at $37^{\circ} \mathrm{C}$, shaking at $150 \mathrm{rpm} .50 \mathrm{ml}$ of the overnight culture was added to 1 I fresh prewarmed LB medium supplemented with the required antibiotics. The culture was grown at $37^{\circ} \mathrm{C}$ and $150 \mathrm{rpm}$ until it reached an $\mathrm{OD}_{600}$ of 0.6-0.7 (mid-log phase). Protein expression was induced by the addition of $1 \mathrm{mM}$ isopropyl- $\beta$-D-thiogalactopyranoside (Sigma). The culture was grown at $37^{\circ} \mathrm{C}$ for two hours (pGEX-KT/Hesx1) or at $22^{\circ} \mathrm{C}$ for six hours (pGEX-KT/Mad2/2) shaking at $140 \mathrm{rpm}$. Afterwards, cells were harvested in at $5000 \mathrm{rpm}$ at $4^{\circ} \mathrm{C}$ for 25 minutes. The supernatant was discarded slowly, and the pellets with the remaining medium was resuspended and transferred into $50 \mathrm{ml} \mathrm{Falcon}{ }^{\mathrm{TM}}$ tubes. The resuspension was centrifuged at $4000 \mathrm{rpm}$ at $4^{\circ} \mathrm{C}$ for 30 minutes and the supernatant discarded again. The cell pellet was frozen at $70^{\circ} \mathrm{C}$ overnight. The pellet was resuspended in $40 \mathrm{ml}$ protein lysis buffer $(50 \mathrm{mM}$ Tris, $\mathrm{pH}$ 7.5, $500 \mathrm{mM} \mathrm{NaCl}, 2 \mathrm{mM}$ EDTA, $5 \mathrm{mM}$ DTT, 10\% glycerol, freshly added $1 \mathrm{mM}$ PMSF and Complete $^{\mathrm{TM}}$-EDTA protease inhibitor tablet (Roche)) on ice. Lysosyme at a concentration of $10 \mathrm{mg} / 10 \mathrm{ml}$ resuspension solution was added and incubated on ice for 30 minutes. The resuspension was then sonicated on ice six times with 20 pulses and a one minute break in between each round. Sonication was done with the $1 \mathrm{~cm}$ tip using the Cell 
Disruptor B15 (Branson Sonifier) under the condition of Output Option 5 and $50 \%$ Duty Cycle. The lysate was centrifuged at $4^{\circ} \mathrm{C}$ for 1 hour at $15300 \mathrm{rpm}$. The supernatant was incubated with $500 \mu \mathrm{l}$ prewashed Glutathione Sepharose 4B (Amersham Biosciences) at 4 ${ }^{\circ} \mathrm{C}$ on a rotating wheel for at 2-5 hours or at room temperature for 30 minutes. The mixture was centrifuged at $800 \mathrm{rpm}$ at $4^{\circ} \mathrm{C}$ for one minute and the supernatant was discarded. The beads were applied to a $10 \mathrm{ml}$ column (Pierce) and washed three times with 1x PBS containing freshly added Complete ${ }^{\mathrm{TM}}$-EDTA protease inhibitor tablet (Roche). The elution was done twice, each time with 2 ml elution buffer (GST-Hesx1 - 50 mM Tris, pH 8.0, 20 mM Glutathione or GST-Mad2I2 - 500 mM Tris, pH 8.0, 100 mM Glutathione both supplemented with protease inhibitor) rotating 30 minutes at room temperature. The proteins were dialyzed in dialysis buffer (20mM Tris-Cl pH 7.5, 1mM EDTA, 1mM DTT) using a dialysis cassettes (Pierce) at $4^{\circ} \mathrm{C}$ overnight. The protein concentrations were measured and determined according to the standard curve. If necessary, the protein was concentrated using Vivaspin concentrators (VIVASCIENCE). The purified protein was aliquoted, shock-frozen in liquid nitrogen and stored at $-80^{\circ} \mathrm{C}$.

\section{Thrombin cleavage of GST-fused recombinant proteins}

GST-Mad212 protein was cleaved with Thrombin protease (Amersham Bioscience) in order to obtain Mad2l2 protein without tag. Cleavage was done on the glutathione sepharose matrix with $50 \mathrm{U}$ thrombin in $950 \mu \mathrm{l} 1 \mathrm{x}$ PBS. The cutting was performed at $22^{\circ} \mathrm{C}$ overnight. The cleavage was stopped by adding $1 \mathrm{mM}$ PMSF and two elutions were performed, by washing the beads with $1 x$ PBS. The elutions were passed through HiTrap Benzamidine FF (high sub) (Amersham Biosciences) columns to remove the thrombin.

\section{Quantification of protein concentrations}

For protein quantification, the Bio-Rad Protein Assay (BioRad) was used following the manufacturer's instructions. BSA of known concentrations was used to generate standard curves (Figure 28). These curves were used to deduce the concentration of the protein solutions. 


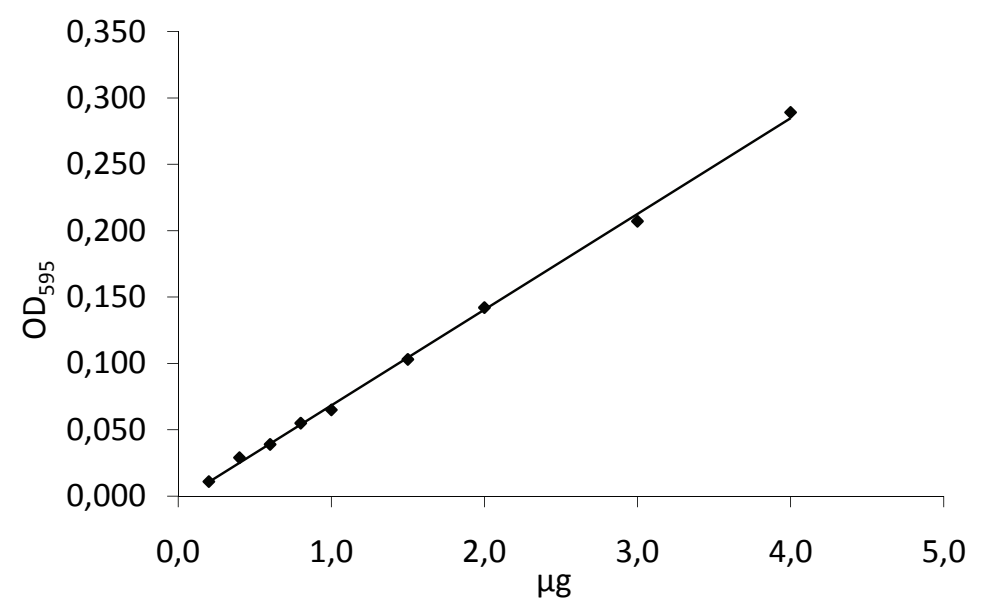

Figure 28. Standard curve for the determination of protein concentrations.

BSA in different concentrations was used to generate standard curves.

\section{In vitro transcription/translation}

The TNT $^{\circledR}$ Reticulocyte Lysate System (Promega) was used for the expression of radiolabeled proteins. The cDNA fragment of interest was cloned into the pSP64 Poly (A) vector (Promega), maxipreparation were performed and the plasmid purified by phenol extraction and ethanol precipitation. The assay was performed according to the instructions of the manufacturer using Redivue ${ }^{\mathrm{TM}} \mathrm{L}-\left[{ }^{35} \mathrm{~S}\right]$ methionine (Amersham Biosciences).

\section{SDS-polyacrylamide gel electrophoresis of proteins (SDS-PAGE)}

The SDS-PAGE was carried out using the Mini-Protean II cell system (BioRad). Different SDS-gel concentrations were used to obtain an optimal protein size resolution (Table 8). The preparation of the different gel parts was done using $4 x$ separating gel buffer $(1.5 \mathrm{M}$ Tris, $\mathrm{pH} 8.8,0.4 \% \mathrm{SDS}$ ) and $4 \mathrm{x}$ stacking gel buffer (0.5 M Tris, $\mathrm{pH} 6.8,0.4 \% \mathrm{SDS}$ ). The separation gel was cast and immediately overlaid with isopropanol to give a smooth surface of the boundary stacking - separation gel. After polymerization the isopropanol was discarded and the stacking gel was poured. The protein samples were mixed with either 2x SDS loading buffer (125 mM Tris, pH 6.8, 20\% glycerol, 0.02\% bromphenol blue, $2 \% \beta$-mercaptoethanol, 4\% SDS) or with 6x SDS loading buffer (350 mM Tris, pH 6.8, 30\% glycerol, $0.012 \%$ bromphenol blue, $0.6 \mathrm{M} \mathrm{DTT}, 10 \% \mathrm{SDS}$ ) and heated at $95^{\circ} \mathrm{C}$ for five minutes or in boiling water for three minutes. After loading of the protein samples and markers (BenchMark ${ }^{\mathrm{TM}}$ Pre-stained, MagicMark ${ }^{\mathrm{TM} X P}$ (Invitrogen)), electrophoresis was done in 1x SDS electrophoresis buffer (25 mM Tris-base, 0.1\% SDS, $192 \mathrm{mM}$ glycine, pH 8.75) running the gel at $20 \mathrm{~mA}$ for approximately one hour. Subsequently, the gel was used directly for western blotting, or fixed ( $45 \%$ methanol, $7.5 \%$ acetate) for five minutes 
and stained with Coomassie blue (0.25\% Coomassie brilliant blue R 250, 45\% methanol, $10 \%$ acetate) for one hour. Destaining of the gel was achieved by washing with $10 \%$ acetate for several hours or overnight.

\begin{tabular}{|c|c|c|c|c|}
\hline Separating gel & $12 \%(14-100 \mathrm{kDa})$ & $15 \%(8-80 \mathrm{kDa})$ & Stacking gel & $5 \%$ \\
\hline 4x Seperation gel buffer & $2.5 \mathrm{ml}$ & $2.5 \mathrm{ml}$ & 4x Stacking gel buffer & $1 \mathrm{ml}$ \\
\hline $\begin{array}{l}30 \% \text { Acrylamide- } \\
\text { bisacrylamide solution }\end{array}$ & $4 \mathrm{ml}$ & $5 \mathrm{ml}$ & $\begin{array}{l}30 \% \text { Acrylamide- } \\
\text { bisacrylamide solution }\end{array}$ & $670 \mu \mathrm{l}$ \\
\hline $\mathrm{dH}_{2} \mathrm{O}$ & $3.4 \mathrm{ml}$ & $2.4 \mathrm{ml}$ & $\mathrm{dH}_{2} \mathrm{O}$ & $2.3 \mathrm{ml}$ \\
\hline APS (10\%) & $100 \mu \mathrm{l}$ & $100 \mu \mathrm{l}$ & APS (10\%) & $40 \mu \mathrm{l}$ \\
\hline TEMED & $4 \mu \mathrm{l}$ & $4 \mu \mathrm{l}$ & TEMED & $4 \mu \mathrm{l}$ \\
\hline
\end{tabular}

Table 8. SDS-polyacrylamide gel preparation.

\section{Western blot analysis}

After SDS-PAGE, western blotting and subsequent immunostaining was performed using primary and secondary antibodies specified in Table 9. For western blotting a Protran BA 85 nitrocellulose membrane (Schleicher \& Schuell) and 4 pieces of Whatman 3MM paper were prepared at similar sizes to the gel, with the Whatman paper slightly larger. The membrane and the papers were presoaked in blot buffer ( $48 \mathrm{mM}$ Trisbase, $3.9 \mathrm{mM}$ glycine, $0.037 \%$ SDS, $20 \%$ methanol). The SDS-gel was placed on top of a double-layered Whatman paper, the nitrocellulose membrane was placed onto the gel followed by a double layer of Whatman paper, carefully avoiding any air bubble in between this sandwich. Electrophoretic transfer was performed in blot buffer using the Mini Trans-Blot electrophoretic Transfer cell (Bio-Rad) with the membrane close to the anode and the gel close to the cathode. Blotting was done at $15 \mathrm{~V}$ overnight or $100 \mathrm{~V}$ for one hour with a cooling chamber. The following steps were performed in small plastic boxes on a rocker (Biometra). After the transfer was completed the membrane was briefly washed in wash buffer A (10 mM Tris, pH 7.4, 0.9\% NaCl, 0.05\% Tween 20), and then incubated in Ponceau $\mathrm{S}$ for $5 \mathrm{~min}$ to control if the protein transfer had worked. The membrane was then almost completely destained in wash buffer $\mathrm{A}$ and afterwards blocked in blocking buffer A ( $5 \%$ low fat milk powder in wash buffer A) for one hour at room temperature. The primary antibody was applied in the right concentration, diluted in $1 \%$ blocking buffer $\mathrm{A}$, and the membrane was incubated at $4{ }^{\circ} \mathrm{C}$ with shaking overnight (preferred) or at room temperature for 1-2 hours. Afterwards the membrane was washed rocking at room temperature using the following sequence: wash buffer $A$, twice wash buffer $B(0.9 \%$ $\mathrm{NaCl}, 0.5 \%$ Triton $\mathrm{X}-100,0.1 \% \mathrm{SDS}$ ), buffer $\mathrm{A}$ (each step for 10 minutes). The secondary 
HRP-conjugated antibody was diluted in 1\% blocking solution and incubated at room temperature rocking for 40 minutes. The membrane was washed again in the same way as described before. Finally, the bound antibodies were detected by using the SuperSignal West Pico or Femto Chemiluminescent Substrate (Pierce) and a phosphorimager (Lumilmager ${ }^{\mathrm{TM}}$, Boehringer Mannheim) by exposing the membrane for 1 second to 20 minutes to a Lumi-Imager (Boehringer Mannheim) or to CL-XPosure ${ }^{\mathrm{TM}}$ films (Pierce) followed by developing with the Curix 60 developing machine (Agfa).

\section{Antibodies}

\begin{tabular}{|c|c|c|c|c|}
\hline Name & Host and type & $\begin{array}{l}\text { Dilution } \\
\text { WB }\end{array}$ & $\begin{array}{l}\text { Dilution } \\
\text { IHC }\end{array}$ & Company/Source \\
\hline \multicolumn{5}{|l|}{ Primary antibody } \\
\hline Anti-FLAG & Rabbit polyclonal & 1:1000 & $1: 1000$ & Sigma \\
\hline Anti-alpha-Tubulin & $\begin{array}{l}\text { Mouse } \\
\text { monoclonal }\end{array}$ & 1:4000 & - & Sigma \\
\hline Anti-MAD2B (Mad2I2) & $\begin{array}{l}\text { Mouse } \\
\text { monoclonal }\end{array}$ & $1: 1000$ & - & BD Biosciences \\
\hline $\begin{array}{l}\text { Anti- } \gamma-H 2 A . X \text { (phospho } \\
\text { S139) }\end{array}$ & Rabbit polyclonal & $1: 1000$ & $1: 100$ & Abcam \\
\hline Anti-HA & Rat monoclonal & $1: 500$ & $1: 100$ & Roche \\
\hline Anti-Hesx1 & Goat polyclonal & $1: 500$ & - & Santa Cruz \\
\hline Anti-rACTH & Rabbit antiserum & - & 1:1000 & NHPP \\
\hline Anti-rTSH $\beta$ & Rabbit antiserum & - & 1:1000 & NHPP \\
\hline Anti-mGH & Rabbit antiserum & - & $1: 1000$ & NHPP \\
\hline Anti-rLH $\beta$ & Rabbit antiserum & - & $1: 1000$ & NHPP \\
\hline Anti-rPRL & Rabbit antiserum & - & $1: 1000$ & NHPP \\
\hline Anti-raGSU & Rabbit antiserum & - & $1: 200$ & NHPP \\
\hline \multicolumn{5}{|l|}{ Secondary antibody } \\
\hline Anti-rabbit-HRP & Goat antiserum & $1: 5000$ & - & Covance \\
\hline Anti-mouse-HRP & Goat polyclona & $1: 10000$ & - & Dianova \\
\hline Anti-goat-HRP & Rabbit polyclonal & $1: 7500$ & - & Abcam \\
\hline Anti-rat-HRP & Goat polyclonal & $1: 5000$ & - & Dianova \\
\hline Anti-rat-Alexa 594 & chicken & - & 1:1000 & MoBiTec \\
\hline Anti-rabbit-Alexa 488 & goat & - & $1: 1000$ & MoBiTec \\
\hline
\end{tabular}

Table 9. List of antibodies. 


\section{Analysis of protein-protein interactions}

\section{GST Pull-down assay}

The GST pull-down analysis was used to study the protein-protein interactions in vitro. The whole procedure was performed at $4^{\circ} \mathrm{C} .50 \mu \mathrm{l}(40 \mu \mathrm{l}$ bed volume) Glutathione Sepharose 4B beads (Amersham Bioscience) were prewashed with $500 \mu$ pull-down binding buffer (20 mM Tris, pH 7.5, 100 mM NaCl, 1 mM EDTA, 0.1\% NP-40, freshly added $1 \mathrm{mM}$ PMSF and Complete ${ }^{\mathrm{TM}}$-EDTA protease inhibitor (Roche)). The beads were sedimented by centrifugation at $500 \mathrm{~g}$ for five minutes and the supernatant discarded. 40-50 $\mu \mathrm{g}$ GST-Hesx1/Mad2/2 and GST were coupled to the beads in $500 \mu \mathrm{l}$ pull-down binding buffer rotating overnight. Beads were sedimented by brief centrifugation and washed once with $500 \mu \mathrm{l}$ pull-down binding buffer rotating for three minutes, to remove unbound protein. In a next step the beads were spun down again, the supernatant was discarded and the beads were incubated with $45 \mu \mathrm{l}$ in vitro transcription/translation product in $500 \mu \mathrm{l}$ pull-down binding buffer rotating for two hours. The remaining $5 \mu \mathrm{l}$ of the in vitro transcription/translation product was mixed as a control with $2 x$ SDS loading buffer and boiled at $95^{\circ} \mathrm{C}$ for five minutes. After the binding reaction, the beads were again sedimented and washed with pull-down binding buffer twice rotating for five minutes each. Two more washing steps were performed using pull-down washing buffer (20 mM Tris, pH 7.5, $150 \mathrm{mM} \mathrm{NaCl} 1 \mathrm{mM}$ EDTA, 0.1\% NP-40, freshly added 1 mM PMSF and Complete ${ }^{\mathrm{TM}}$-EDTA protease inhibitor (Roche)) rotating for five minutes each step. Finally, the beads were spun down again and the supernatant was carefully aspirated. The protein was eluted by the addition of $40 \mu \mathrm{L} 2 x$ SDS loading buffer and subsequent heating at $95^{\circ} \mathrm{C}$ for five minutes. The beads were sedimented again and $20 \mu \mathrm{l}$ supernatant and 10 $\mu l$ control were subjected to SDS-PAGE. After electrophoresis the gel was placed on a wet Whatman paper and dried with a vacuum gel drier (Biometra) at $60^{\circ} \mathrm{C}$ for three hours. The dried gel together with the Whatman paper was wrapped in cling film and fixed in a film cassette. After exposure to an X-ray film (Biomax MR film, Kodak) at $-70^{\circ} \mathrm{C}$ overnight, the film was subsequent developed with the Curix 60 developing machine (Agfa).

\section{Peptide array analysis}

The peptide array was done to further characterize the protein-protein interaction site. A Hesx1 PepSpots ${ }^{\mathrm{TM}}$ peptide membrane (JPT Peptide Technologies $\mathrm{GmbH}$ ) was used to 
determine the interaction site with Mad212. The entire Hesx1 sequence was spotted as overlapping peptides on a Whatman 50 cellulose support. The peptides were covalently bound to the membrane with their $\mathrm{C}$-terminus and were $\mathrm{N}$-terminal acetylated to repress degradation. The sequence was synthesized as 20 meric peptides which were overlapping by 17 amino acids.

The peptide membrane was rinsed with a small volume of ethanol for one minute. Afterwards the membrane was washed three times with TBS $(50 \mathrm{mM}$ Tris, pH 8.0, 137mM $\mathrm{NaCl}, 2.7 \mathrm{mM} \mathrm{KCl}$ ) rocking for 10 minutes each time. Blocking of the membrane was achieved by incubating the membrane in blocking solution (1.5\% BSA in western wash buffer A) rocking for three hours at room temperature. The membrane was washed once

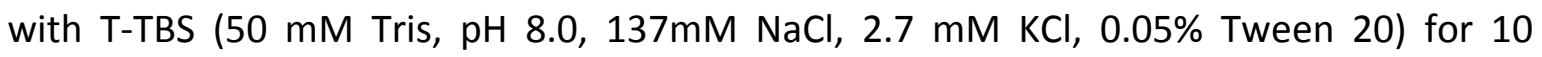
minutes and then incubated in blocking solution containing $1 \mu \mathrm{g} / \mathrm{ml}$ recombinant Mad2/2 protein overnight at room temperature. The next day, the membrane was washed three times for one minute with T-TBS. For the semi-dry blotting the peptide membrane was placed on Whatman paper presoaked with cathode buffer (25mM Tris, pH 9.2,40 mM 6aminohexanoic acid, 20\% methanol). The PVDF membrane was briefly rinsed with methanol and equilibrated in anode buffer I (30 mM Tris, 20\% methanol) for at least 10 minutes. This PVDF membrane was placed on top of the peptide membrane and then covered with two sheets of Whatman paper presoaked with anode buffer I and two sheets presoaked with anode buffer II (300 mM Tris, 20\% methanol). Blotting took place at $1.0 \mathrm{~mA} / \mathrm{cm}^{2}$ for 30 minutes. The blotting process was repeated twice, the third time blotting was done for one hour. Afterwards the PVDF membranes were washed with western wash buffer A, twice with wash buffer B and again with wash buffer $A$ for 10 minutes each time. The following steps were the same as described for western blotting, starting from the incubation of the primary antibody. Regeneration of the peptide membranes was done as described by the manufacturer.

\section{Co-immunoprecipitation}

To study protein-protein interactions in vivo, co-immunoprecipitiation experiments were performed. COS-7 cells were cultured in $10 \mathrm{~cm}$ dishes and transiently co-transfected with different combination of the following plasmids: pCMV-HA/Mad2l2, pCMV-HA/Cdh1, pFLAG-CMV/Hesx1, pFLAG-CMV/Hesx1 $\Delta$ HD, pFLAG-CMV/Hesx1 $\Delta$ eh1, pFLAG- 
$\mathrm{CMV} / \operatorname{Hes} \times 1 \Delta 2 / 3 \mathrm{HD}$ and pFLAG-CMV ${ }^{\mathrm{TM}}-2$. Cells were harvested 24-36 hours after the transfection. Immunoprecipitation was performed using the FLAG $^{\circledR}$ Tagged Protein immunoprecipitation Kit (SIGMA). The assay was carried out according to the manufacturer's instructions, including the optional washing step to remove any traces of unbound ANTI-FLAG antibody. The binding step was carried out for at least three hours and protein elution was mostly done under native conditions by a competition with $3 x$ FLAG peptide.

\section{In vivo ubiquitination assay}

The in vivo ubiquitination was performed in NIH-3T3 cells. Cells were cultured in $10 \mathrm{~cm}$ dishes and transiently co-transfected with different combinations of the PCMVHA/Mad2I2, pCMV-HA/Cdh1, pFLAG-CMV/Hesx1, pEGFP-N2 and pcDNA3.1(-)$\mathrm{His}_{6}$ Ubiquitin plasmids. The cells were incubated for 24 hours after the transfection. 10 hours before harvesting, the proteasome inhibitor MG 132 (10-25 $\mu \mathrm{M}$, SIGMA) was added to the culture medium. Cells were washed twice with ice-cold PBS and then lysed with 6 ml Guanidium-HCl buffer ( $6 \mathrm{M}$ Guanidium Hydrochloride, $100 \mathrm{mM} \mathrm{Na} 2 \mathrm{HPO}_{4} / \mathrm{NaH}_{2} \mathrm{PO}_{4}, \mathrm{pH}$ 8.0, $10 \mathrm{mM}$ Tris- $\mathrm{HCl}, \mathrm{pH} 8.0$ and $10 \mathrm{mM} \beta$-mercaptoethanol added directly before use). Cells were collected by scrapping, and transferred into $15 \mathrm{ml}$ Falcon ${ }^{\mathrm{TM}}$ tubes. The cell lysate was sonicated with the Cell Disruptor B15 (Branson Sonifier) under the condition of Output Option 5 and 50 \% Duty Cycle for one minute on ice. Meanwhile $160 \mu$ (50\% slurry, per $10 \mathrm{~cm}$ dish) Ni-NTA Agarose (QIAGEN) was washed twice with Guanidium- $\mathrm{HCl}$ buffer and spun down at $800 \times \mathrm{g}$ for 10 seconds. $150 \mu \mathrm{l}$ of the cell lysate was taken as input control and subject to $\mathrm{MeOH} / \mathrm{CHCl}_{3}$ precipitation (see below). The remaining lysate was incubated with $160 \mu \mathrm{l} \mathrm{Ni-NTA}$ resin (50\% slurry) and $30 \mu \mathrm{l}$ of $2 \mathrm{M}$ imidazole rotating for three hours at room temperature or overnight at $4^{\circ} \mathrm{C}$. Resin was sedimented by centrifugation at $800 \times \mathrm{g}$ for 10 seconds and transferred into a $1.5 \mathrm{ml}$ tube. The following washing steps were performed at room temperature rotating for 10 minutes each step, sedimenting the resin was carried out by centrifugation as described above. Resin was washed with $1.2 \mathrm{ml}$ each time: 1) Guanidium-HCl buffer containing $10 \mathrm{mM}$ imidazole, 2) urea buffer ( $8 \mathrm{M}$ urea, $100 \mathrm{mM} \mathrm{Na} 2 \mathrm{HPO}_{4} / \mathrm{NaH}_{2} \mathrm{PO}_{4}, 10 \mathrm{mM}$ Tris- $\mathrm{HCl}$, pH 8.0) containing 10 mM imidazole, 3) urea buffer ( $8 \mathrm{M}$ urea, $100 \mathrm{mM} \mathrm{Na} 2 \mathrm{HPO}_{4} / \mathrm{NaH}_{2} \mathrm{PO}_{4}, 10 \mathrm{mM}$ Tris- $\mathrm{HCl}, \mathrm{pH}$ 6.3) containing $10 \mathrm{mM}$ imidazole, 4) urea buffer ( $8 \mathrm{M}$ urea, $100 \mathrm{mM} \mathrm{Na}{ }_{2} \mathrm{HPO}_{4} / \mathrm{NaH}_{2} \mathrm{PO}_{4}$, $10 \mathrm{mM}$ Tris- $\mathrm{HCl}, \mathrm{pH}$ 6.3) containing $10 \mathrm{mM}$ imidazole and $0.2 \%$ Triton-X-100, 5) urea 
buffer ( $8 \mathrm{M}$ urea, $100 \mathrm{mM} \mathrm{Na} 2 \mathrm{HPO}_{4} / \mathrm{NaH}_{2} \mathrm{PO}_{4}, 10 \mathrm{mM}$ Tris- $\mathrm{HCl}$, pH 6.3) containing $10 \mathrm{mM}$ imidazole and $0.1 \%$ Triton-X-100 and finally with urea buffer $(8 \mathrm{M}$ urea, $100 \mathrm{mM}$ $\mathrm{Na}_{2} \mathrm{HPO}_{4} / \mathrm{NaH}_{2} \mathrm{PO}_{4}, 10 \mathrm{mM}$ Tris- $\mathrm{HCl}, \mathrm{pH}$ 6.3) containing $10 \mathrm{mM}$ imidazole. The buffer was completely removed after the last washing step using a Hamilton ${ }^{\mathrm{TM}}$ syringe. Proteins were eluted by incubating the resin with $60 \mu \mathrm{l} 2$ x SDS loading buffer containing $250 \mathrm{mM}$ imidazole in boiling water for six minutes. The eluate was transferred into a new $1.5 \mathrm{ml}$ tube and together with the input control subject to SDS-PAGE and western blotting as described earlier.

\section{$\mathrm{MeOH} / \mathrm{CHCl}_{3}$ precipitation}

Protein precipitation from the in vivo ubiquitination cell lysate input control ( $2 \mathrm{ml}$ tube) was performed by adding four volumes of methanol and two volumes of $\mathrm{CHCl}_{3}$. This was mixed and briefly centrifuged at $9000 \times \mathrm{g}$ for 10 seconds. Afterwards, three volumes of $\mathrm{dH}_{2} \mathrm{O}$ were added and everything vortexed for one minute. To separate the different phases, a centrifugation step at $9000 \times \mathrm{g}$ for five minutes was carried out and the upper phase was subsequently removed. Three volumes (in relation to initial volume) methanol were added, and the tube was mixed. After a centrifugation at $9000 \times \mathrm{g}$ for two minutes, the supernatant was carefully removed, and the protein pellet air dried for two to six minutes. Finally, the pellet was dissolved in $50 \mu \mathrm{l}$ SDS loading buffer and boiled for 10 minutes.

\section{Analysis of protein-DNA associations}

\section{Electrophoretic mobility shift assay (EMSA)}

Gel retardation assays were performed to study in vitro the influence of Mad2/2 on the ability of Hesx1 to bind to DNA. It is known that Hesx1 protein binds to an oligonucleotide containing a palendromic PIII site (PrdQ) (Dattani et al., 1998; Sornson et al., 1996; Wilson et al., 1993). The oligo used for EMSAs is described in Table 4. The radioactive labeled PrdQ oligonucleotide was created by incubating $1 \mu$ l sense strand $(0.1 \mathrm{nmol}), 2 \mu \mathrm{l}$ polynucleotide kinase buffer (Roche), $3 \mu \mathrm{k}$-[22 P]-dATP (30mCi, Amersham Biosciences),

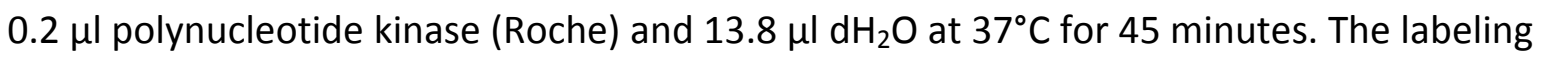
reaction was filled up with $\mathrm{dH}_{2} \mathrm{O}$ to $50 \mu \mathrm{l}$ and then purified with a ProbeQuant G-50 Sephadex Micro Column (GE Healthcare). The approximately $60 \mu$ of flow through were mixed with $6 \mu \mathrm{l} 1 \mathrm{M} \mathrm{KCl}$ and $1 \mu \mathrm{l}$ of the antisense strand $(0.1 \mathrm{nmol})$ and then completely 
denatured at $95^{\circ} \mathrm{C}$ in a thermoblock. Annealing of the sense and antisense strand was achieved by switching off the thermoblock to allow a slow cool down over several hours. The radioactivity of the double-stranded oligo was determined by using the LS1701 counter (Beckman) and the oligo was diluted with $\mathrm{dH}_{2} \mathrm{O}$ to get $20000 \mathrm{cpm} / \mu \mathrm{l}$. Binding reaction was setup, preincubating $4 \mu \mathrm{l}$ in vitro transcribed/translated Hesx1 with $7.5 \mu \mathrm{l} 4 \mathrm{x}$ binding buffer (40 mM Tris- $\mathrm{HCl}$ (pH 8), 200 mM KCl, 4 mM EDTA, 4 mM DTT, 40\% glycerol and $4 \mathrm{mg} / \mathrm{ml} \mathrm{BSA}$ ) and $\mathrm{dH}_{2} \mathrm{O}$ for 15 minutes on ice. 0-6 $\mu \mathrm{g}$ of recombinant Mad2/2 protein was added followed by an additional incubation of 30 minutes. Then, $100 \mathrm{ng}$ poly[dl-dC] was added and the reaction incubated for five minutes at $30^{\circ} \mathrm{C}$. Finally, $1 \mu$ of the diluted radioactive oligo was given to the reaction and it was incubated for additional 30 minutes at $30^{\circ} \mathrm{C}$. The shift was performed on a $9 \%$ acrylamid gel $(6 \mathrm{ml} 30 \%$ acrylamidebisacrylamide 29:1, $200 \mu \mathrm{l}$ glycerol, $13.69 \mathrm{ml}$ 0.5x TBE, $106.5 \mu \mathrm{l}$ 10\% APS and $10.65 \mu \mathrm{l}$ TEMED - total volume of $20 \mathrm{ml}$ ). The gel polymerized within an hour and was pre-run for 45 minutes at $200 \mathrm{~V}$ and $4^{\circ} \mathrm{C}$ using $0.5 \%$ TBE buffer. Afterwards, the samples were applied and electrophoresis was performed at $200 \mathrm{~V}$ and $4{ }^{\circ} \mathrm{C}$ for two and an half hours. The gel was fixed with cling film on one of the glass plates in a film cassette and exposed to a Biomax MR film (Kodak) at $-70^{\circ} \mathrm{C}$ for $12-36$ hours. The film was subsequent developed with the Curix 60 developing machine (Agfa).

\section{Generation of the Mad2/2 conditional knockout vector via recombineering}

In order to generate Mad2/2 deficient mice, a conditional knockout (cko) targeting vector was designed. This vector was created using a method described as recombineering (recombination-mediated genetic engineering) or recombinogenic engineering (Liu et al., 2003; Muyrers et al., 2001; Warming et al., 2005). Recombineering is based on homologous recombination via the gap repair mechanism. The method makes use of $E$. coli strains containing a defective $\lambda$ prophage in the bacterial genome. This defective prophage expresses the recombination genes exo, bet and gam from the $\lambda \mathrm{P}_{\mathrm{L}}$ promoter, which is under the control of the temperature-sensitive repressor $\lambda$ c/857. exo encodes a 5'-3' exonuclease (Exo) that creates single-stranded overhangs on introduced linear DNA, bet encodes a pairing protein (Beta) which protects these overhangs and promotes the subsequent recombination process and gam encodes for the Gam protein that prevents degradation of linear DNA by inhibiting $E$. coli RecBCD protein. When the bacteria are 
cultured at $32^{\circ} \mathrm{C}$ no recombinant proteins are expressed, at $42^{\circ} \mathrm{C}$ the repressor is inactive and exo, bet and gam are produced. Linear DNA with 300-500 bp of homology in the 5' and $3^{\prime}$ ends to the target DNA (already present in the bacteria) can now be electroporated into the cells and undergoes homologous recombination with the target molecule (Liu et al., 2003; Warming et al., 2005). After each retrieval and targeting $1 \mathrm{ng}$ of the plasmid was retransformed into wild-type $\mathrm{DH} 10 \mathrm{~B}$ cells and subsequently isolated. This process was done since the repression of $E$. coli $\operatorname{RecBCD}$ protein might lead to rolling circle replication and will eventually convert the plasmid into multimers (Feiss et al., 1982). Retransformation favors plasmid monomers and therefore eliminates the plasmid multimers.

To create Mad2/2 deficient mice the entire coding sequence was flanked by loxP sites to generate a null allele upon expression of Cre. To minimize the probability of deleting an intronic sequence conserved among species which might have a regulatory function, introns were analyzed using the databases of the National Center for Biotechnology Information (NCBI, http://www.ncbi.nih.org). The overall size of the targeting region was $12193 \mathrm{bp}$ and the loxP sites were introduced $113 \mathrm{bp}$ upstream of the first coding exon and $20 \mathrm{bp}$ downstream of the last exon, deleting finally a region of $5330 \mathrm{bp}$. The 5' homology arm was $3853 \mathrm{bp}$ and the 3' homology arm $3012 \mathrm{bp}$. For gene targeting in ES cells a Notl site was introduced at the $5^{\prime}$ end of the construct to be able to linearize it prior to the electroporation into ES cells. The different steps in the recombineering process are described in Figure 29 and below. 


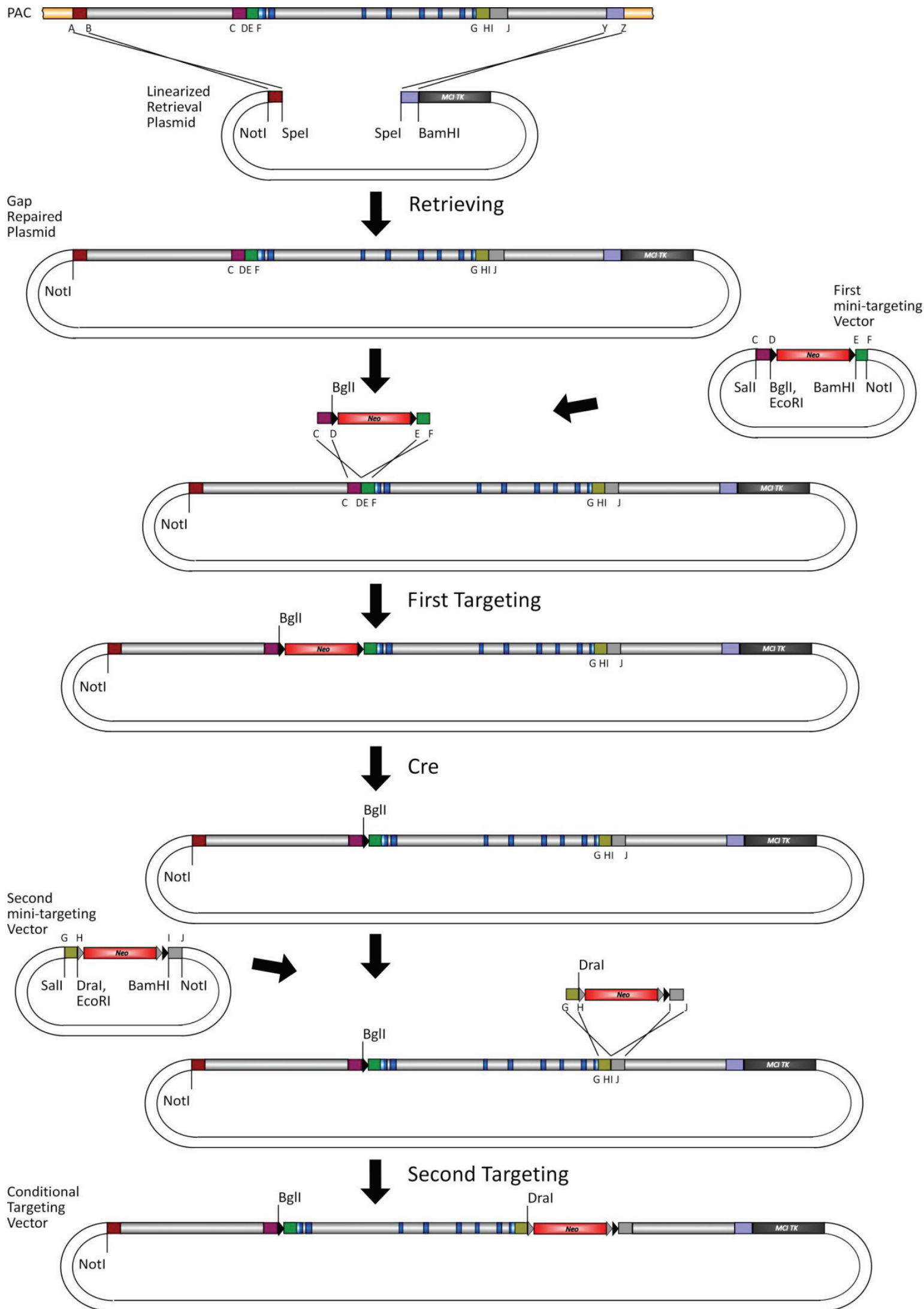

Figure 29. Generation of the Mad2/2 conditional knockout vector via recombineering.

Targeting region is depicted in grey. Blue are Mad2/2 coding exons and light blue display untranslated regions. Black arrow heads are loxP sites and grey arrow heads are frt sites. The Neo cassette is depicted in red whereas the $t k$ cassette is grey. 


\section{Construction of retrieval and targeting vectors}

To obtain the genomic DNA for the targeting construct, the Mouse PAC (RPCl-21) library 711 (Strain: 129/SvevTACfBR) (RZPD; now imaGenes; (Osoegawa et al., 2000)) was screened using a radioactive labeled probe of the Mad2/2 orf. The assay and analysis was performed according to the instructions of the manufacturer. Positive clones were ordered and analyzed by PCR if they contained the genomic region needed to construct the targeting vector.

Primer sequences used for the generation of the Mad2/2 conditional knockout vector are listed in Table 4. These primers were used to amplify the following homology fragments using the genomic PAC clone as a template: 378 bp with A, B; 403 bp with Y, Z; 420 bp with C, D; 304 bp with E, F; 459 bp with G, H and 483 bp with I, J. All PCRs were done using Pwo DNA polymerase (Roche) to prevent the occurrence of mutations.

The retrieval vector was created by ligating the PCR fragment $A, B$ (Notl/Spel) and $Y, Z$ (Spel/BamHI) into plasmid PL253 (Notl/BamHI). This plasmid contains a Mc1-driven Thymidine Kinase $(t k)$ cassette for negative selection in ES cells.

The first mini targeting vector was generated by cloning the PCR fragments $C, D$ (Sall/EcoRI) and E, F (BamHI/Notl) into PL452, a vector containing a neomycin (neo) cassette flanked by two loxp sites. Expression of the neo gene is achieved by a prokaryotic promoter (em7) a eukaryotic promoter $(P g K)$. A new Bgll restriction site was created in front of the 5' IoxP site that was later used to identify correctly targeted ES cells by southern blot.

The second mini targeting vector was created by cloning the fragments $G, H$ (Sall/EcoRI) and I, J (BamHI/Notl) into the PL451 vector, generating a Dral site upstream of the $5^{\prime} \mathrm{frt}$ site which was used for southern blot analysis. The PL451 plasmid contains a neo cassette flanked by two frt and one loxP site. The expression of the neo gene is as well regulated by the $e m 7$ and $P g K$ promoter.

\section{Transformation of PAC or plasmid DNA into recombinogenic strains}

For each transformation the electrocompetent recombinogenic bacterial strains were prepared fresh. A $5 \mathrm{ml}$ overnight culture of the recombinogenic strain was inoculated from the glycerol stock (or a single colony from a plate containing already the target 
plasmid) and incubated shaking at $32^{\circ} \mathrm{C}$. The next day, the overnight culture was diluted 1:50 in $25 \mathrm{ml} \mathrm{LB}$ medium and incubated three to five hours at $32^{\circ} \mathrm{C}$ until bacteria had reached an $\mathrm{OD}_{600}$ of 0.6 . Now the culture was cooled down in an ice/waterbath for a few minutes and spun down in $50 \mathrm{ml} \mathrm{Falcon}{ }^{\mathrm{TM}}$ tubes for five minutes at $5000 \mathrm{rpm}$ and $4^{\circ} \mathrm{C}$. The supernatant was poured off and the pellet in $1 \mathrm{ml}$ ice-cold $10 \%$ glycerol resuspended by gently shaking the tube in the ice/waterbath. The cells were transferred in an eppendorf tube and spun down for 20 seconds at $13200 \mathrm{rpm}$ at $4^{\circ} \mathrm{C}$. This step was repeated twice, and the cells were resuspended in the residual amount of $10 \%$ glycerol (volume should be around $50 \mu \mathrm{l})$. For the electroporation the cells were mixed with the DNA (1-10 ng plasmid DNA; 1-5 $\mu$ g freshly prepared PAC DNA or 100 ng purified targeting cassette) to be transformed and incubated on ice for $5 \mathrm{~min}$. Transformation was done by electroporation as described earlier. After the transformation the bacteria were transferred into $950 \mu \mathrm{l}$ of LB medium and incubated at $32^{\circ} \mathrm{C}$ in a shaking heat block for one hour. Finally the bacteria were plated on selective medium and incubated at $32^{\circ} \mathrm{C}$ for 18-24 hours. Several colonies were analyzed by restriction digestion.

\section{Retrieving and targeting}

SW102 (temperature-sensitive exo, bet, and gam genes) bacteria containing the target plasmid or PAC were cultured as described above. When the culture reached an $\mathrm{OD}_{600}$ of 0.6, $10 \mathrm{ml}$ were transferred into a $50 \mathrm{ml}$ Falcon $^{\mathrm{TM}}$ tube and incubated shaking at $42^{\circ} \mathrm{C}$ for 15 minutes. This heat-shock enables the bacteria to produce a sufficient amount of recombination proteins for the subsequent homologous recombination. The rest of the bacteria served as a control and were put back at $32^{\circ} \mathrm{C}$. The heat shock-induced and the uninduced cultures were now cooled down by gently shaking them in an ice/waterbath for a few minutes and transformed as describe above.

\section{Excision of the Neo cassette}

To excise the first neo cassette leaving only the $5^{\prime}$ loxP site and to control if all loxP and frt sites were functional, the target plasmid was transformed into arabinose induced SW106 (ara-inducible Cre gene) or SW105 (ara-inducible Flpe gene) bacteria. The bacteria were cultured as described earlier until they reached $a n \mathrm{OD}_{600}$ of $0.6 .10 \mathrm{ml}$ of the culture were transferred into a $50 \mathrm{ml} \mathrm{Falcon}{ }^{\mathrm{TM}}$ tube and $100 \mu \mathrm{l}$ of $10 \% \mathrm{~L}(+)$ arabinose (Sigma-Aldrich) was added. The induction took place at $32^{\circ} \mathrm{C}$ shaking for one hour, and the remainder of 
the culture was used for the control experiment. Transformation was performed as described above.

\section{Gene targeting in mouse ES cells and production of chimeras}

The Mad2/2 cko-targeting vector was subsequently linearized with Notl, a phenol extraction and ethanol precipitation was performed. $40 \mu \mathrm{g}$ of the vector was electroporated into the MPI-II ES cells. ES cells underwent positive/negative selection with G418 and ganciclovir (Ganc) respectively. Cells containing the neo cassette survive the exposure to G418. If a targeted homologous recombination occurred, the ES cells lost the $t k$ cassette and survive as well the exposure to ganciclovir. Electroporation, selection and culture of the ES cells was carried out by Sharif Mashur. The G418 ${ }^{r}$ Ganc $^{r}$ ES cells colonies were picked for southern analysis to confirm targeted insertion of the ckoconstruct. Positive ES cells were used for the production of aggregation chimeras. The ES cells were aggregated with diploid CD-1 ${ }^{\circledR} / \mathrm{ICR}$ morula-stage embryos and cultured to the blastocyst-stage. The aggregated blastocyst was transferred into the oviduct of pseudopregnant female recipient mice. Aggregation and oviduct transfer was performed by Ulrich Franke. Chimeric mice which gave germ-line transmission were crossed with CMV-Cre mice (CMV promoter driven Cre recombinase; (Schwenk et al., 1995)) to generate Mad2/2 ${ }^{+/-}$(heterozygous) offspring.

\section{Isolation and analysis of embryos and mice}

\section{Dissection and fixation of mouse embryos}

Dissection of mouse embryos was performed in the whole as described in "Manipulating the Mouse Embryo: A Laboratory Manual" (Nagy et al., 2003). Briefly, pregnant mice at the desired stage of embryonic development were sacrificed by cervical dislocation. The abdominal cavity was opened and the uterus was dissected by cutting the uterus below the oviduct and separating it from the mesometrium and cutting across the cervix. After the uterus was dissected it was washed in ice-cold PBS and opened by cutting the antimesometrial wall with the tip of a pair of fine scissors. The decidua were now shelled out of the uterus with forceps. Embryos were dissected from the decidua and a tissue sample from the yolk sack, the amnion or the tail was taken from each embryo. These samples were used to extract genomic DNA for genotyping. The embryos were staged 
according to "The anatomical basis of mouse development" (Kaufman and Bard, 1999) and fixed in 4\% PFA/PBS overnight and subsequently washed in PBS.

\section{Bouin's fixation of postnatal mouse heads}

Postnatal mice were sacrificed, the head was cut off and the skin was removed. The head was briefly washed in ice-cold PBS and then incubated for two to four days in Bouin's Fix (Sigma). Bouin's fix has the advantage that it decalcifies the skull which simplifies sectioning later on. After fixation, the heads were dehydrated using an ascending ethanol concentration $(70 \%, 80 \%, 90 \%, 95 \% 97,5 \% 100 \%)$ and a final incubation in isopropanol. Each step was done overnight at $4^{\circ} \mathrm{C}$. Then, they were incubated for two days in toluol at room temperature and for three days in liquid paraplast $60^{\circ} \mathrm{C}$ (replacing it every day). The embedding and sectioning procedure was performed as describe below.

\section{Paraffin embedding and sectioning}

The PFA fixed embryos were washed three times with PBS to remove the fixative and three times with $0.86 \% \mathrm{NaCl}$ to wash out salt crystals. Each washing step was performed for one hour at $4^{\circ} \mathrm{C}$. Following this washing steps the embryos were dehydrated with an ascending ethanol concentration. They were incubated twice in 50\% ethanol for 15 minutes, two times in $70 \%$ ethanol for 15 minutes (or overnight), three times in $80 \%$ ethanol for 20 minutes, three times in $90 \%$ ethanol for 30 minutes, four times in $96 \%$ ethanol for 30 minutes and five times in pure ethanol for 20 minutes at $4^{\circ} \mathrm{C}$. Finally the embryos were transferred into isopropanol and incubated for overnight at $4^{\circ} \mathrm{C}$. The infiltration procedure was done at room temperature. The embryos were incubated in $25 \%$ toluol/isopropanol, $50 \%$ toluol/isopropanol and $75 \%$ toluol/isopropanol each step for 30 minutes. Afterwards they were incubated three times in $100 \%$ toluol for one hour before they were transferred into liquid paraplast $\left(60^{\circ} \mathrm{C}\right)$. Paraplast was changed every day for three days. The embryos were embedded in appropriate paraplast filled blocks. The resulting blocks were stored at $4^{\circ} \mathrm{C} .10 \mu \mathrm{m}$ thick sections were produced using a microtome (Leica). Right after cutting, the sections were transferred into a heated waterbath $\left(43^{\circ} \mathrm{C}\right)$ to allow them to spread. Afterwards the sections were collected on microscope glass slides, dried overnight at $37^{\circ} \mathrm{C}$ and stored at $4^{\circ} \mathrm{C}$. 


\section{Hematoxylin and Eosin staining (H\&E staining)}

The H\&E staining was used to get a histological overview of the examined tissue. Hematoxylin is a basic dye, which colors basophilic structures of the cell, mostly nucleic acids with blue-purple hue. The alcohol-based eosin Y colors intra- and extracellular protein. It stains predominantly the cytoplasm in pink.

Paraffin sections were deparaffinzed by washing them three times for three minutes with Xylene and rehydrated in decreasing concentrations of ethanol $(100 \%, 90 \%, 70 \%$ and $50 \%$, each for two minutes). Sections were placed in deionized $\mathrm{H}_{2} \mathrm{O}$ for five minutes and afterwards stained with Hematoxylin (Sigma HHS16) for ten minutes. Then, the sections were washed three times for three minutes with tap water and destained with acid ethanol $(5 \mathrm{ml}$ concentrated $\mathrm{HCl}+400 \mathrm{ml} 70 \%$ ethanol) for 20 seconds. Afterwards the sections were washed again two times with deionized $\mathrm{H}_{2} \mathrm{O}$ and stained with Eosin for 15 seconds. Sections were dehydrated, and placed in Xylene three times for three minutes. Finally, stained sections were mounted on coverslips using Eukitt (Kindler) mounting medium, and dried overnight in the hood.

\section{Whole mount in situ-hybridization}

The whole mount in situ-hybridization analysis was performed as described (Pilarski, 2004). In brief, after fixation the embryos were transferred into nets, which fit into six well plates. They were dehydrated and the plasma membranes were removed by an ascending methanol series. Afterwards the embryos were rehydrated and bleached by $\mathrm{H}_{2} \mathrm{O}_{2}$ to increase the transparency of the tissue. The proteinase $\mathrm{K}(10 \mu \mathrm{g} / \mathrm{ml})$ digest was done to reach a higher permeability of the tissue and to remove proteins which are bound to RNA and therefore making the RNA easier accessible for the antisense RNA probe. To increase the tissue permeability again, the embryos were incubated in RIPA buffer (150 mM NaCl, 50 mM Tris pH 8.0, 1 mM EDTA pH 8.0, 1\% NP40 (Nonidet P40), $0.5 \%$ DOC, $0.1 \%$ SDS). The embryos were then refixed in PFA because the proteinase $\mathrm{K}$ digest and the RIPA buffer treatment reduced their mechanical stability extensively. The prehybridization ( $50 \%$ Formamide, $5 x \mathrm{SSC}$ pH 4.5, $1 \%$ SDS, $50 \mu \mathrm{g} / \mathrm{ml}$ yeast tRNA, $50 \mu \mathrm{g} / \mathrm{ml}$ heparin) as well as the hybridization (antisense RNA probe in a volume ratio 1:100 to the prehybridization buffer) was performed shaking at $70^{\circ} \mathrm{C}$. Hybridization was performed overnight. To remove the unspecific bound antisense RNA probes the embryos were 
brought through several, solution $2(10 \mathrm{ml} 20 \mathrm{x} \mathrm{SSC}, \mathrm{pH} \mathrm{7,50} \mathrm{ml} \mathrm{Formamide,} 100 \mu \mathrm{l}$ Tween-20 and $\mathrm{dH}_{2} \mathrm{O}$ ad $100 \mathrm{ml}$.) and MABT (100 mM Maleic acid, $150 \mathrm{mM} \mathrm{NaCl}, \mathrm{pH}$ 7.5, adjusted using $\mathrm{NaOH}, 0.1 \%$ Tween-20), washing steps. In addition they were incubated in freshly prepared RNase A $(100 \mu \mathrm{g} / \mathrm{ml})$ in RNase buffer $(10 \mathrm{ml} 5 \mathrm{M} \mathrm{NaCl}, 1 \mathrm{ml} 1 \mathrm{M} \mathrm{Tris}-\mathrm{HCl}$, $\mathrm{pH} 7.5,0.1 \mathrm{ml}$ Tween-20 and $\mathrm{dH}_{2} \mathrm{O}$ ad $100 \mathrm{ml}$.) to reduce the unspecific background and in blocking solution (12 $\mathrm{ml} \mathrm{MABT}, 4 \mathrm{ml}$ heat inactivated FCS and $4 \mathrm{ml} 10 \% \mathrm{BBR} / \mathrm{MAB}$ ) to block unspecific binding site for the antibody. Finally the embryos were brought into blocking solution containing anti-digoxigenin-AP, Fab fragments (Roche, 1:2000) and incubated overnight at $4^{\circ} \mathrm{C}$. Unspecific bound antibodies were removed by several washing steps in MABT and subsequently NTMT $(100 \mathrm{mM} \mathrm{NaCl}, 100 \mathrm{mM}$ Tris- $\mathrm{HCl}$ pH 9.5, $50 \mathrm{mM} \mathrm{MgCl} 2$ and $1 \%$ Tween-20). After passing through the washing steps the embryos were transferred into small glass bottles and on a rotor to optimize the washing procedure. The color reaction varies dramatically corresponding to the number of transcripts therefore it was necessary to monitor it all the time. The embryos were brought back into nets and 6 well plates. The staining solution NBT/BCIP (Roche) was diluted 1:50 in NTMT containing $2 \mathrm{mM}$ levamisol. The reaction was performed under light exclusion and stopped by washing with PBT. Afterwards embryos were refixed with PFA and brought into $80 \%$ glycerin where they can be stored at $4^{\circ} \mathrm{C}$. They were documented on agarose dishes using the Olympus SZX 12 binocular.

\section{Immunohistochemistry}

Deparaffinization of paraffin-sections was done using Histoclear (Vogel GmbH). Slides were dewaxed twice for three minutes, transferred into $50 \%$ Histoclear/ethanol for additional three minutes and washed twice in $100 \%$ ethanol for three minutes. Individual sections were then encircled with the ImmEdge ${ }^{\mathrm{TM}}$ Pen (Vector Laboratories) and rehydrated in a descending concentration of ethanol $(95 \%, 70 \%, 50 \%)$ and finally tap water for three minutes each step. The slides were boiled in Antigen Unmasking Solution (1:100 in $\mathrm{dH}_{2} \mathrm{O}$, Vector Laboratories) for five minutes and immediately washed with running tap water. Afterwards the sections were washed twice for five minutes in PBS and then twice in $0.025 \%$ Triton X-100/PBS for five minutes. The long incubations were all done in a wet-chamber to prevent the sections from drying out. To block unspecific binding sites, the slides were incubated in blocking solution (10\% FCS, 1\% BSA, in PBS) for 45 minutes to two hours. The primary antibody was applied diluted in blocking solution 
for overnight at $4^{\circ} \mathrm{C}$. The next day slides were rinsed in $0.025 \%$ Triton X-100/PBS twice for five minutes and the fluorophore-conjugated secondary antibody diluted in blocking solution was applied. This incubation as well as the following steps were done in the dark to avoid photobleaching. Incubation took place at room temperature for two hours. The sections were washed in PBS three times for five minutes and mounted with VECTASHIELD ${ }^{\circledR}$ Mounting Medium with DAPI (Vector Laboratories). The coverslip was sealed using nail polish.

\section{Cell culture}

Cell lines

\begin{tabular}{|c|c|c|c|c|c|}
\hline Cell line & Cell type & $\begin{array}{l}\text { DSMZ } \\
\text { no. }\end{array}$ & Morphology & Reference & Culture medium \\
\hline COS-7 & $\begin{array}{l}\text { African green } \\
\text { monkey kidney }\end{array}$ & ACC 60 & $\begin{array}{l}\text { Fibroblast- } \\
\text { like }\end{array}$ & $\begin{array}{l}\text { (Gluzman, } \\
\text { 1981) }\end{array}$ & $\begin{array}{l}\text { DMEM + 4mM L-glutamine + } \\
4,5 \mathrm{mg} / \mathrm{ml} \text { glucose }+10 \% \text { FCS }\end{array}$ \\
\hline NIH-3T3 & $\begin{array}{l}\text { Swiss mouse } \\
\text { embryo }\end{array}$ & ACC 59 & Fibroblast & $\begin{array}{l}\text { (Aaronson and } \\
\text { Todaro, 1968) }\end{array}$ & $\begin{array}{l}\text { DMEM + 4mM L-glutamine + } \\
4,5 \mathrm{mg} / \mathrm{ml} \text { glucose }+10 \% \text { FCS }\end{array}$ \\
\hline MPI-II & $\begin{array}{l}\text { Mouse } \\
\text { embryonic } \\
\text { stem cells }\end{array}$ & - & $\begin{array}{l}\text { Embryonic } \\
\text { stem cells }\end{array}$ & Gruss, P. 1993 & $\begin{array}{l}\text { DMEM }+20 \% \text { FCS }+1 \% \text { non- } \\
\text { essential amino acids } \\
+1 \% \text { sodium pyruvate } \\
(100 \mathrm{mM})+1 \% \text { L-glutamine } \\
(200 \mathrm{mM})+\text { Lif } 1000 \mathrm{U} / \mathrm{ml} \\
+0.1 \mathrm{mM} \beta \text {-mercaptoethanol }\end{array}$ \\
\hline \multicolumn{6}{|c|}{ Primary cells } \\
\hline $\begin{array}{l}\text { MEF- } \\
\text { Mad2I2 } \\
(+/+;-/-)\end{array}$ & Mouse embryo & & Fibroblast & (This study) & $\begin{array}{l}\text { DMEM + 4mM L-glutamine + } \\
4,5 \mathrm{mg} / \mathrm{ml} \text { glucose }+10 \% \text { FCS }\end{array}$ \\
\hline
\end{tabular}

Table 10. Cell lines used in this study.

\section{Revival, subculture and cryopreservation of cells}

Cell vials from the liquid nitrogen storage were thawed as rapidly as possible in a $37^{\circ} \mathrm{C}$ water bath, to minimize intracellular ice crystal growth during the warming process. The cell suspension was then transferred into a $15 \mathrm{ml} \mathrm{Falcon}^{\mathrm{TM}}$ tube and slowly diluted in 10 $\mathrm{ml}$ of the appropriate culture medium. Rapid dilution reduces cell viability because sudden dilution may cause severe osmotic damage. The cells were centrifuged at $210 \times \mathrm{g}$ for five minutes and the medium was carefully aspirated. Subsequently, cells were resuspended in the appropriate volume of culture medium by pipetting up and down. The cell suspension was plated on an appropriate culture dish and gently shaken (five times 
left-right and back and forth) to distribute the cells equally. The cells were cultured in a humidified $\mathrm{BBD} 6220$ incubator (Heraeus) at $37^{\circ} \mathrm{C}$ and a $5 \% \mathrm{CO}_{2}$ atmosphere.

Generally cells were passaged when they had reached $70-95 \%$ of confluence. The culture medium was removed and the cells were washed twice with the same amount of prewarmed PBS $\left(37^{\circ} \mathrm{C}\right)$. Cells were dissociated applying an appropriate amount of Trypsin (0.05\% Trypsin/EDTA; Gibco BRL ${ }^{\circledR}$ ) on the dish $(2 \mathrm{ml} / 10 \mathrm{~cm}$ dish), followed by an incubation of five minutes in a humidified incubator. Right after the incubation the dish was shaken until all the cells were floating and then five times the amount of culture medium was added to the dish. The cell suspension was pipetted up and down a few times to disperse the cells and subsequently transferred into $15 \mathrm{ml} \mathrm{Falcon}{ }^{\text {TM }}$ tubes. To sediment the cells they were centrifuged at $210 \times \mathrm{g}$ for five minutes and afterwards resuspended in the desired volume of culture medium. For subculture, the cells were usually diluted $1: 6$. If necessary the concentration of the cell suspension was determined using a Hemocytometer slide (improved Neubauer). $10 \mu \mathrm{l}$ of the cell suspension were applied to the Hemocytometer and four of the $1 \mathrm{~mm}^{2}$ squares were counted to improve accuracy of the result. The following equation was used to determine the concentration: concentration $_{(\text {cells } / \mathrm{ml})}=\frac{\text { number of cells }}{4} \times 10^{4}$.

If the cells were subjected to cryopreservation, the cells of a $10 \mathrm{~cm}$ dish were resuspended in $2 \mathrm{ml}$ of culture medium. $500 \mu \mathrm{l}$ of this cell suspension was transferred into a CryoTube ${ }^{\mathrm{TM}}$ (NUNC ${ }^{\mathrm{TM}}$ ) containing $500 \mu \mathrm{l}$ of $2 x$ freezing medium (culture medium, $16.6 \%$ DMSO, 20\% FCS) and mixed by inverting. The tubes were frozen at $-20^{\circ} \mathrm{C}$ for three hours to overnight, then transferred to $-80^{\circ} \mathrm{C}$ for overnight up to a month and finally stored in liquid nitrogen.

\section{Cell transfection}

Cells were transfected by lipofection with one or several plasmids using FuGENE ${ }^{\circledR} 6$ Transfection Reagent (Roche). Plasmid DNAs used for transfections were always subject to phenol extraction and ethanol precipitation to prevent contamination of the cell cultures. The entire procedure was performed according to the instructions of the manufacturer. 


\section{Preparation of primary mouse embryonic fibrobasts (MEF's)}

The uterus of a pregnant mouse $(13.5 \mathrm{dpc})$ was dissected into warm $\left(37^{\circ} \mathrm{C}\right) \mathrm{PBS}$ and transferred in a cell culture hood. Embryos were dissected from the uterus into fresh PBS (10 cm dishes). In a next step, individual embryos were transferred into fresh PBS and extremities, head, tail and inner organs were removed. The tail was used for isolation of genomic DNA and subsequent genotyping. The remaining corpus of the embryos was placed in a $35 \mathrm{~mm}$ Petri dish containing $2 \mathrm{ml}$ of Trypsin (0.05\% Trypsin/EDTA; Gibco BRL ${ }^{\circledR}$ ). Embryos were first disrupted, using two forceps until only small cell clusters remained. Afterwards they were transferred into $15 \mathrm{ml} \mathrm{Falcon}^{\mathrm{TM}}$ tubes. Cell clusters were disrupted by pipetting up and down. To remove the Trypsin, cells were centrifuged for five minutes at $210 \times \mathrm{g}$ (Heraeus Megafuge 1.0 - 1000rpm). Carefully, the trypsin was (might be problematic due to the viscousity) removed with a pipette and the cell pellet redisolved in culture medium. One embryo resulted in enough cells for a $15 \mathrm{~cm}$ dish. After cells were attached the medium was replaced.

\section{Measurement of cell proliferation rates}

The quantification of culture growth was done to determine the characteristic of growth pattern of Mad2/2 ${ }^{-/}$MEF's and wild type MEF's. For an initial quantification a series of 12 well plates with cultures at three different cell concentrations $\left(1 \times 10^{4} / \mathrm{ml}, 3 \times 10^{4} / \mathrm{ml}, 1 \times\right.$ $10^{4} / \mathrm{ml}$ ) was set up and counted with a Hemocytometer at a daily basis for three days. In addition a duplicate at each density was stained with Giemsa and documented. To monitor the growth rate over a longer period, cells were seeded in 24-, 12- and 6-well plates at a concentration of $1 \times 10^{4}$. The cell suspension was added slowly from the center of the well and not shaken to prevent an accumulation of cells in the middle of the well. Cell concentration was determined at daily intervals by trypsinizing (volume was adjusted according to the well size) the culture and counting the cells with the Hemocytometer.

\section{Giemsa staining}

Giemsa stain is a polychromatic stain which stains the nucleus pink-magenta, the nucleoli dark blue, and the cytoplasm pale gray-blue. It provides a convenient method for staining complete culture dishes. The Giemsa solution was prepared by mixing $500 \mathrm{ml}$ glycerol with $500 \mathrm{ml}$ methanol and subsequent addition of $8.5 \mathrm{~g}$ of Giemsa-stain (Sigma). The staining solution was incubated mixing at room temperature overnight. To stain the cells 
directly in the multiwell plate, the medium was removed and was washed once with PBS. Afterwards $50 \%$ methanol/PBS was added and the culture was incubated for two minutes. The $50 \%$ methanol/PBS solution was removed and displaced by methanol. After an incubation of 10 minutes the methanol was removed and the culture was briefly rinsed with fresh methanol. Giemsa stain was added in a way that the entire cell monolayer was covered. The culture was incubated for two minutes, before the staining solution was diluted (1:5) with water and it was incubated agitated gently for a further two minutes. The stain was displaced with water so that the scum that forms due to oxidation was carefully removed without coating the cells. Now the cells were gently washed in running tap water for ten to twenty seconds and then washed once with $\mathrm{dH}_{2} \mathrm{O}$. The cells were examined and documented while still wet using the SZX12 stereo microscope and cell^D software (both Olympus). The cultures can be stored dry, and are rewetted to re-examine.

\section{Immunohystochemistry}

The cells were passaged and cultured on coverslips in 24-well plates. When the cells reached the desired confluency the medium was removed and the cells were washed twice with PBS. The cells were fixed with 4\% PFA for 20 minutes at room temperature and three times rinsed with PBS incubating them for five minutes each step. To permeabilize the cells they were incubated with $0.5 \%$ Triton X-100/PBS for five minutes and then washed twice with PBT (0.1\% Tween 20/PBS) for five minutes each time. Blocking of unspecific binding sites was done in blocking solution (10\% FCS, 1\% BSA, in PBT) at room temperature for one to two hours. The incubation with the appropriately diluted primary antibody was performed in blocking solution in a wet-chamber at $4^{\circ} \mathrm{C}$ overnight. The next day coverslips were washed with PBT twice and once with blocking solution for five minutes each time. Afterwards the cells were incubated with the diluted fluorophoreconjugated secondary antibody at room temperature and in the dark for one hour. Finally, cells were washed three times with PBT for five minutes, rinsed briefly with water and subsequently mounted with VECTASHIELD ${ }^{\circledR}$ Mounting Medium with DAPI (Vector Laboratories). The coverslips were sealed using nail polish. The samples were monitored and documented with the BX-60 fluorescence microscope (Olympus) using the cell^P software (Olympus). 


\section{TUNEL assay}

The TUNEL (Terminal deoxynucleotidyltransferase-mediated dUTP-biotin nick end labeling) assay was used to examine the occurrence of apoptosis in transgenic MEF's. This method detects DNA strand breaks enzymatically by labeling the free 3'-OH termini with modified nucleotides (Gavrieli et al., 1992). This labeling is the basis of the ApopTag ${ }^{\circledR}$ Red In Situ Apoptosis Detection Kit (CHEMICON ${ }^{\circledR}$ International) which was used in this study. The MEF's were cultured on coverslips in 24 well plates for two days. The assay was carried out according to the instructions of the manufacturer and the coverslips were mounted with VECTASHIELD ${ }^{\circledR}$ Mounting Medium with DAPI (Vector Laboratories). The coverslips were sealed using nail polish. The samples were examined and documented with the BX-60 fluorescence microscope (Olympus) using the cell^P software (Olympus).

\section{FACS analysis of mouse embryonic fibroblasts}

Flow cytometric analysis was performed to determine the cell-cycle phase distribution of the wild type and transgenic MEF's. The CycleTESTTM PLUS DNA Reagent Kit (Becton Dickinson) was used to stein cell nuclei with propidium iodide. The procedure involves dissolving of the cell membrane lipids with a nonionic detergent, removing the cytoskeleton and nuclear proteins with trypsin and digesting the RNA. The nuclear chromatin is stabilized with spermine and in the clean, isolated nuclei DNA is bound stoichiometrically by propidium iodide.

The medium of the MEF's was collected and used to resuspend the cells after the trypsinization. After removal of the medium, cells were washed with PBS and incubated with trypsin $\left(0.05 \%\right.$ Trypsin/EDTA; Gibco BRL $\left.{ }^{\circledR}\right)$ in a humidified incubator at $37^{\circ} \mathrm{C}$ for five minutes. The trypsin was inactivated by transferring the previously removed medium into the culture dish and pipetting up and down for a few times. Cell concentration was determined using a Hemocytometer as described earlier. $1 \times 10^{6}$ cells were transferred into a $15 \mathrm{ml}$ Falcon $^{\mathrm{TM}}$ tube and sedimented by centrifugation at $210 \times \mathrm{g}$ for five minutes. Afterwards the medium was carefully removed without disturbing the cell pellet. Cells were twice resuspended in $2 \mathrm{ml}$ PBS and sedimented. Finally the cell pellet was resuspended in $1 \mathrm{ml}$ of PBS, transferred into a freezer-safe tube with screw cap and rapidly frozen in a mixture of dry ice and $99 \%$ ethanol. Samples were stored at $-80^{\circ} \mathrm{C}$. Right before analysis the cells were thawed as fast as possible in a water-bath at $37^{\circ} \mathrm{C}$ 
without allowing them to reach this temperature. The cell suspension was transferred into $12 \times 75$ mm capped polypropylene tubes (Becton Dickinson Falcon) and centrifuged at $400 \times \mathrm{g}$ for five minutes at room temperature. The supernatant was carefully removed and residual drops were removed with a tissue. $250 \mu$ Solution A (trypsin buffer) was added, the tube was mixed by gently tapping and it was incubated for 10 minutes at room temperature. This procedure was repeated by adding an additional $200 \mu$ l of Solution B (RNase buffer). After an incubation time of 10 minutes, $200 \mu$ of ice cold Solution C (propidium iodide stain solution) was added, the suspension was gently mixed and incubated for 10 minutes in the dark on ice. The samples were now ready for analysis and needed to run on the flow cytometer within three hours. The tubes were vortexed immediately before the measurement with the FACS Calibur Flow Cytometer (Beckton Dickincon) and the obtained data were analyzed with the Moldifit LT software (Verify Software House Inc.). The staining procedure as well as the flow cytometry analysis was performed in the group of Prof. Dr. Detlef Doenecke (Biochemie und Molekulare Zellbiologie, Georg-August University of Göttingen) with the help of Krisitina Haenecke and Dr. Nicole Happel. 


\section{BIBLIOGRAPHY}

Aaronson, S.A., and Todaro, G.J. (1968). Development of 3T3-like lines from Balb-c mouse embryo cultures: transformation susceptibility to SV40. J Cell Physiol 72, 141-148.

Andersen, B., and Rosenfeld, M.G. (2001). POU domain factors in the neuroendocrine system: lessons from developmental biology provide insights into human disease. Endocr Rev 22, 2-35.

Andersen, P.L., Xu, F., and Xiao, W. (2008). Eukaryotic DNA damage tolerance and translesion synthesis through covalent modifications of PCNA. Cell Res 18, 162-173.

Andoniadou, C.L., Signore, M., Sajedi, E., Gaston-Massuet, C., Kelberman, D., Burns, A.J., Itasaki, N., Dattani, M., and Martinez-Barbera, J.P. (2007). Lack of the murine homeobox gene Hesx1 leads to a posterior transformation of the anterior forebrain. Development 134, 1499-1508.

Araki, M., Yu, H., and Asano, M. (2005). A novel motif governs APC-dependent degradation of Drosophila ORC1 in vivo. Genes Dev 19, 2458-2465.

Aravind, L., and Koonin, E.V. (1998). The HORMA domain: a common structural denominator in mitotic checkpoints, chromosome synapsis and DNA repair. Trends Biochem Sci 23, 284-286.

Bashir, T., Dorrello, N.V., Amador, V., Guardavaccaro, D., and Pagano, M. (2004). Control of the SCF(Skp2-Cks1) ubiquitin ligase by the APC/C(Cdh1) ubiquitin ligase. Nature 428, 190-193.

Bayramov, A.V., Martynova, N.Y., Eroshkin, F.M., Ermakova, G.V., and Zaraisky, A.G. (2004). The homeodomain-containing transcription factor X-nkx-5.1 inhibits expression of the homeobox gene Xanf-1 during the Xenopus laevis forebrain development. Mech Dev $121,1425-1441$.

Bemark, M., Khamlichi, A.A., Davies, S.L., and Neuberger, M.S. (2000). Disruption of mouse polymerase zeta (Rev3) leads to embryonic lethality and impairs blastocyst development in vitro. Curr Biol 10, 1213-1216.

Birnboim, H.C., and Doly, J. (1979). A rapid alkaline extraction procedure for screening recombinant plasmid DNA. Nucleic Acids Res 7, 1513-1523.

Borges, H.L., Linden, R., and Wang, J.Y. (2008). DNA damage-induced cell death: lessons from the central nervous system. Cell Res 18, 17-26.

Brickman, J.M., Clements, M., Tyrell, R., McNay, D., Woods, K., Warner, J., Stewart, A., Beddington, R.S., and Dattani, M. (2001). Molecular effects of novel mutations in Hesx1/HESX1 associated with human pituitary disorders. Development 128, 5189-5199.

Cahill, D.P., da Costa, L.T., Carson-Walter, E.B., Kinzler, K.W., Vogelstein, B., and Lengauer, C. (1999). Characterization of MAD2B and other mitotic spindle checkpoint genes. Genomics 58, 181-187.

Camper, S.A., Saunders, T.L., Katz, R.W., and Reeves, R.H. (1990). The Pit-1 transcription factor gene is a candidate for the murine Snell dwarf mutation. Genomics 8, 586-590.

Campisi, J., and d'Adda di Fagagna, F. (2007). Cellular senescence: when bad things happen to good cells. Nat Rev Mol Cell Biol 8, 729-740. 
Carvalho, L.R., Woods, K.S., Mendonca, B.B., Marcal, N., Zamparini, A.L., Stifani, S., Brickman, J.M., Arnhold, I.J., and Dattani, M.T. (2003). A homozygous mutation in HESX1 is associated with evolving hypopituitarism due to impaired repressor-corepressor interaction. J Clin Invest 112, 1192-1201.

Chan, S.H., Hung, F.S., Chan, D.S., and Shaw, P.C. (2001). Trichosanthin interacts with acidic ribosomal proteins $\mathrm{P} 0$ and $\mathrm{P} 1$ and mitotic checkpoint protein MAD2B. Eur J Biochem 268, 2107-2112.

Charles, M.A., Suh, H., Hjalt, T.A., Drouin, J., Camper, S.A., and Gage, P.J. (2005). PITX genes are required for cell survival and Lhx3 activation. Mol Endocrinol 19, 1893-1903.

Chen, J., and Fang, G. (2001). MAD2B is an inhibitor of the anaphase-promoting complex. Genes Dev 15, 1765-1770.

Cheung, H.W., Chun, A.C., Wang, Q., Deng, W., Hu, L., Guan, X.Y., Nicholls, J.M., Ling, M.T., Chuan Wong, Y., Tsao, S.W., et al. (2006). Inactivation of human MAD2B in nasopharyngeal carcinoma cells leads to chemosensitization to DNA-damaging agents. Cancer Res 66, 4357-4367.

Chevray, P.M., and Nathans, D. (1992). Protein interaction cloning in yeast: identification of mammalian proteins that react with the leucine zipper of Jun. Proc Natl Acad Sci U S A 89, 5789-5793.

Chou, S.J., Hermesz, E., Hatta, T., Feltner, D., El-Hodiri, H.M., Jamrich, M., and Mahon, K. (2006). Conserved regulatory elements establish the dynamic expression of Rpx/Hesxl in early vertebrate development. Dev Biol 292, 533-545.

Christensen, K.L., Brennan, J.D., Aldridge, C.S., and Ford, H.L. (2006). Cell cycle regulation of the human Six1 homeoprotein is mediated by APC(Cdh1). Oncogene.

Cohen, R.N., Cohen, L.E., Botero, D., Yu, C., Sagar, A., Jurkiewicz, M., and Radovick, S. (2003). Enhanced repression by HESX1 as a cause of hypopituitarism and septooptic dysplasia. J Clin Endocrinol Metab 88, 4832-4839.

Couly, G., and Le Douarin, N.M. (1988). The fate map of the cephalic neural primordium at the presomitic to the 3-somite stage in the avian embryo. Development 103 Suppl, 101113.

Curtis, M.J., and Hays, J.B. (2007). Tolerance of dividing cells to replication stress in UVBirradiated Arabidopsis roots: requirements for DNA translesion polymerases eta and zeta. DNA Repair (Amst) 6, 1341-1358.

Cushman, L.J., Watkins-Chow, D.E., Brinkmeier, M.L., Raetzman, L.T., Radak, A.L., Lloyd, R.V., and Camper, S.A. (2001). Persistent Prop1 expression delays gonadotrope differentiation and enhances pituitary tumor susceptibility. Hum Mol Genet 10, 11411153.

Darzynkiewicz, Z., Juan, G., Li, X., Gorczyca, W., Murakami, T., and Traganos, F. (1997). Cytometry in cell necrobiology: analysis of apoptosis and accidental cell death (necrosis). Cytometry 27, 1-20.

Dasen, J.S., Barbera, J.P., Herman, T.S., Connell, S.O., Olson, L., Ju, B., Tollkuhn, J., Baek, S.H., Rose, D.W., and Rosenfeld, M.G. (2001). Temporal regulation of a paired-like homeodomain repressor/TLE corepressor complex and a related activator is required for pituitary organogenesis. Genes Dev 15, 3193-3207. 
Dattani, M.T. (2004). Novel insights into the aetiology and pathogenesis of hypopituitarism. Horm Res 62 Supp/ 3, 1-13.

Dattani, M.T. (2005). Growth hormone deficiency and combined pituitary hormone deficiency: does the genotype matter? Clin Endocrinol (Oxf) 63, 121-130.

Dattani, M.T., Martinez-Barbera, J.P., Thomas, P.Q., Brickman, J.M., Gupta, R., Martensson, I.L., Toresson, H., Fox, M., Wales, J.K., Hindmarsh, P.C., et al. (1998). Mutations in the homeobox gene HESX1/Hesx1 associated with septo-optic dysplasia in human and mouse. Nat Genet 19, 125-133.

Deckbar, D., Birraux, J., Krempler, A., Tchouandong, L., Beucher, A., Walker, S., Stiff, T., Jeggo, P., and Lobrich, M. (2007). Chromosome breakage after G2 checkpoint release. J Cell Biol 176, 749-755.

Diaz, M., Verkoczy, L.K., Flajnik, M.F., and Klinman, N.R. (2001). Decreased frequency of somatic hypermutation and impaired affinity maturation but intact germinal center formation in mice expressing antisense RNA to DNA polymerase zeta. J Immunol 167, 327-335.

Diffley, J.F. (2004). Regulation of early events in chromosome replication. Curr Biol 14, R778-786.

Dower, W.J., Miller, J.F., and Ragsdale, C.W. (1988). High efficiency transformation of E. coli by high voltage electroporation. Nucleic Acids Res 16, 6127-6145.

Eagleson, G.W., and Harris, W.A. (1990). Mapping of the presumptive brain regions in the neural plate of Xenopus laevis. J Neurobiol 21, 427-440.

Eeken, J.C., Romeijn, R.J., de Jong, A.W., Pastink, A., and Lohman, P.H. (2001). Isolation and genetic characterisation of the Drosophila homologue of (SCE)REV3, encoding the catalytic subunit of DNA polymerase zeta. Mutat Res 485, 237-253.

Ermakova, G.V., Alexandrova, E.M., Kazanskaya, O.V., Vasiliev, O.L., Smith, M.W., and Zaraisky, A.G. (1999). The homeobox gene, Xanf-1, can control both neural differentiation and patterning in the presumptive anterior neurectoderm of the Xenopus laevis embryo. Development 126, 4513-4523.

Ermakova, G.V., Solovieva, E.A., Martynova, N.Y., and Zaraisky, A.G. (2007). The homeodomain factor Xanf represses expression of genes in the presumptive rostral forebrain that specify more caudal brain regions. Dev Biol 307, 483-497.

Eroshkin, F., Kazanskaya, O., Martynova, N., and Zaraisky, A. (2002). Characterization of cis-regulatory elements of the homeobox gene Xanf-1. Gene 285, 279-286.

Esposito, G., Godindagger, I., Klein, U., Yaspo, M.L., Cumano, A., and Rajewsky, K. (2000). Disruption of the Rev3l-encoded catalytic subunit of polymerase zeta in mice results in early embryonic lethality. Curr Biol 10, 1221-1224.

Fang, G., Yu, H., and Kirschner, M.W. (1998). Direct binding of CDC20 protein family members activates the anaphase-promoting complex in mitosis and G1. Mol Cell 2, 163171.

Fang, S., and Weissman, A.M. (2004). A field guide to ubiquitylation. Cell Mol Life Sci 61, 1546-1561. 
Feiss, M., Siegele, D.A., Rudolph, C.F., and Frackman, S. (1982). Cosmid DNA packaging in vivo. Gene 17, 123-130.

Furuta, T., Tuck, S., Kirchner, J., Koch, B., Auty, R., Kitagawa, R., Rose, A.M., and Greenstein, D. (2000). EMB-30: an APC4 homologue required for metaphase-to-anaphase transitions during meiosis and mitosis in Caenorhabditis elegans. Mol Biol Cell 11, 14011419.

Gabellini, D., Colaluca, I.N., Vodermaier, H.C., Biamonti, G., Giacca, M., Falaschi, A., Riva, S., and Peverali, F.A. (2003). Early mitotic degradation of the homeoprotein HOXC10 is potentially linked to cell cycle progression. EMBO J 22, 3715-3724.

Gage, P.J., Brinkmeier, M.L., Scarlett, L.M., Knapp, L.T., Camper, S.A., and Mahon, K.A. (1996). The Ames dwarf gene, df, is required early in pituitary ontogeny for the extinction of Rpx transcription and initiation of lineage-specific cell proliferation. Mol Endocrinol 10, 1570-1581.

Gan, G.N., Wittschieben, J.P., Wittschieben, B.O., and Wood, R.D. (2008). DNA polymerase zeta (pol zeta) in higher eukaryotes. Cell Res 18, 174-183.

Gavrieli, Y., Sherman, Y., and Ben-Sasson, S.A. (1992). Identification of programmed cell death in situ via specific labeling of nuclear DNA fragmentation. J Cell Biol 119, 493-501.

Gieffers, C., Peters, B.H., Kramer, E.R., Dotti, C.G., and Peters, J.M. (1999). Expression of the $\mathrm{CDH} 1$-associated form of the anaphase-promoting complex in postmitotic neurons. Proc Natl Acad Sci U S A 96, 11317-11322.

Gleiberman, A.S., Fedtsova, N.G., and Rosenfeld, M.G. (1999). Tissue interactions in the induction of anterior pituitary: role of the ventral diencephalon, mesenchyme, and notochord. Dev Biol 213, 340-353.

Glotzer, M., Murray, A.W., and Kirschner, M.W. (1991). Cyclin is degraded by the ubiquitin pathway. Nature 349, 132-138.

Gluzman, Y. (1981). SV40-transformed simian cells support the replication of early SV40 mutants. Cell 23, 175-182.

Golden, A., Sadler, P.L., Wallenfang, M.R., Schumacher, J.M., Hamill, D.R., Bates, G., Bowerman, B., Seydoux, G., and Shakes, D.C. (2000). Metaphase to anaphase (mat) transition-defective mutants in Caenorhabditis elegans. J Cell Biol 151, 1469-1482.

Hermesz, E., Mackem, S., and Mahon, K.A. (1996). Rpx: a novel anterior-restricted homeobox gene progressively activated in the prechordal plate, anterior neural plate and Rathke's pouch of the mouse embryo. Development 122, 41-52.

Hermesz, E., Williams-Simons, L., and Mahon, K.A. (2003). A novel inducible element, activated by contact with Rathke's pouch, is present in the regulatory region of the Rpx/Hesx1 homeobox gene. Dev Biol 260, 68-78.

Hershko, A., and Ciechanover, A. (1998). The ubiquitin system. Annu Rev Biochem 67, 425-479.

Hoege, C., Pfander, B., Moldovan, G.L., Pyrowolakis, G., and Jentsch, S. (2002). RAD6dependent DNA repair is linked to modification of PCNA by ubiquitin and SUMO. Nature $419,135-141$. 
Holbeck, S.L., and Strathern, J.N. (1997). A role for REV3 in mutagenesis during doublestrand break repair in Saccharomyces cerevisiae. Genetics 147, 1017-1024.

Hsu, J.Y., Reimann, J.D., Sorensen, C.S., Lukas, J., and Jackson, P.K. (2002). E2F-dependent accumulation of hEmi1 regulates $S$ phase entry by inhibiting APC(Cdh1). Nat Cell Biol 4 , 358-366.

Irniger, S., Piatti, S., Michaelis, C., and Nasmyth, K. (1995). Genes involved in sister chromatid separation are needed for B-type cyclin proteolysis in budding yeast. Cell 81, 269-278.

Ito, H., Fukuda, Y., Murata, K., and Kimura, A. (1983). Transformation of intact yeast cells treated with alkali cations. J Bacteriol 153, 163-168.

Iwai, H., Kim, M., Yoshikawa, Y., Ashida, H., Ogawa, M., Fujita, Y., Muller, D., Kirikae, T., Jackson, P.K., Kotani, S., et al. (2007). A bacterial effector targets Mad2L2, an APC inhibitor, to modulate host cell cycling. Cell 130, 611-623.

Japon, M.A., Rubinstein, M., and Low, M.J. (1994). In situ hybridization analysis of anterior pituitary hormone gene expression during fetal mouse development. J Histochem Cytochem 42, 1117-1125.

Jimenez, G., Paroush, Z., and Ish-Horowicz, D. (1997). Groucho acts as a corepressor for a subset of negative regulators, including Hairy and Engrailed. Genes Dev 11, 3072-3082.

Juo, P., and Kaplan, J.M. (2004). The anaphase-promoting complex regulates the abundance of GLR-1 glutamate receptors in the ventral nerve cord of C. elegans. Curr Biol 14, 2057-2062.

Kannouche, P.L., Wing, J., and Lehmann, A.R. (2004). Interaction of human DNA polymerase eta with monoubiquitinated PCNA: a possible mechanism for the polymerase switch in response to DNA damage. Mol Cell 14, 491-500.

Kaufman, M.H., and Bard, M.H. (1999). The anatomical basis of mouse development. Academic Press.

Kawamura, K., J, O.W., Bahar, R., Koshikawa, N., Shishikura, T., Nakagawara, A., Sakiyama, S., Kajiwara, K., Kimura, M., and Tagawa, M. (2001). The error-prone DNA polymerase zeta catalytic subunit (Rev3) gene is ubiquitously expressed in normal and malignant human tissues. Int J Oncol 18, 97-103.

Kazanskaya, O.V., Severtzova, E.A., Barth, K.A., Ermakova, G.V., Lukyanov, S.A., Benyumov, A.O., Pannese, M., Boncinelli, E., Wilson, S.W., and Zaraisky, A.G. (1997). Anf: a novel class of vertebrate homeobox genes expressed at the anterior end of the main embryonic axis. Gene 200, 25-34.

Kim, A.H., and Bonni, A. (2007). Thinking within the D box: initial identification of Cdh1APC substrates in the nervous system. Mol Cell Neurosci 34, 281-287.

Kioussi, C., Briata, P., Baek, S.H., Rose, D.W., Hamblet, N.S., Herman, T., Ohgi, K.A., Lin, C., Gleiberman, A., Wang, J., et al. (2002). Identification of a Wnt/Dvl/beta-Catenin --> Pitx2 pathway mediating cell-type-specific proliferation during development. Cell 111, 673-685.

Kissinger, C.R., Liu, B.S., Martin-Blanco, E., Kornberg, T.B., and Pabo, C.O. (1990). Crystal structure of an engrailed homeodomain-DNA complex at $2.8 \mathrm{~A}$ resolution: a framework for understanding homeodomain-DNA interactions. Cell 63, 579-590. 
Knoetgen, H., Viebahn, C., and Kessel, M. (1999). Head induction in the chick by primitive endoderm of mammalian, but not avian origin. Development 126, 815-825.

Konishi, Y., Stegmuller, J., Matsuda, T., Bonni, S., and Bonni, A. (2004). Cdh1-APC controls axonal growth and patterning in the mammalian brain. Science 303, 1026-1030.

Kornberg, T.B. (1993). Understanding the homeodomain. J Biol Chem 268, 26813-26816.

Kraft, C., Herzog, F., Gieffers, C., Mechtler, K., Hagting, A., Pines, J., and Peters, J.M. (2003). Mitotic regulation of the human anaphase-promoting complex by phosphorylation. EMBO J 22, 6598-6609.

Kraft, C., Vodermaier, H.C., Maurer-Stroh, S., Eisenhaber, F., and Peters, J.M. (2005). The WD40 propeller domain of Cdh1 functions as a destruction box receptor for APC/C substrates. Mol Cell 18, 543-553.

Kyriakis, J.M., and Avruch, J. (2001). Mammalian mitogen-activated protein kinase signal transduction pathways activated by stress and inflammation. Physiol Rev 81, 807-869.

Lasorella, A., Stegmuller, J., Guardavaccaro, D., Liu, G., Carro, M.S., Rothschild, G., de la Torre-Ubieta, L., Pagano, M., Bonni, A., and lavarone, A. (2006). Degradation of Id2 by the anaphase-promoting complex couples cell cycle exit and axonal growth. Nature 442, 471474.

Lawrence, C.W. (2002). Cellular roles of DNA polymerase zeta and Rev1 protein. DNA Repair (Amst) 1, 425-435.

Lawrence, C.W., Das, G., and Christensen, R.B. (1985). REV7, a new gene concerned with UV mutagenesis in yeast. Mol Gen Genet 200, 80-85.

Lehmann, A.R. (2006). Translesion synthesis in mammalian cells. Exp Cell Res 312, 26732676.

Li, S., Crenshaw, E.B., 3rd, Rawson, E.J., Simmons, D.M., Swanson, L.W., and Rosenfeld, M.G. (1990). Dwarf locus mutants lacking three pituitary cell types result from mutations in the POU-domain gene pit-1. Nature 347, 528-533.

Li, X., and Heyer, W.D. (2008). Homologous recombination in DNA repair and DNA damage tolerance. Cell Res 18, 99-113.

Li, Y., Gorbea, C., Mahaffey, D., Rechsteiner, M., and Benezra, R. (1997). MAD2 associates with the cyclosome/anaphase-promoting complex and inhibits its activity. Proc Natl Acad Sci U S A 94, 12431-12436.

Li, Z., Zhang, H., McManus, T.P., McCormick, J.J., Lawrence, C.W., and Maher, V.M. (2002). hREV3 is essential for error-prone translesion synthesis past UV or benzo[a]pyrene diol epoxide-induced DNA lesions in human fibroblasts. Mutat Res 510, 71-80.

Lin, W., Wu, X., and Wang, Z. (1999). A full-length cDNA of hREV3 is predicted to encode DNA polymerase zeta for damage-induced mutagenesis in humans. Mutat Res 433, 89-98.

Littlepage, L.E., and Ruderman, J.V. (2002). Identification of a new APC/C recognition domain, the $A$ box, which is required for the Cdh1-dependent destruction of the kinase Aurora-A during mitotic exit. Genes Dev 16, 2274-2285.

Liu, P., Jenkins, N.A., and Copeland, N.G. (2003). A highly efficient recombineering-based method for generating conditional knockout mutations. Genome Res 13, 476-484. 
Lobrich, M., and Jeggo, P.A. (2007). The impact of a negligent G2/M checkpoint on genomic instability and cancer induction. Nat Rev Cancer 7, 861-869.

Mantovani, G., Asteria, C., Pellegrini, C., Bosari, S., Alberti, L., Bondioni, S., Peverelli, E., Spada, A., and Beck-Peccoz, P. (2006). HESX1 expression in human normal pituitaries and pituitary adenomas. Mol Cell Endocrinol 247, 135-139.

Marangos, P., Verschuren, E.W., Chen, R., Jackson, P.K., and Carroll, J. (2007). Prophase I arrest and progression to metaphase I in mouse oocytes are controlled by Emi1dependent regulation of APC(Cdh1). J Cell Biol 176, 65-75.

Martinez-Barbera, J.P., Rodriguez, T.A., and Beddington, R.S. (2000). The homeobox gene Hesx1 is required in the anterior neural ectoderm for normal forebrain formation. Dev Biol 223, 422-430.

Martynova, N., Eroshkin, F., Ermakova, G., Bayramov, A., Gray, J., Grainger, R., and Zaraisky, A. (2004). Patterning the forebrain: FoxA4a/Pintallavis and Xvent2 determine the posterior limit of Xanf1 expression in the neural plate. Development 131, 2329-2338.

Martynova, N.Y., Eroshkin, F.M., Ermolina, L.V., Ermakova, G.V., Korotaeva, A.L., Smurova, K.M., Gyoeva, F.K., and Zaraisky, A.G. (2008). The LIM-domain protein Zyxin binds the homeodomain factor Xanf1/Hesx1 and modulates its activity in the anterior neural plate of Xenopus laevis embryo. Dev Dyn 237, 736-749.

Masuda, Y., Ohmae, M., Masuda, K., and Kamiya, K. (2003). Structure and enzymatic properties of a stable complex of the human REV1 and REV7 proteins. J Biol Chem 278, 12356-12360.

McCulloch, S.D., and Kunkel, T.A. (2008). The fidelity of DNA synthesis by eukaryotic replicative and translesion synthesis polymerases. Cell Res 18, 148-161.

McNally, K., Neal, J.A., McManus, T.P., McCormick, J.J., and Maher, V.M. (2008). hRev7, putative subunit of hPolzeta, plays a critical role in survival, induction of mutations, and progression through S-phase, of UV((254nm))-irradiated human fibroblasts. DNA Repair (Amst).

Mülhardt, C. (2004). Der Experimentator: Molekularbiologie/Genomics, 4th edn (Spektrum, Akad. Verl.).

Murakumo, Y. (2002). The property of DNA polymerase zeta: REV7 is a putative protein involved in translesion DNA synthesis and cell cycle control. Mutat Res 510, 37-44.

Murakumo, Y., Ogura, Y., Ishii, H., Numata, S., Ichihara, M., Croce, C.M., Fishel, R., and Takahashi, M. (2001). Interactions in the error-prone postreplication repair proteins hREV1, hREV3, and hREV7. J Biol Chem 276, 35644-35651.

Murakumo, Y., Roth, T., Ishii, H., Rasio, D., Numata, S., Croce, C.M., and Fishel, R. (2000). A human REV7 homolog that interacts with the polymerase zeta catalytic subunit hREV3 and the spindle assembly checkpoint protein hMAD2. J Biol Chem 275, 4391-4397.

Muyrers, J.P., Zhang, Y., and Stewart, A.F. (2001). Techniques: Recombinogenic engineering--new options for cloning and manipulating DNA. Trends Biochem Sci 26, 325331.

Nagy, A., Gertsenstein, M., Vintersten, K., and Behringer, R. (2003). Manipulating the Mouse Embryo: A Laboratory Manual. In Cold Spring Harbor Laboratory Press. 
Nasonkin, I.O., Ward, R.D., Raetzman, L.T., Seasholtz, A.F., Saunders, T.L., Gillespie, P.J., and Camper, S.A. (2004). Pituitary hypoplasia and respiratory distress syndrome in Prop1 knockout mice. Hum Mol Genet 13, 2727-2735.

Nelson, J.R., Lawrence, C.W., and Hinkle, D.C. (1996). Thymine-thymine dimer bypass by yeast DNA polymerase zeta. Science $272,1646-1649$.

Nelson, K.K., Schlondorff, J., and Blobel, C.P. (1999). Evidence for an interaction of the metalloprotease-disintegrin tumour necrosis factor alpha convertase (TACE) with mitotic arrest deficient 2 (MAD2), and of the metalloprotease-disintegrin MDC9 with a novel MAD2-related protein, MAD2beta. Biochem J 343 Pt 3, 673-680.

Okada, T., Sonoda, E., Yoshimura, M., Kawano, Y., Saya, H., Kohzaki, M., and Takeda, S. (2005). Multiple roles of vertebrate REV genes in DNA repair and recombination. Mol Cell Biol 25, 6103-6111.

Olson, L.E., Tollkuhn, J., Scafoglio, C., Krones, A., Zhang, J., Ohgi, K.A., Wu, W., Taketo, M.M., Kemler, R., Grosschedl, R., et al. (2006). Homeodomain-mediated beta-catenindependent switching events dictate cell-lineage determination. Cell 125, 593-605.

Osoegawa, K., Tateno, M., Woon, P.Y., Frengen, E., Mammoser, A.G., Catanese, J.J., Hayashizaki, Y., and de Jong, P.J. (2000). Bacterial artificial chromosome libraries for mouse sequencing and functional analysis. Genome Res 10, 116-128.

Paroush, Z., Finley, R.L., Jr., Kidd, T., Wainwright, S.M., Ingham, P.W., Brent, R., and IshHorowicz, D. (1994). Groucho is required for Drosophila neurogenesis, segmentation, and sex determination and interacts directly with hairy-related bHLH proteins. Cell 79, 805815.

Paull, T.T., Rogakou, E.P., Yamazaki, V., Kirchgessner, C.U., Gellert, M., and Bonner, W.M. (2000). A critical role for histone H2AX in recruitment of repair factors to nuclear foci after DNA damage. Curr Biol 10, 886-895.

Peters, J.M. (2002). The anaphase-promoting complex: proteolysis in mitosis and beyond. Mol Cell 9, 931-943.

Peters, J.M. (2006). The anaphase promoting complex/cyclosome: a machine designed to destroy. Nat Rev Mol Cell Biol 7, 644-656.

Pfleger, C.M., and Kirschner, M.W. (2000). The KEN box: an APC recognition signal distinct from the D box targeted by Cdh1. Genes Dev 14, 655-665.

Pfleger, C.M., Salic, A., Lee, E., and Kirschner, M.W. (2001). Inhibition of Cdh1-APC by the MAD2-related protein MAD2L2: a novel mechanism for regulating Cdh1. Genes Dev 15, 1759-1764.

Pickart, C.M. (2001). Mechanisms underlying ubiquitination. Annu Rev Biochem 70, 503533.

Pilarski, S. (2004). Interaction partners of the homeoprotein Hesx1. In Max-PlanckInstitute for Biophysical Chemistry, Dept Molecular Cell Biology, Research Group Developmental Biology (Göttingen, Georg August University Göttingen), pp. 59.

Pravtcheva, D.D., and Wise, T.L. (1996). A transgene-induced mitotic arrest mutation in the mouse allelic with Oligosyndactylism. Genetics 144, 1747-1756. 
Prinz, S., Hwang, E.S., Visintin, R., and Amon, A. (1998). The regulation of Cdc20 proteolysis reveals a role for APC components $\mathrm{Cdc} 23$ and $\mathrm{Cdc} 27$ during $\mathrm{S}$ phase and early mitosis. Curr Biol 8, 750-760.

Quirk, J., and Brown, P. (2002). Hesx1 homeodomain protein represses transcription as a monomer and antagonises transactivation of specific sites as a homodimer. J Mol Endocrinol 28, 193-205.

Raetzman, L.T., Ward, R., and Camper, S.A. (2002). Lhx4 and Prop1 are required for cell survival and expansion of the pituitary primordia. Development 129, 4229-4239.

Rattray, A.J., Shafer, B.K., McGill, C.B., and Strathern, J.N. (2002). The roles of REV3 and RAD57 in double-strand-break-repair-induced mutagenesis of Saccharomyces cerevisiae. Genetics 162, 1063-1077.

Reimann, J.D., Gardner, B.E., Margottin-Goguet, F., and Jackson, P.K. (2001). Emi1 regulates the anaphase-promoting complex by a different mechanism than Mad2 proteins. Genes Dev 15, 3278-3285.

Reis, A., Levasseur, M., Chang, H.Y., Elliott, D.J., and Jones, K.T. (2006). The CRY box: a second APCcdh1-dependent degron in mammalian cdc20. EMBO Rep 7, 1040-1045.

Reis, A., Madgwick, S., Chang, H.Y., Nabti, I., Levasseur, M., and Jones, K.T. (2007). Prometaphase APCcdh1 activity prevents non-disjunction in mammalian oocytes. Nat Cell Biol 9, 1192-1198.

Reynaud, R., Saveanu, A., Barlier, A., Enjalbert, A., and Brue, T. (2004). Pituitary hormone deficiencies due to transcription factor gene alterations. Growth Horm IGF Res 14, 442448.

Rizzoti, K., and Lovell-Badge, R. (2005). Early development of the pituitary gland: induction and shaping of Rathke's pouch. Rev Endocr Metab Disord 6, 161-172.

Robertson, G., Bilenky, M., Lin, K., He, A., Yuen, W., Dagpinar, M., Varhol, R., Teague, K., Griffith, O.L., Zhang, X., et al. (2006). cisRED: a database system for genome-scale computational discovery of regulatory elements. Nucleic Acids Res 34, D68-73.

Rogakou, E.P., Pilch, D.R., Orr, A.H., Ivanova, V.S., and Bonner, W.M. (1998). DNA doublestranded breaks induce histone H2AX phosphorylation on serine 139. J Biol Chem 273, 5858-5868.

Rudner, A.D., and Murray, A.W. (2000). Phosphorylation by Cdc28 activates the Cdc20dependent activity of the anaphase-promoting complex. J Cell Biol 149, 1377-1390.

Saiki, R.K., Gelfand, D.H., Stoffel, S., Scharf, S.J., Higuchi, R., Horn, G.T., Mullis, K.B., and Erlich, H.A. (1988). Primer-directed enzymatic amplification of DNA with a thermostable DNA polymerase. Science $239,487-491$.

Sajedi, E., Gaston-Massuet, C., Andoniadou, C.L., Signore, M., Hurd, P.J., Dattani, M., and Martinez-Barbera, J.P. (2007). DNMT1 interacts with the developmental transcriptional repressor HESX1. Biochim Biophys Acta.

Sakamoto, A., Lan, V.T., Hase, Y., Shikazono, N., Matsunaga, T., and Tanaka, A. (2003). Disruption of the AtREV3 gene causes hypersensitivity to ultraviolet $B$ light and gammarays in Arabidopsis: implication of the presence of a translesion synthesis mechanism in plants. Plant Cell 15, 2042-2057. 
Sauer, B. (1998). Inducible gene targeting in mice using the Cre/lox system. Methods 14, 381-392.

Sauer, B., and Henderson, N. (1989). Cre-stimulated recombination at loxP-containing DNA sequences placed into the mammalian genome. Nucleic Acids Res 17, 147-161.

Schiestl, R.H., and Gietz, R.D. (1989). High efficiency transformation of intact yeast cells using single stranded nucleic acids as a carrier. Curr Genet 16, 339-346.

Schwenk, F., Baron, U., and Rajewsky, K. (1995). A cre-transgenic mouse strain for the ubiquitous deletion of loxP-flanked gene segments including deletion in germ cells. Nucleic Acids Res 23, 5080-5081.

Scully, K.M., and Rosenfeld, M.G. (2002). Pituitary development: regulatory codes in mammalian organogenesis. Science 295, 2231-2235.

Seet, B.T., Dikic, I., Zhou, M.M., and Pawson, T. (2006). Reading protein modifications with interaction domains. Nat Rev Mol Cell Biol 7, 473-483.

Sheng, H.Z., Zhadanov, A.B., Mosinger, B., Jr., Fujii, T., Bertuzzi, S., Grinberg, A., Lee, E.J., Huang, S.P., Mahon, K.A., and Westphal, H. (1996). Specification of pituitary cell lineages by the LIM homeobox gene Lhx3. Science 272, 1004-1007.

Sigrist, S.J., and Lehner, C.F. (1997). Drosophila fizzy-related down-regulates mitotic cyclins and is required for cell proliferation arrest and entry into endocycles. Cell 90, 671681.

Simmons, D.M., Voss, J.W., Ingraham, H.A., Holloway, J.M., Broide, R.S., Rosenfeld, M.G., and Swanson, L.W. (1990). Pituitary cell phenotypes involve cell-specific Pit-1 mRNA translation and synergistic interactions with other classes of transcription factors. Genes Dev 4, 695-711.

Smith, S.T., and Jaynes, J.B. (1996). A conserved region of engrailed, shared among all en-, gsc-, Nk1-, Nk2- and msh-class homeoproteins, mediates active transcriptional repression in vivo. Development 122, 3141-3150.

Sobrier, M.L., Maghnie, M., Vie-Luton, M.P., Secco, A., di lorgi, N., Lorini, R., and Amselem, S. (2006). Novel HESX1 mutations associated with a life-threatening neonatal phenotype, pituitary aplasia, but normally located posterior pituitary and no optic nerve abnormalities. J Clin Endocrinol Metab 91, 4528-4536.

Sobrier, M.L., Netchine, I., Heinrichs, C., Thibaud, N., Vie-Luton, M.P., Van Vliet, G., and Amselem, S. (2005). Alu-element insertion in the homeodomain of HESX1 and aplasia of the anterior pituitary. Hum Mutat 25, 503.

Sornson, M.W., Wu, W., Dasen, J.S., Flynn, S.E., Norman, D.J., O'Connell, S.M., Gukovsky, I., Carriere, C., Ryan, A.K., Miller, A.P., et al. (1996). Pituitary lineage determination by the Prophet of Pit-1 homeodomain factor defective in Ames dwarfism. Nature 384, 327-333.

Spieler, D., Baumer, N., Stebler, J., Koprunner, M., Reichman-Fried, M., Teichmann, U., Raz, E., Kessel, M., and Wittler, L. (2004). Involvement of Pax6 and Otx2 in the forebrainspecific regulation of the vertebrate homeobox gene ANF/Hesx1. Dev Biol 269, 567-579.

Stegmuller, J., Huynh, M.A., Yuan, Z., Konishi, Y., and Bonni, A. (2008). TGFbeta-Smad2 signaling regulates the Cdh1-APC/SnoN pathway of axonal morphogenesis. J Neurosci 28, 1961-1969. 
Stegmuller, J., Konishi, Y., Huynh, M.A., Yuan, Z., Dibacco, S., and Bonni, A. (2006). Cellintrinsic regulation of axonal morphogenesis by the Cdh1-APC target SnoN. Neuron 50, 389-400.

Stelter, P., and Ulrich, H.D. (2003). Control of spontaneous and damage-induced mutagenesis by SUMO and ubiquitin conjugation. Nature 425, 188-191.

Sudakin, V., Chan, G.K., and Yen, T.J. (2001). Checkpoint inhibition of the APC/C in HeLa cells is mediated by a complex of BUBR1, BUB3, CDC20, and MAD2. J Cell Biol 154, 925936.

Suh, H., Gage, P.J., Drouin, J., and Camper, S.A. (2002). Pitx2 is required at multiple stages of pituitary organogenesis: pituitary primordium formation and cell specification.

Development 129, 329-337.

Susa, T., Nakayama, M., Kitahara, K., Kimoto, F., Kato, T., and Kato, Y. (2007). Homeodomain transcription factor Hesx1/Rpx occupies Prop-1 activation sites in porcine follicle stimulating hormone (FSH) beta subunit promoter. Biochem Biophys Res Commun 357, 712-717.

Szeto, D.P., Rodriguez-Esteban, C., Ryan, A.K., O'Connell, S.M., Liu, F., Kioussi, C., Gleiberman, A.S., Izpisua-Belmonte, J.C., and Rosenfeld, M.G. (1999). Role of the Bicoidrelated homeodomain factor Pitx1 in specifying hindlimb morphogenesis and pituitary development. Genes Dev 13, 484-494.

Tajima, T., Hattorri, T., Nakajima, T., Okuhara, K., Sato, K., Abe, S., Nakae, J., and Fujieda, K. (2003). Sporadic heterozygous frameshift mutation of HESX1 causing pituitary and optic nerve hypoplasia and combined pituitary hormone deficiency in a Japanese patient. J Clin Endocrinol Metab 88, 45-50.

Takahashi, S., Sakamoto, A., Sato, S., Kato, T., Tabata, S., and Tanaka, A. (2005). Roles of Arabidopsis AtREV1 and AtREV7 in translesion synthesis. Plant Physiol 138, 870-881.

Takao, N., Kato, H., Mori, R., Morrison, C., Sonada, E., Sun, X., Shimizu, H., Yoshioka, K., Takeda, S., and Yamamoto, K. (1999). Disruption of ATM in p53-null cells causes multiple functional abnormalities in cellular response to ionizing radiation. Oncogene $18,7002-$ 7009.

Thomas, P., and Beddington, R. (1996). Anterior primitive endoderm may be responsible for patterning the anterior neural plate in the mouse embryo. Curr Biol 6, 1487-1496.

Thomas, P.Q., Dattani, M.T., Brickman, J.M., McNay, D., Warne, G., Zacharin, M., Cameron, F., Hurst, J., Woods, K., Dunger, D., et al. (2001). Heterozygous HESX1 mutations associated with isolated congenital pituitary hypoplasia and septo-optic dysplasia. Hum Mol Genet 10, 39-45.

Thomas, P.Q., Johnson, B.V., Rathjen, J., and Rathjen, P.D. (1995). Sequence, genomic organization, and expression of the novel homeobox gene Hesx1. J Biol Chem 270, 38693875.

Thomas, P.Q., and Rathjen, P.D. (1992). HES-1, a novel homeobox gene expressed by murine embryonic stem cells, identifies a new class of homeobox genes. Nucleic Acids Res 20, 5840 .

Thornton, B.R., and Toczyski, D.P. (2006). Precise destruction: an emerging picture of the APC. Genes Dev 20, 3069-3078. 
Thrower, J.S., Hoffman, L., Rechsteiner, M., and Pickart, C.M. (2000). Recognition of the polyubiquitin proteolytic signal. EMBO J 19, 94-102.

Todaro, G.J., and Green, H. (1963). Quantitative studies of the growth of mouse embryo cells in culture and their development into established lines. J Cell Biol 17, 299-313.

Tolkunova, E.N., Fujioka, M., Kobayashi, M., Deka, D., and Jaynes, J.B. (1998). Two distinct types of repression domain in engrailed: one interacts with the groucho corepressor and is preferentially active on integrated target genes. Mol Cell Biol 18, 2804-2814.

van den Hurk, W.H., Martens, G.J., Geurts van Kessel, A., and van Groningen, J.J. (2004). Isolation and characterization of the Xenopus laevis orthologs of the human papillary renal cell carcinoma-associated genes PRCC and MAD2L2 (MAD2B). Cytogenet Genome Res 106, 68-73.

van Roessel, P., Elliott, D.A., Robinson, I.M., Prokop, A., and Brand, A.H. (2004). Independent regulation of synaptic size and activity by the anaphase-promoting complex. Cell 119, 707-718.

Van Sloun, P.P., Romeijn, R.J., and Eeken, J.C. (1999). Molecular cloning, expression and chromosomal localisation of the mouse Rev3l gene, encoding the catalytic subunit of polymerase zeta. Mutat Res 433, 109-116.

Vidal, M. (1997). The Reverse Two-Hybrid System in The Two-Hybrid System. (Bartel, P. and Fields, S., eds.). Oxford University Press, New York, 109.

Vilenchik, M.M., and Knudson, A.G. (2003). Endogenous DNA double-strand breaks: production, fidelity of repair, and induction of cancer. Proc Natl Acad Sci U S A 100, 12871-12876.

Wan, Y., and Kirschner, M.W. (2001). Identification of multiple CDH1 homologues in vertebrates conferring different substrate specificities. Proc Natl Acad Sci U S A 98, 1306613071.

Warming, S., Costantino, N., Court, D.L., Jenkins, N.A., and Copeland, N.G. (2005). Simple and highly efficient BAC recombineering using galK selection. Nucleic Acids Res 33, e36.

Wei, W., Ayad, N.G., Wan, Y., Zhang, G.J., Kirschner, M.W., and Kaelin, W.G., Jr. (2004). Degradation of the SCF component Skp2 in cell-cycle phase G1 by the anaphasepromoting complex. Nature 428, 194-198.

Weterings, E., and Chen, D.J. (2008). The endless tale of non-homologous end-joining. Cell Res 18, 114-124.

Wilson, D., Sheng, G., Lecuit, T., Dostatni, N., and Desplan, C. (1993). Cooperative dimerization of paired class homeo domains on DNA. Genes Dev 7, 2120-2134.

Wilson, D.S., Guenther, B., Desplan, C., and Kuriyan, J. (1995). High resolution crystal structure of a paired ( $\mathrm{Pax}$ ) class cooperative homeodomain dimer on DNA. Cell 82, 709719.

Wirth, K.G., Ricci, R., Gimenez-Abian, J.F., Taghybeeglu, S., Kudo, N.R., Jochum, W., Vasseur-Cognet, M., and Nasmyth, K. (2004). Loss of the anaphase-promoting complex in quiescent cells causes unscheduled hepatocyte proliferation. Genes Dev 18, 88-98. 
Wittschieben, J., Shivji, M.K., Lalani, E., Jacobs, M.A., Marini, F., Gearhart, P.J., Rosewell, I., Stamp, G., and Wood, R.D. (2000). Disruption of the developmentally regulated Rev3I gene causes embryonic lethality. Curr Biol 10, 1217-1220.

Wittschieben, J.P., Reshmi, S.C., Gollin, S.M., and Wood, R.D. (2006). Loss of DNA polymerase zeta causes chromosomal instability in mammalian cells. Cancer Res 66, $134-$ 142.

Wu, G., Glickstein, S., Liu, W., Fujita, T., Li, W., Yang, Q., Duvoisin, R., and Wan, Y. (2007). The anaphase-promoting complex coordinates initiation of lens differentiation. Mol Biol Cell 18, 1018-1029.

Yang, X.J. (2005). Multisite protein modification and intramolecular signaling. Oncogene 24, 1653-1662.

Ying, B., and Wold, W.S. (2003). Adenovirus ADP protein (E3-11.6K), which is required for efficient cell lysis and virus release, interacts with human MAD2B. Virology 313, 224-234.

Zander, L., and Bemark, M. (2004). Immortalized mouse cell lines that lack a functional Rev3 gene are hypersensitive to UV irradiation and cisplatin treatment. DNA Repair (Amst) 3, 743-752.

Zaraisky, A.G., Ecochard, V., Kazanskaya, O.V., Lukyanov, S.A., Fesenko, I.V., and Duprat, A.M. (1995). The homeobox-containing gene XANF-1 may control development of the Spemann organizer. Development 121, 3839-3847.

Zaraisky, A.G., Lukyanov, S.A., Vasiliev, O.L., Smirnov, Y.V., Belyavsky, A.V., and Kazanskaya, O.V. (1992). A novel homeobox gene expressed in the anterior neural plate of the Xenopus embryo. Dev Biol 152, 373-382.

Zhang, L., Yang, S.H., and Sharrocks, A.D. (2007). Rev7/MAD2B links c-Jun N-terminal protein kinase pathway signaling to activation of the transcription factor Elk-1. Mol Cell Biol 27, 2861-2869.

Zhou, Y., Ching, Y.P., Ng, R.W., and Jin, D.Y. (2002). The APC regulator CDH1 is essential for the progression of embryonic cell cycles in Xenopus. Biochem Biophys Res Commun 294, 120-126.

Zhu, X., Gleiberman, A.S., and Rosenfeld, M.G. (2007). Molecular physiology of pituitary development: signaling and transcriptional networks. Physiol Rev 87, 933-963.

Zhu, X., Lin, C.R., Prefontaine, G.G., Tollkuhn, J., and Rosenfeld, M.G. (2005). Genetic control of pituitary development and hypopituitarism. Curr Opin Genet Dev 15, 332-340. 


\section{CURRICULUM VITAE}

\section{Personal Information}

Name: Sven Pilarski

Date of birth: April $4^{\text {th }} 1978$

Place of birth: Wolfsburg

Nationality: German

Education

Since 2004 Max Planck Institute for Biophysical Chemistry Göttingen

PhD thesis in Prof. Dr. Michael Kessel's laboratory

Dept. Molecular Cell Biology/Research Group Developmental Biology

2003-2004 Max Planck Institute for Biophysical Chemistry Göttingen

MSc thesis in Prof. Dr. Michael Kessel's laboratory

Dept. Molecular Cell Biology/Research Group Developmental Biology

2002-2003 Georg August University Göttingen

MSc/PhD Program "Molecular Biology"

International Max Planck Research School

1999-2002 Georg August University Göttingen

Biology

Internships \& Additional Education

07-09/2001 Harvard Medical School, Dept. of Genetics, Boston/MA, USA

Developmental Biology in Prof. Clifford J. Tabin, Ph.D.'s laboratory

2000-2002 DeveloGen AG, Obesity Research Group, Göttingen

Experimental Genetics in Dr. Günter Brönner's laboratory

Scholarships

2007-2008 Scholarship of the Max Planck Society

2004-2007 Georg Christoph Lichtenberg PhD-Stipend of the State Lower Saxony

2002-2003 Scholarship of the International Max Planck Research School

\section{Contact Details}

Department Molecular Cell Biology

Max Planck Institute for Biophysical Chemistry

Am Fassberg 11

37077 Göttingen, Germany

Phone: + 495512011752

E-mail: spilars@gwdg.de 